CENTRO UNIVERSITÁRIO DA FEI

VINICIUS VONO PERUZZI

ESTUDO DO CASAMENTO ENTRE MOSFETS IMPLEMENTADOS COM GEOMETRIAS DE PORTA NÃO CONVENCIONAIS EM AMBIENTES DE RADIAÇÕES DE RAIOS $X$

São Bernardo do Campo 
VINICIUS VONO PERUZZI

\section{ESTUDO DO CASAMENTO ENTRE MOSFETS IMPLEMENTADOS COM GEOMETRIAS DE PORTA NÃO CONVENCIONAIS EM AMBIENTES DE RADIAÇÕES DE RAIOS X}

Tese de Doutorado apresentada ao Centro Universitário da FEI como parte dos requisitos necessários para obtenção do título de Doutor em Engenharia Elétrica. Orientado pelo Prof. Dr. Salvador Pinillos Gimenez.

São Bernardo do Campo 
Vono Peruzzi, Vinicius.

ESTUDO DO CASAMENTO ENTRE MOSFETS

IMPLEMENTADOS COM GEOMETRIAS DE PORTA

NÃO CONVENCIONAIS EM AMBIENTES DE

RADIAÇÕES DE RAIOS X /

Vinicius Vono Peruzzi. São Bernardo do Campo, 2020.

213 p. : il.

Tese - Centro Universitário FEI.

Orientador: Prof. Dr. Salvador Pinillos Gimenez.

1. Casamento entre dispositivos. 2. nMOSFETs

Diamante. 3. nMOSFETs Octo. 4. Efeitos da Dose Total

Ionizante. 5. Variabilidade.

I. Pinillos Gimenez, Salvador, orient. II. Título.

Elaborada pelo sistema de geração automática de ficha catalográfica da FEI com os dados fornecidos pelo(a) autor(a). 
Título do Trabalho: Estudo do casamento entre mosfets implementados com geometrias de porta não convencionais em ambientes de radiações de raios $x$.

Área de Concentração: Nanoeletrônica e Circuitos Integrados

Orientador: Prof. Dr. Salvador Pinillos Gimenez

Data da realização da defesa: 02/12/2020

\section{ORIGINAL ASSINADA}

Avaliação da Banca Examinadora

São Bernardo do Campo,

\section{MEMBROS DA BANCA EXAMINADORA}

Prof. Dr. Salvador Pinillos Gimenez

Prof. Dr. Renato Camargo Giacomini

Prof. Dr. Roberto Baginski Batista Santos

Prof. Dr. Luis Eduardo Seixas Junior

Prof. Dr. Lester de Abreu Faria

Ass: :
Ass: :
Ass: :
Ass: :
Ass: :

A Banca Examinadora acima-assinada atribuiu ao aluno o seguinte:

APROVADO 区

REPROVADO $\square$

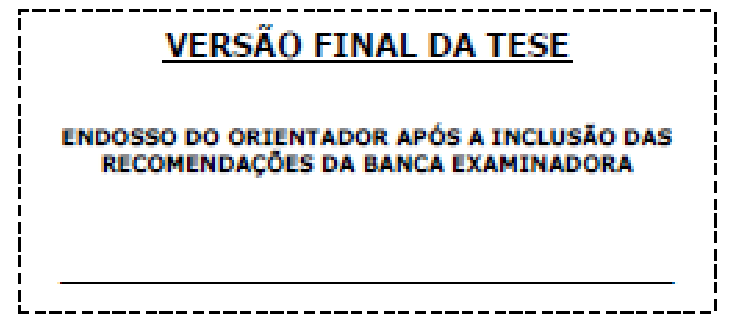

Aprovação do Coordenador do Programa de Pós-graduação

Prof. Dr. Carlos Eduardo Thomaz 
Dedico este trabalho à minha esposa e companheira, que sempre está ao meu lado para realizar nossos sonhos e cumprir com a nossa missão.

Lais Russo Carneiro Peruzzi.

Aos meus pais que sempre foram os grandes exemplos da minha vida. Valdir Peruzzi e Mariza Vono Tancredi. 


\section{AGRADECIMENTOS}

Primeiramente agradeço a Deus por nos oferecer a oportunidade da vida e por nos dar a possibilidade de evolução diária.

Ao meu orientador Prof. Dr. Salvador Pinillos Gimenez por todas as oportunidades de trabalho que me foram ofertadas durante o desenvolvimento desta tese de doutorado, pelo incentivo, pelas ideias que ajudaram enormemente a compor este trabalho e por toda a paciência no desenvolvimento deste trabalho. Por toda a honestidade e por todo o direcionamento no decorrer do trabalho, tanto do meu mestrado quanto do meu doutorado.

A todos os professores que compõem o corpo docente do mestrado e doutorado da FEI, seja pelas disciplinas ministradas por meio das quais pude aprender muito, assim como no dia a dia, pela vivência e por sempre serem solícitos para tirar qualquer tipo de dúvida durante esse período.

À Adriana, ao Ricardo, à Márcia e a Dreycer da secretaria de pós-graduação de mestrado e doutorado, que sempre se mostraram solícitos em me ajudar em relação a questões administrativas.

Aos meus colegas de mestrado e doutorado pela convivência salutar diária. Em especial ao Laercio e ao Douglas pela amizade desenvolvida durante o período em que cursamos a disciplina PME 406 e ao William pelo trabalho em parceria na captura de dados no laboratório D0-15.

Aos meus pais Mariza e Valdir e aos meus avós Walter, Marina, Maria e César, que sempre foram o grande exemplo de cada instante da minha vida e sempre me ajudaram a ser uma pessoa melhor. Além disso, gostaria de agradecê-los por toda a força e carinho em todos os momentos durante a realização deste trabalho.

À minha querida esposa Lais, pela enorme força que sempre me deu em todos os momentos, inclusive nos mais difíceis deles.

Ao professor Dr. Cor Claeys e ao professor Dr. Eddy Simoen pelo grande trabalho de cooperação no desenvolvimento de artigos.

À equipe do Centro de Tecnologia da Informação Renato Archer - CTI, em especial ao Dr. Ricardo Cotrin Teixeira e ao Dr. Luís Eduardo Seixas Júnior por sempre terem sido extremamente solícitos em nos ajudar em todos os momentos no processo de encapsulamento dos chips utilizados nesta tese de doutorado.

Aos que foram involuntariamente esquecidos, mas contribuíram para o desenvolvimento deste trabalho. 
"Sigam-me os que forem brasileiros".

Luís Alves de Lima e Silva (Duque de Caxias) 


\section{RESUMO}

Esta tese de doutorado ilustra os estudos das variabilidades e dos descasamentos entre dispositivos dos MOSFET do tipo "N" (nMOSFETs) de geometria de porta hexagonal (DnM), octogonal $(\mathrm{OnM})$ e retangular $(\mathrm{CnM})$, considerando-se quatro tipos diferentes de polarizações destes nMOSFETs durante o procedimento das radiações ionizantes de raios-X: I- sem polarização elétrica ou com todos os terminais (fonte, porta, dreno e substrato) em aberto (Floating); II- com polarização elétrica dos dispositivos na condição de operação de estadoligado ou "chave-fechada" (On-state); III- com polarização dos dispositivos na condição de operação analógica ou operando como amplificador (Analog); IV- com polarização dos dispositivos na condição de operação de estado-desligado ou "chave-aberta" (Off-state). Considerando-se a polarização Floating, durante o procedimento das radiações ionizantes de raios-X, verificou-se que os DnMs com um ângulo $\alpha$ de $90^{\circ}$ reduzem o descasamento entre dispositivos de 40,7 \% para a tensão de limiar $\left(\mathrm{V}_{\mathrm{TH}}\right)$ e de 56,8 \% para a inclinação de sublimiar (SS), respectivamente, em comparação aos valores encontrados nos CnMs equivalentes. Considerando-se a polarização On-state durante o procedimento das radiações ionizantes de raios-X, observa-se que os OnMs com um ângulo $\alpha$ de $90^{\circ}$ e fator "c" de 50\% melhoram o casamento entre dispositivos de 57,4\% para a $\mathrm{V}_{\mathrm{TH}}$ e de 54,9\% para a SS em comparação àqueles encontrados nos CnMs equivalentes. Nas condições Analog e Off-state durante o procedimento das radiações ionizantes de raios-X, os DnMs e OnMs mostraram um melhor casamento entre dispositivos em comparação aos obtidos com os CnMs equivalentes e com um nível de acerto de $95 \%$. Durante o procedimento das radiações ionizantes de raios-X no modo Floating, a máxima dose total ionizante (TID) utilizada foi da ordem de até 4,5 Mrad. Ademais, durante os procedimentos das radiações ionizantes de raios-X nos modos On-State, Off-State e Analog, as máximas TIDs utilizadas foram de $200 \mathrm{krad}$ para os modos On-State e Analog e $20 \mathrm{krad}$ para o modo Off-State. Portanto, os estilos de leiaute dos tipos Diamante e Octo, podem ser considerados como estratégias alternativas de leiaute para a implementação de MOSFETs a fim de potencializar suas tolerâncias às radiações ionizantes de raios-X, visando às aplicações em circuitos integrados (CIs) implementados com a tecnologia de fabricação do tipo Metal-ÓxidoSemicondutor Complementar (Complementary Metal-Oxide-Semiconductor, CMOS)

Palavras-chave: Casamento entre dispositivos, nMOSFETs Diamante, nMOSFETs Octo, Efeitos da Dose Total Ionizante, Variabilidade. 


\begin{abstract}
This doctoral thesis illustrates the studies of the variability and mismatch between "N" type MOSFET devices (nMOSFETs) with hexagonal (DnM), octagonal (OnM) and rectangular $(\mathrm{CnM})$ gate geometry, considering four different types of bias of these nMOSFETs during the ionizing radiation procedure X-ray: I- without electrical bias or with all terminals (source, door, drain and substrate) open (Floating); II- with electrical bias of the devices in the operating state of "on-state" or "closed-switch" (On-state); III- with bias of the devices in the condition of analogue operation or operating as an amplifier (Analog); IV- with device bias in the state-off or "open-switch" operating condition (Off-state). Considering the Floating bias, during the Xray ionizing radiation procedure, it appears that DnMs with an $\alpha$ angle of $90^{\circ}$ reduce the mismatch between devices by $40.7 \%$ for the threshold voltage $\left(\mathrm{V}_{\mathrm{TH}}\right)$ and $56.8 \%$ for the subthreshold slope (SS), respectively, in comparison to the values found in the CnMs counterparts. Considering the On-state bias during the procedure of X-ray ionizing radiation, it is observed that OnMs with an $\alpha$ angle of $90^{\circ}$ and a $50 \%$ "c" factor improve the matching between devices by $57.4 \%$ for $\mathrm{V}_{\mathrm{TH}}$ and $54.9 \%$ for $\mathrm{SS}$ compared to those found in $\mathrm{CnM}$ counterparts. In the Analog and Off-state bias during the X-ray ionizing radiation procedure, the DnMs and OnMs showed a better matching between devices compared to those obtained with the CnMs counterparts and with a 95\% accuracy level. During the procedure of X-ray ionizing radiation in Floating mode, the maximum total ionizing dose (TID) used was in the order of up to $4.5 \mathrm{Mrad}$. In addition, during ionizing X-ray radiation procedures in On-State, Off-State and Analog modes, the maximum TIDs used were $200 \mathrm{krad}$ for On-State and Analog modes and $20 \mathrm{krad}$ for Off-State mode. Therefore, the Diamond and Octo layout styles can be considered as alternative layout strategies for the implementation of MOSFETs in order to enhance their tolerances to ionizing X-ray radiation, aiming at applications in integrated circuits (ICs) implemented with Complementary Metal-Oxide-Semiconductor (CMOS) manufacturing technology.
\end{abstract}

Keywords: Matching between devices, Diamond nMOSFETs, Octo nMOSFETs, Effects of Total Ionizing Dose, Variability. 


\section{LISTA DE ILUSTRAÇÕES}

Figura 1 - Exemplo de um leiaute do MOSFET do tipo Diamante................................ 31

Figura 2 - Exemplo de um leiaute do MOSFET do tipo Octogonal ............................... 33

Figura 3 - Organização dos capítulos desta tese de doutorado ..................................... 37

Figura 4 - Curva da segunda derivada da corrente de dreno em função da tensão de porta ( $I_{D S}$ em função de $\mathrm{V}_{\mathrm{GS}}$ ), para uma tensão de $\mathrm{V}_{\mathrm{DS}}$ igual a $50 \mathrm{mV}$.

Figura 5 - Gráfico que relaciona a transcondutância em função da tensão de porta ( $\left.\mathrm{V}_{\mathrm{GS}}\right)$ para a obtenção da transcondutância máxima de um dispositivo nMOSFET convencional (geometria de porta retangular)

Figura 6 - Gráfico da corrente de dreno ( $\left.\mathrm{I}_{\mathrm{DS}}\right)$ em função da tensão de dreno ( $\left.\mathrm{V}_{\mathrm{DS}}\right)$ de um nMOSFET, ilustrando as regiões de triodo e de saturação.

Figura 7 - Exemplo de uma curva $I_{D S}$ em função de $V_{D S}$ que indica a região triodo de operação do nMOSFET para a obtenção de $\mathrm{R}_{\mathrm{DS} \text { on }}$ e que é determinada por meio da razão

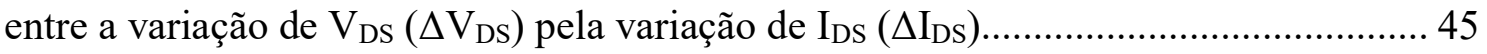

Figura 8 - Exemplo de uma curva de gm/ $\mathrm{I}_{\mathrm{DS}}$ em função de $\mathrm{I}_{\mathrm{DS}} /(\mathrm{W} / \mathrm{L})$ de um nMOSFET.

Figura 9 - Ilustração do estrangulamento do canal em função do aumento do valor da tensão $\mathrm{V}_{\mathrm{DS}}$ acima do valor de $\mathrm{V}_{\mathrm{DSsat}}$ para um MOSFET. 48

Figura 10 - Exemplos de duas curvas de $\mathrm{I}_{\mathrm{DS}}$ em função de $\mathrm{V}_{\mathrm{DS}}$, para dois diferentes valores de sobretensão de porta $\left(\mathrm{V}_{\mathrm{GT} 1}\right.$ e $\left.\mathrm{V}_{\mathrm{GT} 2}\right)$ utilizadas para a extração de $\mathrm{V}_{\mathrm{EA}}$

Figura 11 - Gráfico que relaciona o logaritmo da corrente de dreno ( $\left.\mathrm{I}_{\mathrm{DS}}\right)$ em função da tensão de porta $\left(\mathrm{V}_{\mathrm{GS}}\right)$, para um valor de $\mathrm{V}_{\mathrm{DS}}$.

Figura 12 - Exemplo de um histograma com um perfil considerado normal, levando-se em conta IDSsat, cujo valor médio é igual a 3,5 mA de uma amostra de 20 nMOSFETs do tipo Diamante.

Figura 13 - Exemplo de uma função da densidade de probabilidade normal de IDSsat $_{\text {D }}$ contendo o seu valor médio (IDSsat) que é igual a 3,5 $\mathrm{mA}$ e o valor do seu desviopadrão (s) que é igual a $0,7 \mathrm{~mA}$.

Figura 14 - Exemplo de uma função densidade de probabilidade qui-quadrado com 2 graus de liberdade.

Figura 15 - Exemplo de hipóteses de interesse a serem formalizadas para a comparação de duas variâncias de duas amostras distintas para a aplicação do teste estatístico que efetua a comparação de duas variâncias. 
Figura 16 - Exemplo de um gráfico de FDP $\chi 2$ em função de $\mathrm{F}_{\mathrm{C}}$ indicando a forma pela qual é feita a decisão para aceitar ou rejeitar $\mathrm{H}_{0}$ em função de um valor de $\mathrm{F}$, que é obtido da tabela de distribuição $\mathrm{F}$ em função do nível de significância $\alpha^{\prime}$, que foi adotado igual a 5\%, para a aplicação do teste estatístico de comparação entre duas variâncias. 64 Figura 17 - Critério de rejeição de $\mathrm{H}_{0}$ para a aplicação do teste estatístico de comparação entre duas variâncias 65

Figura 18 - Ideia básica para aplicação do teste ANOVA nas $\mathrm{V}_{\mathrm{TH}} \mathrm{S}$ extraídas de 3 tipos diferentes de nMOSFETs (DnM, OnM e CnM) quando irradiados com doses diferentes de radiações ionizantes de raios- $\mathrm{X}$

Figura 19- Ilustração para mostrar o conceito da aplicação do teste ANOVA para uma amostra de dados 68

Figura 20 - Condição para hipótese $\mathrm{H}_{0}$ verdadeira ao aplicar o teste ANOVA. 69

Figura 21 - Condição para $\mathrm{H}_{0}$ rejeitada e $\mathrm{H}_{1}$ aceita ao aplicar o teste ANOVA 70 Figura 22 - Ilustração da variação entre os valores médios devido à diferença entre as amostras. 71

Figura 23 - Cálculo da variabilidade de todas as populações considerando a soma da variação dentro de cada amostra e então somam-se todas as amostras. 72 Figura 24 - Exemplo de um gráfico de FDP $\chi 2$ em função de $\mathrm{F}_{\mathrm{C}}$ indicando a forma pela qual é feita a decisão para aceitar ou rejeitar $\mathrm{H}_{0}$ em função de um valor de $\mathrm{F}$, que é obtido da tabela de distribuição $\mathrm{F}$ em função do nível de significância $\alpha^{\prime}$, que foi adotado igual a 5\%, para a aplicação do teste estatístico ANOVA 74 Figura 25 - Exemplo de uma ilustração em que existem 4 médias a serem comparadas entre si para a aplicação do teste estatístico de Tukey .................................................. 75 Figura 26 - Exemplo de um leiaute do MOSFET do tipo Diamante............................... 77 Figura 27 - Exemplos de leiautes dos MOSFETs do tipo Diamante (a) e do tipo Convencional equivalente (b), respectivamente. 78 Figura 28 - Ilustração do DM dado por infinitesimais MOSFETs convencionais conectados em paralelo (a) e o seu devido circuito elétrico equivalente (b). 81 Figura 29 - Ilustração do DM e suas linhas de campo elétrico longitudinal ao longo do canal. 84

Figura 30 - Representação do leiaute do MOSFET do tipo Octogonal.......................... 85

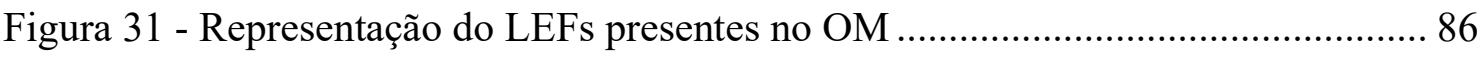
Figura 32 - Representação do OM por infinitesimais MOSFETs convencionais conectados em paralelo (a) e o seu devido circuito elétrico equivalente (b) 88 
Figura 33 - Representação do campo elétrico longitudinal em uma das regiões de bico de pássaro de um CM (a) e de um OM (b).

Figura 34 - Ilustração simplificada do cinturão de Van Allen relacionadas às radiações ionizantes do planeta Terra. 94

Figura 35 - Raios cósmicos terrestre 95

Figura 36 - Fluxo de elétrons em uma escala de energia que vai de 2,6 MeV a 8,0 MeV e fluxo de prótons numa escala de energia que vai de $29 \mathrm{MeV}$ a $248 \mathrm{MeV}$, provenientes do EPT da Proba-V 96

Figura 37 - Classificação dos efeitos das radiações ionizantes espaciais nos MOSFETs em função de suas respectivas fontes irradiantes 99

Figura 38 - Ilustração do efeito fotoelétrico 100

Figura 39 - Efeitos das radiações ionizantes no óxido de porta 102 Figura 40 - Estruturas isolantes convencionais usadas para a fabricação de CIs CMOS, LOCOS e STI de um nMOSFET com geometria de porta retangular, indicando as regiões de bico de pássaro e o seu circuito elétrico equivalente Figura 41 - Curvas de $\mathrm{I}_{\mathrm{DS}}$ em função de $\mathrm{V}_{\mathrm{GS}}$, indicando os valores das $\mathrm{V}_{\mathrm{THS}}$ quando influenciados principalmente pelas cargas positivas induzidas no óxido em MOSFETs submetidos às radiações ionizantes 105 Figura 42 - Curvas de $\mathrm{I}_{\mathrm{DS}}$ em função de $\mathrm{V}_{\mathrm{GS}}$, indicando as variações das SSs e $\Delta V T H S$ levando-se em conta o efeito do aprisionamento de cargas na interface $\mathrm{Si} / \mathrm{SiO}_{2}$ do MOSFET 107

Figura 43 - Leiaute do CI utilizado para a realização deste estudo comparativo experimental entre os DnMs, OnMs e CnMs, que foi fabricado com tecnologia de fabricação de CIs CMOS de Silício-Germânio de $130 \mathrm{~nm}$ 110 Figura 44 - Leiautes dos nMOSFETs utilizados no desenvolvimento deste trabalho: (a) leiaute do T5 e T9, (b) leiaute do T8, (c) leiaute do T37, (d) leiaute do T6 e (e) leiaute do T17. 112

Figura 45 - Esquema de ligações dos CIs no encapsulamento..... 114 Figura 46 - Foto do sistema de caracterização elétrica de dispositivos semicondutores "Keithley 4200-SCS" 115

Figura 47 - Foto da fonte de alimentação "Keithley 2636B" 116

Figura 48 - Foto do difratômetro de raios-X Shimadzu XRD-6100 116 
Figura 49 - Fotos do microprovador Cascade Microtech com uma placa de teste utilizada para a caracterização elétrica dos nMOSFETs: (a) Sistema completo e (b) ampliação do local onde a placa de teste é colocada para efetuar sua caracterização elétrica 119 Figura 50 - Conjunto de equipamentos utilizados para a caracterização elétrica (Keithley 2636B e Keithley LR:8028) dos nMOSFETs estudados

Figura 51 - Representação elétrica dos modos de polarização dos nMOSFETs a serem estudados durante a realização do processo de radiação de raios-X. (a) On-state, (b) Offstate, (c) Analog.

Figura 52 - Quantidade de nMOSFETs de porta hexagonal, octogonal e retangular utilizados para o desenvolvimento do estudo dos efeitos da TID, na condição sem polarização elétrica durante o procedimento das radiações ionizantes de raios-X....... 126 Figura 53 - Ilustração do procedimento para a realização do estudo estatístico da variabilidade que mede o descasamento entre os parâmetros elétricos extraídos dos nMOSFETs dos tipos Diamante, Octogonal e dos convencionais equivalentes

Figura 54 - Gráfico que relaciona o coeficiente de variação na condição de pré e pósirradiação das $\mathrm{V}_{\mathrm{THS}}$ extraídas experimentalmente dos DnMs, OnMs e CnMs em função da TID, para $\mathrm{V}_{\mathrm{DS}}$ igual a $50 \mathrm{mV}$

Figura 55 - Gráfico que relaciona o coeficiente de variação na condição de pré e pósirradiação das SSs extraídas experimentalmente dos DnMs, OnMs e CnMs em função da TID, para $\mathrm{V}_{\mathrm{DS}}$ igual a $50 \mathrm{mV}$

Figura 56 - Gráfico que relaciona os valores das $\mathrm{V}_{\mathrm{THS}}$ em função das SSs extraídas experimentalmente dos DnMs, OnMs e CnMs em função das TIDs aplicadas, para os dispositivos irradiados na condição de polarização Floating, para $\mathrm{V}_{\mathrm{DS}}$ igual a 50mV 134 Figura 57 - Valores dos desvios-padrão em relação às $\mathrm{V}_{\mathrm{TH}} \mathrm{S}$ extraídas experimentalmente dos dispositivos DnMs, OnMs e CnMs em função das TIDs estudadas, na condição sem polarização elétrica durante o procedimento das radiações ionizantes de raios-X....... 136 Figura 58 - Valores dos desvios-padrão em relação às SSs extraídas experimentalmente dos dispositivos DnMs, OnMs e CnMs em função das TIDs estudadas, na condição sem polarização elétrica durante o procedimento das radiações ionizantes de raios-X....... 137 Figura 59 - Coeficientes de variação dos parâmetros $\mathrm{I}_{\mathrm{DSsat}} /(\mathrm{W} / \mathrm{L}), \operatorname{gm}_{\mathrm{MAX}} /(\mathrm{W} / \mathrm{L})$, $\operatorname{gm}_{\mathrm{MAX}} / \mathrm{I}_{\mathrm{DSsa}}, \mathrm{R}_{\mathrm{DSon}} /(\mathrm{L} / \mathrm{W}), \mathrm{g}_{\mathrm{D}} /(\mathrm{W} / \mathrm{L}), \mathrm{V}_{\mathrm{EA}} / \mathrm{L}, \mathrm{f}_{\mathrm{T}} /(\mathrm{W} / \mathrm{L}), \mathrm{A}_{\mathrm{V}}, \mathrm{I}_{\mathrm{ON}} /(\mathrm{W} / \mathrm{L}), \mathrm{I}_{\mathrm{OFF}} /(\mathrm{W} / \mathrm{L})$, ION/IOFF e $\mathrm{I}_{\mathrm{LEAK}} /(\mathrm{W} / \mathrm{L})$ extraídos experimentalmente dos DnMs, OnMs e CnMs, para as condições de pré-irradiação (a), 0,5 $\operatorname{Mrad}(\mathrm{b})$, 1,0 $\operatorname{Mrad}(\mathrm{c})$, 1,5 $\operatorname{Mrad}(\mathrm{d})$, 3,0 $\operatorname{Mrad}(\mathrm{e})$ e 4,5 $\operatorname{Mrad}(\mathrm{f})$. 
Figura 60 - Ilustração do procedimento para a realização do estudo do casamento entre os parâmetros elétricos extraídos experimentalmente dos OnMs e CnMs

Figura 61 - Os coeficientes de variação pré e pós-irradiação das $\mathrm{V}_{\mathrm{TH}} \mathrm{S}$ dos OnMs e CnMs em função da TID estudada, para $\mathrm{V}_{\mathrm{DS}}$ igual a $50 \mathrm{mV}$

Figura 62 - Os coeficientes de variação pré e pós-irradiação das SSs dos OnMs e CnMs em função da TID estudada, para $\mathrm{V}_{\mathrm{DS}}$ igual a $50 \mathrm{mV}$ 155 Figura 63 - Gráfico que relaciona os valores das $\mathrm{V}_{\mathrm{THS}}$ em função das SSs extraídas experimentalmente dos OnMs e CnMs em função das TIDs aplicadas, para os dispositivos irradiados na condição de polarização On-state, para $\mathrm{V}_{\mathrm{DS}}$ igual a $50 \mathrm{mV}$ 156 Figura 64 - Valores dos desvios-padrão em relação às $\mathrm{V}_{\mathrm{TH}}$ extraídas experimentalmente dos dispositivos DnMs, OnMs e CnMs em função das TIDs estudadas, na condição de polarização On-State, durante o procedimento das radiações ionizantes de raios-X ... 158 Figura 65 - Valores dos desvios-padrão em relação às SSs extraídas experimentalmente dos dispositivos DnMs, OnMs e CnMs em função das TIDs estudadas, na condição de polarização On-State, durante o procedimento das radiações ionizantes de raios-X ... 159 Figura 66 - Procedimento para a obtenção das amostras das $\mathrm{V}_{\mathrm{TH}}$ e das SS extraídas experimentalmente dos DnMs, OnM e CnM durante as aplicações das radiações ionizantes do tipo raios-X, valendo-se de uma polarização no modo Analog. Figura 67 - Diagrama de blocos do procedimento realizado para a aplicação dos testes estatísticos ANOVA e de Tukey das amostras das $\mathrm{V}_{\mathrm{THS}}$ e das SSs extraídas dos DnMs, OnM e CnM considerando-se de uma polarização no modo Analog, durante o procedimento das radiações ionizantes de raios-X 164 Figura 68 - As hipóteses nula e alternativa levadas em conta para a aplicação do teste de Anderson - Darling nas amostras das $\mathrm{V}_{\mathrm{TH}} \mathrm{S}$ extraídas experimentalmente dos DnMs, OnM e CnM, considerando-se de uma polarização no modo Analog, durante o procedimento das radiações ionizantes de raios-X 165 Figura 69 - Hipóteses nula e alternativa levadas em conta para a aplicação do teste para comparação de duas variâncias das amostras das $\mathrm{V}_{\mathrm{THS}}$ extraídas experimentalmente dos DnMs, OnM e CnM durante as aplicações das radiações ionizantes do tipo raios-X, valendo-se de uma polarização no modo Analog Figura 70 - As hipóteses nula e alternativa levadas em conta para a aplicação do Teste ANOVA aplicado nas médias das amostras das $\mathrm{V}_{\mathrm{THS}}$ extraídas experimentalmente dos DnMs, OnM e CnM durante as aplicações das radiações ionizantes do tipo raios-X, valendo-se de uma polarização no modo Analog 169 
Figura 71 - Histograma da amostra de dados das $\mathrm{V}_{\mathrm{TH}} \mathrm{S}$ extraídas experimentalmente dos DnMs, OnM e CnM durante as aplicações das radiações ionizantes do tipo raios-X, valendo-se de uma polarização no modo Analog

Figura 72 - Gráfico dos intervalos máximos e mínimos e dos valores médios das $\mathrm{V}_{\mathrm{TH}} \mathrm{S}$ extraídas experimentalmente dos DnMs, OnM e CnM durante as aplicações das radiações ionizantes do tipo raios-X, valendo-se de uma polarização no modo Analog. 172 Figura 73 - As hipóteses nula e alternativa levadas em conta para a aplicação do teste de Anderson - Darling nas amostras das SSs extraídas experimentalmente dos DnMs, OnM e CnM durante as aplicações das radiações ionizantes do tipo raios-X, valendo-se de uma polarização no modo Analog

Figura 74 - Hipóteses nula e alternativa levadas em conta para a aplicação do teste para comparação de duas variâncias das SSs extraídas experimentalmente dos DnMs, OnM e $\mathrm{CnM}$ durante as aplicações das radiações ionizantes do tipo raios-X, valendo-se de uma polarização no modo Analog 174

Figura 75 - As hipóteses nula e alternativa levadas em conta para a aplicação do teste ANOVA nos valores médios das SSs extraídas experimentalmente dos DnMs, OnM e $\mathrm{CnM}$ durante as aplicações das radiações ionizantes do tipo raios-X, valendo-se de uma polarização no modo Analog 176 Figura 76 - Histograma das SSs extraídas experimentalmente dos DnMs, OnM e CnM durante as aplicações das radiações ionizantes do tipo raios-X, valendo-se de uma polarização no modo Analog

Figura 77 - Gráfico dos intervalos máximos e mínimos e dos valores médios das SSs extraídas experimentalmente dos DnMs, OnM e CnM durante as aplicações das radiações ionizantes do tipo raios-X, valendo-se de uma polarização no modo Analog. Figura 78 - Procedimento para a obtenção das amostras das $\mathrm{V}_{\mathrm{THS}}$ e SSs extraídas dos DnMs, OnM e CnM durante as aplicações das radiações ionizantes do tipo raios-X, valendo-se de uma polarização no modo Off-state 181 Figura 79 - Diagrama de blocos para a aplicação dos testes estatísticos ANOVA e de Tukey das $\mathrm{V}_{\mathrm{TH}}$ e e SSs extraídas experimentalmente dos DnMs, OnM e CnM durante as aplicações das radiações ionizantes do tipo raios-X, valendo-se de uma polarização no modo Off-state.

Figura 80 - As hipóteses nula e alternativa levadas em conta para a aplicação do teste de Anderson - Darling nas amostras das $\mathrm{V}_{\mathrm{THS}}$ extraídas experimentalmente dos DnMs, OnM 
e CnM durante as aplicações das radiações ionizantes do tipo raios-X, valendo-se de uma polarização no modo Off-state

Figura 81 - Hipóteses nula e alternativa levadas em conta para a aplicação do teste para comparação de duas variâncias das amostras das $\mathrm{V}_{\mathrm{TH}} \mathrm{S}$ extraídas experimentalmente dos DnMs, OnM e CnM durante as aplicações das radiações ionizantes do tipo raios-X, valendo-se de uma polarização no modo Off-state 186 Figura 82 - As hipóteses nula e alternativa levadas em conta para a aplicação do teste ANOVA aplicado nas médias das amostras das $\mathrm{V}_{\mathrm{THS}}$ extraídas experimentalmente dos DnMs, OnM e CnM durante as aplicações das radiações ionizantes do tipo raios-X, valendo-se de uma polarização no modo Off-state.

Figura 83 - Histograma da amostra de dados das $\mathrm{V}_{\mathrm{TH}} \mathrm{S}$ extraídas experimentalmente dos DnMs, OnM e CnM durante as aplicações das radiações ionizantes do tipo raios-X, valendo-se de uma polarização no modo Off-state 190 Figura 84 - Gráfico dos intervalos máximos e mínimos e dos valores médios das $\mathrm{V}_{\mathrm{TH}} \mathrm{S}$ extraídas experimentalmente dos DnMs, OnM e CnM durante as aplicações das radiações ionizantes do tipo raios-X, valendo-se de uma polarização no modo Off-state Figura 85 - As hipóteses nula e alternativa levadas em conta para a aplicação do teste de Anderson - Darling nas amostras das SSs extraídas experimentalmente dos DnMs, OnM e CnM durante as aplicações das radiações ionizantes do tipo raios-X, valendo-se de uma polarização no modo Off-state.

Figura 86 - Hipóteses nula e alternativa levadas em conta para a aplicação do teste para comparação de duas variâncias das amostras das SSs extraídas experimentalmente dos DnMs, OnM e CnM durante as aplicações das radiações ionizantes do tipo raios-X, valendo-se de uma polarização no modo Off-state...

Figura 87 - As hipóteses nula e alternativa levadas em conta para a aplicação do teste ANOVA aplicado nas médias das amostras das SSs extraídas experimentalmente dos DnMs, OnM e CnM durante as aplicações das radiações ionizantes do tipo raios-X, valendo-se de uma polarização no modo Off-state.

Figura 88 - Histograma da amostra de dados das SSs extraídas experimentalmente dos DnMs, OnM e CnM durante as aplicações das radiações ionizantes do tipo raios-X, valendo-se de uma polarização no modo Off-state

Figura 89 - Gráfico dos intervalos máximos e mínimos e dos valores médios das SSs extraídas experimentalmente dos DnMs, OnM e CnM durante as aplicações das radiações ionizantes do tipo raios-X, valendo-se de uma polarização no modo Off-state 198 


\section{LISTA DE TABELAS}

Tabela 1 - Exemplo de uma tabela que descreve o procedimento utilizado para o cálculo das médias de "k" amostras

Tabela 2 - Características dimensionais dos DnMs, OnMs e CnMs de SiGe utilizados nos estudos experimentais.

Tabela 3 - Condições adotadas para efetuar a configuração do difratômetro para a aplicação das radiações ionizantes de raios-X nas amostras

Tabela 4 - Valores dos desvios-padrão em relação às $V_{\mathrm{THS}}$ extraídas experimentalmente dos dispositivos DnMs, OnMs e CnMs em função das TIDs estudadas, na condição sem polarização elétrica durante o procedimento das radiações ionizantes de raios-X........ 135 Tabela 5 - Valores dos desvios-padrão em relação às SSs extraídas experimentalmente dos dispositivos DnMs, OnMs e CnMs em função das TIDs estudadas, na condição sem polarização elétrica durante o procedimento das radiações ionizantes de raios-X....... 137 Tabela 6 - Valores dos erros relativos calculados e descritos como $\varepsilon_{\mathrm{r} 1}, \varepsilon_{\mathrm{r} 2}, \varepsilon_{\mathrm{r} 3}, \varepsilon_{\mathrm{r} 4}$ e $\varepsilon_{\mathrm{r} 5}$ em função das TIDs estudadas

Tabela 7 - Coeficientes de variação dos parâmetros $\mathrm{I}_{\mathrm{DSsa}} /(\mathrm{W} / \mathrm{L}), \operatorname{gm}_{\mathrm{MAX}} /(\mathrm{W} / \mathrm{L})$, $\operatorname{gm}_{\mathrm{MAX}} / \mathrm{I}_{\mathrm{DSsat}}, \mathrm{R}_{\mathrm{DSon}} /(\mathrm{L} / \mathrm{W}), \mathrm{g}_{\mathrm{D}} /(\mathrm{W} / \mathrm{L}), \mathrm{V}_{\mathrm{EA}} / \mathrm{L}, \mathrm{f}_{\mathrm{T}} /(\mathrm{W} / \mathrm{L}), \mathrm{A}_{\mathrm{V}}, \mathrm{I}_{\mathrm{ON}} /(\mathrm{W} / \mathrm{L}), \mathrm{I}_{\mathrm{OFF}} /(\mathrm{W} / \mathrm{L})$, ION/IOFF e ILEAK/(W/L) extraídos experimentalmente dos CnMs, para cada uma das TIDs estudadas

Tabela 8 - Coeficientes de variação dos parâmetros $\mathrm{I}_{\mathrm{DSsa}} /(\mathrm{W} / \mathrm{L}), \operatorname{gm}_{\mathrm{MAX}} /(\mathrm{W} / \mathrm{L})$, $\mathrm{gm}_{\mathrm{MAX}} / \mathrm{I}_{\mathrm{DSsat}}, \mathrm{R}_{\mathrm{DSon}} /(\mathrm{L} / \mathrm{W}), \mathrm{g}_{\mathrm{D}} /(\mathrm{W} / \mathrm{L}), \mathrm{V}_{\mathrm{EA}} / \mathrm{L}, \mathrm{f}_{\mathrm{T}} /(\mathrm{W} / \mathrm{L}), \mathrm{Av}_{\mathrm{v}}, \mathrm{I}_{\mathrm{ON}} /(\mathrm{W} / \mathrm{L}), \mathrm{I}_{\mathrm{OFF}} /(\mathrm{W} / \mathrm{L})$, $\mathrm{I}_{\mathrm{ON}} / \mathrm{I}_{\mathrm{OFF}}$ e $\mathrm{I}_{\mathrm{LEAK}} /(\mathrm{W} / \mathrm{L})$ extraídos experimentalmente dos DnMs, para cada uma das TIDs estudadas

Tabela 9 - Coeficientes de variação dos parâmetros $\mathrm{I}_{\mathrm{DSsa}} /(\mathrm{W} / \mathrm{L}), \operatorname{gm}_{\mathrm{MAX}} /(\mathrm{W} / \mathrm{L})$, $\operatorname{gm}_{\mathrm{MAX}} / \mathrm{I}_{\mathrm{DSsat}}, \mathrm{R}_{\mathrm{DSon}} /(\mathrm{L} / \mathrm{W}), \mathrm{g}_{\mathrm{D}} /(\mathrm{W} / \mathrm{L}), \mathrm{V}_{\mathrm{EA}} / \mathrm{L}, \mathrm{f}_{\mathrm{T}} /(\mathrm{W} / \mathrm{L}), \mathrm{A}_{\mathrm{V}}, \mathrm{I}_{\mathrm{ON}} /(\mathrm{W} / \mathrm{L}), \mathrm{I}_{\mathrm{OFF}} /(\mathrm{W} / \mathrm{L})$, ION/IOFF e I IEAK/(W/L) extraídos experimentalmente dos OnMs, para cada uma das TIDs estudadas

Tabela 10 - Valores médios dos coeficientes de variação dos parâmetros $\mathrm{I}_{\mathrm{DSsat}}(\mathrm{W} / \mathrm{L})$, $\mathrm{gm}_{\mathrm{MAX}} /(\mathrm{W} / \mathrm{L}), \mathrm{gm}_{\mathrm{MAX}} / \mathrm{I}_{\mathrm{DSsat}}, \mathrm{R}_{\mathrm{DSon}} /(\mathrm{L} / \mathrm{W}), \mathrm{g}_{\mathrm{D}} /(\mathrm{W} / \mathrm{L}), \mathrm{V}_{\mathrm{EA}} / \mathrm{L}, \mathrm{f}_{\mathrm{T}} /(\mathrm{W} / \mathrm{L}), \mathrm{Av}_{\mathrm{v}}, \mathrm{I}_{\mathrm{ON}} /(\mathrm{W} / \mathrm{L})$, $\mathrm{I}_{\mathrm{OFF}} /(\mathrm{W} / \mathrm{L}), \mathrm{I}_{\mathrm{ON}} / \mathrm{I}_{\mathrm{OFF}}$ e $\mathrm{I}_{\mathrm{LEAK}} /(\mathrm{W} / \mathrm{L})$ extraídos experimentalmente dos CnMs, DnMs e OnMs, para cada uma das TIDs estudadas neste trabalho 146 
Tabela 11 - Valores dos desvios-padrão das $\mathrm{V}_{\mathrm{TH}} \mathrm{S}$ extraídas experimentalmente dos dispositivos OnMs e CnMs em função das TIDs estudadas

Tabela 12 - Valores dos desvios-padrão das SSs extraídas experimentalmente dos dispositivos OnMs e CnMs em função das TIDs estudadas. 158

Tabela 13 - Valores dos erros relativos calculados e descritos como $\varepsilon_{\mathrm{r} 1}, \varepsilon_{\mathrm{r} 2}$ e $\varepsilon_{\mathrm{r} 3}$ em função das TIDs estudadas 160

Tabela 14 - Valores de p do teste estatístico de Anderson - Darling das V $\mathrm{V}_{\mathrm{THS}}$ extraídas experimentalmente dos DnMs, OnM e CnM, considerando-se de uma polarização no modo Analog, durante o procedimento das radiações ionizantes de raios-X. 166 Tabela 15 - Valores de p do teste para comparação de duas variâncias das $\mathrm{V}_{\mathrm{THS}}$ extraídas experimentalmente dos DnMs, OnM e CnM considerando-se de uma polarização no modo Analog, durante o procedimento das radiações ionizantes de raios-X e razão estimada entre as variâncias analisadas. 168

Tabela 16 - Resultado do teste ANOVA das médias das amostras das $\mathrm{V}_{\mathrm{THS}}$ extraídas experimentalmente dos DnMs, OnM e CnM considerando-se de uma polarização no modo Analog, durante o procedimento das radiações ionizantes de raios-X.

Tabela 17 - Resultado do teste estatístico de Tukey aplicado às médias das $\mathrm{V}_{\mathrm{TH}} \mathrm{S}$ extraídas experimentalmente dos DnMs, OnM e CnM considerando-se de uma polarização no modo Analog, durante o procedimento das radiações ionizantes de raios-X ................ 170 Tabela 18 - Valores de p do teste estatístico de Anderson - Darling das SSs extraídas experimentalmente dos DnMs, OnM e CnM considerando-se de uma polarização no modo Analog, durante o procedimento das radiações ionizantes de raios-X 174 Tabela 19 - Valores de p do teste para comparação de duas variâncias das SSs extraídas experimentalmente dos DnMs, OnM e CnM considerando-se de uma polarização no modo Analog durante o procedimento das radiações ionizantes de raios-X, e a razão estimada entre as variâncias analisadas. 175 Tabela 20 - Resultado do teste ANOVA das médias das SSs extraídas experimentalmente dos DnMs, OnM e CnM considerando-se de uma polarização no modo Analog durante o procedimento das radiações ionizantes de raios-X.

Tabela 21 - Resultado do teste estatístico de Tukey nos valores médios das SSs extraídas experimentalmente dos DnMs, OnM e CnM considerando-se de uma polarização no modo Analog, durante o procedimento das radiações ionizantes de raios-X 178 
Tabela 22 - Valores de p do teste estatístico de Anderson - Darling das $\mathrm{V}_{\mathrm{THS}}$ extraídas experimentalmente dos DnMs, OnM e CnM considerando-se de uma polarização no modo Off-state, durante o procedimento das radiações ionizantes de raios-X

Tabela 23 - Valores de $\mathrm{p}$ do teste para comparação de duas variâncias das $\mathrm{V}_{\mathrm{TH}} \mathrm{S}$ extraídas experimentalmente dos DnMs, OnM e CnM considerando-se de uma polarização no modo Off-state, durante o procedimento das radiações ionizantes de raios-X e razão estimada entre as variâncias analisadas. 186

Tabela 24 - Resultado do teste ANOVA dos valores médios das $\mathrm{V}_{\mathrm{THS}}$ extraídas experimentalmente dos DnMs, OnM e CnM considerando-se de uma polarização no modo Off-state, durante o procedimento das radiações ionizantes de raios-X 188 Tabela 25 - Resultado do teste estatístico de Tukey nas médias das $\mathrm{V}_{\mathrm{TH}} \mathrm{S}$ extraídas experimentalmente dos DnMs, OnM e CnM considerando-se de uma polarização no modo Off-state, durante o procedimento das radiações ionizantes de raios-X 189 Tabela 26 - Valores de p do teste estatístico de Anderson - Darling das SSs extraídas experimentalmente dos $\mathrm{DnMs}$, OnM e CnM considerando-se de uma polarização no modo Off-state, durante o procedimento das radiações ionizantes de raios-X.

Tabela 27 - Valores de p do teste para comparação de duas variâncias das SSs extraídas experimentalmente dos DnMs, OnM e CnM considerando-se de uma polarização no modo Off-state durante o procedimento das radiações ionizantes de raios-X e razão estimada entre as variâncias analisadas. 194

Tabela 28 - Resultado do teste ANOVA das médias das amostras das SSs extraídas experimentalmente dos DnMs, OnM e CnM considerando-se de uma polarização no modo Off-state, durante o procedimento das radiações ionizantes de raios-X.

Tabela 29 - Resultado do teste estatístico de Tukey nos valores médios das SSs extraídas experimentalmente dos DnMs, OnM e CnM considerando-se de uma polarização no modo Off-state, durante o procedimento das radiações ionizantes de raios-X 196 


\section{LISTA DE SÍMBOLOS}

\begin{tabular}{|c|c|}
\hline $\mathrm{A}_{\mathrm{G}}$ & Área da porta do MOSFET $\left[\mathrm{m}^{2}\right]$ \\
\hline$A_{V}$ & Ganho de tensão intrínseco do MOSFET (V/V) \\
\hline $\mathrm{b}$ & Menor comprimento de canal (m) \\
\hline B & Maior comprimento de canal (m) \\
\hline $\mathrm{B}^{\prime}$ & $\begin{array}{l}\text { Comprimento de Canal do DnM que resultará no comprimento de canal } \\
\text { do OnM (m) }\end{array}$ \\
\hline $\mathrm{c}$ & Fator de corte do MOSFET do tipo Octo [\%] \\
\hline$C^{\prime}$ & $\begin{array}{l}\text { Quantidade de comparações a ser realizada para a aplicação do teste } \\
\text { estatístico de Tukey }\end{array}$ \\
\hline $\mathrm{C}_{\mathrm{ox}}$ & Capacitância do óxido de porta por unidade de área $\left(\mathrm{F} / \mathrm{m}^{2}\right)$ \\
\hline $\mathrm{C}_{\mathrm{L}}$ & Capacitância de carga $[\mathrm{F}]$ \\
\hline $\mathrm{e}^{+}$ & Pósitron \\
\hline $\mathrm{e}^{-}$ & Elétron \\
\hline $\mathrm{E}$ & Campo elétrico longitudinal (V/m) \\
\hline$f_{g}$ & Fator geométrico (adimensional) \\
\hline $\mathrm{f}_{\mathrm{T}}$ & Frequência de ganho de tensão unitário (Hz) \\
\hline$g_{\mathrm{D}}$ & Condutância de Dreno (S) \\
\hline $\mathrm{gl}$ & Graus de liberdade \\
\hline gm & Transcondutância (S) \\
\hline gm $_{\text {máx }}$ & Transcondutância máxima (S) \\
\hline $\mathrm{H}_{0}$ & Hipótese Nula \\
\hline $\mathrm{H}_{1}$ & Hipótese Alternativa \\
\hline IDS & Corrente entre dreno e fonte de um MOSFET (A) \\
\hline IDSsat & Corrente de dreno na região de saturação de um MOSFET (A) \\
\hline $\mathrm{I}_{\text {LEAK }}$ & Corrente de fuga de um MOSFET [A] \\
\hline IOFF & Corrente de dreno de estado desligado de um MOSFET [A] \\
\hline $\mathrm{I}_{\mathrm{ON}}$ & Corrente de dreno de estado ligado de um MOSFET [A] \\
\hline $\mathrm{L}$ & Comprimento do canal (m) \\
\hline Lef & Comprimento efetivo do canal do MOSFET (m) \\
\hline $\mathrm{N}_{\mathrm{A}}$ & Concentração de impurezas aceitadoras em um semicondutor $\left(\mathrm{m}^{-3}\right)$. \\
\hline q & Carga elementar do elétron $\left(\mathrm{q}=1,6 \times 10^{-19} \mathrm{C}\right)$ \\
\hline$Q_{\mathrm{n}}$ & Quantidade total de elétrons ao longo do canal (adimensional) \\
\hline
\end{tabular}


Qox Densidade de carga fixa no óxido de porta do transistor MOS convencional $\left(\mathrm{C} / \mathrm{m}^{2}\right)$

$\mathrm{R}_{\mathrm{DSon}} \quad$ Resistência série entre dreno e fonte de estado ligado $(\Omega)$

$\mathrm{S}$

Desvio-padrão

$\mathrm{s}^{2} \quad$ Variância

SS

Inclinação de sublimiar ( $\mathrm{mV} /$ década)

$\mathrm{SiO}_{2} \quad$ Óxido de silício

$t_{\text {ox }}$

Espessura do óxido de porta de um MOSFET (m)

$\mathrm{V}_{\mathrm{D}}$

Tensão de dreno (V)

$\mathrm{V}_{\mathrm{DD}}$

Tensão de alimentação (V)

$\mathrm{V}_{\mathrm{DS}}$

Tensão entre os terminais de dreno e fonte de um MOSFET (V)

VDSAT

Tensão entre dreno e fonte de saturação (V)

VEA

Tensão Early (V)

$\mathrm{V}_{\mathrm{FB}}$

Tensão de faixa plana (V)

$\mathrm{V}_{\mathrm{G}}$

Tensão de porta (V)

$\mathrm{V}_{\mathrm{GS}}$

Tensão entre os terminais de porta e fonte (V)

$\mathrm{V}_{\mathrm{GT}}$

Sobretensão de porta (V)

$\mathrm{V}_{\mathrm{S}}$

Tensão da fonte (V)

$\mathrm{V}_{\mathrm{TH}}$

Tensão de limiar (V)

$\mathrm{W}$

Largura de canal (m)

$\mathrm{W}_{\mathrm{R}}$

Largura da parte retangular do hexágono da região de canal do DnM (m)

$\mathrm{W}_{\mathrm{T}}$

Largura da parte trapezoidal do hexágono da região de canal do DnM (m)

W/L Fator geométrico ou razão de aspecto

Xdmáx

Espessura máxima da camada de depleção (m)

$\alpha$

Ângulo entre as junções metalúrgicas do filme de silício (região do canal)

e as regiões de dreno e fonte decorrente da geometria hexagonal e octogonal de porta do MOSFET do tipo Diamante e Octogonal, respectivamente $\left(^{\circ}\right)$

$\alpha^{\prime} \quad$ Nível de significância

$\varepsilon_{r} \quad$ Coeficiente de Variação (\%)

$\lambda \quad$ Fator de modulação do comprimento de canal [ $\left[\mathrm{V}^{-1}\right]$

$\bar{k} \quad$ Média de uma amostra

$\mu_{\mathrm{n}} \quad$ Mobilidade de elétrons na camada de inversão do MOSFET $\left[\mathrm{m}^{2} / \mathrm{V}\right.$.s $]$

$\varphi_{F} \quad$ Potencial de Fermi (V) 
Partícula fundamental múon de carga negativa

Partícula fundamental píon de carga negativa

$\pi^{+}$

Partícula fundamental píon de carga positiva

$\Delta \mathrm{I}_{\mathrm{DS}}$

Variação da corrente entre dreno e fonte (A)

$\Delta \mathrm{V}_{\mathrm{DS}}$

Variação da tensão entre dreno e fonte (V)

$\Delta \mathrm{V}_{\mathrm{TH}}$

Variação da $\mathrm{V}_{\mathrm{TH}}(\mathrm{V})$

$\Delta \mathrm{L}$

Redução do comprimento do canal em função do deslocamento do ponto de estrangulamento $(\mathrm{m})$ 


\section{LISTA DE SIGLAS}

ANOVA

BBR

CE

CI

CITAR

CMOS

$\mathrm{CM}$

$\mathrm{CnM}$

$\mathrm{CSnM}$

CTI

DD

DEPAMBBRE

DLECRE

DM

DnM

DSnM

ECS

ELT

ESD

FinFET

FEI

FET

GAA

GEO

HBD

IBM
Estudo estatístico denominado de Análise de Variância

Região de Bico de Pássaro (Bird's Beak Region)

Efeito de Canto (Corner Effect)

Circuito Integrado

Circuitos Integrados Tolerantes à Radiação (Projeto FINEP/CTI número 01.12.0224.00)

Metal-Óxido-Semicondutor Complementar (Complementary Metal-Oxide-Semiconductor)

Conventional MOSFET (geometria de porta retangular)

Conventional nMOSFET (geometria de porta retangular)

Conventional SOI nMOSFET (geometria de porta retangular)

Centro de Tecnologia da Informação Renato Archer

Danos por deslocamento (Displacement Damage)

Efeito da desativação dos MOSFETs parasitários das regiões de bico de pássaro (Deactivation of the Parasitic MOSFETs in the Bird's Beak Regions Effect)

Efeito da redução da corrente de fuga (Drain Leakage Current Reduction Effect)

Diamond MOSFET (geometria de porta hexagonal)

Diamond nMOSFET (geometria de porta hexagonal)

Diamond SOI nMOSFET (geometria de porta hexagonal)

The Electrochemical Society

MOSFET de leiaute fechado (Enclosed Layout Transistors)

Descargas eletrostáticas (Electrostatic Discharge)

Transistor de Efeito de Campo do tipo "Fin" (Fin Field Effect Transistor)

Fundação Educacional Inaciana Padre Sabóia de Medeiros

Transistor de efeito de campo (Field Effect Transistor)

Porta Circundante (Gate All Around)

Órbita Geoestacionária (Geosinchronous Equatorial Orbit)

Robustez pelo Estilo de Leiaute (Hardening-by-Design)

International Business Machines 
LCE

LEF

LEO

LOCOS

LERI

MEO

MEP

MIL-STD

MOS

MOSFET

nMOSFET

pMOSFET

$\mathrm{OM}$

OnM

PAMDLE

PEL

RF

RLEF

SAA

SCE

SEB

SEE

SEGR

SHE

SEL

SET

SEU

SQT

SQE

SQR

STI
Efeito de canto longitudinal (Longitudinal Corner Effect)

Campo Elétrico Longitudinal (Longitudinal Electric Field)

Satélites de Órbita Baixa (Low Earth Orbit)

Oxidação local do silício (LOCal Oxidation of Silicon)

Laboratório de Efeitos da Radiação Ionizante

Satélites de Órbita Média (Medium Earth Orbit)

Programa educacional MOSIS (MOSIS Educational Program)

Diretriz de teste military (Military Test Guideline)

Metal-Óxido-Semicondutor (Metal Oxide Semiconductor)

Transistor de Efeito de Campo Metal-Óxido-Semicondutor (Metal

Oxide Semiconductor Field Effect Transistor).

MOSFET do tipo "N"

MOSFET do tipo "P"

Octogonal MOSFET (geometria de porta octogonal)

Octogonal nMOSFET (geometria de porta octogonal)

Efeito da associação paralela de MOSFETs com diferentes comprimentos de canais (Parallel Association of MOSFETs with Different Channel Lengths).

Pares elétrons-lacunas

Rádio frequência

Linhas de Campo Elétrico Longitudinal Resultantes

Anomalia Magnética do Atlântico Sul (South Atlantic Anomaly)

Efeito de Canal Curto (Short Channel Effect)

Evento único de queima (Single Event Burnout)

Efeitos de evento único (Single Event Effects)

Evento de ruptura de porta (Single Event Gate Rupture)

Erro único fatal (Single Hard Error)

Evento de travamento único (Single Event Latchup)

Evento transiente único (Single Event Transient)

Evento perturbante único (Single Event Upset)

Soma de quadrados total

Soma de quadrados dos erros

Soma de quadrados da regressão

Isolação do tipo trincheira (Shallow-Trench Isolation) 
Transferência linear de energia

$\mathrm{UV}$

Raios ultravioleta

Wave MOSFET com formato do canal similar a letra "S" 


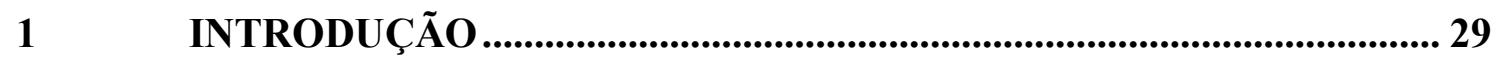

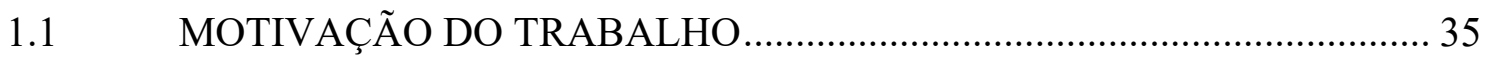

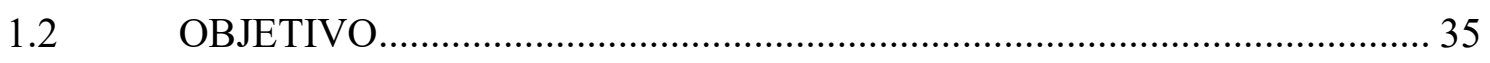

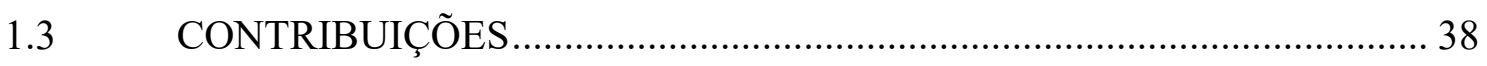

2 CONCEITOS FUNDAMENTAIS ........................................................... 39

2.1 PARÂMETROS ELÉTRICOS DOS MOSFETS ……………………........ 39

2.1.1 Tensão de Limiar $\left(\mathrm{V}_{\mathrm{TH}}\right)$............................................................................ 39

2.1.2 Transcondutância (gm)................................................................................ 41

2.1.3 Corrente Elétrica entre Dreno e Fonte (IDs) de um nMOSFET ............... 42

2.1.4 Resistência entre Dreno e Fonte de Estado Ligado (RSon) ........................ 44

2.1.5 Razão entre a transcondutância e a corrente de dreno (gm/IDs) .............. 45

2.1.6 Inclinação de Sublimiar (SS) ........................................................................ 46

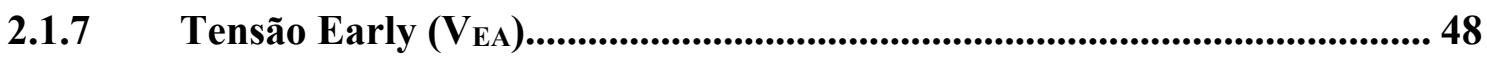

2.1.8 Corrente entre dreno e fonte de Estado Ligado (IoN), desligado (IOFF) e de fuga (ILEAK). ................................................................................................... 50

2.1.9 Ganho de tensão intrínseco de um MOSFET (Av) .................................... 51

2.1.10 Frequência de Ganho de Tensão Unitário (f $\left.\mathrm{f}_{\mathrm{T}}\right)$...........................................52

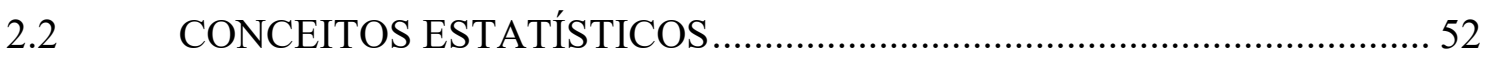

2.2.1 Variância $\left(\mathrm{s}^{2}\right)$...................................................................................... 52

2.2.2 Desvio-Padrão (s) (........................................................................................ 53

2.2.3 Graus de Liberdade (gl) ......................................................................... 53

2.2.4 Distribuição Normal .................................................................................... 54

2.2.5 Distribuição Qui - Quadrado..................................................................... 56

2.2.6 Testes Paramétricos e Não Paramétricos..................................................... 58

2.2.7 Testes de Hipóteses.......................................................................................... 58

2.2.8 Nível de Significância $\left(\alpha^{\prime}\right)$........................................................................ 59

2.2.9 Intervalo e Nível de Confiança.................................................................... 59

2.2.10 Coeficiente de Variação .......................................................................... 59

2.2.11 Testes Estatísticos Usados Neste Trabalho .................................................. 60

2.2.11.1 Teste estatístico de normalidade de Anderson - Darling .............................. 60

2.2.11.2 Teste estatístico para a comparação de duas variâncias ............................... 61

2.2.11.3 Teste estatístico da Análise de Variância (ANOVA)..................................... 65 
2.2.11.4 Teste estatístico de Tukey....................................................................................... 74

2.3 ESTUDO DAS PRINCIPAIS CARACTERÍSTICAS DOS MOSFETS DE LEIAUTE DE PORTA HEXAGONAL (MOSFET DIAMANTE) E OCTOGONAL (MOSFET OCTO), ....................................................... 76

2.3.1 MOSFET DE LEIAUTE DE PORTA HEXAGONAL ........................... 77

2.3.2 MOSFET DE LEIAUTE DE PORTA OCTOGONAL ............................ 84

2.4 EFEITOS DAS RADIAÇÕES IONIZANTES EM MOSFETS …................ 90

2.4.1 Tipos de Radiações Ionizantes ............................................................................. 92

2.4.2 Fontes de Radiações Ionizantes ...............................................................93

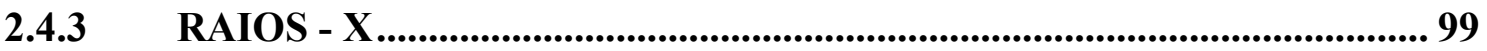

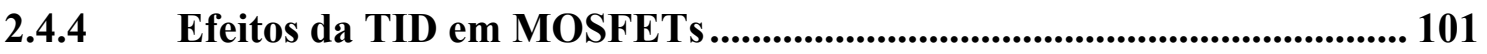

2.4.5 Influência da TID nos Parâmetros dos MOSFETs ................................... 104

2.4.5.1 Desvio da tensão de limiar ............................................................................... 105

2.4.5.2 Redução da transcondutância ........................................................... 106

2.4.5.3 Aumento da inclinação de sublimiar.............................................................. 106

2.4.5.4 Aumento da corrente de fuga ................................................................ 107

3 MATERIAIS E MÉTODOS .................................................................... 109

3.1 PROJETO E FABRICAÇÃO DOS NMOSFETS UTILIZADOS NESTE

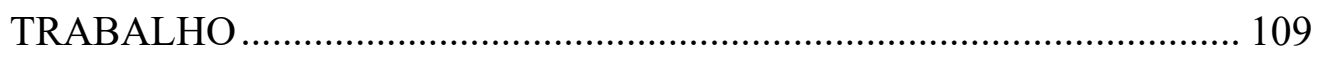

3.2 EQUIPAMENTOS UTILIZADOS NO DESENVOLVIMENTO DO

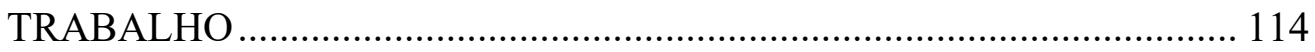

3.2.1 Aparelho de caracterização Keithley 4200 - SCS ..................................... 114

3.2.2 Fonte de alimentação Keithley 2636B ...................................................... 115

3.2.3 Difratômetro de raios-X Shimadzu XRD-6100 ........................................ 116

PROCEDIMENTOS EXPERIMENTAIS …............................................. 117

3.3.1 Caracterização elétrica dos dispositivos não encapsulados...................... 118

3.3.2 Caracterização elétrica dos dispositivos encapsulados ............................. 119

3.4 PROCESSO DE IRRADIAÇÃO POR RAIOS-X DOS DISPOSITIVOS .. 120

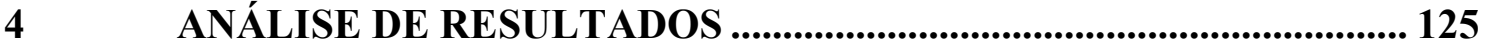

4.1 ANÁLISE COMPARATIVA EXPERIMENTAL ESTATÍSTICA DOS EFEITOS DA TID ENTRE NMOSFETS DE PORTA HEXAGONAL, OCTOGONAL E RETANGULAR, SEM QUE OS DISPOSITIVOS ESTIVESSEM POLARIZADOS DURANTE OS PROCEDIMENTOS DAS RADIAÇÕES IONIZANTES DE RAIOS-X 
4.1.1 Análise do Coeficiente de Variação da Tensão de Limiar (VTH) em Função das TIDs Estudadas . 128

4.1.2 Análise do Coeficiente de Variação da Inclinação de Sublimiar (SS) em Função das TIDs Estudadas 131

4.1.3 Estudo do coeficiente de variação entre a tensão de limiar e a inclinação de sublimiar. 138

4.1.4 Gráficos do tipo radar para a análise dos parâmetros $I_{D S s a t} /(W / L)$, $\operatorname{gm}_{M A X} /(W / L), g_{M A X} / I_{D S s a t}, R_{D S o n} /(L / W), g_{D} /(W / L), V_{E A} / L, f_{T} /(W / L), A v$, Ion/(W/L), IofF/(W/L), Ion/Ioff e ILEAK/(W/L) 141

4.2 ANÁLISE COMPARATIVA EXPERIMENTAL ESTATÍSTICA DOS EFEITOS DA TID ENTRE UM MOSFET DE PORTA OCTOGONAL E RETANGULAR, POLARIZADOS NO MODO ON-STATE DURANTE OS PROCEDIMENTOS DAS RADIAÇÕES IONIZANTES DE RAIOS-X ... 150

4.2.1 Análise do Coeficiente de Variação da Tensão de Limiar (VTH) em Função das TIDs Estudadas 152

4.2.2 Análise do Coeficiente de Variação da Inclinação de Sublimiar (SS) em Função das TIDs Estudadas. 154

4.2.3 Estudo do coeficiente de variação entre a tensão de limiar e a inclinação de sublimiar. 159

4.3 ESTUDO ESTATÍSTICO DOS EFEITOS DA TID ENTRE UM MOSFET DE PORTA HEXAGONAL, OCTOGONAL E RETANGULAR POLARIZADOS NO MODO ANALOG DURANTE OS PROCEDIMENTOS DAS RADIAÇÕES IONIZANTES DE RAIOS-X .................................. 162

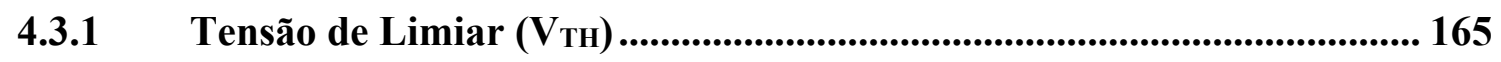

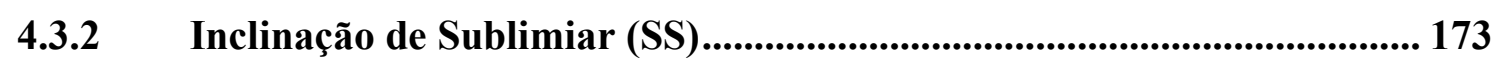

4.4 ESTUDO ESTATÍSTICO DOS EFEITOS DA TID ENTRE UM MOSFET DE PORTA HEXAGONAL, OCTOGONAL E RETANGULAR POLARIZADOS NO MODO OFF-STATE DURANTE OS PROCEDIMENTOS DAS RADIAÇÕES IONIZANTES DE RAIOS-X ... 181

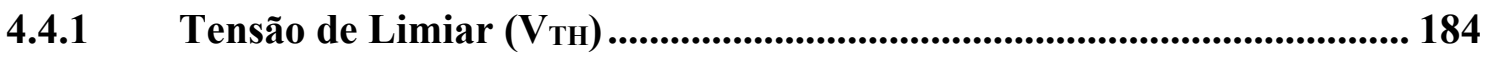

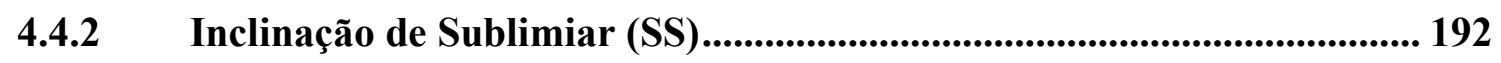

5 CONCLUSÕES E TRABALHOS FUTUROS ....................................... 199

REFERÊNCIAS ............................................................................... 203

APÊNDICE A - PUBLICAÇÕES............................................................... 212 


\section{INTRODUÇÃO}

Valendo-se dos avanços da microeletrônica, verifica-se que as empresas de dispositivos semicondutores e circuitos integrados (CIs), assim como a comunidade científica, vêm realizando elevados investimentos em pesquisas, visando a melhorar continuamente o desempenho elétrico e reduzir as dimensões dos dispositivos eletrônicos. Isto ocorre, fundamentalmente, objetivando-se a reduzir os custos dos equipamentos eletrônicos, principalmente os móveis (mobiles), os quais fazem parte do cotidiano da humanidade (microcomputadores pessoais, telefones celulares, televisores, marca-passos etc.) [1], [2]. Atualmente, a tecnologia mais utilizada para a fabricação de transistores e de circuitos integrados (CIs) é a Metal-Óxido-Semicondutor (Metal-OxideSemiconductor Field Effect Transistor, MOSFET), que podem ser implementados de forma planar e não planar (FinFETs, Multi-Gates, Surrouding-Gate, etc.) [3], [4]. Além disso, existem grandes investimentos também para mitigar os efeitos das radiações ionizantes nesses dispositivos eletrônicos, principalmente aquelas voltadas para as aplicações nas áreas aeroespacial, médica, de física nuclear e de partículas [5], [6]. Dessa forma, é de fundamental importância fazer todos os esforços para garantir que, mesmo sob a influência das radiações ionizantes, os dispositivos eletrônicos continuem funcionando de forma adequada, com confiabilidade e robustez nos sistemas eletrônicos onde são utilizados [6], [7]. Para apontar um exemplo, pode-se citar que nas aplicações espaciais, é imperativo que os CIs implementados com a tecnologia de fabricação do tipo Metal-Óxido-Semicondutor Complementar (Complementary Metal-OxideSemiconductor, CMOS) possuam uma maior tolerância aos efeitos das radiações ionizantes, visando a garantir o funcionamento correto dos sistemas eletrônicos. Assim, as melhorias implementadas nos MOSFETs que são aplicados na área espacial, também podem ser utilizadas nas aplicações em que os efeitos da Dose Total Ionizante (Total Ionizing Dose, TID) são importantes, como por exemplo, nos equipamentos eletrônicos destinados para área de aviônicos (computador de bordo etc.), nuclear (instrumentação etc.) e médicas (marca-passos etc.) [8].

No que diz respeito ao escalonamento dos dispositivos eletrônicos, o objetivo é pelo menos manter ou melhorar ainda mais os seus desempenhos elétricos e também as suas tolerâncias aos efeitos das radiações ionizantes, porém geralmente acarretam no surgimento dos efeitos secundários indesejados, tais como os efeitos de canal curto, o aumento da resistência parasitária de fonte e dreno, o aumento da corrente de fuga etc. 
[9], [10]. Além disso, observa-se que o processo de redução das dimensões também acarreta uma maior probabilidade de falhas nesses dispositivos em relação aos efeitos da TID, em que se tem como consequência a alteração da tensão de limiar $\left(\mathrm{V}_{\mathrm{TH}}\right)$, um aumento da corrente de fuga ( $\mathrm{I}_{\text {LEAK }}$ ), assim como a degradação da inclinação de sublimiar (SS) etc. [11]. Estas variações nos parâmetros elétricos e nas figuras de mérito decorrentes das radiações ionizantes ocorrem principalmente pela indução e armadilhamento de cargas positivas nas camadas isolantes (óxidos) dos MOSFETs [6], [8].

Neste cenário, verifica-se que existem muitas abordagens para permitir que os dispositivos eletrônicos continuem funcionando com confiabilidade nas mais diversas aplicações, como por exemplo a utilização de novos materiais de fabricação dos dispositivos semicondutores e CIs [12], [13], novas estruturas planares e tridimensionais dos MOSFETs [14], [15], novos processos de fabricação, etc. [16].

Pode-se afirmar que a tecnologia de silício-sobre-isolante (Silicon-On-Insulator, SOI) CMOS pode ser uma alternativa para a fabricação de CIs CMOS digitais e analógicos de baixa potência e de baixa tensão (Low-Power Low-Voltage, LPLV) devido às vantagens observadas dessa tecnologia em relação à tecnologia CMOS Convencional (Bulk) [17], tais como as menores capacitâncias parasitas, menor área utilizada de silício, menor efeito de canal curto (Short Channel Effect, SCE), menor estreitamento da barreira de potencial induzido pelo dreno (Drain Induced Barrier Lowering, DIBL), maior frequência de operação, proteção do dispositivo contra Latch-Up etc. [17].

Em relação aos transistores não planares, isto é, tridimensionais, com o objetivo de melhorar ainda mais o desempenho dos CIs CMOS analógicos e digitais, pode-se citar os casos dos Gate-All-Around (GAA) [18], FinFETs, DELTA, П-gate, $\Omega$-gate, Pillar Surrounding Gate (PSG) e CYNTHIA (transistor vertical com secção transversal circular), com base no processo de fabricação de CIs SOI CMOS, por apresentarem um maior controle eletrostático da região de porta do que aqueles observados pelos MOSFETs não planares [18], [19].

Deve-se ressaltar que uma possível alternativa para a implementação de MOSFETs, que não adiciona qualquer custo para o atual processo de fabricação de CIs CMOS, é a denominada de "Engenharia de Junção PN entre as regiões de Dreno-Canal e Canal-Fonte do MOSFET", que se refere ao uso de novos e diferentes estilos de leiautes de porta para a implementação de transistores que possuem formatos de porta não retangulares, ou seja, diferentemente dos MOSFETs convencionais [20]. Alguns exemplos dessas estruturas de leiaute não convencionais de porta são: SOI MOSFETs de 
porta em formato de Anel Circular (CGSMs) [21], [22], MOSFETs do tipo Wave (formato de porta semelhante a letra "S") [23], [24], [25] do tipo Fish [26], [27], do tipo Diamante [28], [29], do tipo Octogonal [30] e do tipo elipsoidal [31].

A mudança da geometria convencional de porta retangular para essas novas geometrias de porta, faz com que novos efeitos sejam incorporados à estrutura do MOSFET, tornando-os capazes de potencializar o seu desempenho elétrico e sua tolerância às radiações ionizantes. Pode-se citar como exemplos desses novos efeitos que potencializam o desempenho elétrico dos MOSFETS, o efeito de canto longitudinal (Longitudinal Corner Effect, LCE), efeito de conexões paralelas de MOSFETs com diferentes comprimentos de canal (PArallel connections of MOSFETs with Different channel Lengths Effect, PAMDLE), efeito da redução da corrente de fuga (Drain LEakage Current Reduction Effect, DLECRE), e quanto à melhoria da robustez às radiações ionizantes, o efeito de desativação dos MOSFETs parasitários nas regiões de bico de pássaro (DEactivation of the PArasitic MOSFETs in the Bird's Beak Regions Effect, DEPAMBBRE) [20].

Dentro do contexto dos MOSFETs do tipo planares, o transistor denominado de MOSFET do tipo Diamante (Diamond MOSFET, DM), foi patenteado no ano de 2008 com o propósito de apresentar melhorias nos seus parâmetros elétricos e figuras de mérito [30]. A Figura 1 ilustra um exemplo do leiaute de um DM.

Figura 1 - Exemplo de um leiaute do MOSFET do tipo Diamante

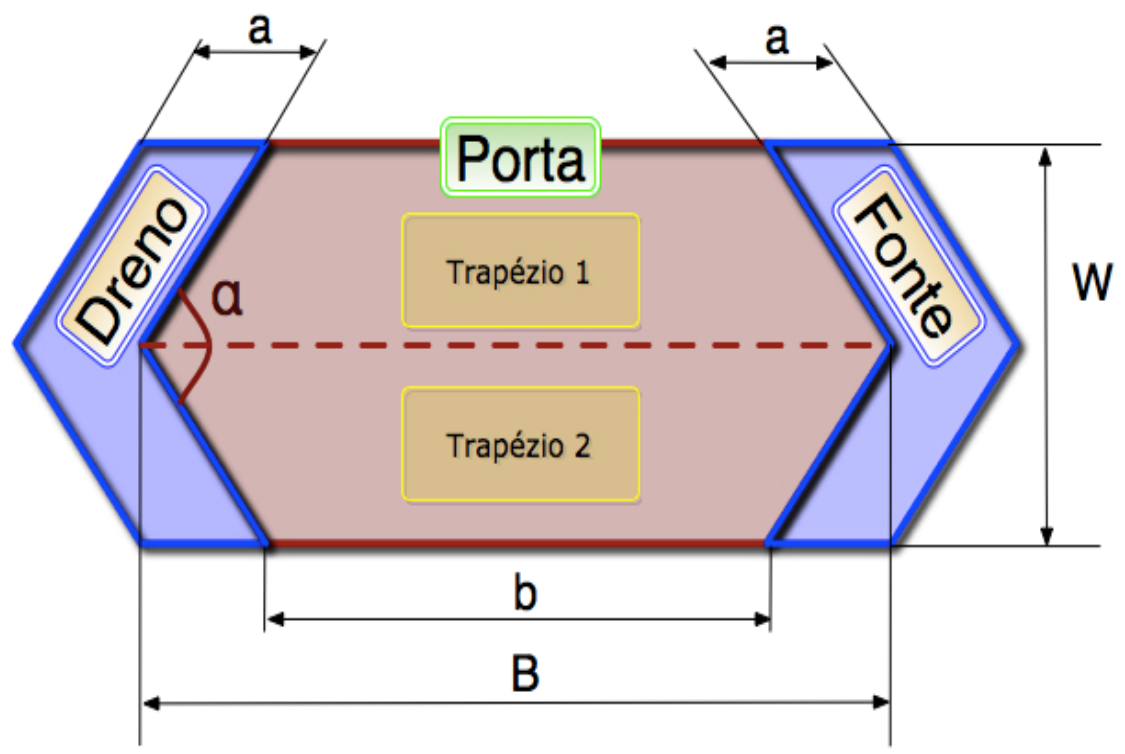

Fonte: Autor 
Na Figura 1, b e B são os comprimentos das bases menor e maior dos dois trapézios que compõem a região hexagonal da porta (trapézios 1 e 2), respectivamente, W é a largura do canal, $\alpha$ é o ângulo entre as junções metalúrgicas do filme de silício (região do canal) e as regiões de dreno e fonte decorrente da geometria de porta hexagonal do MOSFET do tipo Diamante e o termo "a" é o comprimento das regiões de dreno e de fonte [32].

Alguns trabalhos científicos sobre esses novos estilos de leiautes para MOSFETs foram realizados e um desses estudos realizou uma análise comparativa experimental dos efeitos dos raios-X entre as tensões de limiar $\left(\mathrm{V}_{\mathrm{TH}}\right)$ dos SOI nMOSFETs do tipo Diamante (DSnM) e os Convencionais equivalentes [33]. Todos os dispositivos foram polarizados no modo On-state durante o processo de radiação de raios-X para reproduzir as condições reais de operação [33]. Foram utilizados neste estudo seis SOI nMOSFETs de 0,35 $\mu \mathrm{m}$ AMI (On-Semiconductor). Foi mostrado por meio de dados experimentais, que os dispositivos SOI nMOSFETs do tipo Diamante apresentam maiores tolerâncias aos efeitos da TID, provenientes das radiações de raios-X, em comparação aos resultados encontrados nos SOI nMOSFETs Convencionais equivalentes, considerando que eles apresentam os mesmos fatores geométricos $\left(f_{g}\right)$, as mesmas áreas de porta $\left(A_{G}\right)$ e as mesmas condições de polarização [33]. Assim, as V THS dos DSnMs foram menos afetadas do que aquelas dos SOI nMOSFETs Convencionais (CSnM) equivalentes, pois os DSnMs apresentam menores regiões de bico de pássaro em comparação aquelas encontradas nos SOI nMOSFETs convencionais equivalentes e porque eles apresentam o efeito DEPAMBBRE, o que torna os dispositivos DSnM uma excelente alternativa para aplicações em circuitos integrados (CIs) em ambientes radioativos [33].

Outro estudo desenvolvido, foi a análise comparativa experimental dos efeitos das radiações ionizantes de prótons entre nMOSFETs do tipo Diamante com diferentes ângulos $\alpha\left(36,9^{\circ}, 90,0^{\circ}\right.$ e $\left.144,1^{\circ}\right)$ e os seus convencionais equivalentes, considerando-se que eles apresentaram os mesmos $f_{g}$, as mesmas $A_{G}$ e as mesmas condições de polarização [34]. Todos os dispositivos foram polarizados no modo On-state durante o processo de radiação de prótons para reproduzir condições reais de operação [34]. Os dispositivos foram desenvolvidos por meio do processo comercial de manufatura CMOS convencional (bulk) de 0,35 $\mu \mathrm{m}$ AMI (On-Semiconductor) [34]. Observou-se que os nMOSFETs do tipo Diamante, com um ângulo $\alpha$ igual a $90^{\circ}$, apresentaram maior robustez às radiações ionizantes de prótons em comparação aos resultados experimentais observados nos nMOSFETs convencionais equivalentes [34]. Foi visto nesse trabalho que os nMOSFETs 
do tipo Diamante, com um ângulo $\alpha$ igual a $90,0^{\circ}$, apresentaram menores variações das $\mathrm{V}_{\mathrm{THS}}$ (aproximadamente de 3 vezes menor) quando comparados aos resultados encontrados nos nMOSFETs convencionais equivalentes [34], pois apresentam as regiões de bico de pássaro menores do que aquelas presentes nos nMOSFETs convencionais equivalentes [34].

Deve-se ressaltar também que o MOSFET de leiaute de porta octogonal (MOSFET Octo, OM), já foi objeto de muitos estudos comparativos anteriores. A Figura 2 ilustra um exemplo do leiaute de um OM.

Figura 2 - Exemplo de um leiaute do MOSFET do tipo Octogonal

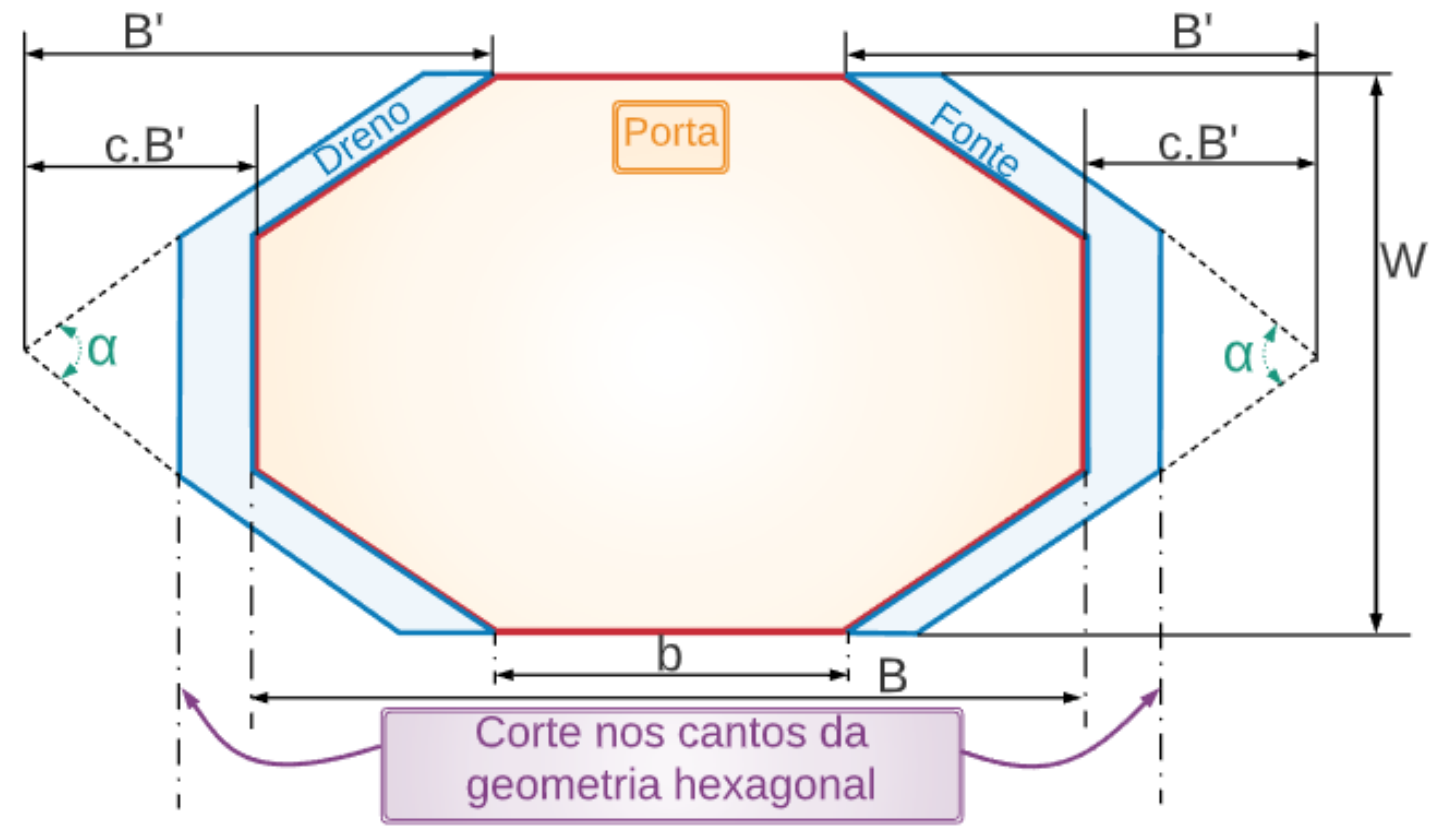

Fonte: Autor

Analisando a Figura 2, "W" representa a largura de canal, "b" e "B" indicam o menor e maior comprimentos de canal (respectivamente), B' é o comprimento de canal do DM que dá origem a estrutura octogonal, "c" é o fator de corte que indica a redução percentual aplicada nas extremidades da geometria hexagonal para obter a estrutura octogonal, " $\alpha$ " indica o ângulo de um DM que deu origem ao OM.

Entre os trabalhos publicados relacionados aos OMs, ressalta-se um estudo comparativo por meio de simulação tridimensional com seu MOSFET convencional equivalente (MOSFET convencional, CM, de porta retangular com mesma área de porta e largura de canal do MOSFET OM) [31], estudos experimentais para comparação das características elétricas do OM com seu CM equivalente [35], [36] e estudos 
comparativos experimentais sobre a influência das radiações ionizantes no $\mathrm{OM}$ e seu CM equivalente [37], [38], [39], [40]. Todos esses estudos foram realizados com MOSFETs do tipo SOI e com tecnologias de $0,35 \mu \mathrm{m}$.

Além disso, estudos experimentais sobre os efeitos das radiações ionizantes no $\mathrm{OM}$ e no seu $\mathrm{CM}$ equivalente, indicaram uma maior tolerância do $\mathrm{OM}$ às radiações ionizantes que o CM equivalente [37], [38], [39], [40]. Entre os resultados obtidos, o OM apresentou uma corrente de fuga quase sem variação, enquanto no CM equivalente, a corrente de fuga aumentou mais de 9 vezes [37]. A inclinação de sublimiar apresentou uma variação cerca de 8\% menor no OM em comparação ao seu CM equivalente, nas mesmas condições de polarização e de exposição às radiações ionizantes [39]. Ademais, uma outra maneira de se estudar a variabilidade dos parâmetros elétricos e figuras de mérito de dispositivos eletrônicos e como estes podem ser afetados em várias condições de operação, como por exemplo em ambientes de radiação ionizantes, é por meio do estudo do descasamento entre dispositivos [41], [42], [43].

Entre os trabalhos publicados relacionados ao estudo do descasamento entre dispositivos, utilizou-se a aplicação do conceito de variância estatística da tensão de limiar de dispositivos nMOS em um efeito parasita que pode ter um forte impacto no casamento de tensão de porta de pares diferenciais e, como consequência, no desempenho do circuito analógico [41]. Assim, por meio da análise da variância da tensão de limiar, várias soluções foram propostas para limitar ou remover esse efeito parasita [41].

Em um outro estudo publicado sobre a análise do descasamento entre dispositivos, foi desenvolvida uma investigação no descasamento entre correntes de dreno nos canais de MOSFETs devido a flutuações de dopantes locais e foi proposto um novo modelo microscópico de transistor para analisar o impacto da flutuação de dopante local no descasamento do MOSFET de canal longo [43]. Neste estudo foi desenvolvido um novo modelo que é consistente com a observação experimental recente e pode explicar as discrepâncias entre os dados e os modelos existentes. A análise indica que a flutuação de dopante local é a principal causa e é responsável por cerca de $60 \%$ a $80 \%$ do descasamento de corrente quando o MOSFET é operado com tensão de porta baixa, um regime de operação usual para impedância de saída mais alta [43].

Além disso, uma outra figura de mérito também utilizada para quantificar analiticamente o descasamento dos parâmetros elétricos dos dispositivos é o coeficiente de variação [ $\left.\varepsilon_{\mathrm{r}}(\%)\right]$ em porcentagem (\%) [44], [45]. Nestes estudos, o coeficiente de variação foi utilizado como ferramenta estatística em uma amostra de 360 dispositivos 
para estudar o descasamento do estilo de leiaute Diamante (formato de porta hexagonal) nos MOSFETs SOI tipo n (nMOSFETs) em comparação com o estilo de leiaute retangular tradicional, valendo-se dos mesmos valores de $\mathrm{W}$, área de porta e condições de polarização. Os resultados demonstraram que os DSnM com ângulos $\alpha$ iguais a $90^{\circ}$ são capazes de aumentar em mais de 45\% em média, com um desvio-padrão de 20,1\%, o casamento entre dispositivos em comparação aos observados com os CSnM equivalentes [44], [45].

\subsection{MOTIVAÇÃO DO TRABALHO}

O descasamento entre dispositivos pode causar variações aleatórias, independentes do tempo, em parâmetros elétricos de dispositivos com leiautes idênticos [42]. Assim, pode-se afirmar que o descasamento é um fator limitante no processamento de sinal analógico de uso geral, mas especialmente em sistemas analógicos multiplexados, conversores digital para analógico etc. [42]. Em circuitos digitais, o estudo do casamento entre dispositivos também pode ser importante, por exemplo, na leitura e gravação em circuitos de memórias digitais [42]. Além disso, pode-se afirmar que o impacto do descasamento entre dispositivos em MOSFETs tornam-se mais importantes em função das reduções das dimensões dos dispositivos [42].

Assim, sabendo que os CIs CMOS analógicos são fortemente influenciados pelo descasamento entre dispositivos, a principal motivação do desenvolvimento desta tese de doutorado é desenvolver um estudo comparativo experimental do impacto do descasamento nos principais parâmetros elétricos e figuras de mérito do MOSFET do tipo "N" (nMOSFET) de geometria de porta hexagonal e octogonal em relação aos do nMOSFETs de geometria de porta retangular, considerando-se quatro diferentes condições de polarizações dos transistores sob radiações ionizantes por raios-X: passiva (Floating), estado ligado (On-state), estado desligado (Off-state) e no modo analógico (Analog-state).

\subsection{OBJETIVO}

O primeiro objetivo desta tese de doutorado é estudar o descasamento entre dispositivos por meio da figura de mérito denominada de coeficiente de variação, valendo-se dos efeitos da Dose Ionizante Total (TID) nos principais parâmetros elétricos 
e figuras de mérito dos nMOSFETs de geometria de porta hexagonal e octogonal em relação aos dos nMOSFETs de geometria de porta retangular, considerando-se duas diferentes condições de polarizações dos transistores sob radiações ionizantes por raios$\mathrm{X}$ radiações ionizantes de raios-X: passiva (Floating) e estado ligado (On-state).

Face à importância da realização de um estudo da variabilidade estatística das $\mathrm{V}_{\mathrm{THS}}$ e das SSs dos nMOSFET de geometria de porta hexagonal e octogonal em relação aos do nMOSFETs de geometria de porta retangular, também foram aplicados nesta tese de doutorado os testes estatísticos denominados de Análise de Variância (ANOVA) e de Tukey nas $\mathrm{V}_{\mathrm{TH}} \mathrm{S}$ e nas SSs extraídas experimentalmente dos Diamond nMOSFET (DnMs), Octogonal nMOSFET (OnMs) e dos Conventional nMOSFET (CnMs). A principal motivação para a aplicação destes testes estatísticos é que é possível determinar estatisticamente se os valores médios dos parâmetros extraídos dos DnMs e OnMs são estatisticamente diferentes entre si, valendo-se de um nível de confiança de 95\%, e também se os valores médios das amostras das $\mathrm{V}_{\mathrm{TH}} \mathrm{S}$ e das SSs extraídas dos DnMs e OnMs são estatisticamente diferentes em comparação aos valores médios dos parâmetros extraídos dos CnMs, valendo-se de um nível de confiança de 95\%. Este estudo propõe, portanto, uma nova maneira de estudar estatisticamente as vantagens apresentadas do desempenho de funcionamento dos nMOSFETs do tipo Diamante e Octogonal em comparação ao nMOSFET de porta retangular em ambientes de radiação ionizantes de raios-X. A ANOVA e o teste Tukey serão aplicados nas $\mathrm{V}_{\mathrm{THS}}$ e SS extraídas dos DnMs, OnMs e CnMs, considerando-se duas diferentes condições de polarizações dos transistores durante os procedimentos de radiações ionizantes de raios-X: estado desligado (Off-state) e no modo analógico (Analog-state).

A Figura 3 ilustra a organização dos capítulos desta tese de doutorado. Este trabalho subdivide-se em mais quatro capítulos. 
Figura 3 - Organização dos capítulos desta tese de doutorado

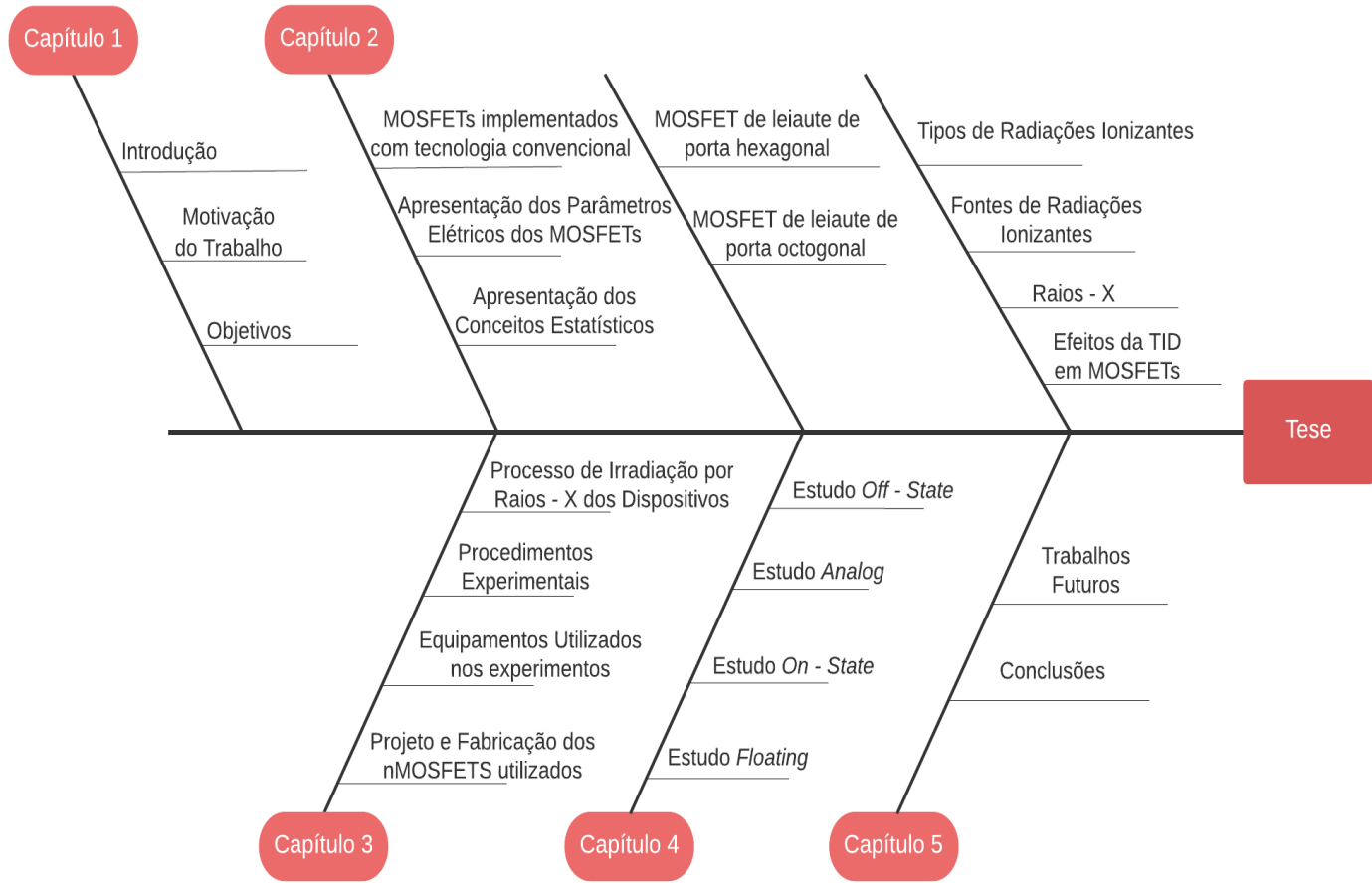

Fonte: Autor

No capítulo 2 são apresentados os conceitos fundamentais utilizados no desenvolvimento deste trabalho, isto é, os parâmetros físicos, elétricos, os conceitos estatísticos, um estudo das principais características dos MOSFET de leiaute de porta hexagonal (MOSFET Diamante) e octogonal (MOSFET Octo) e alguns dos principais efeitos das radiações ionizantes em MOSFETs necessários para o desenvolvimento e entendimento desta tese de doutorado.

O capítulo 3 apresenta as características do projeto e fabricação dos nMOSFETs utilizados neste trabalho, os equipamentos utilizados nos laboratórios, como foram realizadas as caracterizações elétricas dos dispositivos não encapsulados e encapsulados e os procedimentos implementados para a realização do processo de irradiação ionizante por raios-X dos dispositivos.

O capítulo 4 apresenta os principais resultados e as discussões obtidas nesta tese de doutorado.

Por fim, no capítulo 5 estão descritas as conclusões deste trabalho e as propostas de trabalhos futuros. 


\subsection{CONTRIBUIÇÕES}

Uma das contribuições desta tese de doutorado é analisar e corroborar o descasamento entre dispositivos por meio da figura de mérito denominada de coeficiente de variação, valendo-se dos efeitos da Dose Ionizante Total (TID) nos principais parâmetros elétricos e figuras de mérito dos nMOSFETs de geometria de porta hexagonal e octogonal em relação aos dos nMOSFETs de geometria de porta retangular, em dispositivos de tecnologia de Silício-Germânio com dimensão mínima de $130 \mathrm{~nm}$. Estudos anteriores para análise comparativa entre DSnM e CSnM já foram propostos, como por exemplo, utilizando a tecnologia de 0,35 $\mu \mathrm{m}$ AMI (On-Semiconductor) [46] e fabricados com a tecnologia SOI de 0,5 $\mu \mathrm{m}$ da Universidade Católica de Louvain [47].

Além disso, uma outra contribuição desta tese de doutorado é por meio da aplicação dos testes estatísticos ANOVA e Tukey, para determinar estatisticamente se os valores médios dos parâmetros $\mathrm{V}_{\mathrm{TH}} \mathrm{S}$ e SSs extraídos dos DnMs e OnMs são estatisticamente diferentes entre si, em ambiente de irradiação ionizante por raios-X. Ademais, também é possível determinar por meio da aplicação dos testes ANOVA e Tukey, se os valores médios das $\mathrm{V}_{\mathrm{THS}}$ e das SSs extraídas dos DnMs e OnMs são estatisticamente diferentes em comparação aos valores médios das $\mathrm{V}_{\mathrm{THS}}$ e das SSs extraídas dos CnMs, em ambiente de irradiação ionizante por raios-X.

Deve-se ressaltar, também, que este é o primeiro estudo que visa aplicar testes estatísticos visando analisar o descasamento dos nMOSFETs do tipo Diamante e Octogonal de tecnologia de Silício-Germânio com dimensão mínima de $130 \mathrm{~nm}$, em comparação ao nMOSFET de porta retangular em ambientes de radiação ionizantes de raios-X. 


\section{CONCEITOS FUNDAMENTAIS}

Esta seção ilustra conceitos fundamentais necessários sobre os MOSFETs, alguns de seus parâmetros, de forma que possibilitem o entendimento e análise dos dados experimentais apresentados nesta tese.

Além disso, nesta seção também são descritos alguns conceitos estatísticos utilizados na realização do estudo da variabilidade dos nMOSFET do tipo Diamante, do tipo Octogonal e os seus respectivos convencionais equivalentes em ambientes de radiação ionizante do tipo raios-X, um estudo das principais características dos MOSFET de leiaute de porta hexagonal (MOSFET Diamante) e octogonal (MOSFET Octo) e alguns dos principais efeitos das radiações ionizantes em MOSFETs, necessários para o desenvolvimento e entendimento desta tese de doutorado.

\subsection{PARÂMETROS ELÉTRICOS DOS MOSFETS}

Nesta seção serão descritas as principais características e a maneira de obtenção de alguns dos principais parâmetros elétricos e figuras de mérito digitais e analógicos que são utilizados para a elaboração desta tese de doutorado.

\subsubsection{Tensão de Limiar $\left(V_{T H}\right)$}

A tensão de limiar $\left(\mathrm{V}_{\mathrm{TH}}\right)$ é definida como a tensão mínima que precisa ser aplicada à porta do MOSFET para que uma camada fina de inversão de portadores minoritários seja formada na interface entre o óxido de porta e o filme de silício, local onde é formada a região de canal, para que ocorra a passagem de corrente elétrica entre os terminais de fonte e dreno [1], [48]. Assim, a tensão de limiar de um nMOSFET de tecnologia convencional é dada pela equação (1) [1], [48].

$$
\mathrm{V}_{\mathrm{TH}}=\mathrm{V}_{\mathrm{FB}}+2 \cdot \emptyset_{\mathrm{F}}+\frac{\mathrm{q} \cdot \mathrm{N}_{\mathrm{A}} \cdot \mathrm{x}_{\mathrm{d}_{\text {máx }}}}{\mathrm{C}_{\mathrm{OX}}}
$$

onde na equação (1), $V_{F B}$ é definida como a tensão de faixa plana, que é definida pela equação (2), $\phi_{\mathrm{F}}$ é o potencial de Fermi, q é o valor da carga elementar do elétron, $\mathrm{N}_{\mathrm{A}}$ é a 
concentração de dopantes na região de canal por unidade de volume, $\mathrm{x}_{\text {dmáx }}$ é a espessura máxima da região de depleção e $\mathrm{C}_{\mathrm{ox}}$ é a capacitância do óxido de porta por unidade de área [1], [48].

$$
\mathrm{V}_{\mathrm{FB}}=\emptyset_{\mathrm{MS}}-\frac{\mathrm{Q}_{\mathrm{OX}}}{\mathrm{C}_{\mathrm{OX}}}
$$

onde, na equação (2), $\emptyset_{M S}$ é a diferença entre a função de trabalho do metal e do semicondutor, $\mathrm{Q}_{\mathrm{ox}}$ é a quantidade de cargas fixas no óxido de porta por unidade de área.

Para o desenvolvimento deste trabalho, o mecanismo escolhido para a obtenção desse parâmetro foi por meio do pico máximo da segunda derivada da curva da corrente de dreno em função da tensão de porta ( $I_{D S}$ em função de $V_{G S}$ ) para uma tensão de $V_{D S}$ igual a $50 \mathrm{mV}$ (região de triodo) [1], [49].

Desta maneira, calculando a segunda derivada da curva de $\mathrm{I}_{\mathrm{DS}}$ em função de $\mathrm{V}_{\mathrm{DS}}$, obtêm-se um pico máximo da segunda derivada da corrente de dreno, na qual o valor de $\mathrm{V}_{\mathrm{GS}}$ correspondente a esse valor de pico, é definido como a tensão de limiar [1], [49], [48]. A Figura 4 apresenta um gráfico da derivada de segunda ordem de uma curva IDS em função de $V_{G S}$ para $V_{D S}$ igual a $50 \mathrm{mV}$, para ilustrar um exemplo de como é obtida a tensão de limiar $\left(\mathrm{V}_{\mathrm{TH}}\right)$. 
Figura 4 - Curva da segunda derivada da corrente de dreno em função da tensão de porta ( $\mathrm{I}_{\mathrm{DS}}$ em função de $\mathrm{V}_{\mathrm{GS}}$ ), para uma tensão de $\mathrm{V}_{\mathrm{DS}}$ igual a $50 \mathrm{mV}$.

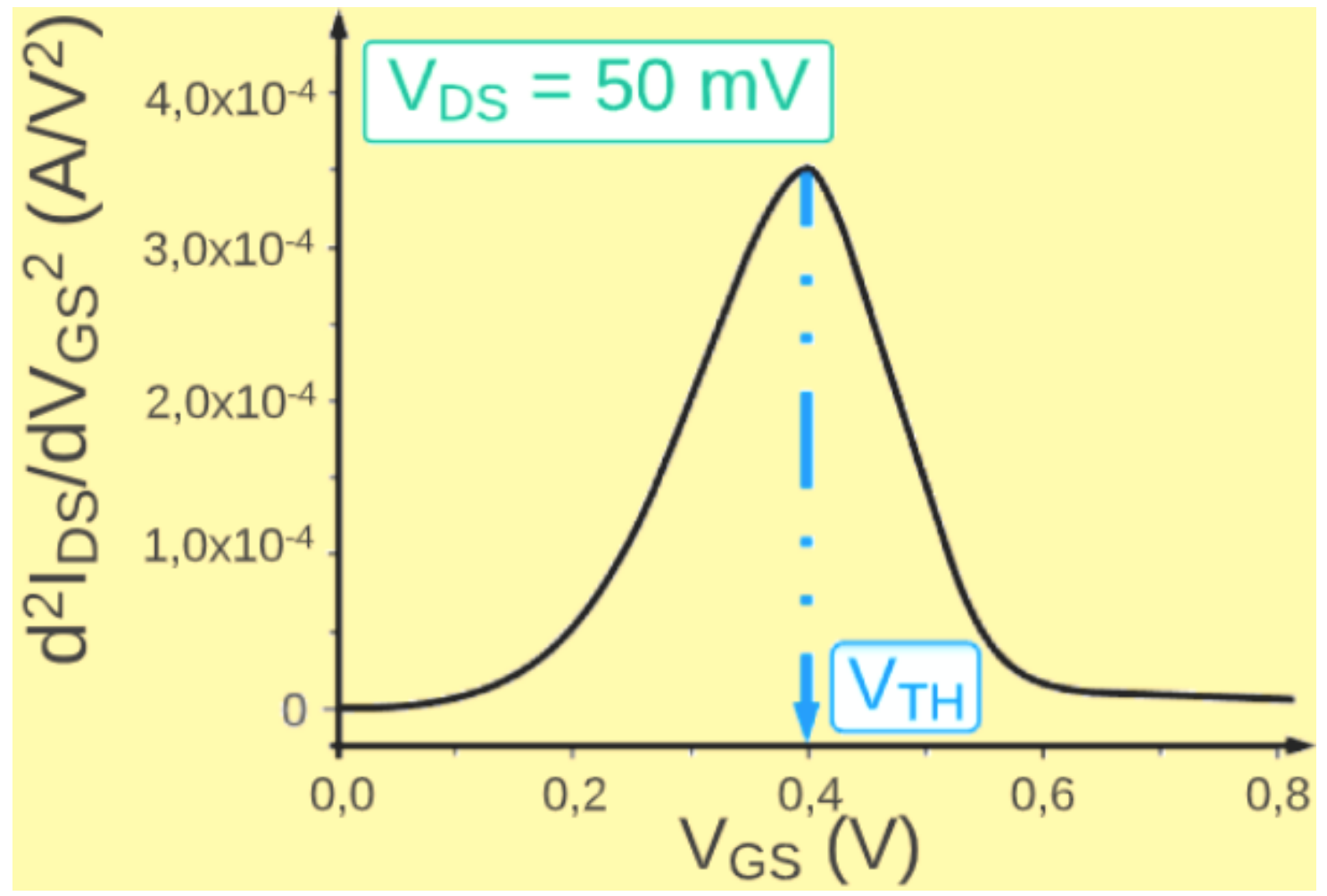

Fonte: Autor.

\subsubsection{Transcondutância (gm)}

A transcondutância (gm) de um nMOSFET é um parâmetro que permite medir a efetividade do controle da corrente de dreno ( $\left.\mathrm{I}_{\mathrm{DS}}\right)$ em função da tensão de porta ( $\left.\mathrm{V}_{\mathrm{GS}}\right)$. Assim, determina-se gm por meio da derivada da curva da corrente de dreno (IDS) em relação ao potencial de porta ( $\left.\mathrm{V}_{\mathrm{GS}}\right)$, de acordo com a equação (3) [1], [49], [48].

$$
\mathrm{gm}=\frac{\partial \mathrm{I}_{\mathrm{DS}}}{\partial \mathrm{V}_{\mathrm{GS}}}=\frac{\mu_{\mathrm{n}} \cdot \mathrm{C}_{\mathrm{OX}} \cdot \mathrm{W}}{\mathrm{L}} \cdot \mathrm{V}_{\mathrm{DS}}
$$

, (região de saturação) (3)

onde na equação (3), $\frac{\partial}{\partial V_{G S}}$ é o operador derivada em relação a $V_{G S}$, IDS é a corrente entre os terminais de fonte e dreno, $\mu_{\mathrm{n}}$ é definida como a mobilidade dos portadores no canal de um transistor tipo n, Cox é a capacitância do óxido de porta por unidade de área, W é a largura do canal e L é o comprimento do canal [1], [49], [48]. 
A Figura 5 ilustra um exemplo de uma curva experimental da transcondutância (gm) em função da polarização da tensão de porta ( $\left.\mathrm{V}_{\mathrm{GS}}\right)$ com uma aplicação de $\mathrm{V}_{\mathrm{DS}}$ igual a $0,5 \mathrm{~V}$ de um nMOSFET Diamante (geometria de porta hexagonal) de largura de canal (W) igual a $0,56 \mu \mathrm{m}$ e de comprimento de canal (L) igual a $0,54 \mu \mathrm{m}$, que foi utilizada como exemplo para mostrar a extração da transcondutância máxima ( $\left(\mathrm{gm}_{\max }\right)$.

Figura 5 - Gráfico que relaciona a transcondutância em função da tensão de porta ( $\left.\mathrm{V}_{\mathrm{GS}}\right)$ para a obtenção da transcondutância máxima de um dispositivo nMOSFET convencional (geometria de porta retangular)

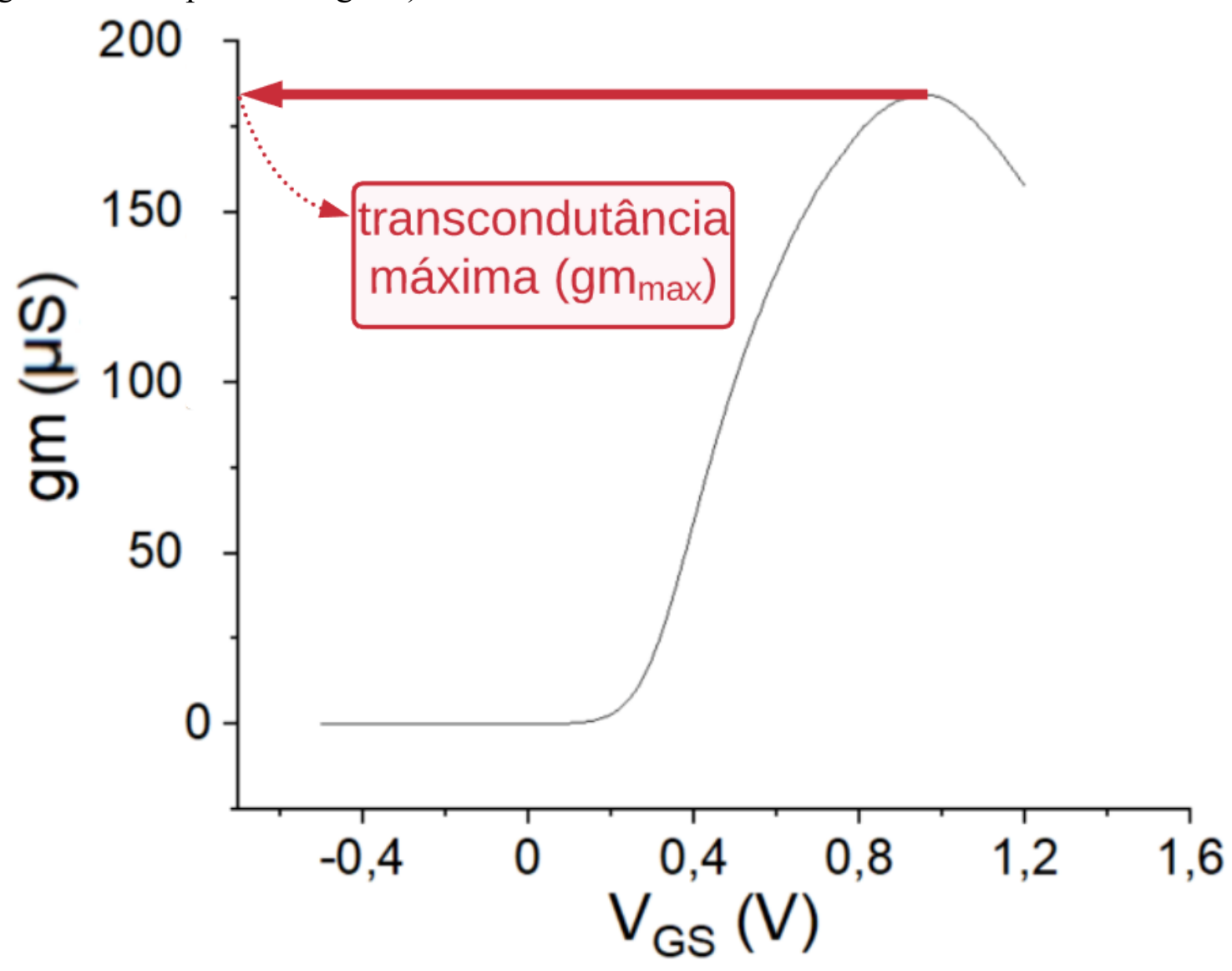

Fonte: Autor.

\subsubsection{Corrente Elétrica entre Dreno e Fonte (IDS) de um nMOSFET}

Define-se IDS como a corrente elétrica que atravessa o canal de um nMOSFET entre as regiões de fonte e de dreno [1], [49], [48]. Esta corrente elétrica $\left(\mathrm{I}_{\mathrm{DS}}\right)$ pode ser representada por meio da equação (4), quando o MOSFET opera na região triodo de uma curva da corrente de dreno ( $\left.\mathrm{I}_{\mathrm{DS}}\right)$ em função da tensão de dreno ( $\left.\mathrm{V}_{\mathrm{DS}}\right)$ [1], [50], [49], [48]. 


$$
\mathrm{I}_{\mathrm{DS}}=\mu_{\mathrm{n}} \cdot \mathrm{C}_{\mathrm{OX}} \cdot \frac{\mathrm{W}}{\mathrm{L}} \cdot\left[\left(\mathrm{V}_{\mathrm{GS}}-\mathrm{V}_{\mathrm{TH}}\right) \cdot \mathrm{V}_{\mathrm{DS}}-\frac{1}{2} \cdot \mathrm{V}_{\mathrm{DS}}^{2}\right]
$$

Na região de saturação, a corrente de dreno ( $\left.\mathrm{I}_{\mathrm{DS}}\right)$ de um nMOSFET pode ser representada por meio da equação (5) [1], [50], [49], [48],

$$
\mathrm{I}_{\mathrm{DS}}=\frac{1}{2} \cdot \mu_{\mathrm{n}} \cdot \mathrm{C}_{\mathrm{OX}} \cdot \frac{\mathrm{W}}{\mathrm{L}} \cdot\left(\mathrm{V}_{\mathrm{GS}}-\mathrm{V}_{\mathrm{TH}}\right)^{2}
$$

A Figura 6 exibe as regiões triodo e de saturação existentes no gráfico da corrente de dreno $\left(\mathrm{I}_{\mathrm{DS}}\right)$ em função da tensão de dreno $\left(\mathrm{V}_{\mathrm{DS}}\right)$ de um nMOSFET.

Figura 6 - Gráfico da corrente de dreno ( $\left.\mathrm{I}_{\mathrm{DS}}\right)$ em função da tensão de dreno ( $\left.\mathrm{V}_{\mathrm{DS}}\right)$ de um nMOSFET, ilustrando as regiões de triodo e de saturação.

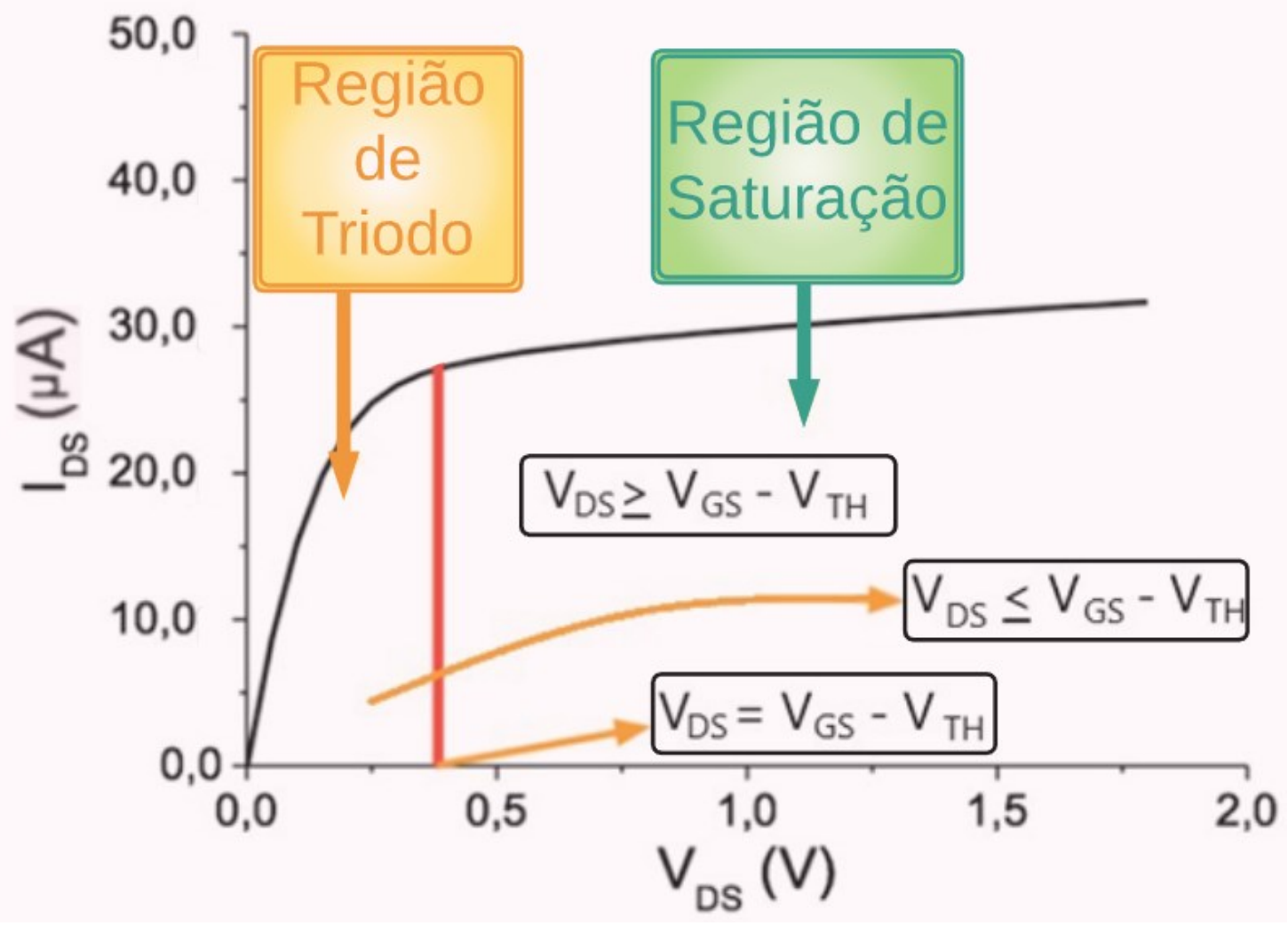

Fonte: Autor. 


\subsubsection{Resistência entre Dreno e Fonte de Estado Ligado (RDSon)}

A resistência série entre dreno e fonte de estado ligado $\left(\mathrm{R}_{\mathrm{DSon}}\right)$ é determinada quando o MOSFET opera na região triodo, ou seja, quando este tipo de dispositivo funciona como uma chave [1], [50], [49], [48]. Em função disto, deve-se considerar a tensão de dreno $\left(\mathrm{V}_{\mathrm{DS}}\right)$ como sendo inferior à sobretensão de porta $\left(\mathrm{V}_{\mathrm{GT}}=\mathrm{V}_{\mathrm{GS}}-\mathrm{V}_{\mathrm{TH}}\right)$, isto é, na região linear da curva, de tal forma que se pode desconsiderar o termo $\mathrm{V}_{\mathrm{DS}}{ }^{2}$ da

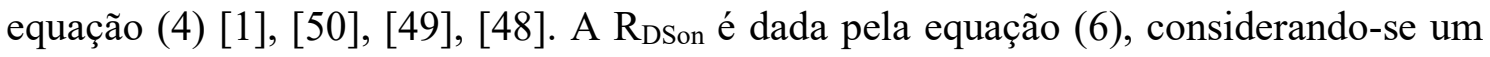
nMOSFET (Bulk) [41, 42, 43, 44].

$$
R_{D S o n}=\frac{V_{D S}}{I_{D S}}=\frac{1}{\mu_{n} \cdot C_{O X} \cdot \frac{W}{L} \cdot\left[\left(V_{G S}-V_{T H}\right)\right]}
$$

A Figura 7 ilustra a curva da $I_{D S}$ em função de $V_{D S}$ de um nMOSFET, que foi utilizada para mostrar a extração de $\mathrm{R}_{\mathrm{DSon}}$ e que é determinada por meio da razão entre a variação de $\mathrm{V}_{\mathrm{DS}}\left(\Delta \mathrm{V}_{\mathrm{DS}}\right)$ pela variação de $\mathrm{I}_{\mathrm{DS}}\left(\Delta \mathrm{I}_{\mathrm{DS}}\right)$ na região de triodo [1], [50], [49], [48]. 
Figura 7 - Exemplo de uma curva $\mathrm{I}_{\mathrm{DS}}$ em função de $\mathrm{V}_{\mathrm{DS}}$ que indica a região triodo de operação do nMOSFET para a obtenção de $\mathrm{R}_{\mathrm{DS} \text { on }} \mathrm{e}$ que é determinada por meio da razão entre a variação de $\mathrm{V}_{\mathrm{DS}}\left(\Delta \mathrm{V}_{\mathrm{DS}}\right)$ pela variação de $\mathrm{I}_{\mathrm{DS}}\left(\Delta \mathrm{I}_{\mathrm{DS}}\right)$.

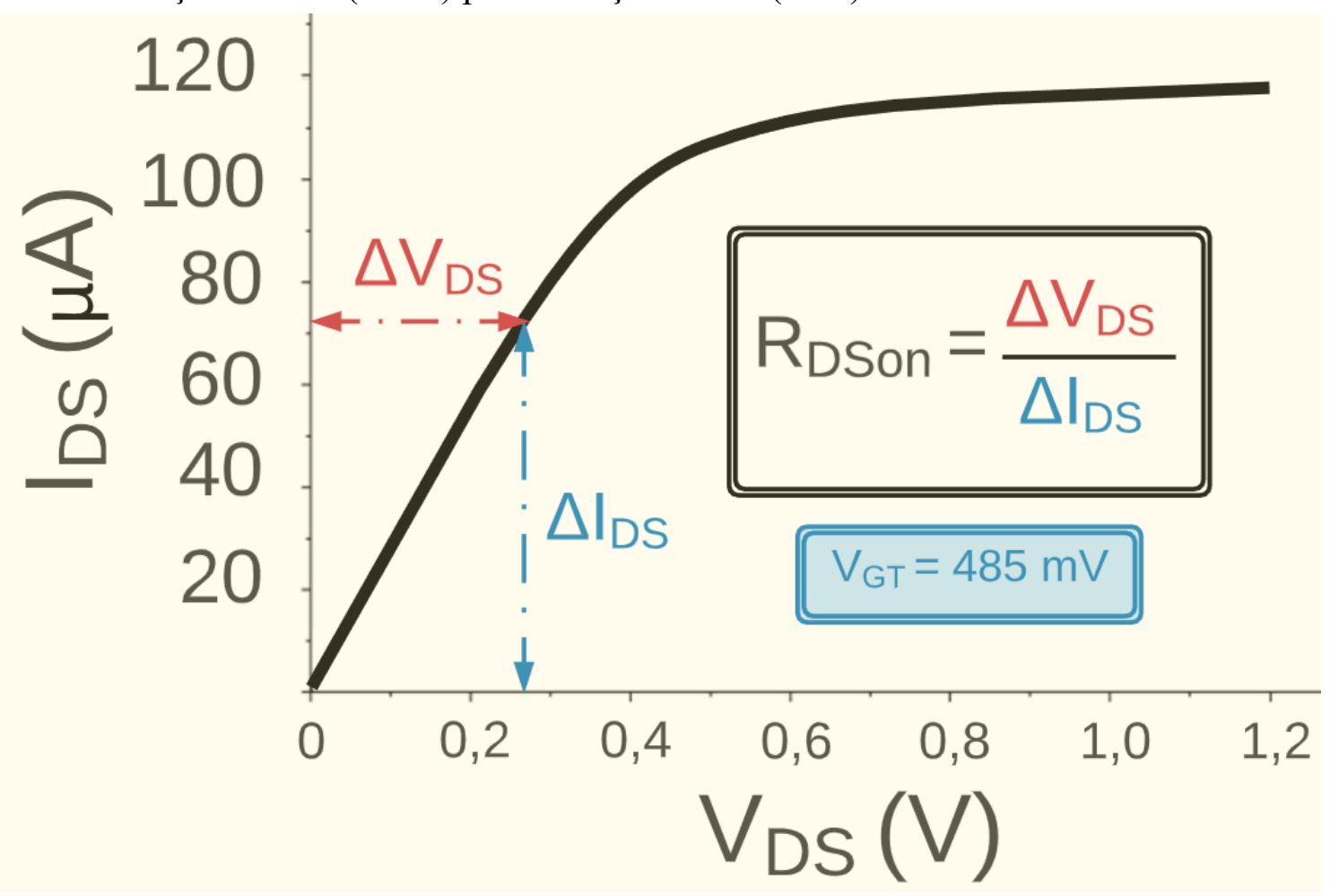

Fonte: Autor.

\subsubsection{Razão entre a transcondutância e a corrente de dreno (gm/IDs)}

A razão entre a transcondutância e a corrente de dreno $\left(\mathrm{gm} / \mathrm{I}_{\mathrm{DS}}\right)$ mede a eficiência de um MOSFET em converter uma dada corrente de polarização em transcondutância [1], [50], [49], [48].

O valor máximo do parâmetro gm/I $\mathrm{I}_{\mathrm{DS}}$ ocorre quando o MOSFET está operando no regime de inversão fraca, podendo ser determinada por meio da equação (7) [1], [50], [49], [48], [51].

$$
\frac{\mathrm{gm}}{\mathrm{I}_{\mathrm{DS}}}=\frac{1}{I_{D S}} \cdot \frac{\partial I_{D S}}{\partial V_{G S}}=\frac{\partial\left(\ln I_{D S}\right)}{\partial V_{G S}}=\frac{\partial\left\{\ln \left(\frac{I_{D S}}{\frac{W}{L}}\right)\right\}}{\partial V_{G S}}
$$


No regime de inversão forte, gm/I $\mathrm{I}_{\mathrm{DS}}$ de um nMOSFET (Bulk) é menor do aquele encontrado no regime de inversão fraca e é calculada por meio da equação (8) [1], [50], [49], [48], [51].

$$
\frac{\mathrm{gm}}{\mathrm{I}_{\mathrm{DS}}}=\sqrt{\frac{2 \cdot \mu_{\mathrm{n}} \cdot \mathrm{C}_{\mathrm{OX}} \cdot \frac{\mathrm{W}}{\mathrm{L}}}{\mathrm{I}_{\mathrm{DS}}}}
$$

A Figura 8 apresenta um exemplo de curva gm/IDs em função de $\mathrm{IDS}_{\mathrm{DS}} /(\mathrm{W} / \mathrm{L})$ de um nMOSFET.

Figura 8 - Exemplo de uma curva de gm/IDS em função de $\mathrm{I}_{\mathrm{DS}} /(\mathrm{W} / \mathrm{L})$ de um nMOSFET.

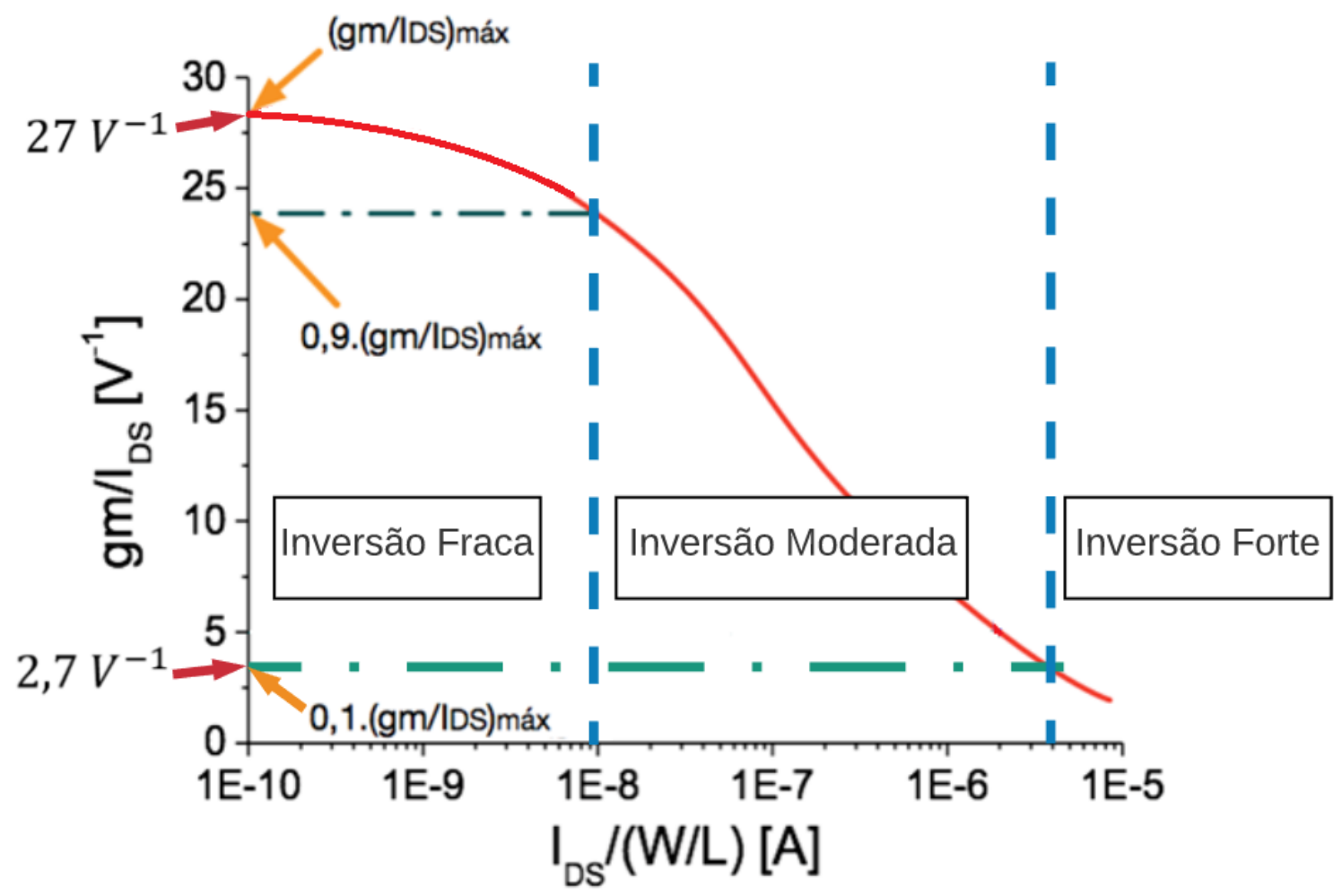

Fonte: Autor

\subsubsection{Inclinação de Sublimiar (SS)}

O parâmetro elétrico denominado de inclinação de sublimiar ou o inverso da inclinação de sublimiar (SS) é um parâmetro muito importante a ser caracterizado e estudado em transistores implementados com tecnologia MOS, pois ele fornece o valor 
da tensão que deve ser aplicada ao contato de porta, a fim de que exista um aumento de uma década na corrente de dreno do dispositivo [1], [50], [49], [48], [51]. Este parâmetro pode ser observado nas curvas do logaritmo de $\mathrm{I}_{\mathrm{DS}}$ em função de $\mathrm{V}_{\mathrm{GS}}$ para valores de tensão de porta menores do que $\mathrm{V}_{\mathrm{TH}}$ [1], [50], [49], [48], [51].

$\mathrm{Na}$ região de operação de sublimiar, a corrente entre dreno e fonte ( $\mathrm{I}_{\mathrm{DS}}$ ) é basicamente formada pela corrente de difusão, pois a tensão aplicada ao dreno é muito baixa e o campo elétrico longitudinal não é forte o suficiente para afetar a velocidade dos portadores, como é apresentado na equação (9), para um nMOSFET (Bulk) [1], [50], [49], [48], [51].

$$
I_{D S}=-q \cdot A \cdot D_{n} \cdot \frac{d n}{d y}=q \cdot A \cdot D_{n} \cdot \frac{n(0)-n(L)}{L}
$$

onde na equação (9), q é a carga elementar do elétron, A é a área da seção transversal da região de canal, $\mathrm{D}_{\mathrm{n}}$ é o coeficiente de difusão dos elétrons, $\frac{\partial n}{\partial y}$ é a variação infinitesimal da concentração de elétrons ao longo do comprimento de canal e $n(0)$ e $n(L)$ são as concentrações de elétrons nos limites das regiões de fonte e dreno, respectivamente e L é o comprimento do canal do transistor [1], [50], [49], [48], [51].

A inclinação de sublimiar é definida como o inverso da derivada do logaritmo da corrente de dreno em função da tensão aplicada à porta [49], [48], [51]. A equação (10) apresenta a expressão da inclinação de sublimiar de um MOSFET [1], [50], [49], [48], [51].

$$
\mathrm{SS}=\frac{1}{\frac{\partial\left[\log \left(\mathrm{I}_{\mathrm{DS}}\right)\right]}{\partial \mathrm{V}_{\mathrm{GS}}}}
$$

Para MOSFETs implementados com tecnologia CMOS convencional (bulk), a inclinação de sublimiar normalmente varia de $80 \mathrm{mV} /$ dec. a $120 \mathrm{mV} /$ dec., em temperatura ambiente. [1], [50], [49], [48], [51]. 


\subsubsection{Tensão Early ( $\left.\mathrm{V}_{\mathrm{EA}}\right)$}

Observa-se que uma vez estrangulado o canal na interface entre a região de canal e a região de dreno, um aumento gradual de $\mathrm{V}_{\mathrm{DS}}$ provocará uma redução do comprimento efetivo de canal. Isso significa dizer que este aumento no valor de $\mathrm{V}_{\mathrm{DS}}$, acima da tensão de dreno de saturação ( $\mathrm{V}_{\mathrm{DSsat}}$ ), acarretará o deslocamento do ponto de estrangulamento da região do dreno em direção à região da fonte [50], [49], [48], [51]. A Figura 9 ilustra um exemplo do estrangulamento do canal em função do aumento do valor da tensão $\mathrm{V}_{\mathrm{DS}}$ acima do valor de $\mathrm{V}_{\text {DSsat }}$. Verifica-se que este aumento do valor da tensão $\mathrm{V}_{\mathrm{DS}}$ provoca uma redução no comprimento efetivo de canal.

Figura 9 - Ilustração do estrangulamento do canal em função do aumento do valor da tensão $\mathrm{V}_{\mathrm{DS}}$ acima do valor de $\mathrm{V}_{\mathrm{DSsat}}$ para um MOSFET.

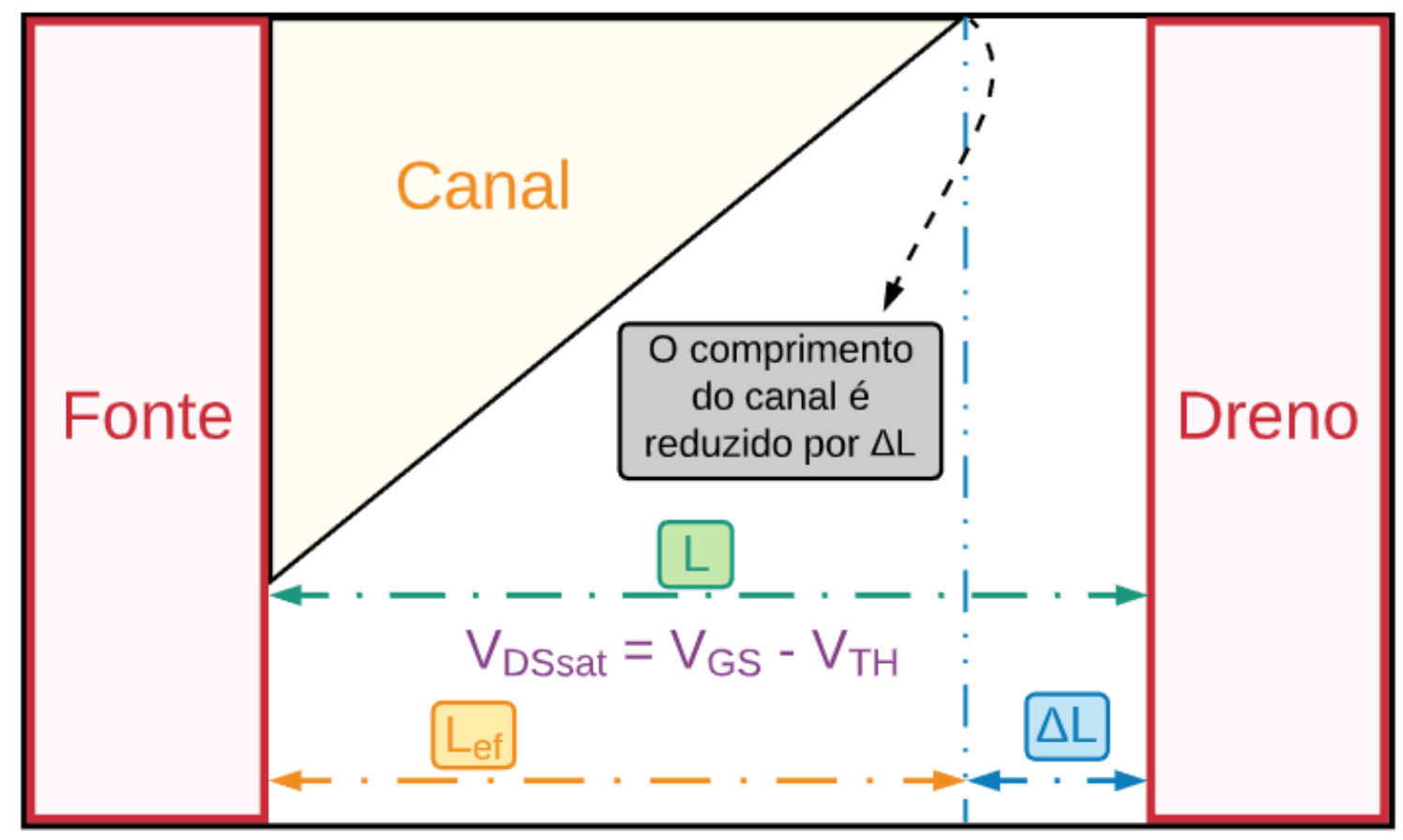

Fonte: Autor.

Na Figura 9, $\Delta$ L é a redução do comprimento do canal em função do deslocamento do ponto de estrangulamento para dentro da região do canal na direção da região de fonte devido ao incremento da polarização de dreno $\mathrm{V}_{\mathrm{DS}}$ e $\mathrm{L}_{\mathrm{ef}}$ é o comprimento efetivo de canal [50], [49], [48], [51].

Esta variação no comprimento efetivo do canal é conhecida como modulação do comprimento do canal [50], [49], [48], [51]. Desta forma, observa-se que o valor de $\mathrm{I}_{\mathrm{DS}}$ 
passa a aumentar com o aumento gradativo de $V_{D S}$, visto que $I_{D S}$ é inversamente proporcional ao comprimento efetivo do canal $\left(\mathrm{L}_{\mathrm{ef}}=\mathrm{L}-\Delta \mathrm{L}\right)$ [50], [49], [48], [51].

A Figura 10 mostra duas curvas de $\mathrm{I}_{\mathrm{DS}}$ em função de $\mathrm{V}_{\mathrm{DS}}$, para dois diferentes valores de sobretensão de porta $\left(\mathrm{V}_{\mathrm{GT} 1}\right.$ e $\left.\mathrm{V}_{\mathrm{GT} 2}\right)$ utilizadas para a extração de $\mathrm{V}_{\mathrm{EA}}$. Assim, é possível verificar as particularidades típicas que ocorrem na curva de IDs em função da tensão $\mathrm{V}_{\mathrm{DS}}$, quando há a ocorrência do efeito de modulação do comprimento do canal.

Figura 10 - Exemplos de duas curvas de $I_{D S}$ em função de $V_{D S}$, para dois diferentes valores de sobretensão de porta ( $\mathrm{V}_{\mathrm{GT} 1}$ e $\left.\mathrm{V}_{\mathrm{GT} 2}\right)$ utilizadas para a extração de $\mathrm{V}_{\mathrm{EA}}$.

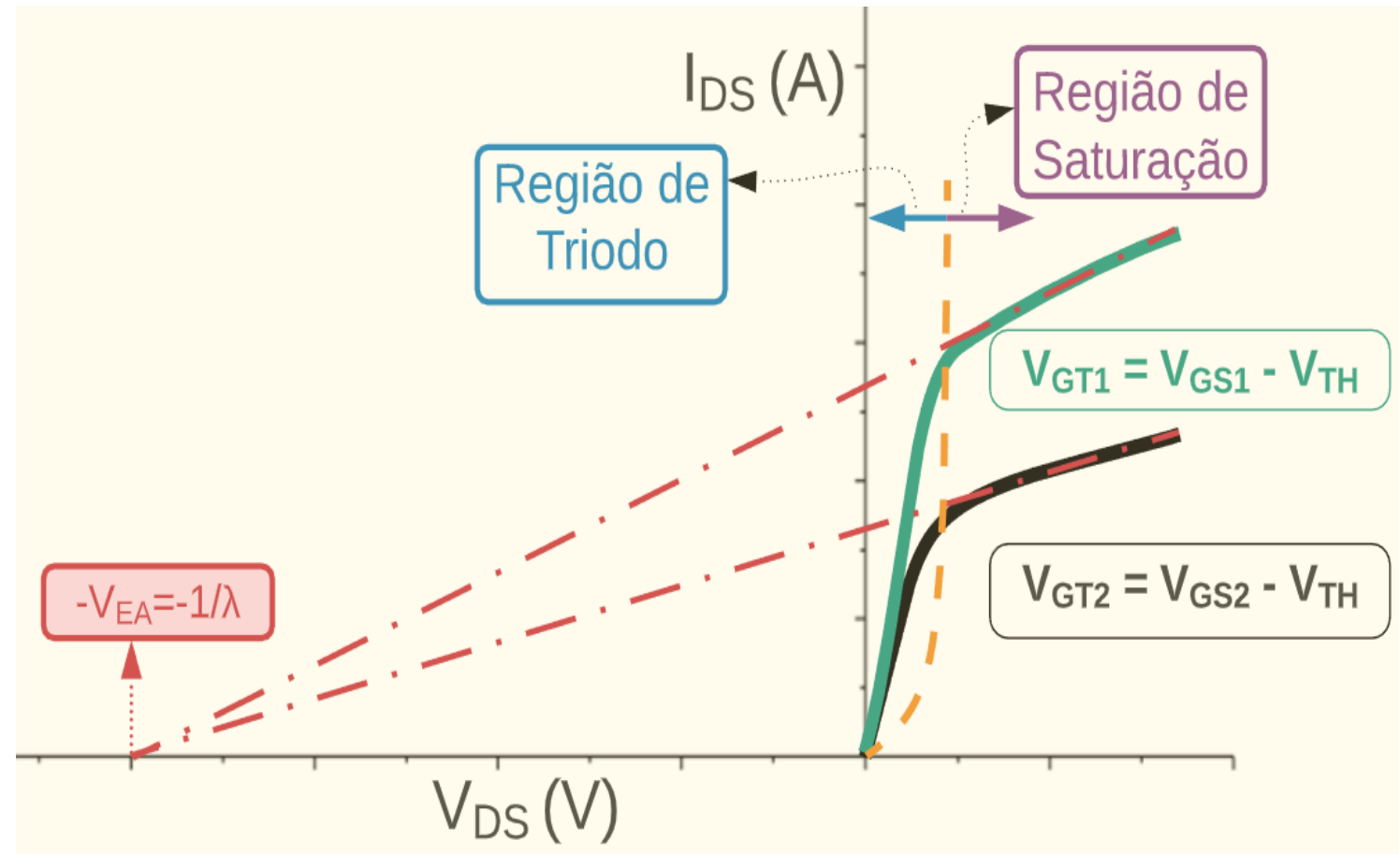

Fonte: Autor.

Na Figura 10, $\lambda$ é o fator de modulação do comprimento de canal, $V_{\mathrm{EA}}$ é a tensão Early, $\mathrm{V}_{\mathrm{GS} 1}$ e $\mathrm{V}_{\mathrm{GS} 2}$ são as tensões elétricas aplicadas entre a porta e a fonte $\left(\mathrm{V}_{\mathrm{GS} 2}\right.$ é maior que $\left.\mathrm{V}_{\mathrm{GS} 1}\right)$.

Além disso, observa-se que a extrapolação da curva de IDs na região de saturação intercepta o eixo de $V_{D S}$ no ponto o qual $V_{D S}$ é igual a $-1 / \lambda$. Este valor de tensão é denominado de tensão Early $\left(\mathrm{V}_{\mathrm{EA}}\right)$ [50], [49], [48], [51]. A representação matemática da dependência linear da corrente $\mathrm{I}_{\mathrm{DS}}$ em função do aumento da tensão $\mathrm{V}_{\mathrm{DS}}$ na região de saturação é concebida pelo acréscimo do fator $\left(1+\lambda . \mathrm{V}_{\mathrm{DS}}\right)$ na equação (5). A equação (11) representa $\mathrm{I}_{\mathrm{DS}}$ levando-se em conta o efeito da modulação do comprimento de canal [50], [49], [48], [51], quando o nMOSFET (Bulk) opera na região de saturação. 


$$
\mathrm{I}_{\mathrm{DS}}=\frac{1}{2} \cdot \mu_{\mathrm{n}} \cdot \mathrm{C}_{\mathrm{OX}} \cdot \frac{\mathrm{W}}{\mathrm{L}} \cdot\left[\left(\mathrm{V}_{\mathrm{GS}}-\mathrm{V}_{\mathrm{TH}}\right)^{2}\right] \cdot\left(1+\lambda \cdot \mathrm{V}_{\mathrm{DS}}\right)
$$

onde $\lambda$ é dado por $-1 / \mathrm{V}_{\text {EA }}$.

\subsubsection{Corrente entre dreno e fonte de Estado Ligado (Ion), desligado (Ioff) e de fuga (ILEAK).}

Define-se a corrente de estado ligado ( $\left.\mathrm{I}_{\mathrm{ON}}\right)$ como a corrente de dreno que é medida na situação em que o MOSFET está operando com valores da tensão de porta ( $\left.\mathrm{V}_{\mathrm{GS}}\right)$ superiores ao valor da tensão de limiar $\left(\mathrm{V}_{\mathrm{TH}}\right)$ e $\mathrm{V}_{\mathrm{DS}}$ próximo a zero (chave fechada) [50], [49], [48], [51]. Ion é comumente extraída a partir da curva do logaritmo da corrente de dreno $\left[\left(\log \left(\mathrm{I}_{\mathrm{DS}}\right)\right)\right]$ em função da tensão de porta $\left(\mathrm{V}_{\mathrm{GS}}\right)$, realizando a leitura do valor máximo de $\mathrm{I}_{\mathrm{DS}}$ em função do máximo valor de $\mathrm{V}_{\mathrm{GS}}$ aplicado no MOSFET, na situação do MOSFET estar operando na região de triodo [50], [49], [48], [51].

A corrente de dreno de estado desligado $\left(\mathrm{I}_{\mathrm{OFF}}\right)$ por sua vez, é a corrente elétrica entre dreno e fonte observada no MOSFET para um certo valor de $\mathrm{V}_{\mathrm{DS}}$, quando $\mathrm{V}_{\mathrm{GS}}$ é igual a $0 \mathrm{~V}$. [50], [49], [48], [51]

A corrente de fuga entre dreno e fonte ( $\left.\mathrm{I}_{\mathrm{LEAK}}\right)$ é medida para valores negativos de $V_{G S}$ e assim como a IofF, representa uma corrente elétrica indesejada presente no dispositivo quando ele não deveria estar conduzindo eletricamente. Valores realmente muito baixos de ILEAK são esperados em MOSFETs com bom desempenho elétrico [50], [49], [48], [51].

A Figura 11 apresenta um exemplo de uma curva de [log $\left.\left(I_{D S}\right)\right]$ em função da tensão $\mathrm{V}_{\mathrm{GS}}$ de um nMOSFET (Bulk) para um valor de $\mathrm{V}_{\mathrm{DS}}$, onde está indicado a forma de se extrair I IN, IOFF e ILEAK. 
Figura 11 - Gráfico que relaciona o logaritmo da corrente de dreno ( $\left.\mathrm{I}_{\mathrm{DS}}\right)$ em função da tensão de porta $\left(\mathrm{V}_{\mathrm{GS}}\right)$, para um valor de $\mathrm{V}_{\mathrm{DS}}$.

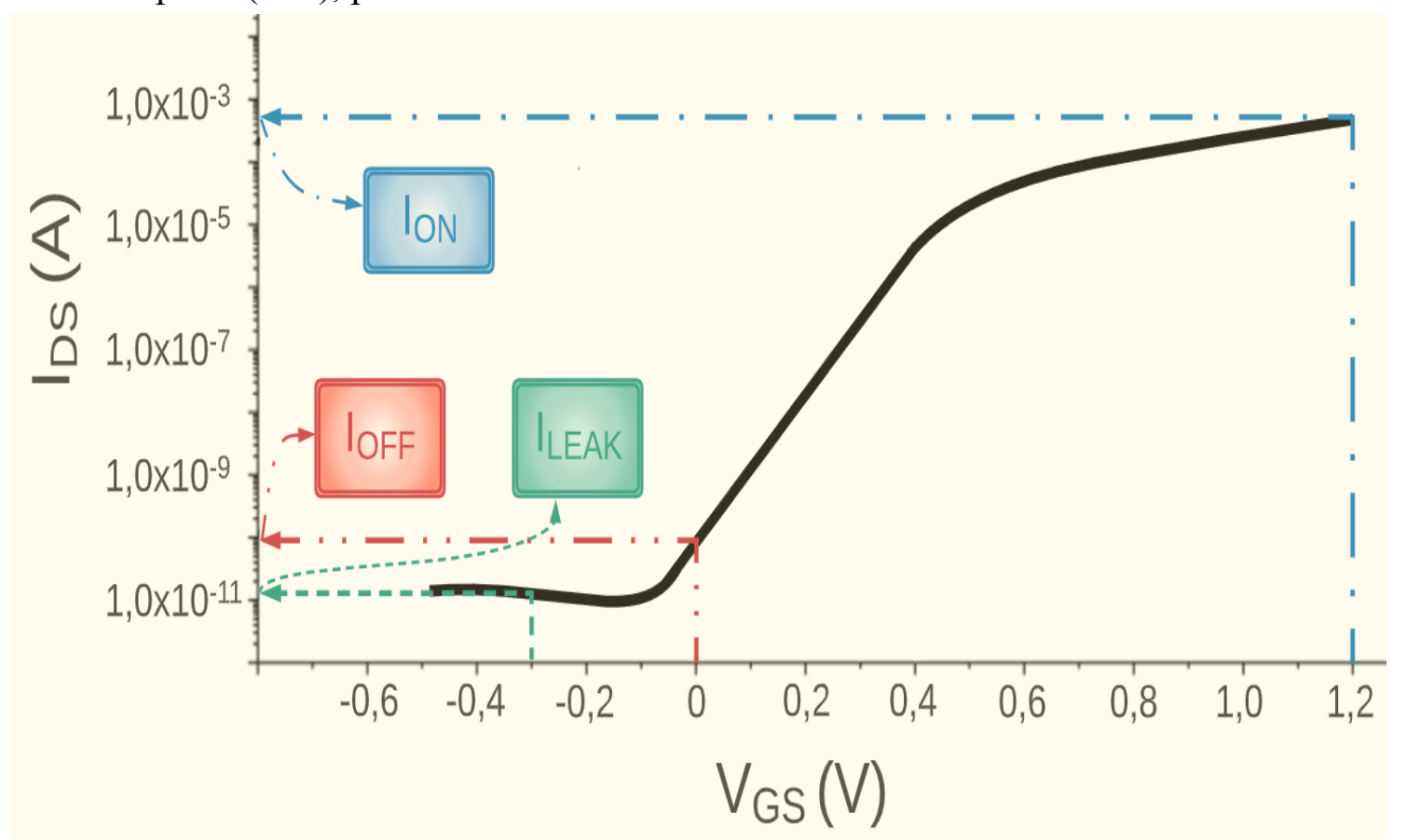

Fonte: Autor.

\subsubsection{Ganho de tensão intrínseco de um MOSFET (Av)}

A equação (12) define o valor do ganho de tensão intrínseco (Av) de um nMOSFET operando na região de saturação.

$$
A_{V}=\frac{g m}{g_{D}} \cong \frac{g m}{I_{D S}} \cdot V_{E A}
$$

onde $g_{D}$ é a condutância de dreno [50], [49], [48], [51].

Pode-se afirmar que, quanto maior for o valor da razão gm/IDS, assim como o valor da respectiva tensão Early, maior será o valor do ganho de tensão. Deve-se ressaltar também que os maiores valores da razão gm/IDs são obtidos no regime de inversão fraca [50], [49], [48], [51]. 


\subsubsection{Frequência de Ganho de Tensão Unitário (f $\mathrm{f}$ )}

A frequência de ganho de tensão unitário $\left(\mathrm{f}_{\mathrm{T}}\right)$ é definida como a frequência em que o ganho de te

nsão é igual a 1. Desta forma, pode-se afirmar que este parâmetro ilustra a frequência de operação dos CIs CMOS, onde a amplitude do sinal de entrada é a mesma amplitude do sinal de saída (ganho unitário de tensão) [50], [49], [48], [51].

A equação (13) representa a expressão matemática utilizada para a determinação do parâmetro f $\mathrm{T}_{\mathrm{T}}$ para um MOSFET [50], [49], [48], [51].

$$
\mathrm{f}_{\mathrm{T}}=\frac{\mathrm{gm}}{2 \cdot \pi \cdot \mathrm{C}_{\mathrm{L}}}
$$

onde $\mathrm{C}_{\mathrm{L}}$ é a capacitância de carga.

\subsection{CONCEITOS ESTATÍSTICOS}

Neste tópico serão analisados alguns dos principais conceitos estatísticos que serão utilizados na elaboração desta tese de doutorado.

\subsubsection{Variância $\left(s^{2}\right)$}

Por meio da obtenção experimental de uma amostra de dados, por exemplo de uma variável elétrica de um dispositivo pertencente a uma amostra de n' dispositivos, pode-se calcular o valor médio desta variável elétrica e também analisar o quanto os valores experimentais desta variável estão próximos ou distantes do valor médio calculado [52], [53], [54].

Portanto, pode-se definir a variância de uma variável elétrica de um dispositivo pertencente a uma amostra de n' dispositivos, como sendo a razão entre os quadrados do quanto um determinado parâmetro de um dispositivo pertencente a essa amostra se afasta do valor médio (desvio) e o total de parâmetros analisados dos transistores que compõem a amostra de dispositivos (n') subtraído de 1 [equação (14)] [52], [53], [54]. 


$$
\mathrm{s}^{2}=\frac{\left(\mathrm{x}_{1}-\overline{\mathrm{x}}\right)^{2}+\left(\mathrm{x}_{2}-\overline{\mathrm{x}}\right)^{2}+\cdots+\left(\mathrm{x}_{\mathrm{n}}-\overline{\mathrm{x}}\right)^{2}}{\mathrm{n}^{\prime}-1}
$$

onde, na equação (14), $\mathrm{x}_{1}, \mathrm{x}_{2}$ e $\mathrm{x}_{\mathrm{n}^{\prime}}$ representam os valores de uma determinada variável dos dispositivos pertencente a uma amostra de n' dispositivos e $\bar{x}$ representa a média do parâmetro levando-se em conta todos os dispositivos pertencentes à amostra estudada [52], [53], [54]. Além disso, deve-se ressaltar que no denominador da equação (14) utiliza-se (n'-1) pois que os dados analisados representam uma parte dos dados de uma população [52], [53], [54].

\subsubsection{Desvio-Padrão (s)}

O desvio-padrão (s) tem como objetivo medir o quanto um determinado parâmetro de uma amostra de dispositivos está distante do valor médio desse parâmetro da amostra de dispositivos considerada. A equação (15) mostra a equação matemática do "s" [52], [53], [54].

$$
s=\sqrt{\frac{1}{n^{\prime}-1} \cdot \sum\left(x_{i}-\bar{x}\right)^{2}}
$$

onde na equação $(15) \mathrm{x}_{\mathrm{i}}$ representa cada parâmetro de um único dispositivo da amostra considerada, i é um índice que vai de um a n', n' representa a quantidade de dados que compõem a amostra de dispositivos em análise e $\bar{x}$ representa a média dos parâmetros dos dispositivos da amostra considerada [52], [53], [54].

\subsubsection{Graus de Liberdade (gl)}

Os graus de liberdade (gl) de uma amostra de dados é definido por meio da equação (16) [52], [53], [54].

$$
\mathrm{gl}=\mathrm{n}^{\prime}-1
$$


Pode-se afirmar que os graus de liberdade dependem diretamente do tamanho da amostra utilizada para o desenvolvimento de um estudo estatístico [52], [53], [54].

\subsubsection{Distribuição Normal}

Pode-se afirmar que uma função apresenta uma distribuição normal, quando ela possui um aspecto em formato de sino [52], [53], [54]. Esta distribuição normal de dados é, por definição, simétrica em relação à média dos parâmetros que leva em conta todos os dispositivos da amostra de dados [52], [53], [54]. A Figura 12 ilustra um exemplo de um histograma que possui uma distribuição considerada normal, levando-se em conta IDSsat, cujo valor médio é igual a 3,5 mA de uma amostra de 20 MOSFETs do tipo Diamante [52], [53], [54].

Figura 12 - Exemplo de um histograma com um perfil considerado normal, levando-se em conta IDSsat, cujo valor médio é igual a $3,5 \mathrm{~mA}$ de uma amostra de $20 \mathrm{nMOSFETs} \mathrm{do}$ tipo Diamante.

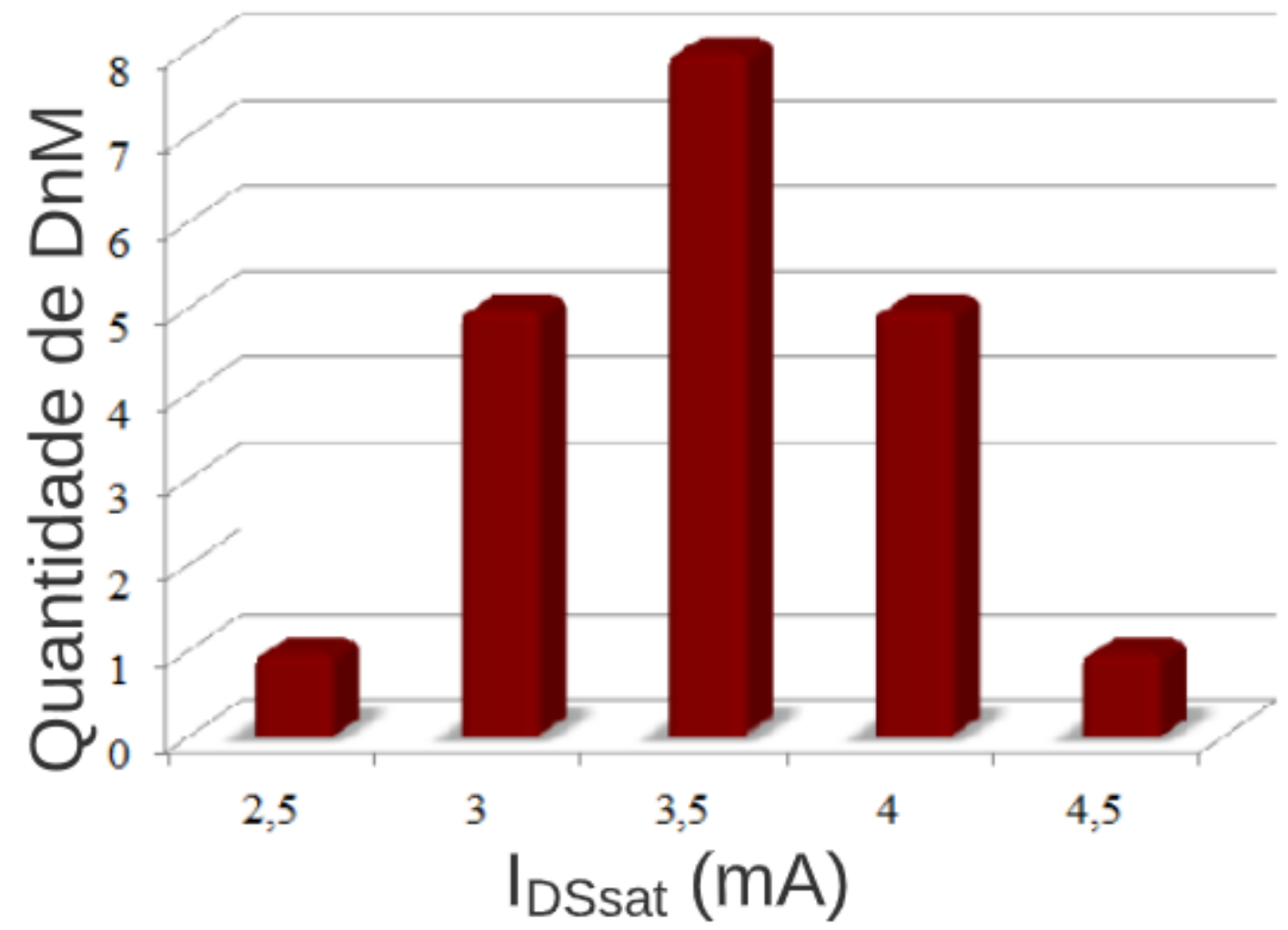

Fonte: Autor "adaptado de" [55], 2013, p. 49. 
Analisando a Figura 12, observa-se que esta amostra apresenta: 8 nMOSFETs onde o valor médio, levando-se em conta todas as IDSsat de todos os dispositivos da amostra, é igual a 3,5 mA, 5 nMOSFETs com valor médio para IDSsat igual a 3,0 mA e mais outros 5 nMOSFETs com valor médio para $\mathrm{I}_{\mathrm{DSsat}}$ igual a 4,0 mA e por fim apresenta 2 nMOSFETs do tipo Diamante, sendo que um deles apresenta valor médio para IDssat igual a 2,5 mA e o outro tem um valor médio para $\mathrm{I}_{\mathrm{DSsat}}$ igual a 4,5 mA.

A equação (17) representa a função densidade de probabilidade normal [f(x)] que é uma função que depende, por definição, do valor da média $(\bar{x})$ de uma amostra de dados e do desvio-padrão (s) dos parâmetros de todos os dispositivos que compõem a amostra e que tem a mesma forma de uma curva de distribuição normal [52], [53], [54].

$$
f(x)=\frac{1}{s \cdot \sqrt{2 \cdot \pi}} \cdot e^{\frac{-(x-\bar{x})^{2}}{2 \cdot s^{2}}}
$$

onde na equação (17), x representa cada parâmetro da amostra considerada.

A Figura 13 apresenta um exemplo de uma função da densidade de probabilidade normal de $\mathrm{I}_{\mathrm{DSsat}}$ de nMOSFETs que pertencem a uma amostra contendo 20 dispositivos com um valor médio $\left(\overline{I_{D S s a t}}\right)$ igual a $3,5 \mathrm{~mA}$ e um desvio-padrão (s) que é igual a 0,7 $\mathrm{mA}$. 
Figura 13 - Exemplo de uma função da densidade de probabilidade normal de $\mathrm{I}_{\mathrm{DSsat}}$ contendo o seu valor médio $\left(\overline{I_{D S s a t}}\right)$ que é igual a $3,5 \mathrm{~mA}$ e o valor do seu desvio-padrão (s) que é igual a $0,7 \mathrm{~mA}$.

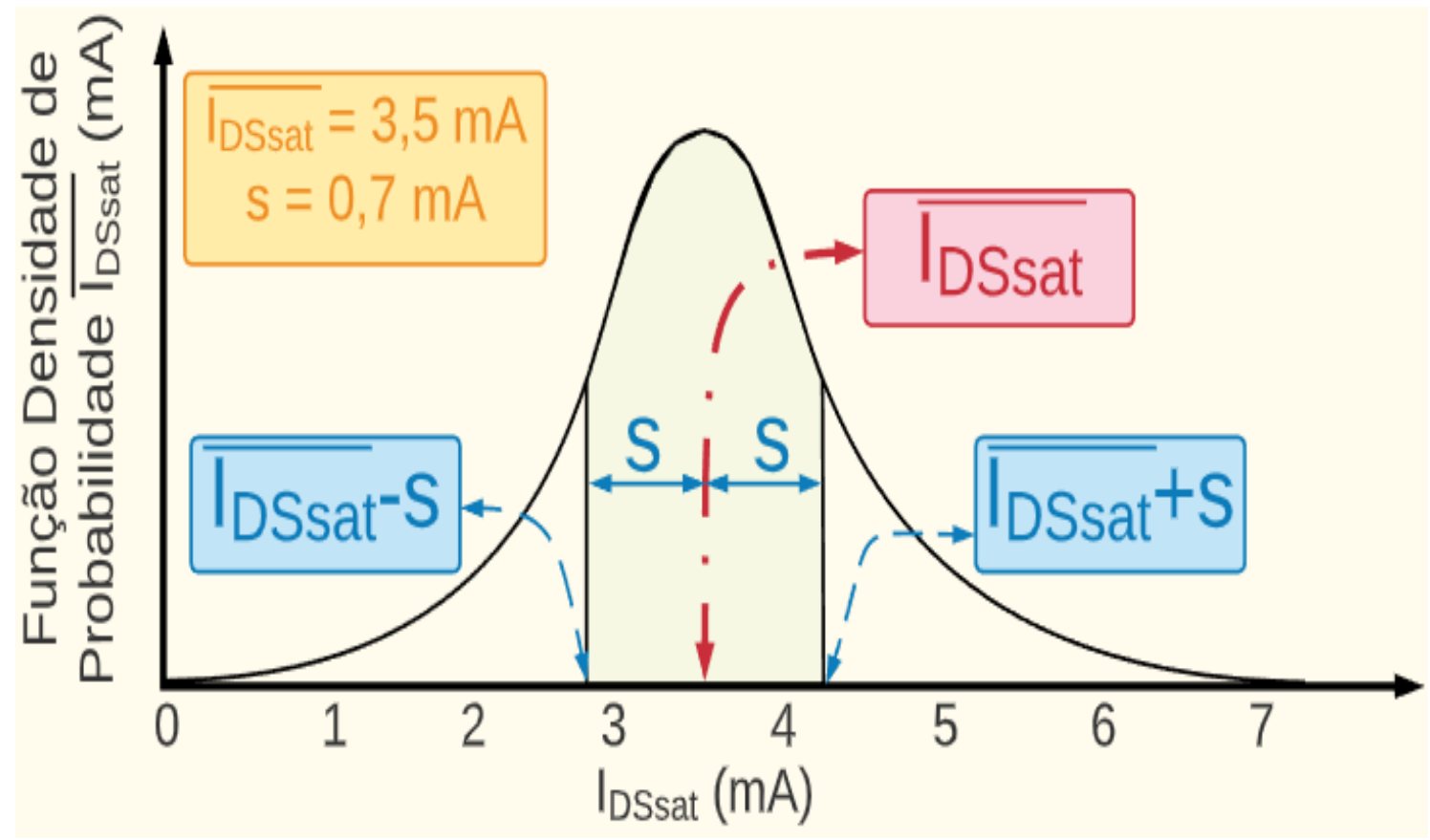

Fonte: Autor.

A função densidade de probabilidade normal para uma população ou amostra de parâmetros será utilizada quando efetuarmos a aplicação do teste estatístico Anderson Darling (descrito na seção 2.2.11.1 desta tese de doutorado).

\subsubsection{Distribuição Qui - Quadrado}

A equação (18) representa a função densidade de probabilidade qui-quadrado (denotada por $\chi_{n_{i}}^{2}$ ) que é uma função que depende, por definição, dos graus de liberdade $\left(\mathrm{gl}_{\mathrm{i}}\right)$ dos parâmetros elétricos de todos os dispositivos que compõem uma amostra [53], [54], [56].

$$
\mathrm{f}(\mathrm{x})=\frac{1}{2^{\frac{\mathrm{gl}_{\mathrm{i}}}{2}} \cdot \int_{0}^{\infty} \mathrm{x}^{\frac{\mathrm{gl}_{\mathrm{i}}}{2}-1} \cdot \mathrm{e}^{-\mathrm{x}} \mathrm{dx}} \cdot \mathrm{x}^{\frac{\mathrm{gl}_{\mathrm{i}}}{2}-1} \cdot \mathrm{e}^{\frac{-\mathrm{x}}{2}}
$$

onde na equação (18), x representa cada parâmetro da amostra considerada. 
A Figura 14 ilustra, a título de exemplo, uma função densidade de probabilidade qui-quadrado com 2 graus de liberdade [56].

Figura 14 - Exemplo de uma função densidade de probabilidade qui-quadrado com 2 graus de liberdade

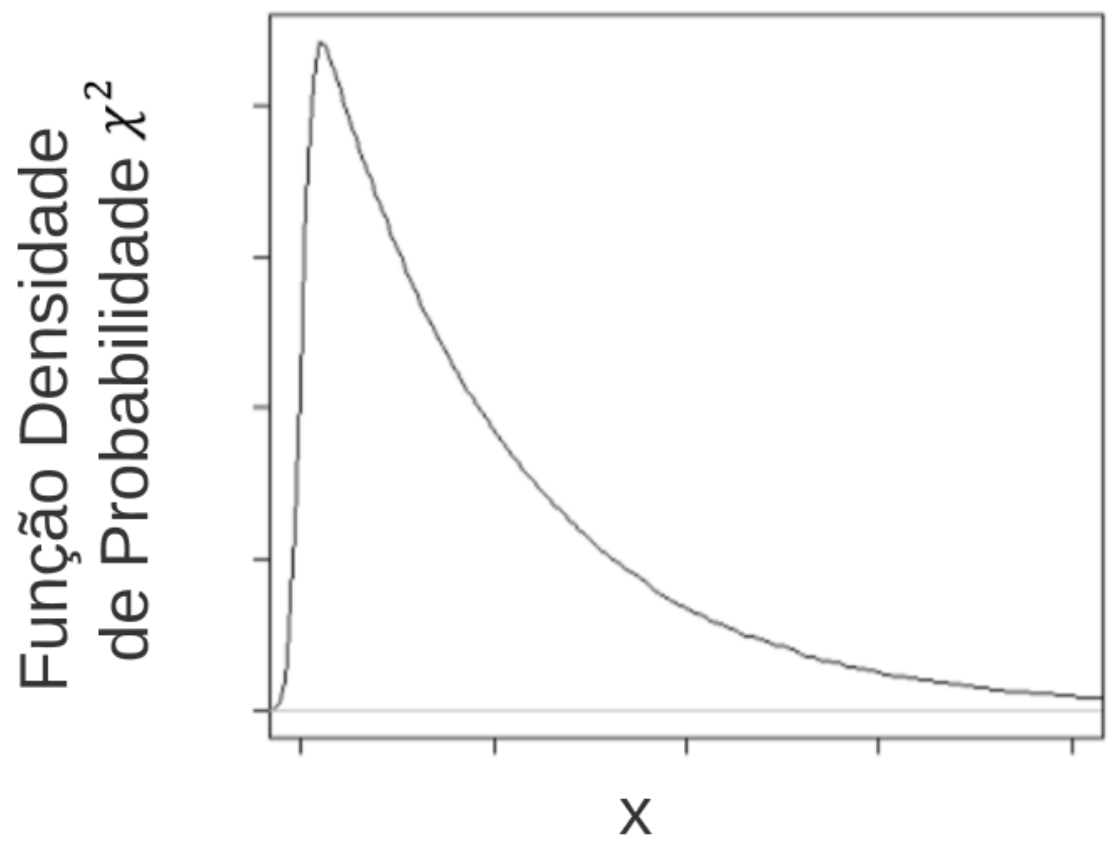

Fonte: Autor "adaptado de" [56].

Analisando-se a Figura 14, observa-se pelo gráfico da densidade de probabilidade qui-quadrado que ela é assimétrica e positiva, sendo que esta característica vale para qualquer grau de liberdade [56]. A título de exemplo, para esta função densidade de probabilidade qui-quadrado com 2 graus de liberdade, estaríamos estudando uma quantidade de 3 populações diferentes de um parâmetro elétrico extraído experimentalmente de nMOSFETs.

A função densidade de probabilidade qui-quadrado será utilizada quando efetuarmos as aplicações dos testes estatísticos para a comparação de duas variâncias (descrito na seção 2.2.11.2 desta tese de doutorado) e ANOVA (descrito na seção 2.2.11.3 desta tese de doutorado). 


\subsubsection{Testes Paramétricos e Não Paramétricos}

Os testes paramétricos utilizam os parâmetros que compõem uma amostra de dados para a aplicação dos testes estatísticos, sem que exista a necessidade de ordenar estes parâmetros (como por exemplo, do menor valor para o maior valor) [52], [53], [54], [57]. Estes testes exigem que a amostra de dados apresente uma distribuição normal ou conhecida [52], [53], [54], [57]. Os testes estatísticos ANOVA e Tukey, que serão aplicados nesta tese de doutorado, são testes estatísticos paramétricos [52], [53], [54], [57].

Os testes não paramétricos utilizam amostras numeradas para a aplicação dos testes estatísticos [52], [53], [54], [57]. Estas amostras numeradas são determinadas por meio da ordenação dos parâmetros que compõem a amostra de dados (como por exemplo, do menor valor para o maior valor) [52], [53], [54], [57]. Estes testes não exigem que a amostra em estudo apresente uma distribuição normal [52], [53], [54], [57].

\subsubsection{Testes de Hipóteses}

Um teste de hipótese é um processo estatístico que verifica se uma afirmação a respeito de um parâmetro populacional (por exemplo a média, o desvio-padrão, a variância etc.) é verdadeira ou falsa [52], [53], [54]. Um exemplo de afirmação seria que o desvio-padrão de determinada amostra de dados é menor que 0,5. Desta forma, uma afirmação sobre um parâmetro populacional (de uma população de dispositivos pertencente a uma amostra) é chamada de hipótese estatística [52], [53], [54].

Sempre devem existir um par de hipóteses para realizar um teste de hipóteses para verificar qual delas é estatisticamente verdadeira [52], [53], [54]. Geralmente as hipóteses são denominadas de duas formas diferentes: a) hipótese nula ou afirmativa, representada por $\left(\mathrm{H}_{0}\right)$ e b) hipótese alternativa, representada por $\left(\mathrm{H}_{1}\right) . \mathrm{H}_{0}$ geralmente significa uma determinada afirmação entre parâmetros populacionais, como por exemplo, se a média de duas amostras distintas são estatisticamente semelhantes, enquanto $\mathrm{H}_{1}$ significa a negação de $\mathrm{H}_{0}$ [52], [53], [54]. 


\subsubsection{Nível de Significância $\left(\alpha^{\prime}\right)$}

O nível de significância $\left(\alpha^{\prime}\right)$ é definido como um limite máximo aceitável de um parâmetro em questão (definido pelo pesquisador) para rejeitar a hipótese afirmativa $\left(\mathrm{H}_{0}\right)$ [52], [53], [54]. Normalmente os níveis de significância utilizados são iguais a 0,5\%, 1\%, 5\% e 10\% para a aplicação de testes estatísticos [52], [53], [54].

Desta forma, pode-se dizer que o nível de significância $\left(\alpha^{\prime}\right)$ indica a porcentagem de certeza na qual o teste estatístico é realizado, ou seja, se o nível de significância for igual a $5 \%$, significa que o teste será realizado com uma precisão de acerto aproximado de $95 \%$ [52], [53], [54].

\subsubsection{Intervalo e Nível de Confiança}

O intervalo de confiança é definido como um intervalo de valores usados para estimar a média, a variância ou o desvio-padrão de um parâmetro estudado de uma determinada amostra [52], [53], [54].

O nível de confiança ou grau de confiança define a probabilidade em porcentagem de que este intervalo de confiança contenha a média, a variância ou o desvio-padrão de um parâmetro e é calculado de acordo com a equação (19) [52], [53], [54].

$$
\text { grau de confiança }=\text { nível de confiança }=1-\alpha^{\prime}
$$

Assim, utiliza-se este intervalo de confiança para estimar um determinado parâmetro populacional [52], [53], [54], ou seja, se a população de um parâmetro qualquer apresenta um valor médio igual a 20, o intervalo de confiança de uma amostra desta população deverá conter este valor médio, que no caso foi especificado como 20.

\subsubsection{Coeficiente de Variação}

A figura de mérito utilizada para quantificar analiticamente o descasamento dos parâmetros elétricos dos dispositivos utilizados neste trabalho é o coeficiente de variação [ $\left.\varepsilon_{\mathrm{r}}(\%)\right]$ em porcentagem (\%), que é dado pela Equação (20) [41], [42], [43], [53].

Idealmente, os parâmetros elétricos estudados não deveriam variar com o aumento da TID aplicada. Assim, o coeficiente de variação expressa a medida da dispersão do 
processo de fabricação e procedimento das radiações ionizantes de raios-X realizada para estimar a variabilidade dos dispositivos [58], [59], [60].

$$
\varepsilon_{r}(\%)=\left(\frac{S}{\bar{\mu}}\right) \cdot 100
$$

Na equação (20), s e $\bar{\mu}$ são o desvio-padrão e o valor médio dos parâmetros elétricos ou figura de mérito (FM) encontrados por meio da amostra de dados dos DnMs, OnMs e os CnMs equivalentes.

\subsubsection{Testes Estatísticos Usados Neste Trabalho}

Nesta seção são apresentadas as principais características dos testes estatísticos que foram aplicados na elaboração desta tese de doutorado.

\subsubsection{Teste estatístico de normalidade de Anderson - Darling}

Existem alguns testes estatísticos que podem somente ser aplicados a uma população de parâmetros que apresente distribuição normal, por tratar-se de testes paramétricos [52], [53], [54]. Portanto, para verificar se uma amostra de dados apresenta uma distribuição normal pode-se aplicar o teste estatístico de Anderson-Darling [61].

O teste estatístico de Anderson - Darling é um dos mais utilizados quando o tamanho da amostra não é superior a 25 [52], [53], [54]. Este teste mede o quão bem uma amostra de parâmetros segue uma distribuição específica, como por exemplo, uma distribuição normal ou exponencial [52], [53], [54].

Para a aplicação do teste de Anderson-Darling, deve-se criar um teste de hipóteses. A primeira delas diz que a amostra de parâmetros segue uma distribuição normal [52], [53], [54]. A outra hipótese, que é a negação da primeira, afirma que a amostra não segue uma distribuição normal [52], [53], [54]. Este teste é aplicado por meio da equação (21) [61], [62], [63]. 


$$
A^{2}=-n^{\prime}-\sum_{i}^{m} \frac{(2 \cdot i-1)}{n^{\prime}} \cdot \ln \left[F\left(x_{i}\right)+\ln \left(1-F\left(x_{\left(n^{\prime}+1\right)-i}\right)\right)\right]
$$

onde i é um índice que vai de 1 até $n$ ', $\mathrm{F}\left(\mathrm{x}_{\mathrm{i}}\right)$ é a função matemática (também pode ser denominada de distribuição cumulativa ou acumulada) que representa a distribuição da amostra de parâmetros de tamanho n' (esta função é calculada pelo software estatístico MINITAB 2020 [64] que foi utilizado no desenvolvimento desta tese de doutorado), $\mathrm{F}\left(\mathrm{x}_{\left(\mathrm{n}^{\prime}+1\right)+1}\right)$ é a função matemática (também pode ser denominada de distribuição cumulativa ou acumulada) que apresenta uma distribuição conhecida [neste caso, esta função $\mathrm{F}\left(\mathrm{x}_{\left(\mathrm{n}^{\prime}+1\right)+1}\right)$ apresenta uma distribuição normal)] [61], [62], [63]. Assim, quanto mais a distribuição de $\mathrm{F}\left(\mathrm{x}_{\mathrm{i}}\right)$ se aproximar da distribuição de $\mathrm{F}\left(\mathrm{x}_{\left(\mathrm{n}^{\prime}+1\right)+1}\right)$, menor é o resultado deste teste estatístico [61], [62], [63].

Quando o software MINITAB 2020 [64] aplica este teste estatístico, ele cria duas regiões denominadas de: a) região de aceitação da hipótese afirmativa e b) região de rejeição da hipótese afirmativa. Este mesmo software também calcula a área desta região de rejeição e fornece o valor de $\mathrm{p}$. Caso este valor de $\mathrm{p}$ apresente valor superior à área de rejeição da hipótese afirmativa, deve-se concluir que a amostra de parâmetros em estudo apresenta uma distribuição normal [61], [62], [63].

\subsubsection{Teste estatístico para a comparação de duas variâncias}

Quando se aplica um teste estatístico com o objetivo de efetuar a comparação entre duas variâncias de uma variável elétrica de um dispositivo pertencentes a duas amostras de n' dispositivos denominadas de $s_{1}^{2}$ e $s_{2}^{2}$, as hipóteses criadas para a aplicação deste teste estatístico podem ser ilustradas por meio da Figura 15 [52], [53], [65] [66]. 
Figura 15 - Exemplo de hipóteses de interesse a serem formalizadas para a comparação de duas variâncias de duas amostras distintas para a aplicação do teste estatístico que efetua a comparação de duas variâncias.

$$
\left\{\begin{array} { l } 
{ H _ { 0 } : s ^ { 2 } { } _ { 1 } = S ^ { 2 } { } _ { 2 } } \\
{ H _ { 1 } : s ^ { 2 } { } _ { 1 } \neq S ^ { 2 } { } _ { 2 } }
\end{array} \text { ou } \quad \left\{\begin{array} { l } 
{ H _ { 0 } : s ^ { 2 } { } _ { 1 } = S ^ { 2 } { } _ { 2 } } \\
{ H _ { 1 } : s ^ { 2 } { } _ { 1 } > s ^ { 2 } { } _ { 2 } }
\end{array} \text { ou } \quad \left\{\begin{array}{l}
H_{0}: s^{2}{ }_{1}=s^{2}{ }_{2} \\
H_{1}: s^{2}{ }_{1}<s^{2}{ }_{2}
\end{array}\right.\right.\right.
$$

Fonte: Autor

Na Figura 15, observa-se que $s_{1}^{2}$ e $s_{2}^{2}$ são as estimativas das variâncias das amostras de n', e n'2

Desta forma, a aplicação deste teste estatístico permite analisar o nível de variabilidade de duas amostras de dados, isto é, se a variância de uma amostra for menor que a variância de uma segunda amostra, pode-se afirmar que a variabilidade desta primeira amostra é menor que a variabilidade da segunda amostra [52], [53], [65] [66].

Ademais, este teste estatístico utiliza o parâmetro F em homenagem a Sir Ronald Fisher (distribuição F, utilizada também no teste estatístico ANOVA) calculado por meio da equação (22) [52], [53], [65] [66], [67].

$$
\mathrm{F}_{\text {calculado }}=\frac{\mathrm{s}_{1}^{2}}{\mathrm{~s}_{2}^{2}}
$$

Verifica-se que o parâmetro $\mathrm{F}_{\text {calculado }}$ é a razão entre os parâmetros $s_{1}^{2}$ e $s_{2}^{2}$. Desta maneira, a amostra de tamanho n' ${ }_{1}$ tem (n' $\left.{ }_{1}-1\right)$ graus de liberdade e a amostra de tamanho n'2 tem (n'2-1) graus de liberdade [52], [53], [65] [66].

Para aceitarmos ou rejeitarmos a hipótese afirmativa $\left(\mathrm{H}_{0}\right)$, pode-se proceder de duas formas diferentes:

a) escolha de um " $F_{\text {crítico" }}\left(\mathrm{F}_{\mathrm{C}}\right)$ por meio de uma tabela denominada de distribuição F para um nível de significância $\alpha$ ' (neste estudo é adotado para ser igual a 0,05 ou 5\%) e é utilizada para a aplicação do teste estatístico da comparação de duas variâncias;

b) por meio da comparação do valor p com o nível de significância escolhido. 
A escolha do $\mathrm{F}_{\mathrm{C}}$ permite criar os intervalos de aceitação e de rejeição das hipóteses escolhidas para o teste estatístico da comparação de duas variâncias, ou seja, se o valor

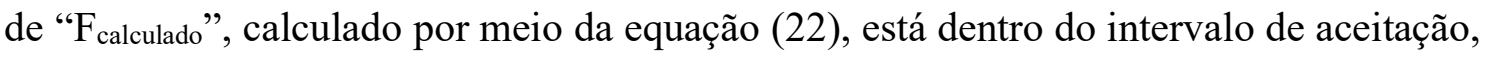
deve-se considerar a hipótese afirmativa como verdadeira, caso contrário, a hipótese afirmativa será considerada falsa [52], [53], [65] [66]. Este valor do $\mathrm{F}_{\mathrm{C}}$ é escolhido por meio da utilização de uma tabela de distribuição F para um nível de significância $\alpha$ ' e em função do número de graus de liberdade (g.l.) das amostras que tem (n'1-1) graus de liberdade no numerador da equação (22) e (n'2-1) graus de liberdade no denominador da equação (22) [52], [53], [65] [66].

A outra maneira de aceitarmos ou rejeitarmos a hipótese afirmativa $\left(\mathrm{H}_{0}\right)$ é por meio da comparação do valor $p$ do teste estatístico da comparação de duas variâncias com o nível de significância escolhido para a aplicação deste teste [52], [53], [65] [66]. O valor de $\mathrm{p}$ é calculado como sendo a área sob a curva de distribuição $\mathrm{F}$ (distribuição proporcional à densidade de probabilidade qui-quadrado, $\chi^{2}$ ) em função do valor do

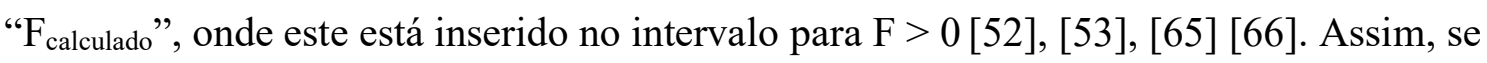
o valor de $\mathrm{p}$ for superior ao valor do nível de significância $\left(\alpha^{\prime}\right)$ escolhido, deve-se considerar $\mathrm{H}_{0}$ verdadeira (com um nível de confiança ou de acerto igual a $\left(1-\alpha^{\prime}\right)$ ), caso o valor de $\mathrm{p}$ seja inferior ao valor do nível de significância $\left(\alpha^{\prime}\right)$, deve-se considerar $\mathrm{H}_{0}$ como falsa (com um nível de confiança ou de acerto igual a (1- $\left.\alpha^{\prime}\right)$ ).

A Figura 16 ilustra um exemplo de um gráfico da função densidade de probabilidade (FDP) $\chi^{2}$ em função de $\mathrm{F}_{\mathrm{C}}$ indicando a forma pela qual é feita a decisão para aceitar ou rejeitar $\mathrm{H}_{0}$, em função de um valor de $\mathrm{F}$ obtido da tabela de distribuição $\mathrm{F}$ e em função do nível de significância $\alpha$ ' adotado igual a 5\%. 
Figura 16 - Exemplo de um gráfico de FDP $\chi^{2}$ em função de $\mathrm{F}_{\mathrm{C}}$ indicando a forma pela qual é feita a decisão para aceitar ou rejeitar $\mathrm{H}_{0}$ em função de um valor de $\mathrm{F}$, que é obtido da tabela de distribuição $\mathrm{F}$ em função do nível de significância $\alpha$, que foi adotado igual a 5\%, para a aplicação do teste estatístico de comparação entre duas variâncias.

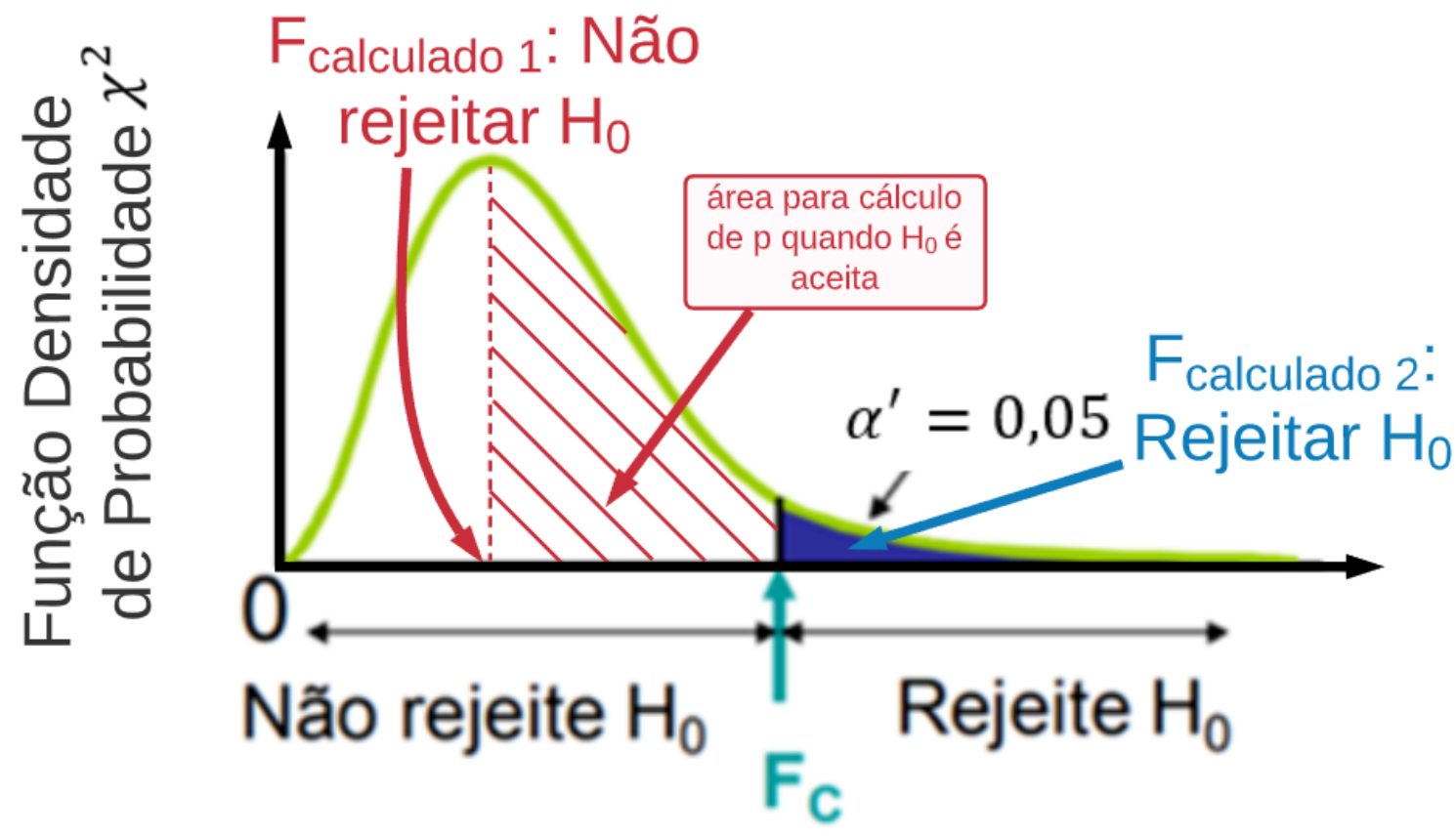

Fonte: Autor "adaptado de" [67], slide 29.

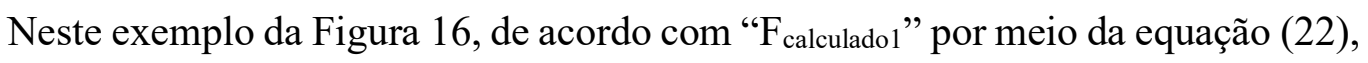
verifica-se que o valor de p é superior a $5 \%$ e assim deve-se aceitar a hipótese $\mathrm{H}_{0}$. Por

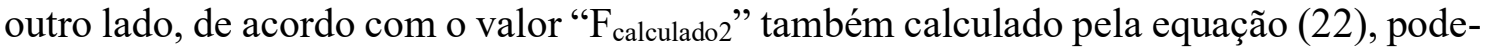
se observar que o valor de p é inferior a 5\% e assim deve-se rejeitar a hipótese $\mathrm{H}_{0}$.

Ainda analisando-se a Figura 16, verifica-se que o critério de rejeição se encontra na ponta direita da curva F. Pode-se proceder desta maneira, sempre colocando o maior valor entre $s_{1}^{2}$ e $s_{2}^{2}$ no numerador da equação (22) e o menor no denominador da equação (22), independentemente de qual seja $\mathrm{H}_{1}$. Assim, a Figura 17 ilustra três exemplos diferentes referente ao procedimento para ser realizado para rejeitar $\mathrm{H}_{0}$. 
Figura 17 - Critério de rejeição de $\mathrm{H}_{0}$ para a aplicação do teste estatístico de comparação entre duas variâncias

$$
\begin{aligned}
& \left\{\begin{array}{l}
\mathrm{H}_{0}: \mathrm{s}^{2} \mathrm{CnM}=\mathrm{s}^{2} \mathrm{DnM} \\
\mathrm{H}_{1}: \mathrm{s}^{2} \mathrm{CnM}>\mathrm{s}^{2} \mathrm{DnM}
\end{array}\right\} p \leq \alpha^{\prime}\left\{\begin{array}{l}
\mathrm{H}_{0}: \mathrm{s}^{2} \mathrm{CnM}=\mathrm{s}^{2} \mathrm{DnM} \\
\mathrm{H}_{1}: \mathrm{s}^{2} \mathrm{CnM} \neq \mathrm{s}^{2} \mathrm{DnM}
\end{array}\right\} p \leq \frac{\alpha^{\prime}}{2} \\
& \mathrm{H}_{0}: \mathrm{s}^{2} \mathrm{snM}=\mathrm{s}^{2} \mathrm{OnM}
\end{aligned}
$$

Fonte: Autor.

Na Figura 17, verifica-se que $s_{C n M}^{2}, s_{D n M}^{2}$ e $s_{O n M}^{2}$ representam as variâncias calculadas das amostras de parâmetros elétricos extraídos experimentalmente dos CnM, DnM e OnM, respectivamente. Ressalta-se que este teste estatístico foi aplicado nesta tese de doutorado utilizando o software estatístico MINITAB 2020 [64].

\subsubsection{Teste estatístico da Análise de Variância (ANOVA)}

A análise da Variância (ANOVA) é um teste estatístico utilizado para verificar se os valores médios de uma variável elétrica de um dispositivo pertencente a três ou mais amostras de n' dispositivos podem ser consideradas estatisticamente equivalentes [53], [67]. A Tabela 1 ilustra um exemplo de procedimento utilizado para o cálculo das médias de "k" amostras [65]. 
Tabela 1 - Exemplo de uma tabela que descreve o procedimento utilizado para o cálculo das médias de "k" amostras

\begin{tabular}{|c|c|c|c|}
\hline Amostra 1 & Amostra 2 & $\cdots$ & Amostra k \\
\hline$x_{11}$ & $x_{21}$ & $\ldots$ & $x_{k 1}$ \\
\hline$x_{12}$ & $x_{22}$ & $\ldots$ & $x_{k 2}$ \\
\hline$x_{13}$ & $x_{23}$ & $\ldots$ & $x_{k 3}$ \\
\hline$\vdots$ & $\vdots$ & $\ldots$ & $\vdots$ \\
\hline$x_{1 n 1}$ & $x_{2 n 2}$ & $\ldots$ & $x_{k n k}$ \\
\hline $\bar{\mu}_{1}$ & $\bar{\mu}_{2}$ & $\ldots$ & $\bar{\mu}_{k}$ \\
\hline
\end{tabular}

Fonte: Autor "adaptado de" [65], p. 92.

Na Tabela $1, \bar{\mu}_{1}$ é a média da Amostra $1, \bar{\mu}_{2}$ é a média da Amostra $2, \bar{\mu}_{k}$ é a média da Amostra k, sendo que os parâmetros $x_{1 n 1}$ são os parâmetros representativos da Amostra 1, os parâmetros $x_{2 n 2}$ são os parâmetros representativos da Amostra 2 e os parâmetros $x_{k n k}$ são os parâmetros representativos da Amostra k. Assim, pode-se afirmar que o objetivo do teste ANOVA é verificar quão grande é a variabilidade entre as médias das amostras em relação à variabilidade que se observa dentro de cada amostra [53], [65], [67]. Dessa maneira, o teste de igualdade de várias médias compara a dispersão (variância) entre as médias das amostras e a dispersão (variância) que existe dentro de cada amostra [53], [65], [67].

Os dados das amostras que são utilizados para a aplicação deste teste estatístico são separados em grupos segundo uma característica (fator). Ressalta-se que fator (ou tratamento) é uma característica que permite distinguir diferentes populações umas das outras [53], [67].

Para ilustrar um exemplo, pode-se analisar as amostras das $\mathrm{V}_{\mathrm{TH}} \mathrm{S}$ extraídas de 3 tipos diferentes de nMOSFETs (DnM, OnM e CnM) quando irradiados com doses diferentes de radiações ionizantes de raios-X (como dose ionizante total, Total Ionizing Dose, TID). Assim, temos um único fator (única variável), que é a geometria de porta e 3 populações das $\mathrm{V}_{\mathrm{THS}}$ diferentes de nMOSFETs [53], [67]. A Figura 18 ilustra, a título de exemplo, a ideia básica para aplicação do teste ANOVA para este exemplo citado. 
Figura 18 - Ideia básica para aplicação do teste ANOVA nas $\mathrm{V}_{\mathrm{TH}} \mathrm{S}$ extraídas de 3 tipos diferentes de nMOSFETs (DnM, OnM e CnM) quando irradiados com doses diferentes de radiações ionizantes de raios- $\mathrm{X}$

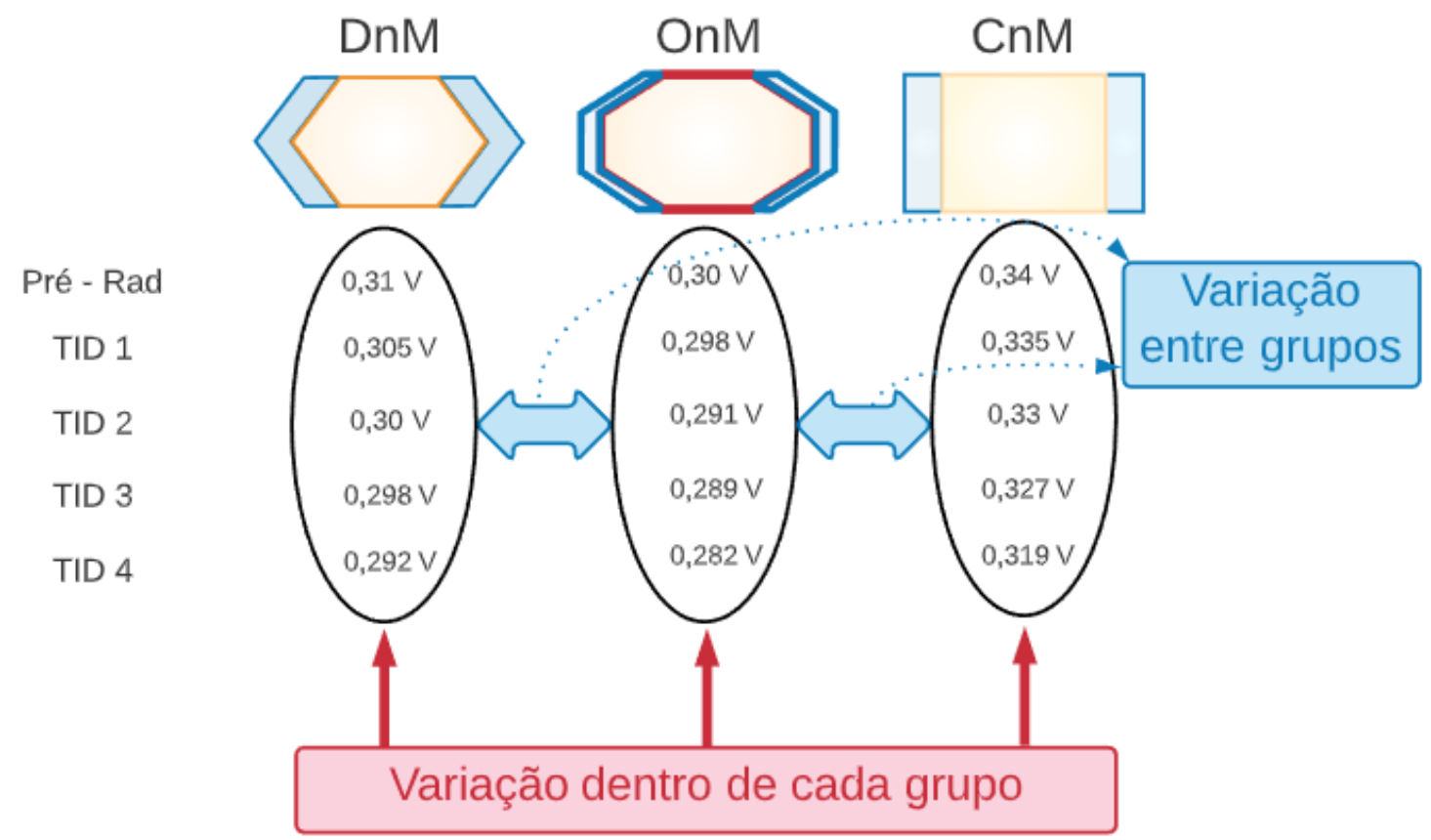

Fonte: Autor.

Na Figura 18, pode-se observar que TID 1, TID 2, TID 3 e TID 4 são as doses de radiações ionizantes do tipo raios-X diferentes aplicadas nos 3 tipos diferentes de nMOSFETs (DnM, OnM e CnM) para a obtenção das $\mathrm{V}_{\mathrm{THS}}$ destes dispositivos. Além disso, ao analisar a Figura 18, verifica-se que o objetivo da aplicação do teste ANOVA, neste exemplo, é o de verificar se a geometria de porta dos nMOSFETs contribui ou não para uma maior robustez dos transistores em um ambiente de radiação ionizante de raios$\mathrm{X}$, isto é, uma menor variação possível dos parâmetros elétricos em estudo.

Assim, pode-se resumir o conceito da aplicação do teste ANOVA para uma amostra de dados por meio da ilustração apresentada na Figura 19. 
Figura 19- Ilustração para mostrar o conceito da aplicação do teste ANOVA para uma amostra de dados

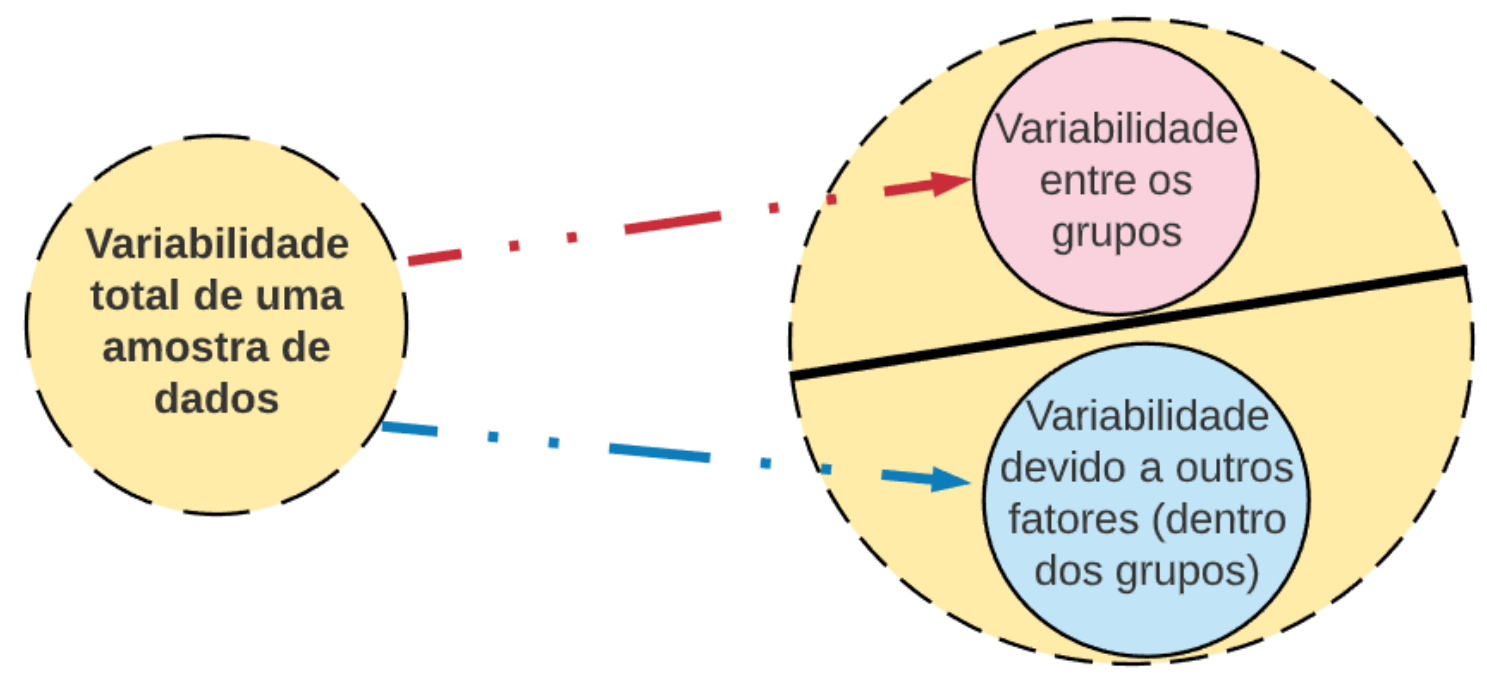

Fonte: Autor "adaptado de" [67], slide 11.

Para que este teste estatístico seja efetuado corretamente, deve-se considerar $\mathrm{k}$ populações, sendo que k deve ser pelo menos igual a 3 [52], [53], [54], [66]. Além disso, as distribuições das populações têm que ter distribuições normais e também as populações têm que ter praticamente as mesmas variâncias $s^{2}$ ou desvios-padrão $s$. Desde que os tamanhos amostrais sejam iguais ou quase iguais, as variâncias das populações podem diferir por quantidades que tornem a maior variância até nove vezes o valor da menor variância (razão estimada entre as variâncias) e os resultados da ANOVA continuarão a ser essencialmente confiáveis [52], [53], [54], [66]. Além disso, as hipóteses a serem criadas para a aplicação deste teste devem apresentar as seguintes características:

$$
\mathrm{H}_{0}: \bar{\mu}_{1}=\bar{\mu}_{2}=\bar{\mu}_{3}=\cdots=\bar{\mu}_{k}
$$

$\mathrm{H}_{1}$ : há pelo menos uma média diferente das demais

Na prática, ao aplicar o teste ANOVA e constatar que a hipótese $\mathrm{H}_{0}$ é verdadeira, teremos a condição ilustrada na Figura 20. 
Figura 20 - Condição para hipótese $\mathrm{H}_{0}$ verdadeira ao aplicar o teste ANOVA.

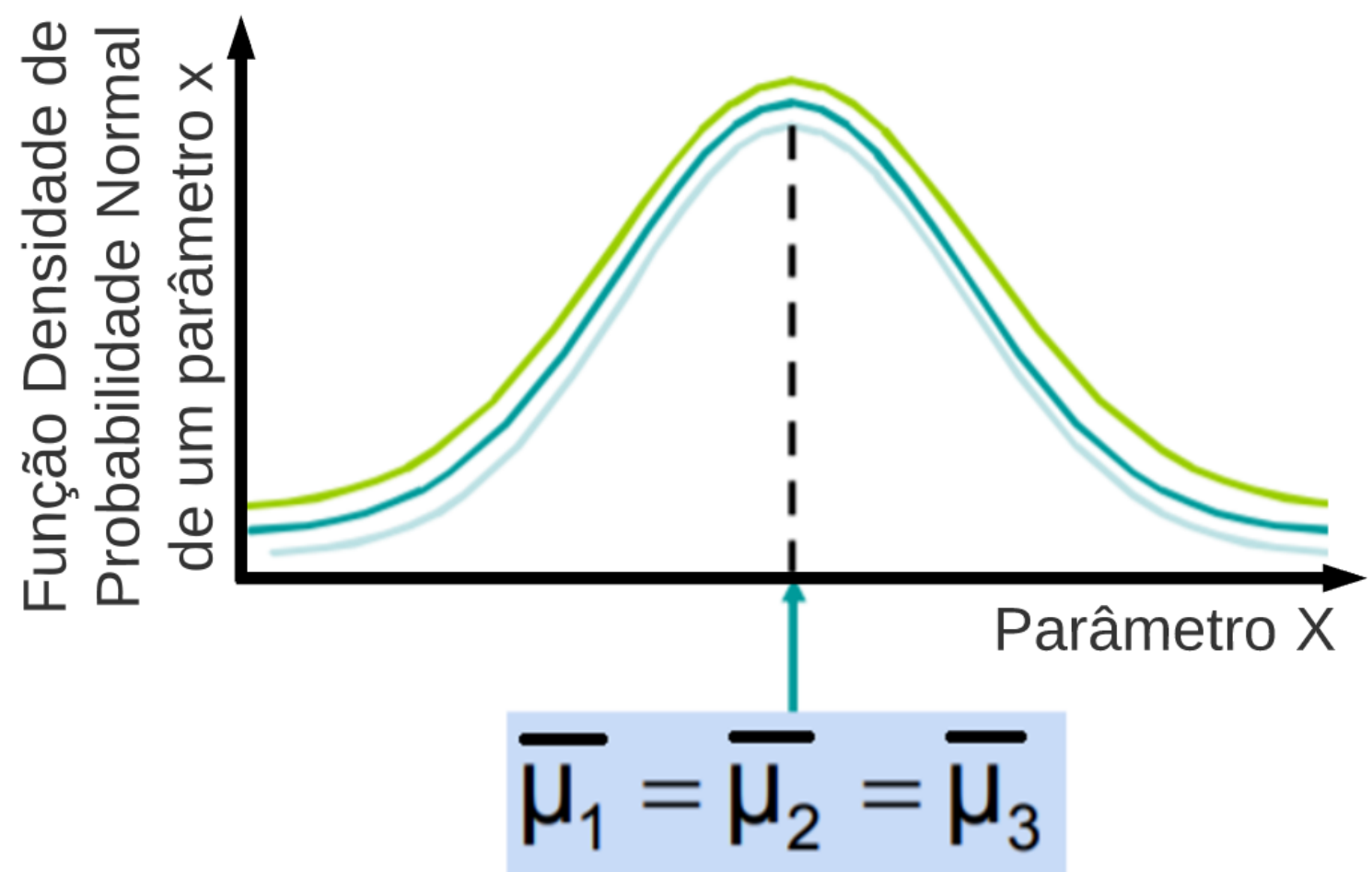

Fonte: Autor "adaptado de" [67], slide 7.

$\mathrm{Na}$ Figura 20 podem-se observar três diferentes funções densidade de probabilidade normais de um parâmetro x qualquer e também três valores médios $\left(\overline{\mu_{1}}, \overline{\mu_{2}}\right.$ e $\overline{\mu_{3}}$ ) das diferentes amostras 1,2 e 3 .

Por outra lado, se $\mathrm{H}_{0}$ for rejeitada e $\mathrm{H}_{1}$ for aceita, teremos a condição ilustrada na Figura 21. 
Figura 21 - Condição para $\mathrm{H}_{0}$ rejeitada e $\mathrm{H}_{1}$ aceita ao aplicar o teste ANOVA

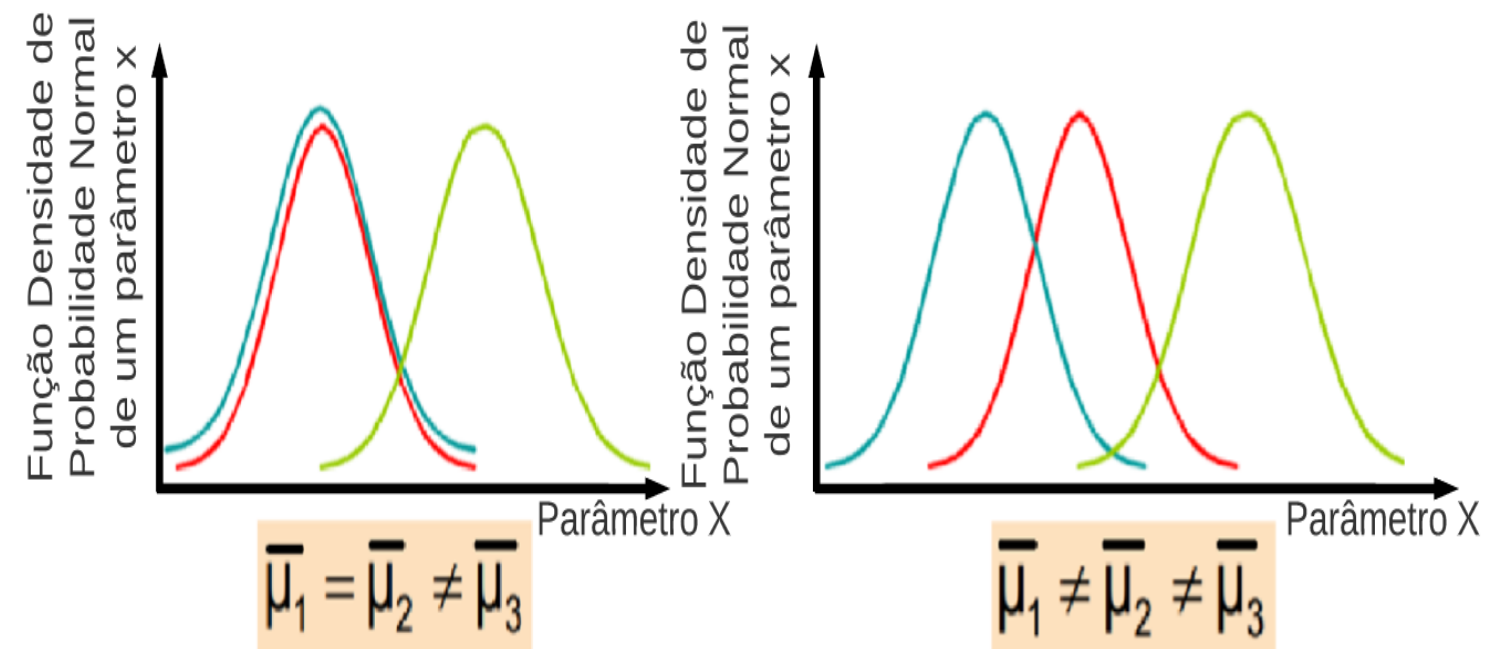

Fonte: Autor "adaptado de" [67], slide 8.

Desta forma, o principal objetivo da aplicação deste teste estatístico ANOVA é comparar a dispersão (variância) entre as médias amostrais e a dispersão (variância) que existe dentro de cada amostra [52], [53], [54], [66].

No processo de montagem desta análise, deve-se trabalhar com o conceito de que a variação total dos dados provém de dois fatores: variação entre as amostras e a variação de dentro das amostras [52], [53], [54], [67], [66].

A equação (23) ilustra como é efetuado o cálculo da variação total entre as amostras para a aplicação do teste ANOVA.

$$
S Q T=\sum_{j=1}^{k} \sum_{i=1}^{n_{j}}\left(x_{i j}-\bar{\mu}\right)^{2}
$$

onde na equação (23), SQT é a soma de quadrados total, $\mathrm{x}_{\mathrm{ij}}$ é um dado de uma amostra que se pretende estudar da amostra “j”, $\bar{\mu}$ é o valor médio do conjunto de $\mathrm{k}$ amostras, $\mathrm{n}_{\mathrm{j}} \mathrm{e}$ o número de observações na amostra “j” e k é o número de amostras [52], [53], [54], [66].

A equação (24) ilustra como é efetuado o cálculo da variação entre as amostras para a aplicação do teste ANOVA [52], [53], [54], [66]. 


$$
S Q E=\sum_{j=1}^{k} n_{j} \cdot\left(\bar{x}_{j}-\bar{\mu}\right)^{2}
$$

onde na equação (24), SQE é a soma de quadrados dos erros, $\bar{x}_{j}$ é um valor médio de uma amostra “j” que se pretende estudar, $\bar{\mu}$ é o valor médio representativo de todas as amostras, $\mathrm{n}_{\mathrm{j}}$ é o número de elementos da amostra “j” e k é o número de amostras [52], [53], [54], [66]. Assim, o valor calculado de SQE é uma medida da variação entre os valores médios devido à diferença entre as amostras, conforme ilustrado na Figura 22 [66], [67].

Figura 22 - Ilustração da variação entre os valores médios devido à diferença entre as amostras.

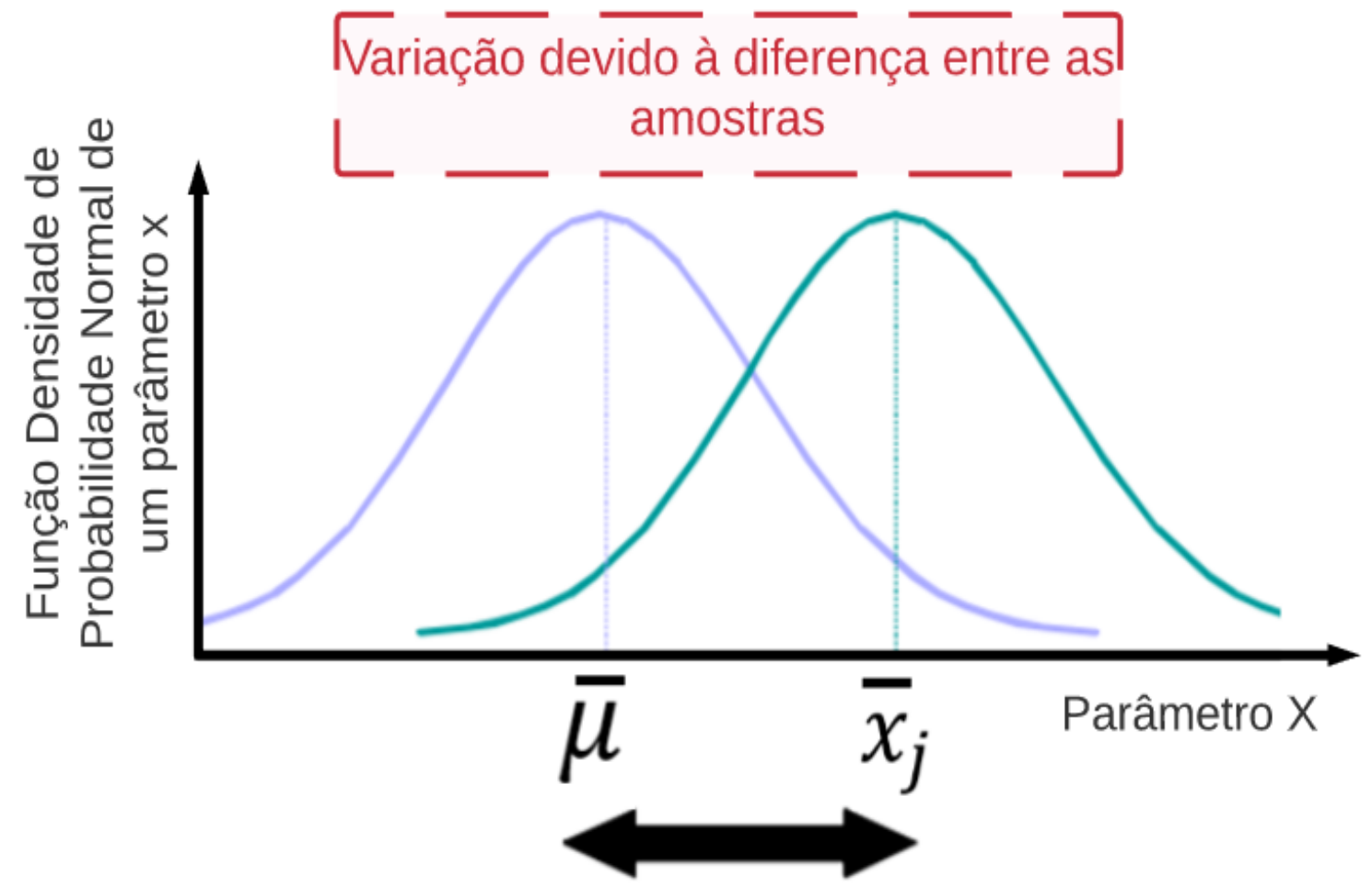

Fonte: Autor "adaptado de" [67], slide 19.

$\mathrm{Na}$ Figura 22 podem-se observar duas diferentes funções densidade de probabilidade normais de um parâmetro x qualquer e também dois diferentes valores médios $\left(\bar{\mu}\right.$ e $\left.\overline{x_{j}}\right)$. 
A equação (25) ilustra como é efetuado o cálculo da variação de dentro das amostras para a aplicação do teste ANOVA [52], [53], [54].

$$
S Q R=\sum_{j=1}^{k} \sum_{i=1}^{n_{j}}\left(x_{i j}-\bar{x}_{J}\right)^{2}
$$

onde na equação (25), SQR é a soma de quadrados da regressão, $\mathrm{n}_{\mathrm{j}}$ é o número de elementos da amostra “j”, k é o número de amostras, $\bar{x}_{j}$ é a média da amostra “j” e $x_{i j}$ é a i-ésima observação na amostra j [52], [53], [54], [66], [67]. Assim, o valor calculado de SQR é a soma de quadrados que representa a variabilidade comum a todas as populações em consideração, conforme ilustrado na Figura 23 [67].

Figura 23 - Cálculo da variabilidade de todas as populações considerando a soma da variação dentro de cada amostra e então somam-se todas as amostras.

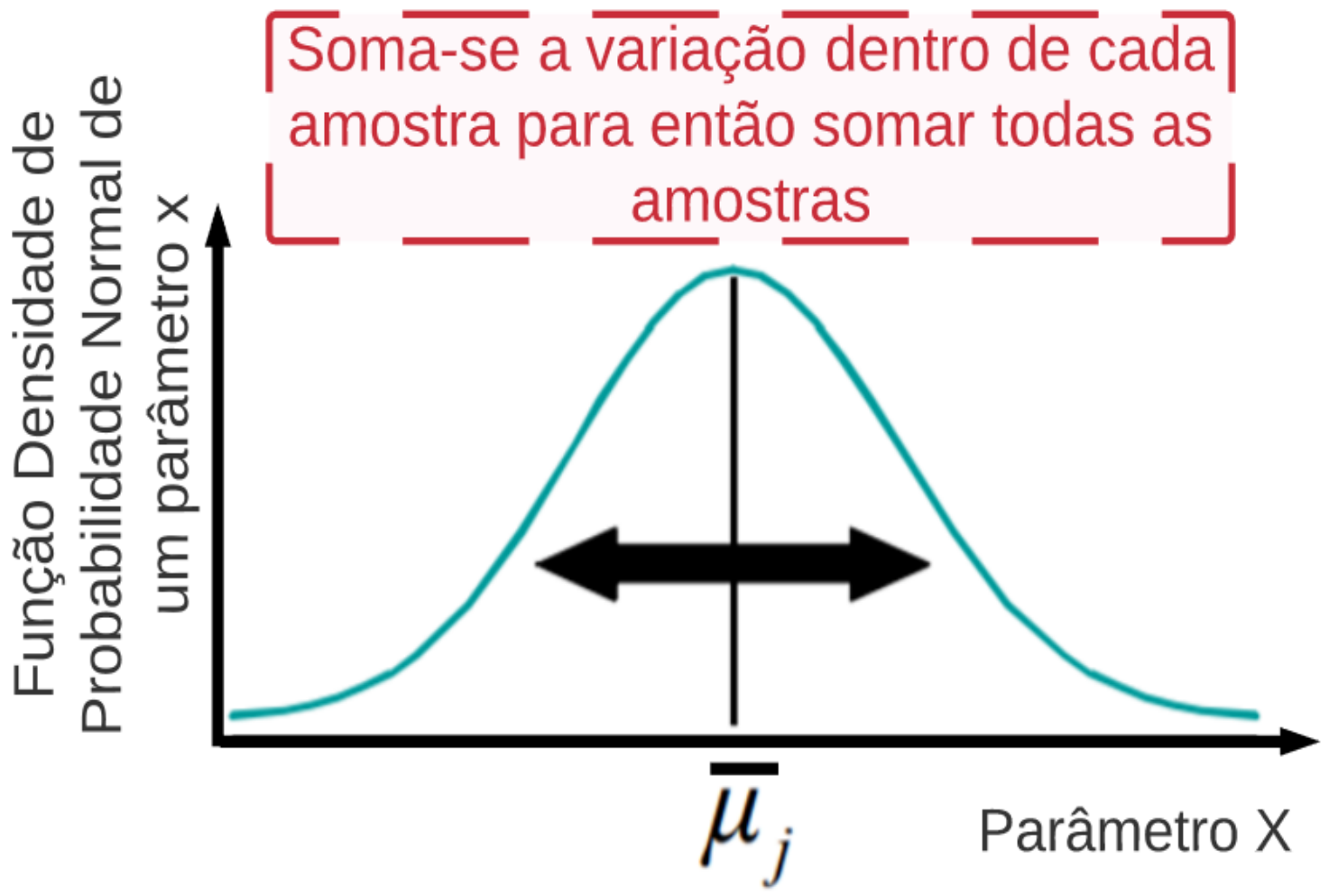

Fonte: Autor "adaptado de" [67], slide 21.

Para aceitarmos ou rejeitarmos a hipótese nula $\left(\mathrm{H}_{0}\right)$, pode-se proceder de duas formas diferentes: 
a) escolha de um $F_{C}$ por meio de uma tabela denominada de distribuição $F$ para um nível de significância $\alpha^{\prime}$ (neste estudo é adotado para ser igual a 0,05 ou 5\%) e é utilizada para a aplicação do teste ANOVA [52], [53], [54], [66];

b) por meio da comparação do valor p com o nível de significância escolhido [52], [53], [54], [66].

A escolha do $\mathrm{F}_{\mathrm{C}}$ permite criar os intervalos de aceitação e de rejeição das hipóteses

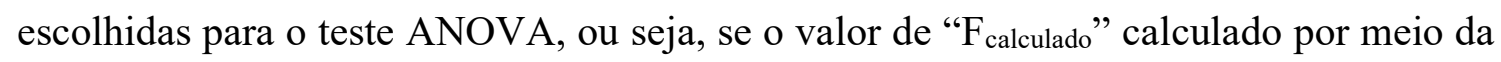
equação (26) está dentro do intervalo de aceitação, deve-se considerar a hipótese afirmativa como verdadeira, caso contrário, a hipótese afirmativa será considerada falsa [52], [53], [65] [66].

$$
F_{\text {calculado }}=\frac{S Q E /(k-1)}{S Q R /\left(n^{\prime}-k\right)}
$$

onde na equação (26) "k-1" representa os graus de liberdade do numerador (g.1.1) e "n'k" representa os de graus de liberdade do denominador (g.1.2) e k representa a quantidade de médias diferentes sendo comparadas. Desta forma, deve-se comparar este valor de "F calculado" com o valor de $\mathrm{F}_{\mathrm{C}}$ obtido da tabela de distribuição $\mathrm{F}$ em função do nível de significância $\alpha^{\prime}$ e em função do número de graus de liberdade (g.l.) das amostras que têm (k-1) graus de liberdade no numerador da equação (26) e (n'-k) graus de liberdade no

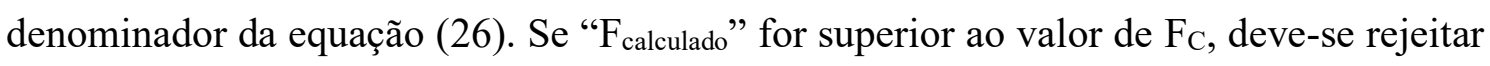
a hipótese nula [52], [53], [54], [67], [66]. A Figura 24 ilustra um exemplo de um gráfico da FDP $\chi^{2}$ em função de $\mathrm{F}_{\mathrm{C}}$ indicando a forma pela qual é feita a decisão para aceitar ou rejeitar $\mathrm{H}_{0}$, em função de um valor de $\mathrm{F}$ obtido da tabela de distribuição $\mathrm{F}$ e em função do nível de significância $\alpha$ ' adotado igual a $5 \%$. 
Figura 24 - Exemplo de um gráfico de FDP $\chi^{2}$ em função de $\mathrm{F}_{\mathrm{C}}$ indicando a forma pela qual é feita a decisão para aceitar ou rejeitar $\mathrm{H}_{0}$ em função de um valor de $\mathrm{F}$, que é obtido da tabela de distribuição $\mathrm{F}$ em função do nível de significância $\alpha^{\prime}$, que foi adotado igual a 5\%, para a aplicação do teste estatístico ANOVA.
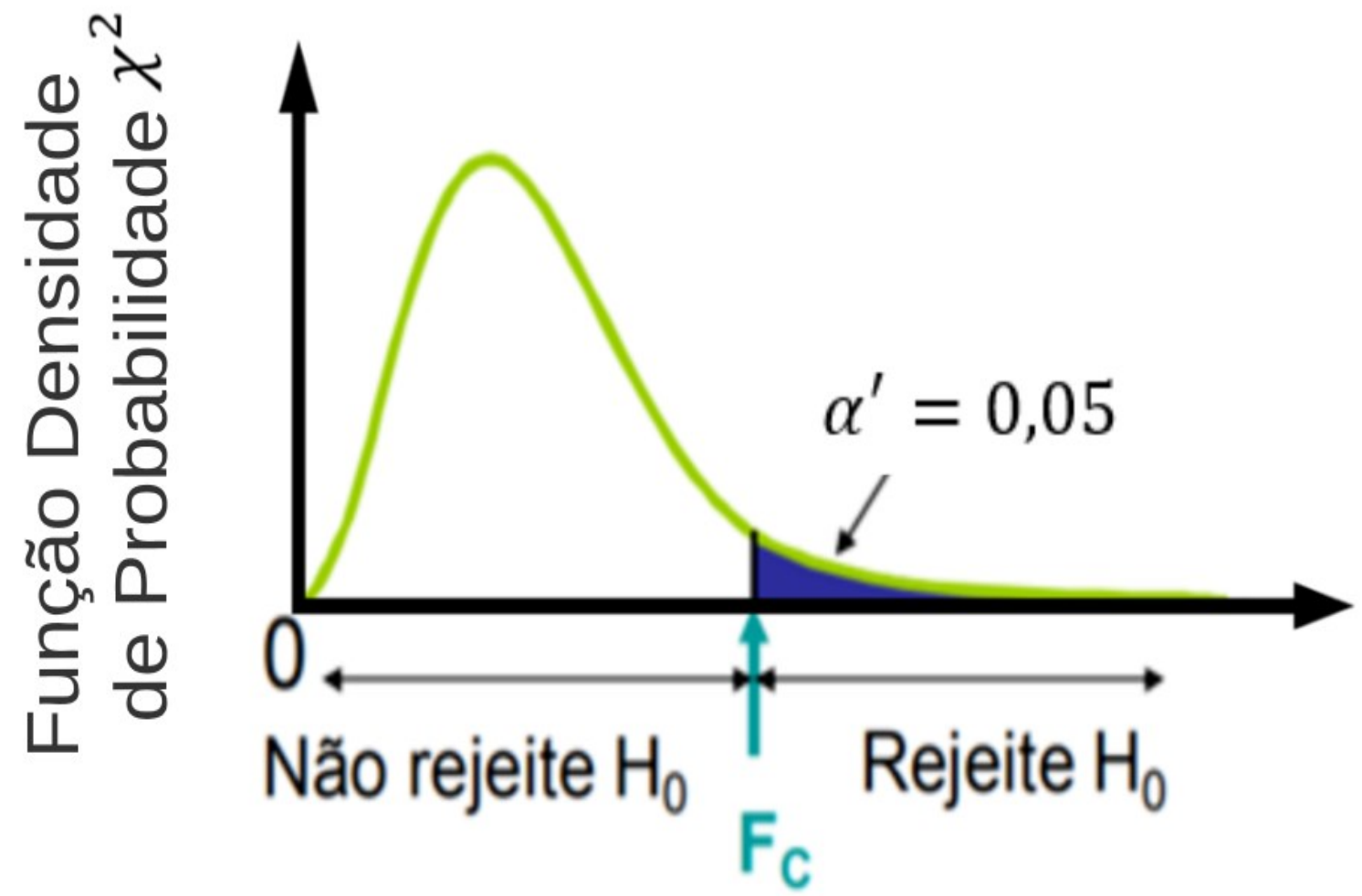

Fonte: Autor "adaptado de" [67], slide 29.

A outra maneira de aceitarmos ou rejeitarmos a hipótese afirmativa $\left(\mathrm{H}_{0}\right)$ é por meio da comparação do valor $\mathrm{p}$ do teste ANOVA com o nível de significância escolhido para a aplicação deste teste [52], [53], [65] [66]. O valor de p é calculado como sendo a área sob a curva de distribuição $\mathrm{F}$ (distribuição proporcional à densidade de probabilidade

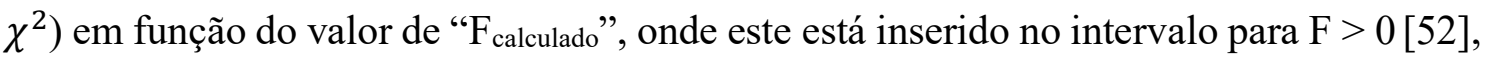
[53], [65], [66]. Assim, se o valor de $\mathrm{p}$ for superior ao valor do nível de significância ( $\left.\alpha^{\prime}\right)$ escolhido, deve-se considerar $\mathrm{H}_{0}$ verdadeira, caso o valor de $\mathrm{p}$ seja inferior ao valor do nível de significância $\left(\alpha^{\prime}\right)$, deve-se considerar $\mathrm{H}_{0}$ como falsa.

Ressalta-se que este teste estatístico foi aplicado nesta tese de doutorado utilizando o software estatístico MINITAB 2020 [64].

\subsubsection{Teste estatístico de Tukey}

O teste proposto por John W. Tukey em 1953 é também conhecido como teste de Tukey da diferença honestamente significativa (honestly significant difference, HSD) ou 
teste de Tukey da diferença totalmente significativa (wholly significant difference, WSD) [68].

Este teste estatístico é um complemento ao teste estatístico ANOVA e pode ser denominado de teste de comparação de médias. Isto ocorre quando se aplica o teste ANOVA e pode-se avaliar que as médias analisadas ou são estatisticamente equivalentes entre si (aceitar a $\mathrm{H}_{0}$ do teste ANOVA) ou que as médias analisadas não são estatisticamente equivalentes entre si (rejeitar a $\mathrm{H}_{0}$ e aceitar a $\mathrm{H}_{1}$ do teste ANOVA). Entretanto, o teste ANOVA não indica quais médias são estatisticamente diferentes entre si [52], [53], [65] [66].

Assim, o teste Tukey tem como principal objetivo testar qual média, ou quais médias, são estatisticamente diferentes entre si. Para isto, deve-se ressaltar que as comparações entre as médias são realizadas sempre utilizando-se duas médias por vez [52], [53], [65] [66]. A Figura 25 ilustra um exemplo em que existam 4 médias a serem comparadas entre si.

Figura 25 - Exemplo de uma ilustração em que existem 4 médias a serem comparadas entre si para a aplicação do teste estatístico de Tukey

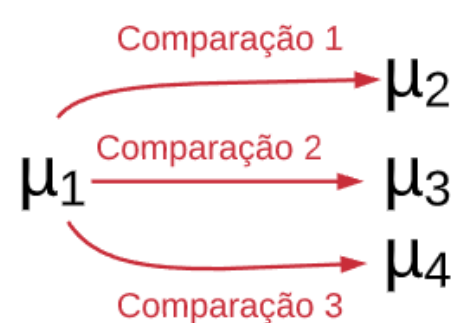

Comparação 4
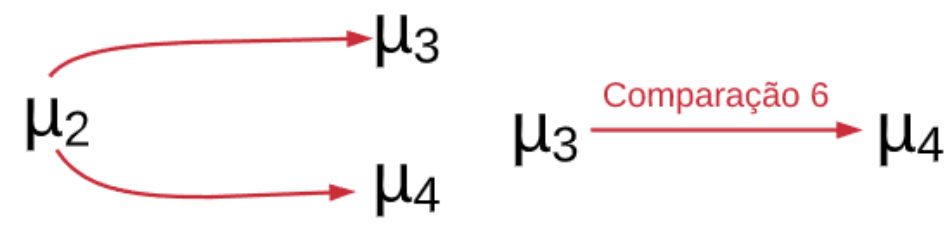

Fonte: Autor.

Por meio da análise da Figura 25, pode-se afirmar que o cálculo da quantidade de comparações a ser realizada é obtido por meio da equação (27).

$$
C_{I}^{\prime}=\frac{I !}{2 ! \cdot(I-2) !}
$$

$\mathrm{Na}$ equação (27), I representa a quantidade de médias comparadas no teste estatístico de Tukey.

Para a aplicação do teste estatístico Tukey, deve-se calcular um parâmetro $\Delta$ por meio da equação (28). 


$$
\Delta=q^{\prime} \cdot \sqrt{\frac{Q M E}{C^{\prime}}}
$$

em que q' é um valor tabelado encontrado na tabela de amplitude “estudentizada q" para um nível de significância $\alpha^{\prime}$ (denominada também de studentized range ou amplitude total estudentizada) [69], [70], C' é o número de comparações a ser realizada e QME é a soma dos quadrados médios para o erro experimental [69], [70].

Assim, para se rejeitar a igualdade da média de duas amostras, devemos levar em consideração a comparação ilustrada na equação (29).

$$
\left|\overline{y_{l}}-\overline{y_{J}}\right|>\Delta
$$

em que $\bar{y}_{l}$ e $\bar{y}_{J}$ são duas médias diferentes de duas amostras de dados que se deseja comparar. Assim, se considerarmos o módulo da diferença entre duas médias e esta diferença for menor que o valor do parâmetro $\Delta$ calculado por meio da equação (28), pode-se afirmar que estas duas médias são estatisticamente equivalentes entre si.

Ressalta-se que este teste estatístico foi aplicado nesta tese de doutorado utilizando o software estatístico MINITAB 2020 [64].

\subsection{ESTUDO DAS PRINCIPAIS CARACTERÍSTICAS DOS MOSFETS DE LEIAUTE DE PORTA HEXAGONAL (MOSFET DIAMANTE) E OCTOGONAL (MOSFET OCTO).}

Nesta seção apresentam-se as principais características de funcionamento dos MOSFETs de leiaute de porta hexagonal (MOSFET Diamante) e octogonal (MOSFET Octo). Tanto para o MOSFET com geometria de porta hexagonal (DM), assim como para o MOSFET com geometria de porta octogonal (OM), podem-se verificar três efeitos físicos, que são o efeito de Canto Longitudinal (Longitudinal Corner Effect, LCE), a conexão paralela de MOSFETs com diferentes comprimentos de canal (PArallel Connection of MOSFETs with Different Channel Lengths Effect, PAMDLE) e a 
desativação dos MOSFETs parasitários nas regiões de Bico de Pássaro (Deactivation of the Parasitic MOSFETs in the Bird's Beak Regions Effect, DEPAMBBRE).

\subsubsection{MOSFET DE LEIAUTE DE PORTA HEXAGONAL}

No ano de 2008 foi patenteado o MOSFET de leiaute de porta hexagonal (MOSFET Diamante, DM) com o principal propósito de apresentar melhorias nas figuras de mérito dos MOSFETs [20], [30]. A Figura 26 ilustra um exemplo do leiaute de um DM.

Figura 26 - Exemplo de um leiaute do MOSFET do tipo Diamante

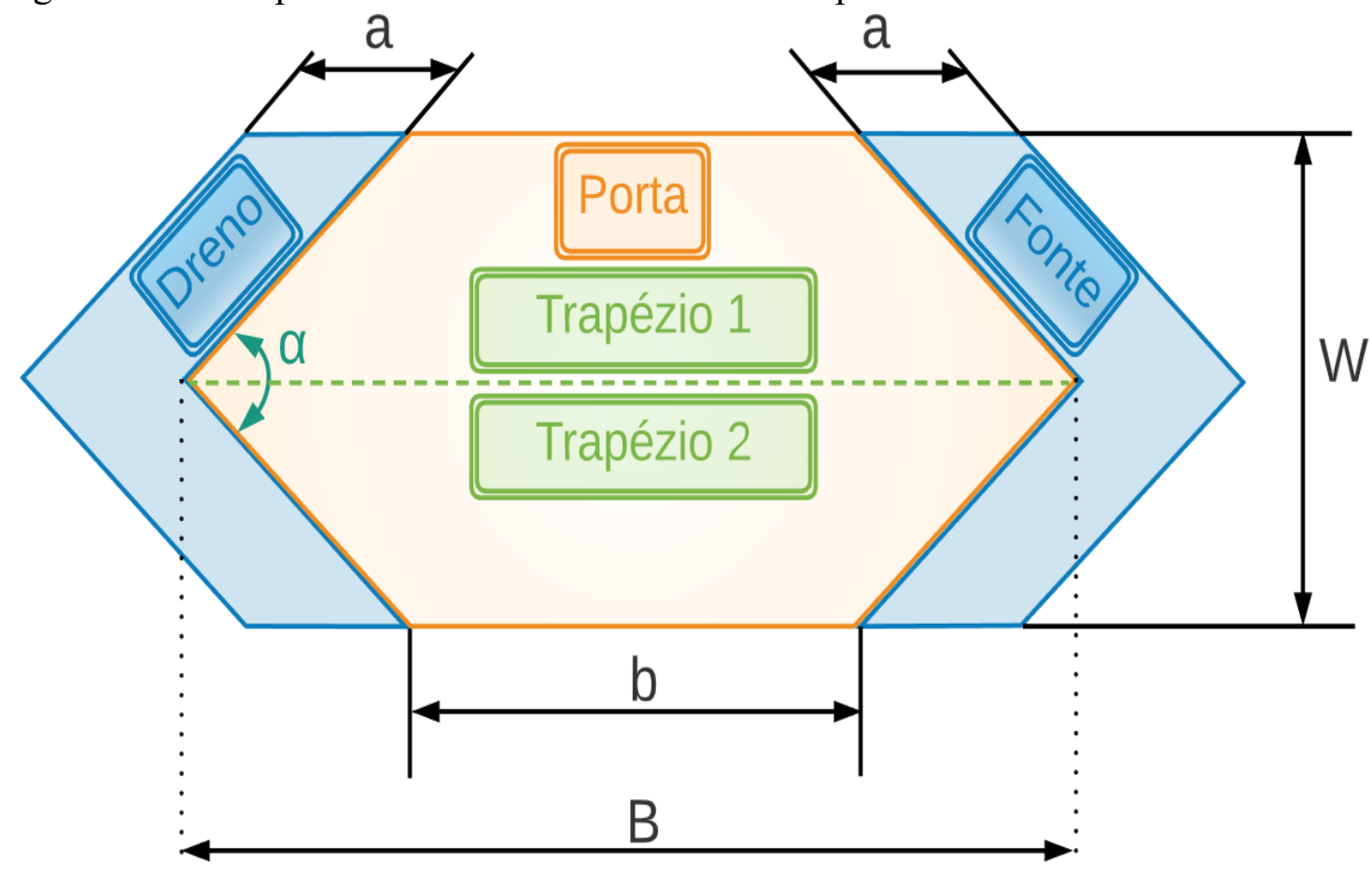

Fonte: Autor.

Na Figura 26, b e B são os comprimentos das bases menor e maior dos dois trapézios que compõem a região hexagonal da porta (trapézios 1 e 2), respectivamente, W é a largura do canal, $\alpha$ é o ângulo entre as junções metalúrgicas do filme de silício (região do canal) e as regiões de dreno e fonte decorrente da geometria de porta hexagonal do MOSFET do tipo Diamante e o termo "a" é o comprimento das regiões de dreno e de fonte [20], [30]. 
Deve-se ressaltar que por uma simples mudança da geometria da porta convencional (retangular) para uma geometria de porta hexagonal (Diamante), considerando-se a mesma área da porta $\left(\mathrm{A}_{\mathrm{G}}\right)$ e largura de canal $(\mathrm{W})$, o $\mathrm{DM}$ foi projetado para ser usado em CIs analógicos, pois o seu comprimento efetivo do canal $\left(\mathrm{L}_{\mathrm{ef}}\right)$ de CIs é sempre maior que a dimensão mínima permitida pelo processo de fabricação CMOS [32], [71], [72].

A Figura 27 ilustra um exemplo do leiaute de um DM (Figura 27.a) e de um MOSFET Convencional equivalente (Convencional MOSFET, CM) (Figura 27.b), considerando a mesma $\mathrm{A}_{\mathrm{G}}, \mathrm{W}$ e regras de projeto correspondente a um determinado processo CMOS de fabricação de CIs.

Figura 27 - Exemplos de leiautes dos MOSFETs do tipo Diamante (a) e do tipo Convencional equivalente (b), respectivamente

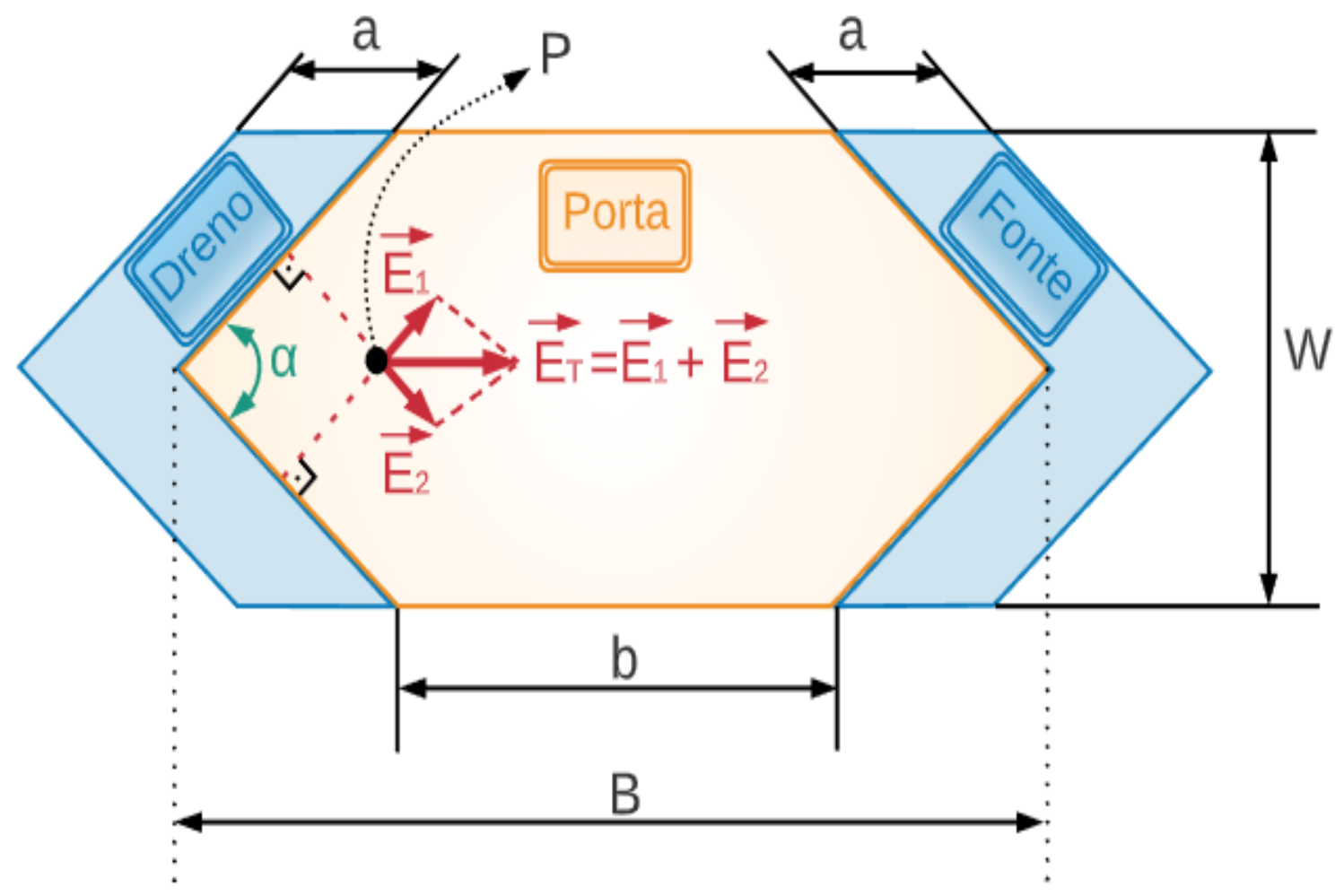

(a) 


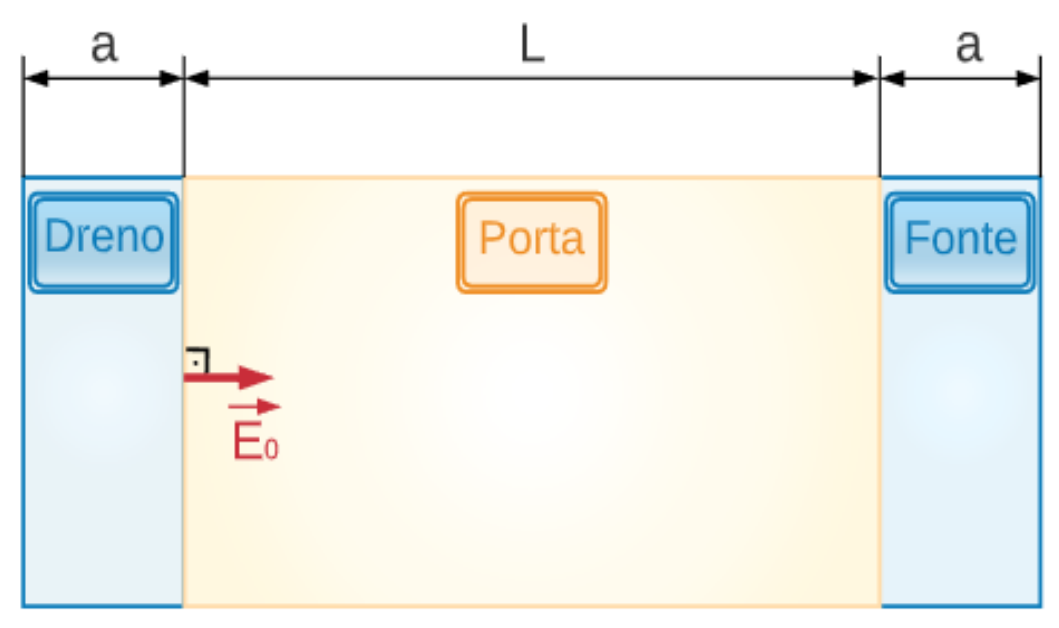

(b)

Fonte: Autor.

Na Figura 27.b, L é o comprimento do canal do CM, "a" é o comprimento das regiões de dreno e de fonte e $\overrightarrow{E_{0}}$ é o vetor do campo elétrico longitudinal existente no $\mathrm{CM}$.

Na Figura 27.a, $\overrightarrow{E_{1}}$ e $\overrightarrow{E_{2}}$ são as duas componentes do vetor do campo elétrico longitudinal no ponto $\mathrm{P}$, que são geradas por meio da aplicação da tensão entre dreno e fonte $\left(\mathrm{V}_{\mathrm{DS}}\right)$ e também pelas interfaces formadas pelas regiões de dreno e o filme de silício da região de canal, $\overrightarrow{E_{T}}$ é o vetor da resultante (equivalente) do campo elétrico longitudinal, dada pela somatória vetorial $\overrightarrow{E_{1}}+\overrightarrow{E_{2}}$ no ponto $\mathrm{P}$, que é maior do que aquela observada no $\mathrm{CnM}$ equivalente, conservando-se a mesma $\mathrm{A}_{\mathrm{G}}[20]$, [30].

Desta forma, este dispositivo inovador utiliza o "efeito de canto" na direção longitudinal do canal, denominado de efeito de canto longitudinal (Longitudinal Corner Effect, LCE), para aumentar o campo elétrico longitudinal ao longo do comprimento do canal (L) e consequentemente aumentar a velocidade de deriva média das cargas móveis no canal, que resulta na melhoria da corrente de dreno ( $\mathrm{DDS}$ ), da transcondutância (gm), da razão entre a transcondutância e a corrente de dreno $\left(\mathrm{gm} / \mathrm{I}_{\mathrm{DS}}\right)$ e da resistência série de estado ligado (R $\left.\mathrm{R}_{\mathrm{DSon}}\right)$ [32], [73], [74].

Deve-se ressaltar que o desempenho elétrico do DM ainda pode ser potencializado com a redução do ângulo $\alpha$ de sua estrutura, já que quanto menor o ângulo $\alpha$, maior é o campo elétrico longitudinal resultante. Entretanto, o projeto de dispositivos com leiaute não convencional é limitado pelas regras do processo de fabricação de CIs CMOS, o que pode limitar o ângulo $\alpha$ do MOSFET [20]. 
Ademais, é possível também observar na Figura 27.a que o DM apresenta diferentes comprimentos de canal ao longo de sua largura, variando de b até B [20]. Essa variação no seu comprimento de canal faz com que o comprimento efetivo de canal do dispositivo seja maior que o mínimo comprimento permitido pelo processo de fabricação de CIs CMOS, em compensação deve-se ressaltar que este tipo de dispositivo tende a ocupar maior área, ou seja, para CIs que exijam maiores densidades, essa passa a não ser uma opção interessante, por conta do tamanho destes dispositivos. (15). No entanto, essa variação também gera um novo efeito no MOSFET, chamado de efeito das conexões paralelas de MOSFETs com diferentes comprimentos de canal (PArallel connections of MOSFETs with Different channel Lengths Effect, PAMDLE) [20], [32]. O PAMDLE é responsável por potencializar ainda mais a corrente elétrica entre dreno e fonte dos MOSFETs, principalmente nas regiões em torno das margens dos dispositivos. [20], [32].

Desta maneira, o DM pode ser representado como conexões paralelas de MOSFETs convencionais infinitesimais com diferentes comprimentos de canal [20], [32]. A Figura 28 descreve estruturalmente o efeito PAMDLE, onde é possível observar que a região de porta de um DM dividida em infinitas partes se aproximam das características de um CM, conforme apresentado pela Figura 28.a. A representação elétrica é ilustrada na Figura 28.b. Nesta figura, observa-se que a representação elétrica dos infinitesimais MOSFETs é dada pela conexão paralela dos mesmos, considerando que eles apresentam a mesma largura de canal dada por "W'=W/i", onde "i" tende ao infinito, mas com diferentes comprimentos de canal, que variam de "b" até "B", ou seja, $\mathrm{b} \leq \mathrm{L}_{\mathrm{i}} \leq \mathrm{B}$, sendo que $\mathrm{L}_{\mathrm{i}}$ é o comprimento de canal do MOSFET de índice "i”" [75]. 
Figura 28 - Ilustração do DM dado por infinitesimais MOSFETs convencionais conectados em paralelo (a) e o seu devido circuito elétrico equivalente (b).

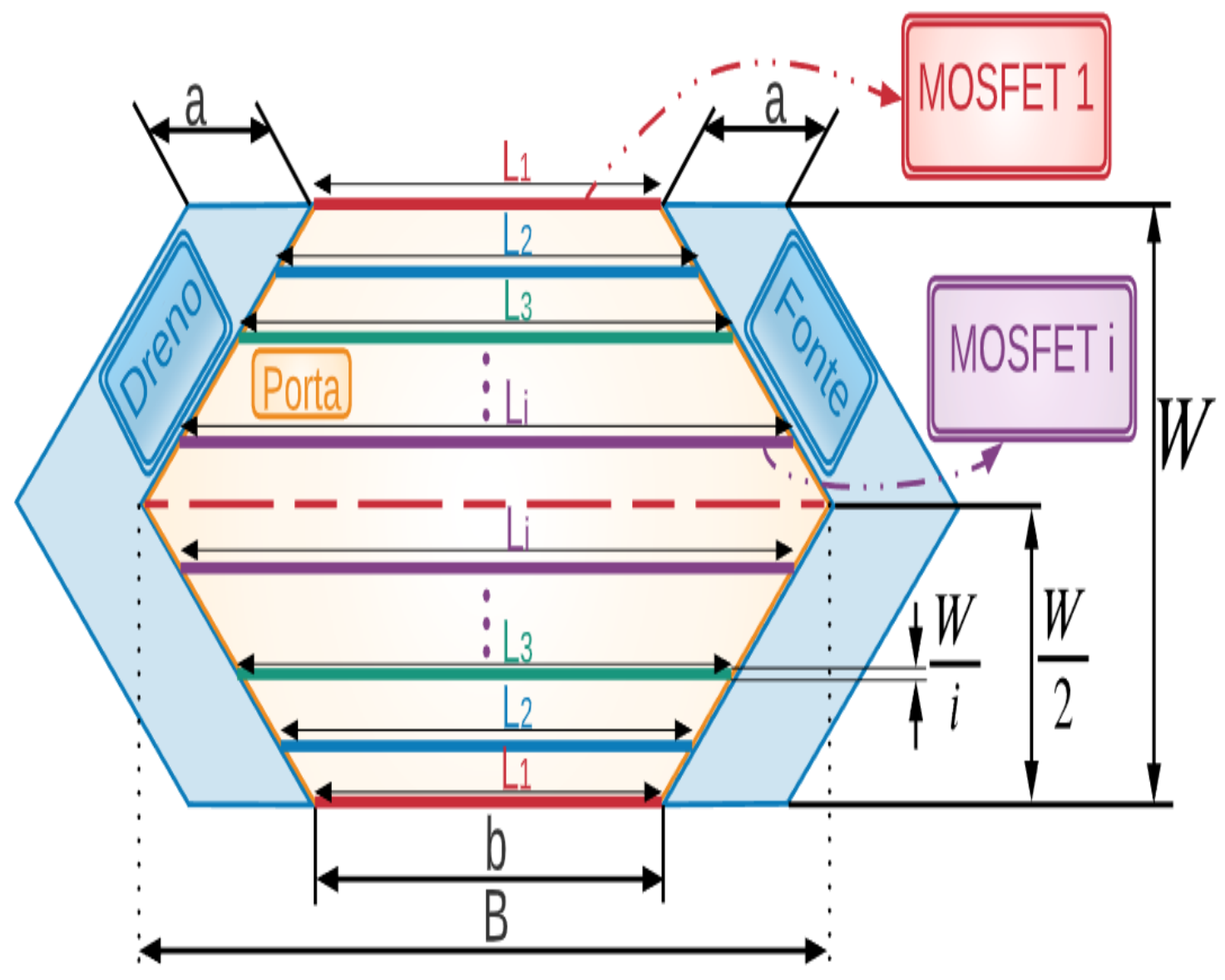

(a)

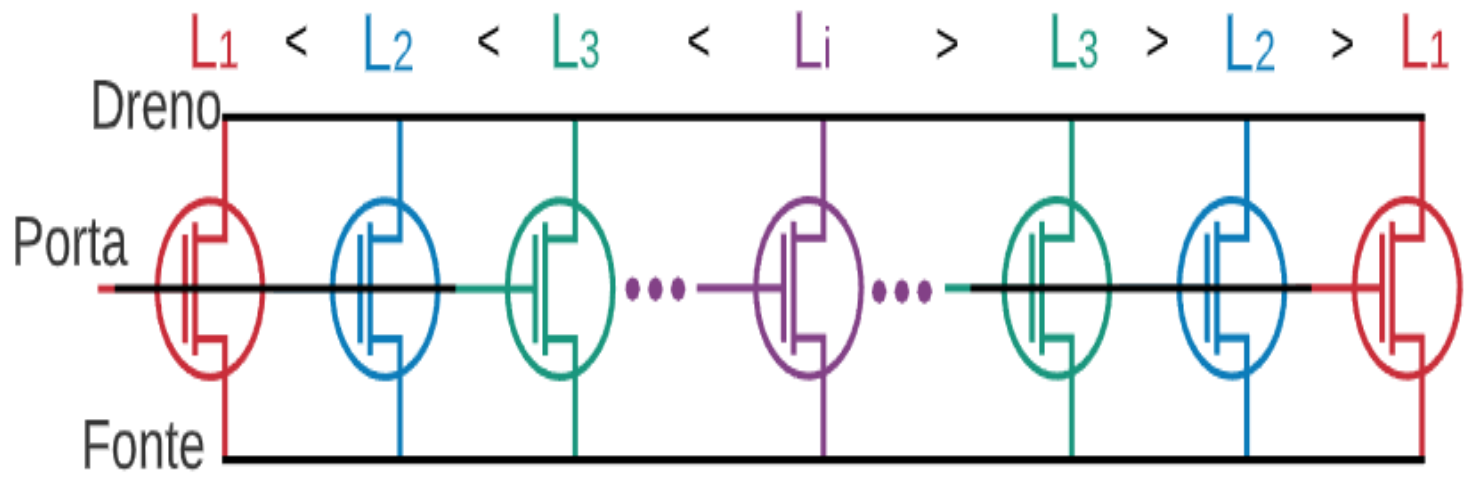

(b)

Fonte: Autor.

Na Figura 28, observa-se que $\mathrm{L}_{1}, \mathrm{~L}_{2}$ e $\mathrm{L}_{3}$ são os comprimentos de canal dos MOSFETs de índice “ 1 ”, “2” e “3”. Esses MOSFETs infinitesimais que compõem o DM têm seus diferentes comprimentos de canal $\left(\mathrm{L}_{1}, \mathrm{~L}_{2}, \mathrm{~L}_{3}, \ldots, \mathrm{L}_{\mathrm{i}}\right)$ e correntes elétricas entre 
dreno e fonte, que juntas são iguais à corrente elétrica entre dreno e fonte da estrutura inteira do DM [20], [75].

A razão de aspecto efetiva (W/Lef_DM) é apresentada por meio da equação (30), onde Lef_DM é comprimento efetivo de canal do DM.

$$
\frac{W}{L_{e f_{-} D M}}=2 \cdot \int_{0}^{\frac{W}{2}} \frac{d y}{L_{i}}=2 \cdot \int_{0}^{\frac{W}{2}} \frac{d y}{b+2 \cdot\left(\frac{y}{\tan (\alpha / 2)}\right)}
$$

Dessa maneira, integrando a equação (30) de 0 a W/2, o comprimento efetivo de canal de DM é obtido por meio da equação (31).

$$
L_{e f_{-} D M}=\frac{B-b}{\ln \left(\frac{B}{b}\right)}
$$

Se considerarmos então um MOSFET de leiaute de porta retangular com a mesma área de porta $(\mathrm{AG})$ e mesma largura de canal (W) que um DM, pode-se observar que o Lef_DM é sempre menor que o comprimento efetivo de canal de seu MOSFET convencional (L) equivalente (mesma área de porta e mesma largura de canal), que é ilustrado por meio da equação (32) [20], [75].

$$
L=\frac{B+b}{2}
$$

Portanto, verifica-se que o DM é capaz de fornecer um comprimento efetivo de canal $\left(\mathrm{L}_{\mathrm{ef}}\right)$ menor que o do seu CM equivalente, considerando que ambos tenham as mesmas áreas de porta e larguras de canal [20], [75]. O cálculo do comprimento de canal (L) do CM é importante, porque ele permite quantificar o quanto o efeito PAMDLE é capaz de potencializar o DM, permitindo que sejam feitas comparações entre o DM e o $\mathrm{CM}$, considerando as mesmas áreas de porta e larguras de canal. Como o DM tem um comprimento de canal menor em suas extremidades, a corrente elétrica entre dreno e fonte 
tende a fluir mais por essas regiões. Dessa maneira, pode-se afirmar que esse efeito faz com que a corrente elétrica entre dreno e fonte do DM seja sempre maior que a de seu $\mathrm{CM}$ equivalente, quando consideradas as mesmas áreas de porta $\left(\mathrm{A}_{\mathrm{G}}\right)$, mesmos $\mathrm{W}$ e as mesmas condições de polarização [20], [75].

Ambos os efeitos, o LCE e o PAMDLE, ocorrem simultaneamente no DM e ambos são responsáveis por melhorar seu comportamento elétrico em comparação ao do CM, considerando-se que ambos apresentam as $\mathrm{A}_{\mathrm{GS}}$ e largura de canal (W) [20], [32].

Além destes dois efeitos apresentados, há um terceiro efeito físico presente na estrutura do DM e extremamente relevante quando se analisam dispositivos para as aplicações em ambientes de radiações ionizantes. Este é o efeito da desativação dos MOSFETs parasitários nas regiões de bico de pássaro (DEactivation the PArasitic MOSFETs in the Bird's Beak Regions Effect, DEPAMBBRE) [20], [76].

O DEPAMBBRE é responsável por desativar eletricamente os transistores parasitários existentes na estrutura dos DnMs [20], [76]. A desativação dos transistores parasitários se dá pelo fato de que as linhas do campo elétrico longitudinal no DM são curvas e acabam não sendo direcionadas às regiões de bico de pássaro. Desta maneira, pode-se observar que os DMs também são mais robustos às radiações ionizantes quando se comparam com o comportamento dos CMs [20], [76].

Estudos mostraram, por exemplo, que a $\mathrm{I}_{\mathrm{OFF}}$ do DM teve uma variação $240 \%$ menor que a do seu CM equivalente após a exposição às radiações ionizantes (considerando a mesma área de porta, largura de canal e mesmas condições de exposição às radiações ionizantes). A Figura 29 ilustra um exemplo do efeito DEPAMBBRE atuando no DM [20], [32]. 
Figura 29 - Ilustração do DM e suas linhas de campo elétrico longitudinal ao longo do canal

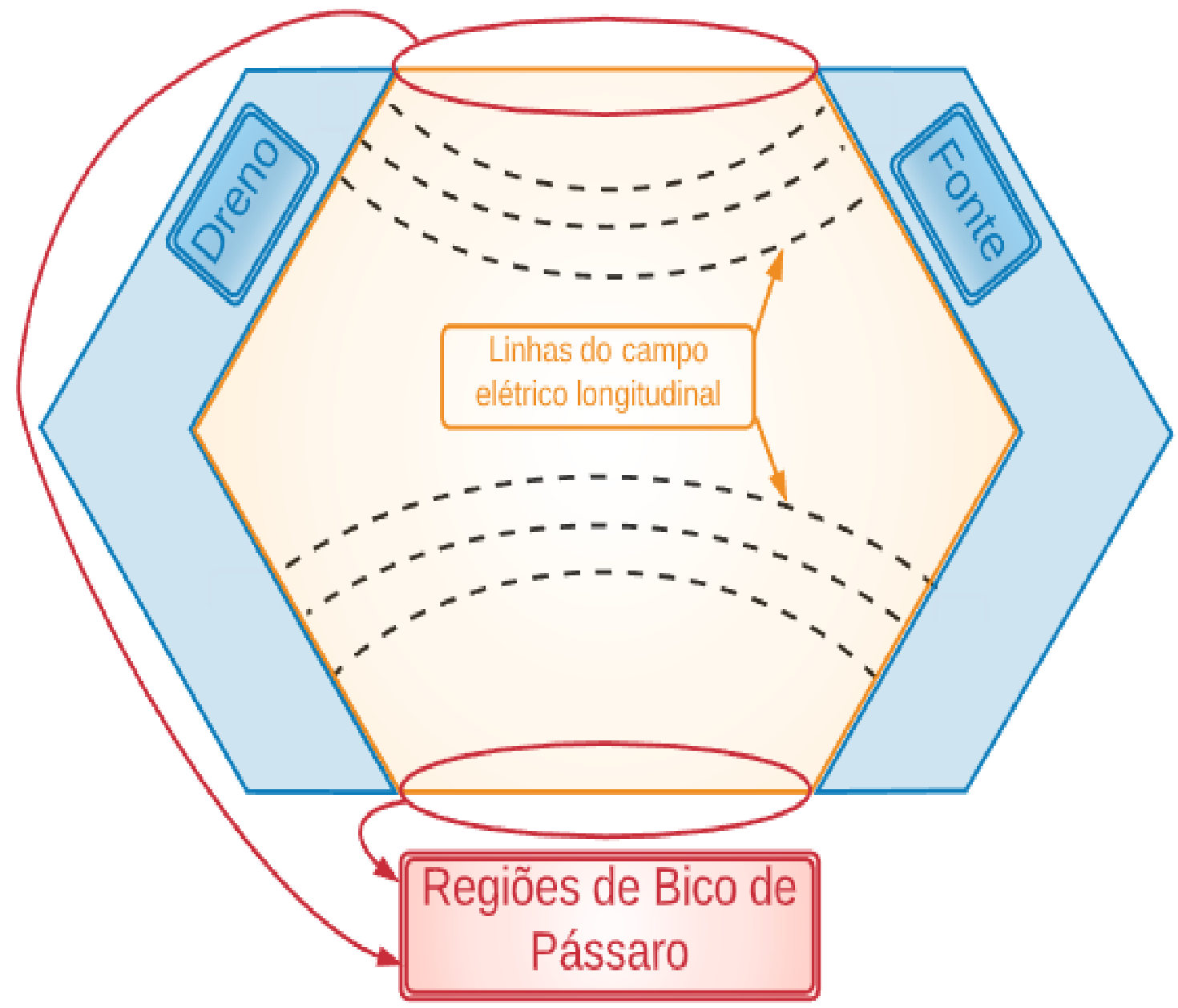

Fonte: Autor.

Deve-se acrescentar também que o DM possui regiões de bico de pássaro menores que seu CM equivalente (MOSFET retangular com mesma área de porta e mesma largura de canal que o CM), propiciando uma menor IofF [20].

\subsubsection{MOSFET DE LEIAUTE DE PORTA OCTOGONAL}

O leiaute de porta octogonal para MOSFETs, assim como o leiaute do tipo Diamante, também apresenta os efeitos LCE, PAMDLE e DEPAMBBRE incorporado em sua estrutura [20], [31], [40]. Da mesma forma que o DM, o campo elétrico longitudinal resultante do MOSFET Octo (OM) é ainda maior, se o seu ângulo $\alpha$ for ainda menor. O ângulo $\alpha$ pode ser limitado pelas regras de projeto do fabricante [20]. 
A Figura 30 representa a vista superior da topologia octogonal de um OM, resultante dos cortes na estrutura hexagonal. Ao polarizarmos o OM, origina-se um novo vetor de campo elétrico longitudinal, quando comparado com a estrutura hexagonal. Este terceiro vetor é representado na Figura 30 , por $\overrightarrow{E_{/ / 3}}$. Também estão presentes na estrutura outros dois vetores representados na Figura 30, que são $\overrightarrow{E_{/ / 1}}$ e $\overrightarrow{E_{/ / 2}}$, respectivamente, que da mesma forma, são comuns à estrutura do DM. Assim, pode-se afirmar que o campo elétrico resultante é dado pela soma vetorial dos três campos elétricos citados, isto é, $\overrightarrow{E_{/ / O M}}=\overrightarrow{E_{/ / 1}}+\overrightarrow{E_{/ / 2}}+\overrightarrow{E_{/ / 3}}$, resultando na melhoria dos valores de corrente de dreno e da transcondutância quando comparadas com o DM equivalente, considerando a mesma área de porta (AG), a mesma razão de aspecto (W/L) e as mesmas condições de polarização [20], [32].

Figura 30 - Representação do leiaute do MOSFET do tipo Octogonal.

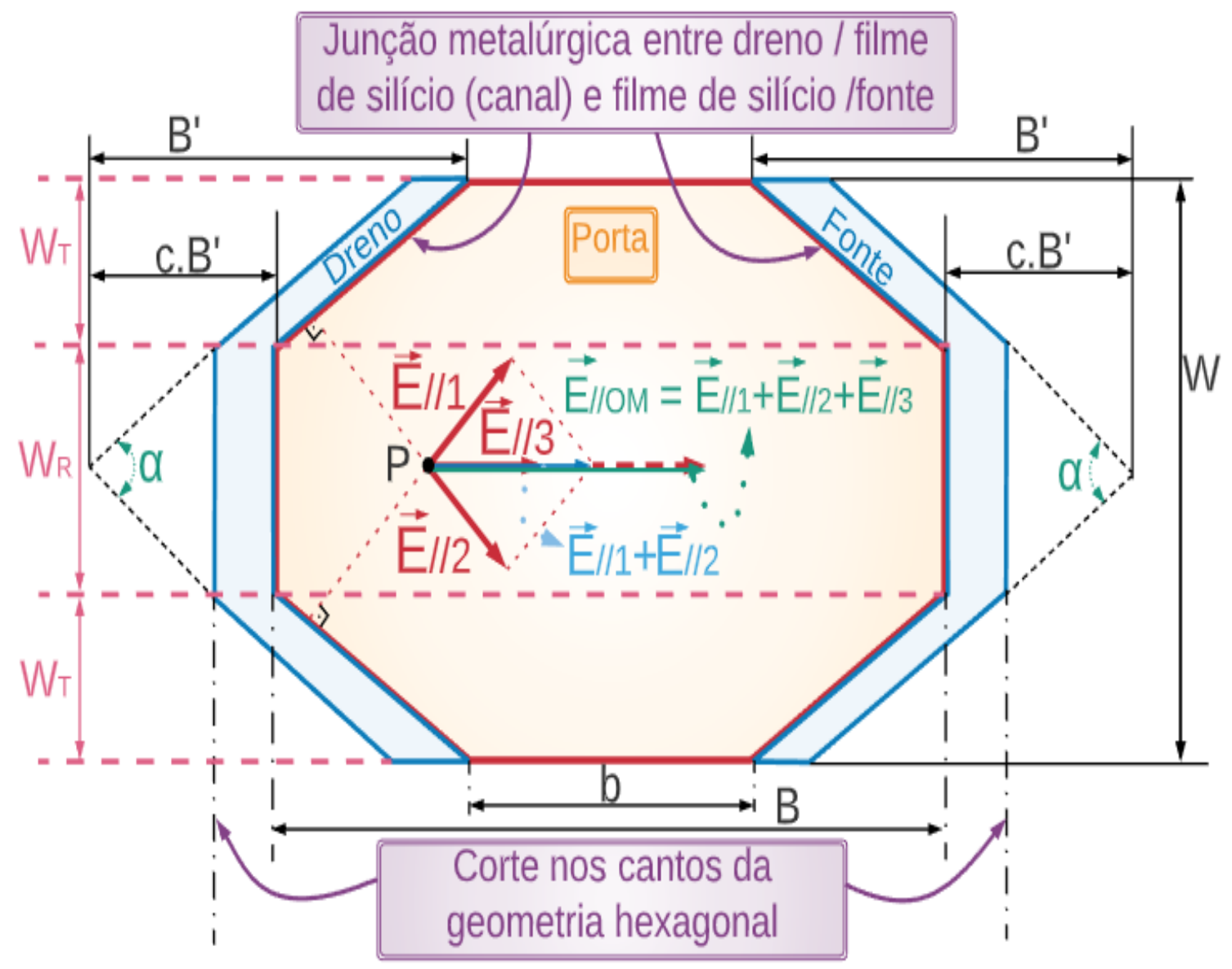

Fonte: Autor. 
Na Figura 30, "W" representa a largura de canal, "b" e "B" indicam o menor e maior comprimentos de canal (respectivamente), B' é o comprimento de canal do DM que dá origem a estrutura octogonal, "c" é o fator de corte que indica a redução percentual aplicada nas extremidades da geometria hexagonal para obter a estrutura octogonal, " $\alpha$ " indica o ângulo de projeto do OM. Adicionalmente, a região de canal octogonal pode ser dividida em três regiões: duas com uma geometria trapezoidal com largura " $\mathrm{W}_{\mathrm{T}}$ " e uma com geometria retangular com largura " $\mathrm{W}_{\mathrm{R}}$ ".

Pode-se observar, portanto, que o comportamento de cada campo elétrico longitudinal (Longitudinal Electric Field, LEF) ocorre perpendicularmente a cada junção pn entre a região de dreno e região de canal, sendo que no caso da geometria octogonal temos a formação de três LEFs, ilustrados na Figura 31 (Figura 31.a, Figura 31.b e Figura 31.c).

Figura 31 - Representação do LEFs presentes no OM

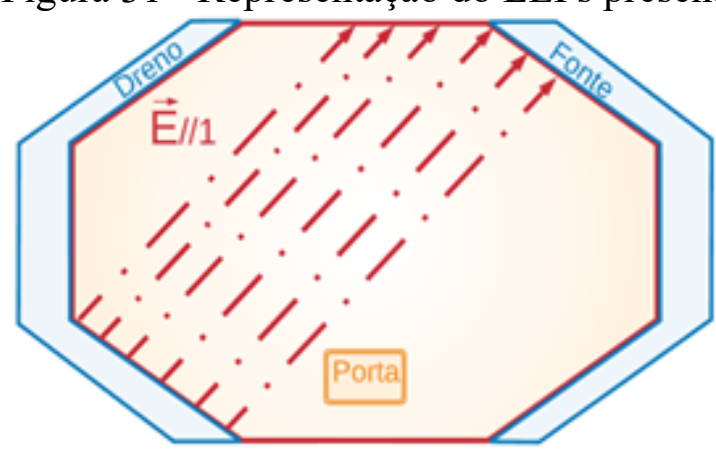

(a)

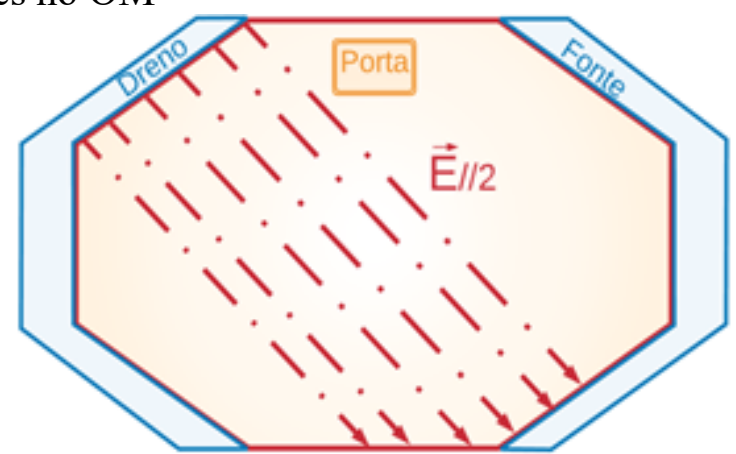

(b)

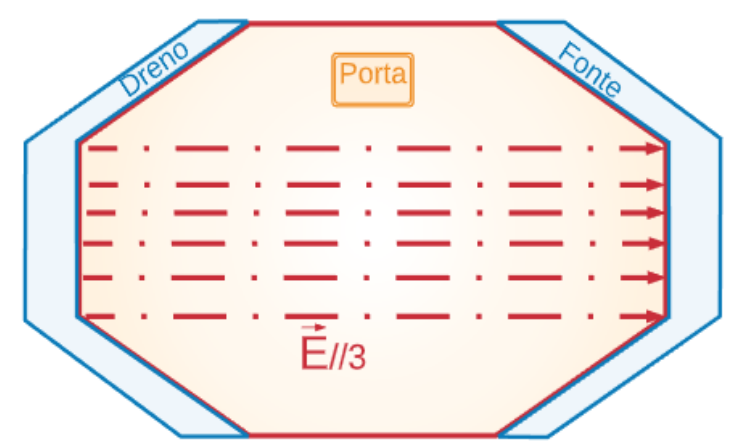

(c)

Fonte: Autor.

Verifica-se, portanto, que a corrente elétrica $\mathrm{I}_{\mathrm{DS}}$ é calculada por meio do campo elétrico resultante e é ilustrada matematicamente por meio da equação (33), considerando-se um nMOSFET. 


$$
I_{D S}=Q_{n} \cdot \mu_{n} \cdot E_{/ /}
$$

onde $\mathrm{Q}_{\mathrm{n}}$ representa a densidade de cargas de elétrons ao longo do canal, $\mu_{\mathrm{n}}$ a mobilidade do elétron e $E_{/ /}$refere-se ao campo elétrico longitudinal resultante, decorrente da aplicação da polarização entre dreno e fonte.

Para projetarmos um CM com a mesma área de porta que a do OM, verifica-se a necessidade de que o comprimento de porta $(\mathrm{L})$ do $\mathrm{CM}$ seja igual à expressão ilustrada na equação (34) [20], [32].

$$
L_{C M}=\frac{b+2 \cdot B}{3}
$$

Ressalta-se que este valor de $\mathrm{L}_{\mathrm{CM}}$ indicado na equação (34) é usado para normalizar os resultados e assim garantir a eliminação do fator geométrico. Ademais, na Figura 32.a é ilustrada a região de porta de um OM dividida em infinitas partes que se aproximam das características de um CM. Além disso, é apresentado o circuito elétrico equivalente na Figura 32.b.

Assim, na Figura 32, é possível observar que a representação elétrica dos infinitos MOSFETs é dada pela conexão paralela dos mesmos, considerando que eles apresentam a mesma largura de canal dada por " $\mathrm{W}$ ' $=\mathrm{W} / \mathrm{i}$ ", onde " $\mathrm{i}$ " tende ao infinito, mas com diferentes comprimentos de canal, que variam de "b" até "B", ou seja, b $\leq \mathrm{Li} \leq \mathrm{B}$, sendo que $\mathrm{L}_{\mathrm{i}}$ é o comprimento de canal do MOSFET de índice “i” [75]. 
Figura 32 - Representação do OM por infinitesimais MOSFETs convencionais conectados em paralelo (a) e o seu devido circuito elétrico equivalente (b)

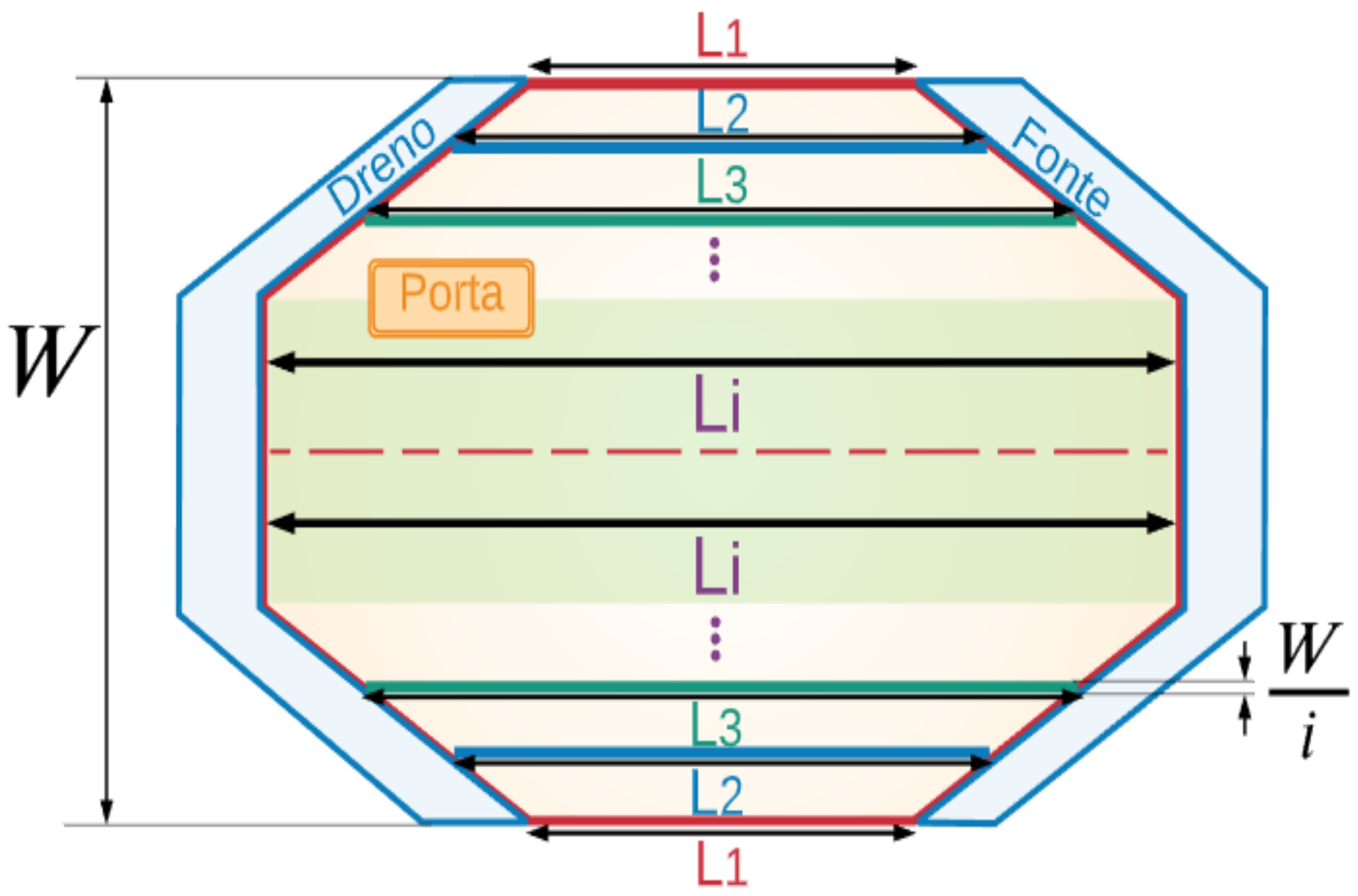

(a)

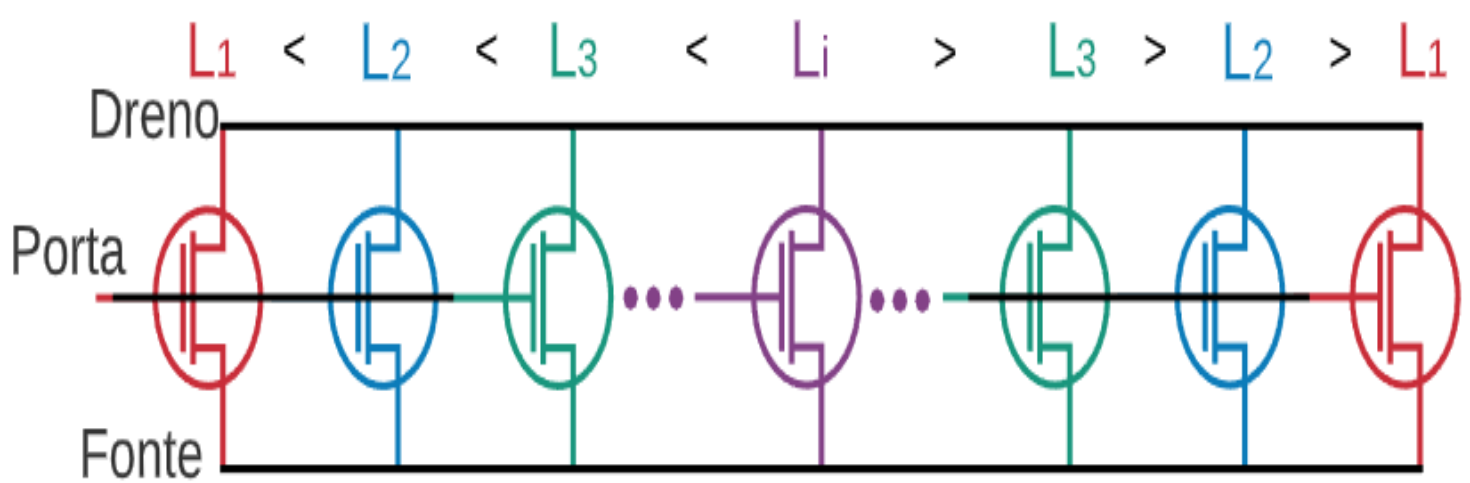

(b)

Fonte: Autor.

Na Figura 32, observa-se que $\mathrm{L}_{1}, \mathrm{~L}_{2}$ e $\mathrm{L}_{3}$ são os comprimentos de canal dos MOSFETs de índice "1", "2" e "3". Os transistores com menor comprimento de canal estão nas extremidades e identificados com a cor vermelha, enquanto os transistores com maior comprimento de canal estão localizados no centro e identificados com a cor roxa. Este fenômeno físico induz a corrente elétrica entre dreno e fonte a fluir de uma forma mais significativa pelas extremidades, resultando no efeito PAMDLE [75]. Desta 
maneira, valendo-se do conceito ilustrado na Figura 32.a, o comprimento efetivo de canal é calculado por meio da equação (35).

$$
\frac{W}{L_{e f}}=2 \cdot \int_{0}^{(1-c) \cdot \frac{W}{2}} \frac{d y}{L_{i}}+2 \cdot \int_{(1-c) \cdot \frac{W}{2}}^{\frac{W}{2}} \frac{d y}{B}
$$

Pela resolução da equação (35), determinamos o comprimento efetivo de canal de um OM, conforme apresentado pela equação (36).

$$
L_{e f}=\frac{1}{\frac{1-c}{B-b} \cdot \ln \left(\frac{B}{b}\right)+\frac{c}{B}}
$$

Por meio da equação (36) é possível observar que quando c é igual a 1, então $\mathrm{L}_{\mathrm{ef}} \mathrm{Om}$ é igual ao $\mathrm{L}_{\mathrm{ef}}$ de um CM retangular, que é igual a B. Já quando c é igual a $0, \mathrm{~L}_{\text {ef_om }}$ é igual a $\mathrm{L}_{\mathrm{ef}} \mathrm{DM}$, pois não há corte algum realizado na estrutura hexagonal [20].

Sendo o comprimento efetivo de canal do OM sempre menor que o do seu CM equivalente (considerando as mesmas $\mathrm{A}_{\mathrm{G}}$ e mesmos $\mathrm{W}$ ), há um ganho na sua corrente elétrica entre dreno e fonte em comparação à do seu equivalente convencional [20], [31].

Deve-se ressaltar que as regiões de bico de pássaro do OM são idênticas às vistas nos DMs, portanto os mesmos efeitos já discutidos e considerações são válidos para este leiaute [20], [40]. Assim, devido à interação entre os campos elétricos longitudinais, as linhas do campo elétrico resultante tomam um perfil curvado. A Figura 33 ilustra a representação do campo elétrico longitudinal em uma das regiões de bico de pássaro de um CM (Figura 33.a) e de um OM (Figura 33.b). 
Figura 33 - Representação do campo elétrico longitudinal em uma das regiões de bico de pássaro de um CM (a) e de um OM (b)

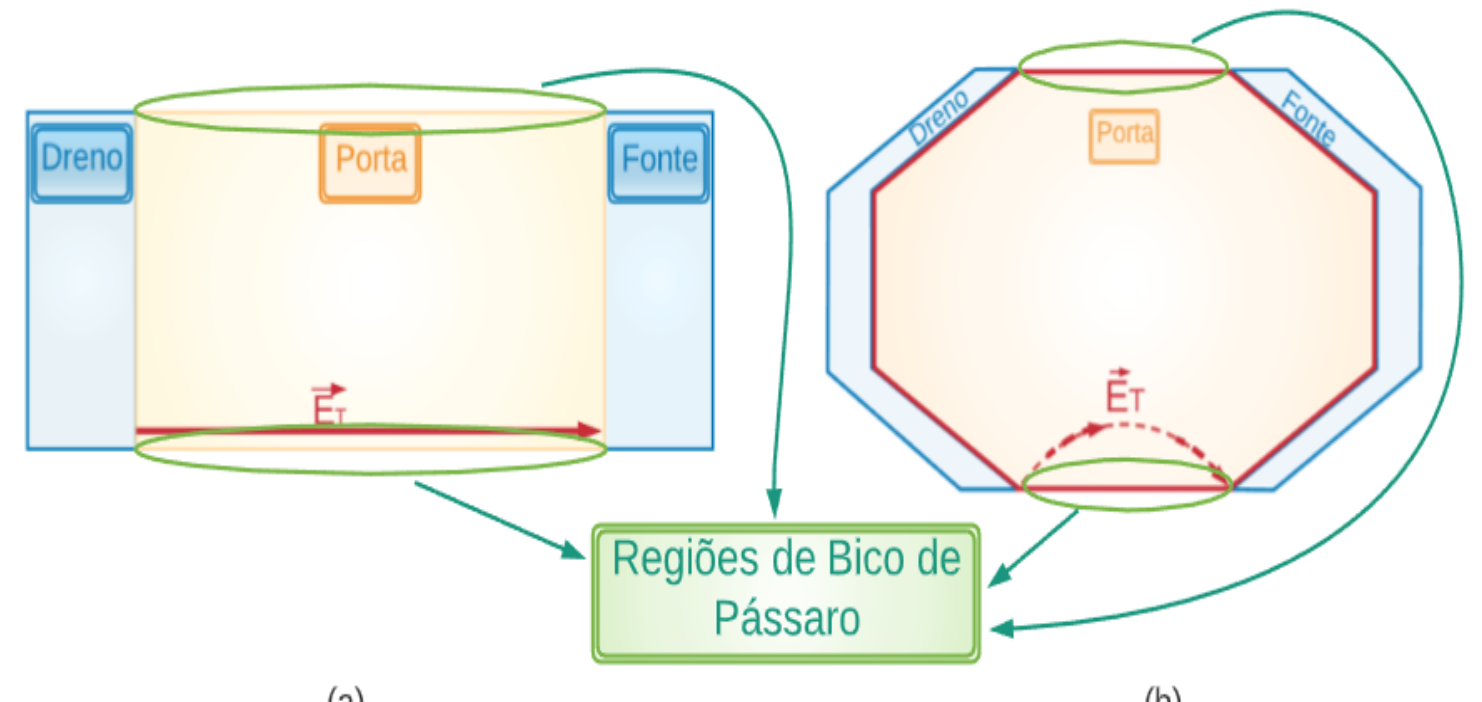

(a)

(b)

Fonte: Autor.

Note que para um CM, as linhas de campo elétrico longitudinal são paralelas, e consequentemente os transistores parasitários associados às regiões de bico de pássaro estarão eletricamente ativados devido à polarização de dreno. Além disso, é importante observar que os transistores parasitários associados às regiões dos bicos de pássaros não são desejados, dado que eles são responsáveis por aumentar a corrente de fuga nos MOSFETs principalmente quando eles operam em ambientes de radiações ionizantes [75].

\subsection{EFEITOS DAS RADIAÇÕES IONIZANTES EM MOSFETS}

Quando se analisam algumas das principais aplicações de CIs CMOS que estão sujeitas às radiações ionizantes, deve-se ressaltar que os MOSFETs precisam ser especialmente projetados e fabricados para aumentar o seu desempenho elétrico e conseguir apresentar uma maior tolerância aos efeitos das radiações ionizantes (como dose ionizante total, Total Ionizing Dose, TID e os efeitos de evento único, Single Event Effects, SEEs) [5].

Verifica-se que, além da tensão de limiar e da mobilidade dos portadores de carga móveis no canal, a corrente de fuga também é um dos principais parâmetros afetados pela TID. Desta maneira, a ILEAK aumenta de forma significativa em função da TID, o que 
normalmente compromete o funcionamento dos CIs CMOS de baixa potência e baixa tensão. Ademais, ressalta-se que os transistores com óxidos de porta fino apresentam uma maior corrente de fuga quando comparados, por exemplo, com MOSFETs fabricados com a tecnologia Silício sobre Isolante (SOI) [5]. Além disso, verifica-se que o SOI não tem a estrutura de dispositivo tiristor (Silicon Controlled Rectifier, SCR) parasitária, normalmente encontrada nos dispositivos Bulk, que podem causar uma falha do tipo Latch-up [5].

Dentro deste contexto, ressalta-se que o primeiro caso estudado e observado sobre a influência das radiações ionizantes no comportamento elétrico de um circuito eletrônico verificou-se em um satélite de telecomunicações (Telstar), no ano de 1962 [77].

No estudo relacionado às radiações ionizantes deve-se levar em consideração algumas unidades, tais como: a unidade de radioatividade no Sistema Internacional de Unidades (SI) é o becquerel (Bq, que é igual a s${ }^{-1}$ ) [78]; a dose absorvida de radiação é definida como sendo a energia absorvida pela matéria por unidade de massa $(\mathrm{dE} / \mathrm{dm})$ durante a exposição [78], sendo que a unidade denominada de Gray (Gy equivale a J/kg) é a unidade no SI e muita utilizada na área de dosimetria, entretanto a unidade "rad", que teve sua origem na expressão inglesa Radiation Absorbed Dose, é a mais utilizada nas aplicações em engenharia e equivale a 0,01 Gy [78]; o fluxo pode ser definido como sendo o número de partículas (ou fótons) que passam por uma determinada área em um intervalo de tempo e sua unidade é definida como sendo $\mathrm{m}^{-2} \mathrm{~s}^{-1}$ [5]; a unidade de energia no SI é o joule $(\mathrm{J})$, contudo em reações nucleares, verifica-se que a unidade mais utilizada é o elétron-volt ( $1 \mathrm{eV}$ é igual a $1,6.10^{-19} \mathrm{~J}$ ) [5]; a transferência linear de energia (TLE), também conhecida como stopping power é dada pela razão $\mathrm{dE} / \mathrm{dx}$, que expressa a perda de energia $(\mathrm{dE})$ por unidade de comprimento de uma partícula que penetra em uma determinada densidade de material (o alcance $\mathrm{dx}$ da partícula é a distância percorrida até perder a totalidade de sua energia cinética). A unidade de TLE é [MeV.cm². $\left.\mathrm{mg}^{-1}\right]$ [5], [79].

Pode-se citar que algumas das principais fontes de radiação para o planeta Terra são provenientes do Sol, das atividades cósmicas externas ao sistema solar, das explosões nucleares e a dos reatores nucleares. Dentro deste contexto, cabe ressaltar que a atmosfera terrestre atua de forma equivalente a um filtro ou a uma camada protetora, reduzindo a intensidade das radiações ionizantes direcionadas à superfície do planeta Terra [5].

As radiações ionizantes são mais intensas em altas altitudes e nas proximidades das regiões polares do planeta Terra (devido às influências dos cinturões de radiação). 
Deve-se acrescentar também que baixos níveis de radiações ionizantes são encontrados mesmo ao nível do mar, porém este tipo de radiação ionizante é inofensiva para a saúde humana, assim como não altera de forma significativa o funcionamento dos MOSFETs [80].

\subsubsection{Tipos de Radiações Ionizantes}

Verifica-se que existem 6 principais tipos de radiações ionizantes que podem afetar o funcionamento dos CIs CMOS: radiação por íons pesados, radiação por próton, radiação por nêutron, radiação por partícula $\alpha$, radiação por Partícula $\beta$, radiação por raios- $\gamma$ e raios- $\mathrm{X}[5]$.

Quando se estudam os efeitos relacionados à radiação ionizante por próton, podese afirmar que este tipo de radiação corresponde ao núcleo de hidrogênio [5], além do que se trata do tipo de radiação que é mais abundante nos raios cósmicos. Cabe ressaltar que um próton tem sua energia na faixa de $\mathrm{MeV}$, sendo capaz de penetrar dezenas de micrometros no alumínio [5].

Ademais, em relação à radiação ionizante por nêutrons, pode-se observar que este tipo de radiação ocorre pela quebra de um núcleo atômico, de forma natural ou induzida, sendo que este tipo de partícula possui aproximadamente a mesma massa que o próton, todavia apresenta carga nula. Além disso, verifica-se que a ausência de carga do nêutron dificulta o barramento dessa partícula por uma blindagem [5], sendo que a água pode ser considerada uma eficiente blindagem contra este tipo de radiação [81].

Em relação ao tipo de radiação ionizante por partículas $\alpha$, pode-se ressaltar que este tipo de radiação corresponde à interação do núcleo do átomo de hélio (composto por 2 prótons e 2 nêutrons) com a matéria. Pode-se observar que este tipo de radiação, que tem sua energia em uma escala na ordem de $\mathrm{MeV}$, possui uma forte interação com a matéria. A título de exemplo, verifica-se que no silício a partícula $\alpha$ pode penetrar cerca de $23 \mu \mathrm{m}[5]$.

Analisando-se o tipo de radiação ionizante por partícula $\beta$, pode-se afirmar que a partícula $\beta$ possui a mesma massa de um elétron, todavia esta partícula pode possuir carga positiva (pósitron) ou negativa (elétron). Quando se efetua uma comparação da partícula $\beta$ com a partícula $\alpha$, a partícula $\beta$ tem uma maior capacidade de penetração em materiais e uma maior facilidade em ser defletida [5]. 
Por fim, em relação ao tipo de radiação ionizante por raios- $\gamma$ e raios-X, pode-se verificar que estes tipos de radiações ionizantes são, fundamentalmente, ondas eletromagnéticas com pequeno comprimento de onda, isto é, abaixo de $10 \mathrm{~nm}$ aproximadamente. Uma possível maneira de gerar raios-X é por meio do choque de partículas carregadas com uma superfície, maneira esta utilizada nos tubos de raios-X (bremmstrahlung), enquanto os raios- $\gamma$ são originados durante interações nucleares. Ressalta-se que os raios- $\gamma$ e raios- $X$ interagem de forma similar com a matéria, sendo que estes tipos de radiações ionizantes possuem alto poder de penetração na matéria, podendo provocar ionização dos átomos do material penetrado [5].

Além disso, pode-se acrescentar que partículas com energia cinética consideravelmente maior, possuem maior capacidade de dano no funcionamento dos CIs CMOS. Dessa forma, a colisão de uma partícula altamente energética com determinado material pode gerar partículas subatômicas, como por exemplo, pode-se citar o b-méson, o pósitron, o píon, o múon, o neutrino e o quark [5]. Entretanto, deve-se acrescentar que uma partícula muito energética também pode gerar pouca ionização, desde que exista um baixo stopping power e, portanto, irá gerar pouco dano ao atravessar um dispositivo eletrônico [5].

\subsubsection{Fontes de Radiações Ionizantes}

Serão apresentadas duas das principais fontes de radiações ionizantes espaciais: os cinturões de Van Allen (que também ser considerados como um bloqueio ou uma blindagem contra as radiações ionizantes, assim como um reservatório de partículas) e os raios cósmicos.

No espaço, as radiações ionizantes são geradas a partir do vento solar, proveniente dos raios cósmicos solares (Solar Cosmic Rays, SCR), dos raios cósmicos galácticos (Galactic Cosmic Rays, GCR) e do cinturão de Van Allen (Van Allen Belts) [82].

Deve-se ressaltar que os cinturões de Van Allen são regiões do espaço ao redor do planeta Terra, com uma quantidade muito significativa de prótons e elétrons, provenientes da interação do campo magnético terrestre com o vento solar, conforme pode ser visualizado na Figura 34 [83]. 
Figura 34 - Ilustração simplificada do cinturão de Van Allen relacionadas às radiações ionizantes do planeta Terra

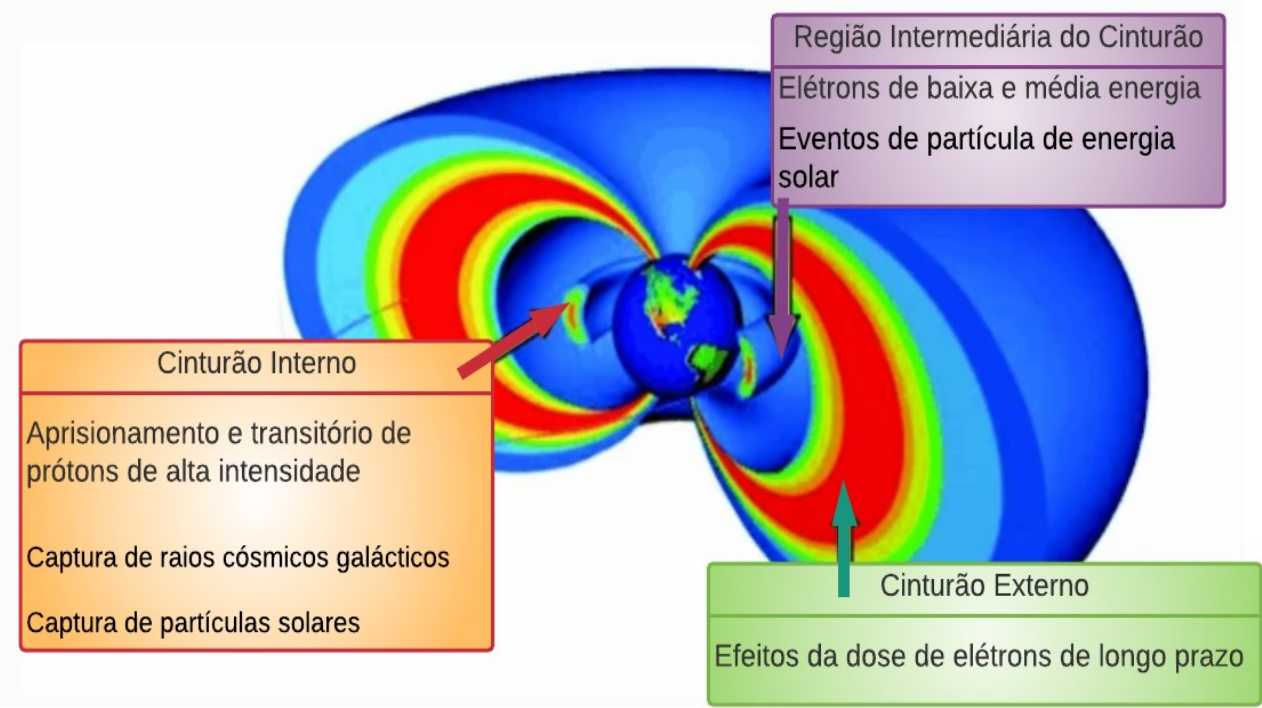

Fonte: Autor "adaptado de" [83], 2018, p.3.

Ao analisar a Figura 34, verifica-se que existem três regiões distintas nos cinturões de Van Allen: cinturão interno, região intermediária do cinturão e o cinturão externo. No cinturão interno verifica-se a captura de partículas solares, captura de raios cósmicos galácticos e aprisionamento e transitório de prótons de alta intensidade. $\mathrm{Na}$ região intermediária do cinturão, verifica-se a presença de elétrons de baixa e de média energia e partículas geradas por meio da energia solar. No cinturão externo pode-se observar, fundamentalmente, os efeitos da dose de elétrons de alta energia nesta região [83].

Em relação aos raios cósmicos galácticos, observa-se que são normalmente divididos em três principais grupos diferentes de raios cósmicos: galácticos, solares e terrestres [84].

Quando se analisam os raios galácticos, pode-se afirmar que estes são originados fora do sistema solar [84], sendo que este tipo de radiação é constituída por $85 \%$ de prótons, $14 \%$ de partículas $\alpha$ e $1 \%$ de núcleos pesados [84].

Valendo-se dos raios cósmicos solares, pode-se verificar que estes são fundamentalmente constituídos por partículas de elementos químicos, raios ultravioletas (UV) e raios-X [5].

Em relação aos raios cósmicos terrestres, pode-se observar que estes são formados principalmente por meio de partículas secundárias, produzidas pelo choque das partículas 
espaciais com a atmosfera terrestre [5], reagindo assim com o oxigênio e o nitrogênio, acarretando na formação de complexas cascatas de partículas secundárias e terciárias que também podem ser denominadas de "chuveiros de partículas" [80], conforme ilustrado na Figura 35 [85].

Figura 35 - Raios cósmicos terrestre

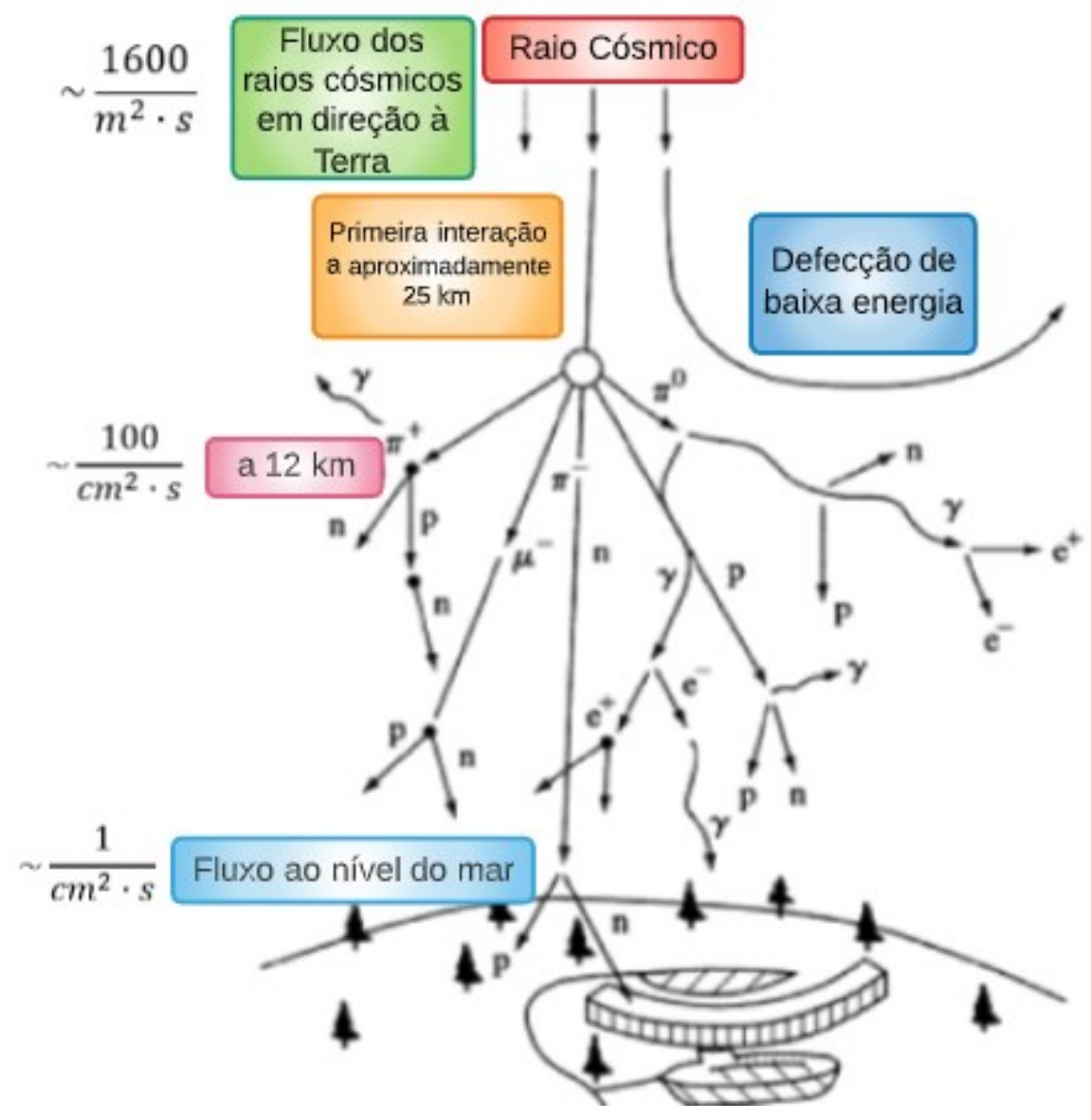

Fonte: Autor "adaptado de" [85], 1996, p. 5.

Por meio da análise da Figura 35, pode-se verificar que "p" significa próton, "n" significa nêutron, $\gamma$ está relacionada aos raios- $\gamma$, "e $\mathrm{e}^{+}$" se refere ao pósitron, " $\mathrm{e}$ " se refere ao elétron, " $\pi^{-"}$, “ $\pi^{0 "}$ e " $\pi^{+}$" são partículas píon de carga negativa, neutra e positiva, respectivamente e " $\mu$ " é denominada de partícula fundamental múon, de carga negativa [85], [82].

Observa-se que no campo magnético terrestre existem prótons, elétrons e íons de oxigênio armadilhados devido à força de Lorentz [84]. Deve-se acrescentar que estas partículas aprisionadas no campo magnético terrestre podem prejudicar o funcionamento de satélites, dependendo de sua altitude, sua inclinação e de sua blindagem [84]. 
Dentro deste contexto, é importante observar que o campo magnético terrestre não é geograficamente uniforme, pois que influências geológicas podem causar inclinação e deslocamento das linhas magnéticas terrestres [5], [84]. Como um dos principais exemplos, pode-se citar a "Anomalia Magnética do Atlântico Sul” (South Atlantic Anomaly, SAA) que é considerada uma distorção magnética que culmina em uma maior influência da radiação no planeta. Por meio da captura de dados de um espectrômetro de partículas ionizantes denominado de EPT (Energetic Particle Telescope) instalado em um satélite denominado de Proba-V lançado pela Agência Espacial Europeia (ESA) em maio de 2013, pode-se visualizar na Figura 36, o comportamento da SAA por meio da captura de uma imagem que ilustra o fluxo e a energia de elétrons e prótons em função da latitude e longitude geográficas [86].

Figura 36 - Fluxo de elétrons em uma escala de energia que vai de 2,6 MeV a 8,0 MeV e fluxo de prótons numa escala de energia que vai de $29 \mathrm{MeV}$ a $248 \mathrm{MeV}$, provenientes do EPT da Proba-V

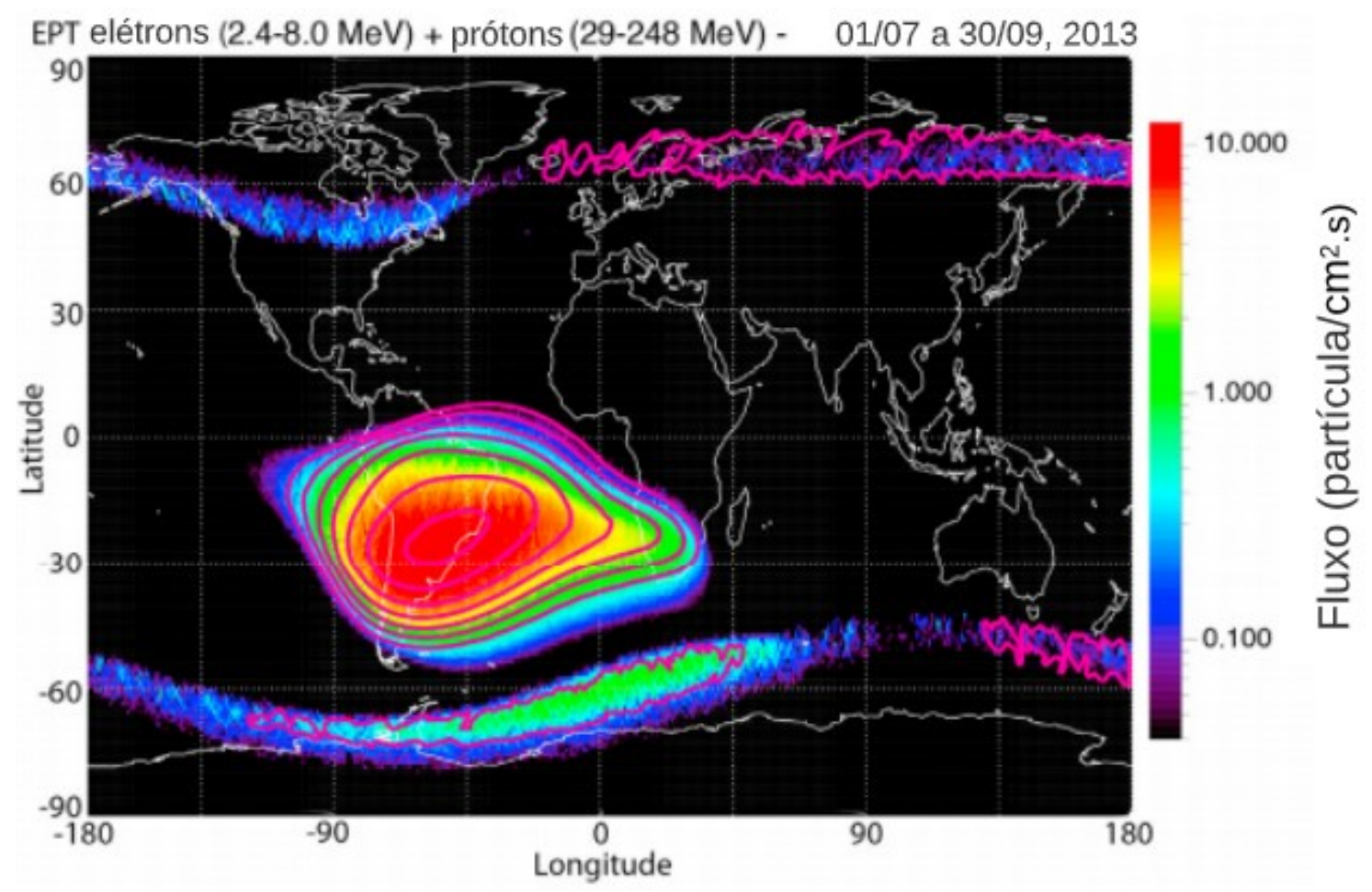

Fonte: Autor "adaptado de" [86], 2018, p. 3.

Deve-se ressaltar que a captura da imagem ilustrada na Figura 36 mostra a posição da SAA em uma órbita de aproximadamente $820 \mathrm{~km}$ [86].

Além deste comportamento citado referente ao campo magnético terrestre, verifica-se que este também pode criar uma blindagem natural aos raios cósmicos [5]. De 
acordo com a força de Lorentz, uma força atua sobre uma determinada partícula carregada quando esta cruza um campo magnético [78]. Assim essa partícula será desviada do planeta Terra caso sua energia seja baixa [5]. Além disso, dentro deste contexto, observase que as aplicações de CIs CMOS espaciais baseiam-se nas missões de explorações espaciais e aplicações em satélites artificiais, sendo que estes podem ser classificados quanto à altitude em que operam e são classificados de acordo com as seguintes especificações [77], [87]: Low Earth Orbit (LEO) para satélites que operam em órbita baixa, Medium Earth Orbit (MEO) para satélites que operam em órbita média e Geosynchronous Equatorial Orbit (GEO) para satélites que operam em órbita geoestacionária.

Em relação satélites em órbita baixa (LEO), estes situam-se em altitudes na faixa de $300 \mathrm{~km}$ a $5.000 \mathrm{~km}$, sendo que são expostos a níveis elevados de radiações ionizantes e para inclinações de órbita inferior a $45^{\circ}$, o satélite estará exposto à Anomalia Magnética do Atlântico Sul. Nas órbitas polares do planeta Terra e suas proximidades, verifica-se a influência dos cinturões de radiação. Deve-se ressaltar que órbitas de aproximadamente $1.400 \mathrm{~km}$ são afetadas por altas doses de radiação [77], [87]. Ademais, levando-se em consideração que o nível de blindagem está relacionado com a dose da radiação a que um sistema eletrônico está exposto, é sempre importante ressaltar e observar o trade-off do peso de lançamento de um satélite ou carga útil, o que nos leva a concluir que por mais que queiramos proteger o nosso sistema, isso tem um preço elevado se formos tentar fazer isso com blindagens, motivando ainda mais a abordagem de melhorar o funcionamento os componentes eletrônicos [77], [87].

Para os satélites em órbita média (MEO), deve-se ressaltar que estes estão situados em órbita acima de $5.000 \mathrm{~km}$ de altitude e abaixo das órbitas geoestacionárias (GEO) [77], [87].

Além disso, os satélites geoestacionários (GEO) referem-se aos satélites localizados aproximadamente a $36.000 \mathrm{~km}$ de altitude [77], [87].

Ademais, as órbitas MEO e GEO estão mais expostas ao cinturão de Van Allen, região onde a maior fonte de radiação são os elétrons [86]. Neste local, as radiações ionizantes podem ser reduzidas ou atenuadas com blindagens de alumínio relativamente fina (por exemplo, da ordem de $4 \mathrm{~mm}$ ), dado o baixo poder de penetração dos elétrons [87].

A título de exemplo, pode-se citar que um satélite GEO operando durante dezoito anos pode acumular até cerca de $100 \mathrm{krad}$, desde que este possua blindagem com $5 \mathrm{~mm}$ 
de espessura de alumínio, entretanto este mesmo tipo de satélite pode acumular até 10 $\mathrm{krad}$, desde que este possua uma blindagem com $10 \mathrm{~mm}$ de espessura de alumínio. Por meio de uma análise comparativa, um satélite localizado a uma altitude de $2000 \mathrm{~km}$ (órbita LEO), durante um período de cinco anos com blindagem de $10 \mathrm{~mm}$ de espessura de alumínio, pode acumular uma dose de até cerca de $300 \mathrm{krad}$ [5], [77].

Entretanto, deve-se acrescentar que os satélites situados nas órbitas LEO, MEO e GEO, estão expostos a íons pesados e partículas de alta energia, que nem sempre podem ser barradas ou atenuadas com as blindagens de alumínio, e, portanto, podem ocorrer alguns efeitos indesejáveis, tais como: Total Ionizing Dose (TID) ou Dose Ionizante Total, Displacement Damage (DD) ou Danos por Deslocamento e Single Event Effects (SEEs).

Em relação à Dose Ionizante Total (TID), esta trata-se de um efeito acumulativo, de longo prazo, que degrada algumas propriedades elétricas dos CIs CMOS, em função do acúmulo de cargas positivas nos materiais isolantes que compõem os transistores que fazem parte destes CI CMOS, podendo ser reversível [11].

Além disso, em relação aos Danos por Deslocamento (DD), pode-se observar que se referem aos danos físicos na estrutura cristalina do material, em função da perda de energia de forma não ionizante das partículas incidentes no material, degradando as propriedades do material incidente [88]. Ressalta-se também que a energia transferida durante uma colisão nuclear, seja ela elástica ou inelástica, pode ser suficiente para deslocar um átomo de seu local de origem no retículo cristalino, ou seja, ocasionando um deslocamento (displacement damage) que acarreta a alteração do arranjo dos átomos de sua organização original [84]. Os danos por deslocamento são, portanto, a desorganização do retículo cristalino formando defeitos denominados de defeitos Frenkel que se caracterizam pela formação de vacâncias e posições intersticiais, as quais respectivamente são definidas como sendo a ausência de um átomo em uma posição do retículo cristalino e posições intersticiais, que é a localização de um átomo fora de sua posição original neste mesmo retículo cristalino [84].

Por fim, pode-se ressaltar os eventos singulares (SEE) que são efeitos que ocorrem devido ao impacto de pelo menos uma partícula energética fortemente ionizante no silício [89], e são classificados da seguinte maneira: Single Event Upset (SEU) ou evento de única perturbação, Single Event Transient (SET), Single Event Latchup (SEL) o qual é também destrutivo, Single Event Burnout (SEB) ou evento único de queima, Single Event Gate Rupture (SEGR) ou designados de evento de ruptura de porta e Single Hard Error 
(SHE) ou erro único fatal que são eventos destrutivos que danificam permanentemente um dispositivo eletrônico [89], [90].

Em relação ao evento de única perturbação (SEU), pode-se afirmar que são eventos em que se verifica a modificação do estado de um bit armazenado em um dispositivo eletrônico de memória [91].

O evento de um único transiente (SET), refere-se a um evento transiente que pode ou não ser capturado por um elemento de memória, podendo ocorrer, tanto em CIs CMOS digitais [92] quanto em analógicos [93].

A Figura 37 ilustra as fontes de radiações ionizantes espaciais com as três classes de defeito [77].

Figura 37 - Classificação dos efeitos das radiações ionizantes espaciais nos MOSFETs em função de suas respectivas fontes irradiantes

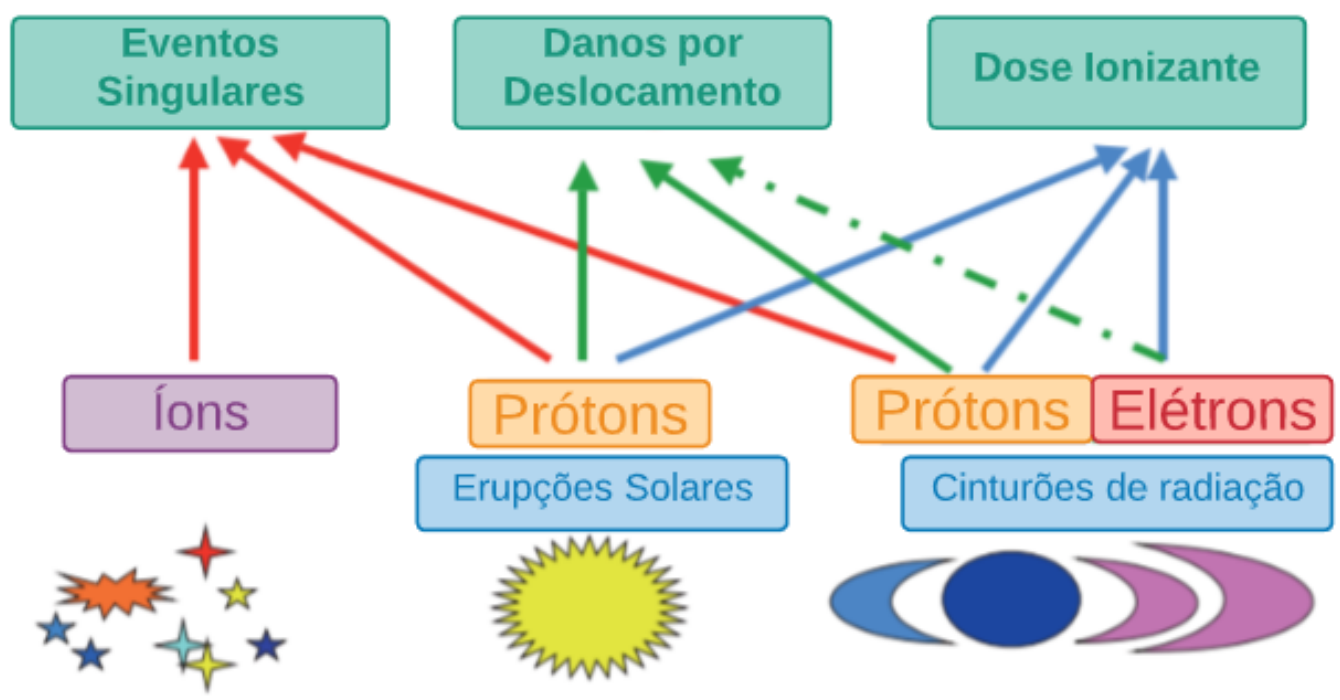

Fonte: Autor "adaptado de" [77], 2007, p. 34.

\subsubsection{RAIOS - X}

Pode-se afirmar que os raios-X são ondas eletromagnéticas extremamente penetrantes [94]. Este tipo de radiação interage com a matéria podendo provocar três diferentes efeitos: efeito fotoelétrico, efeito Compton e produção de pares elétronpósitron. Deve-se ressaltar que as fontes de radiações eletromagnéticas são de interesse para testar os efeitos da TID em dispositivos eletrônicos. Assim, verifica-se que elas emitem fótons por meio de fontes de raios-X e raios-gama. Desta maneira, os fótons interagem com a matéria (o meio), por meio de mecanismos de interações dos fótons com 
a matéria, isto é, por meio dos efeitos fotoelétrico, Compton e produção de pares elétronpósitron [94].

Um fóton de radiação de raios-X pode perder toda ou quase toda energia numa única interação, sendo que a distância que ele percorre antes de interagir com a matéria não pode ser prevista, todavia, verifica-se que é possível estimar valores médios para a distância que ele percorre [94].

A interação de fótons de alta energia ou partículas carregadas com o material culmina com a sua ionização [95], e os danos se iniciam quando pares elétrons-lacunas são gerados no material [5], [6]. A ionização nada mais é do que um processo de adição ou remoção de elétrons (ou outras partículas carregadas) dos átomos. Uma partícula ionizante que incide no material, devido às colisões, é capaz de excitar elétrons da banda de valência dos materiais, que podem ganhar energia suficiente para passar para a banda de condução, gerando deste modo, pares elétrons-lacunas (PEL). Os efeitos das radiações ionizantes dependem basicamente da energia do fóton e do material alvo [5], [6].

Pode-se afirmar que o efeito fotoelétrico é a interação de fótons de raios-X ou raios- $\gamma$, bem como outros fótons (como a luz) com um material, por meio do qual toda a energia do fóton é transferida para um elétron de camada interna, ejetando-o do átomo e deixando o átomo com uma lacuna. Deve-se ressaltar que este efeito físico provoca como consequência a liberação de energia por meio de colisões (ionização do meio) [96]. A Figura 38 ilustra a interação de um fóton com um átomo.

Figura 38 - Ilustração do efeito fotoelétrico

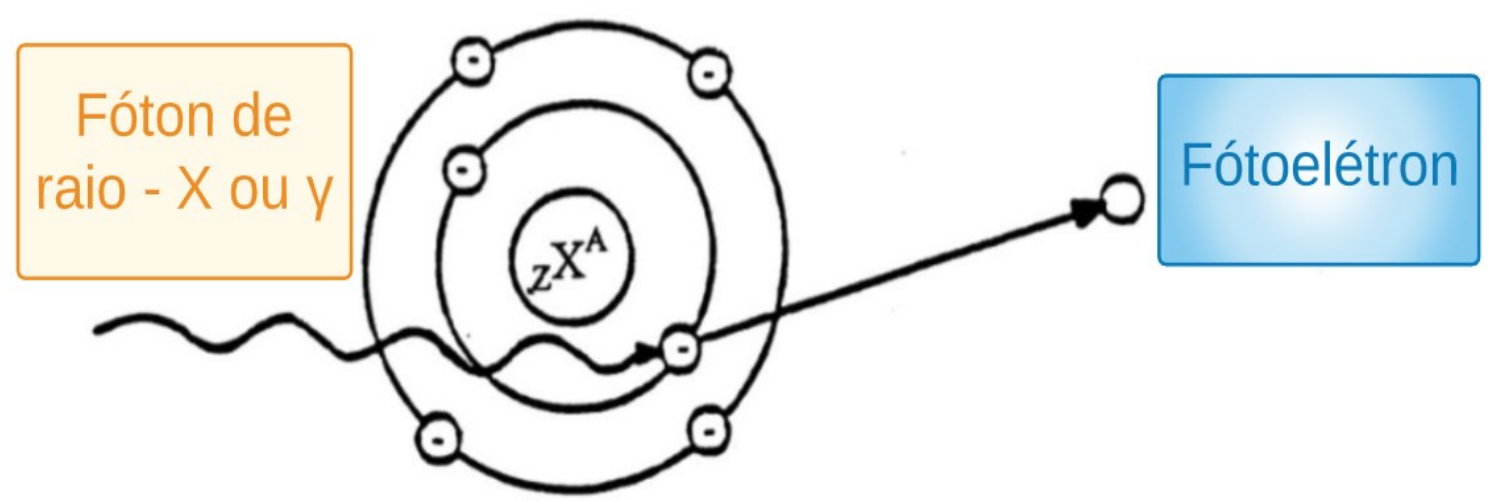

Fonte: Autor "adaptado de" [94], 2012, p. 2

Analisando-se a Figura 38, verifica-se que X é o símbolo do elemento químico, Z é o número atômico do elemento químico, definido como a quantidade de prótons no 
núcleo do átomo e A é o número de massa do elemento químico, definido como a somatória da quantidade de prótons e nêutrons existentes no núcleo atômico [94].

No segundo mecanismo de interação, que é denominado de efeito Compton em homenagem a Arthur Holly Compton, verifica-se o espalhamento elástico do fóton com um elétron fracamente ligado ao átomo. Isso faz com que o fóton mude de direção com menor energia e o elétron seja ejetado da órbita do átomo [94]. Deve-se ressaltar também que neste efeito, o elétron perde sua energia por meio de colisões (provocando a ionização do meio) sendo que o fóton espalhado volta a interagir com o meio novamente [94].

Adicionalmente, verifica-se um terceiro efeito por meio do qual pode ocorrer também a produção de pares elétron-pósitron (desde que se tenha uma energia incidente maior que $1,022 \mathrm{MeV}$ ) [94]. Um fóton de alta energia de raios-X ou raios- $\gamma$ interage com o núcleo do material e desaparece, dando origem assim a um par elétron-pósitron nesta região. A interação deve ocorrer em uma região com campo elétrico elevado, normalmente próxima do núcleo do átomo [94].

\subsubsection{Efeitos da TID em MOSFETs}

A TID refere-se à dose total acumulada por um determinado material ou dispositivo eletrônico devido à exposição às radiações ionizantes ao longo do tempo [5], [77]. Verifica-se que estes efeitos estão atrelados a intensidade da dose, assim como ao tempo de exposição.

A Figura 39 apresenta como as radiações ionizantes de raio- $\mathrm{X}$ atuam no óxido de porta dos MOSFETs [97]. 
Figura 39 - Efeitos das radiações ionizantes no óxido de porta

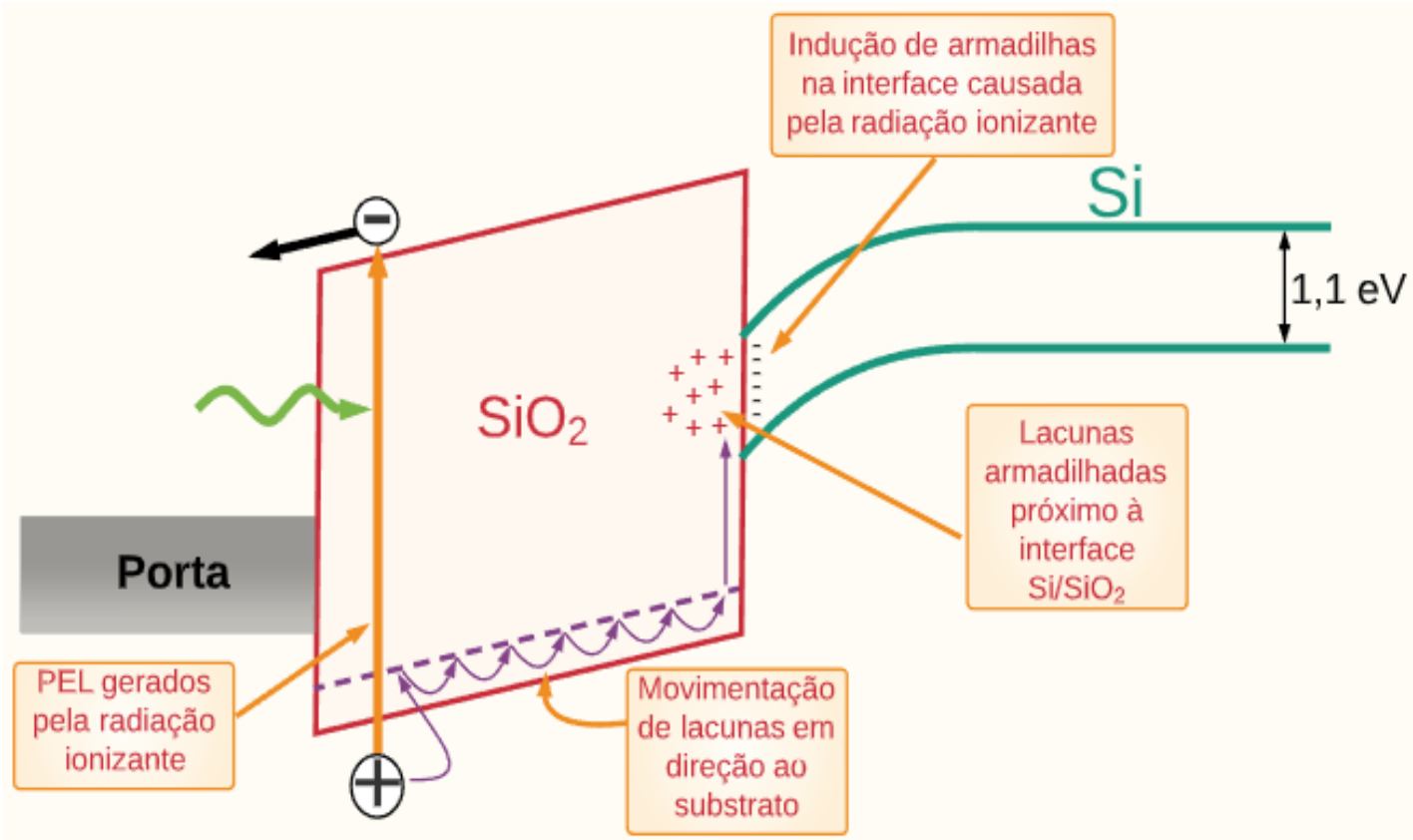

Fonte: Autor "adaptado de" [97], 2006, p. 3107.

Os efeitos apresentados na Figura 39 podem ser resumidos por meio da análise de quatro diferentes etapas:

a) Pares elétrons-lacuna são gerados no óxido de porta durante o processo de irradiação, e os elétrons são atraídos para a porta do MOSFET devido à aplicação de tensão positiva, enquanto que as lacunas se movem na direção do substrato. Neste intervalo, alguns elétrons se recombinam com as lacunas, em que a fração de portadores que se recombinam depende da energia e do tipo de material [97];

b) As lacunas movimentam-se no interior do óxido de porta em direção ao substrato [97];

c) As lacunas localizadas dentro do $\mathrm{SiO}_{2}$ acumulam-se na proximidade da interface $\mathrm{Si} / \mathrm{SiO}_{2}$, alterando a tensão de limiar do MOSFET [97];

d) Cargas positivas são armadilhadas na interface $\mathrm{SiO}_{2}[97]$. 
Conforme ilustrado Figura 39, o aprisionamento das cargas positivas no óxido, acaba por resultar num menor potencial entre porta e dreno, necessário para a formação do canal entre dreno e fonte no MOSFET, podendo fazer com que o dispositivo esteja ligado quando deveria estar desligado [97].

Além do acúmulo observado de cargas positivas no óxido entre a região de porta e canal, verificam-se também outras regiões que são muito afetadas pelo aprisionamento dessas cargas devido às radiações ionizantes, comumente chamadas de regiões de bico de pássaro [11]. Essas regiões são geradas na fabricação do óxido de campo do MOSFET. [11]. A Figura 40 apresenta as regiões de bico de pássaro em duas diferentes estruturas isolantes convencionais usadas para a fabricação de CIs CMOS, denominadas de Oxidação local do silício (LOCal Oxidation of Silicon, LOCOS) e Isolação do tipo trincheira (Shallow-Trench Isolation, STI) e a ilustração das cargas armadilhadas nestas regiões. Pode-se observar que a abordagem STI permite reduzir as imperfeições geradas devido ao processo de fabricação LOCOS, como regiões de bico de pássaro [98].

Figura 40 - Estruturas isolantes convencionais usadas para a fabricação de CIs CMOS, LOCOS e STI de um nMOSFET com geometria de porta retangular, indicando as regiões de bico de pássaro e o seu circuito elétrico equivalente

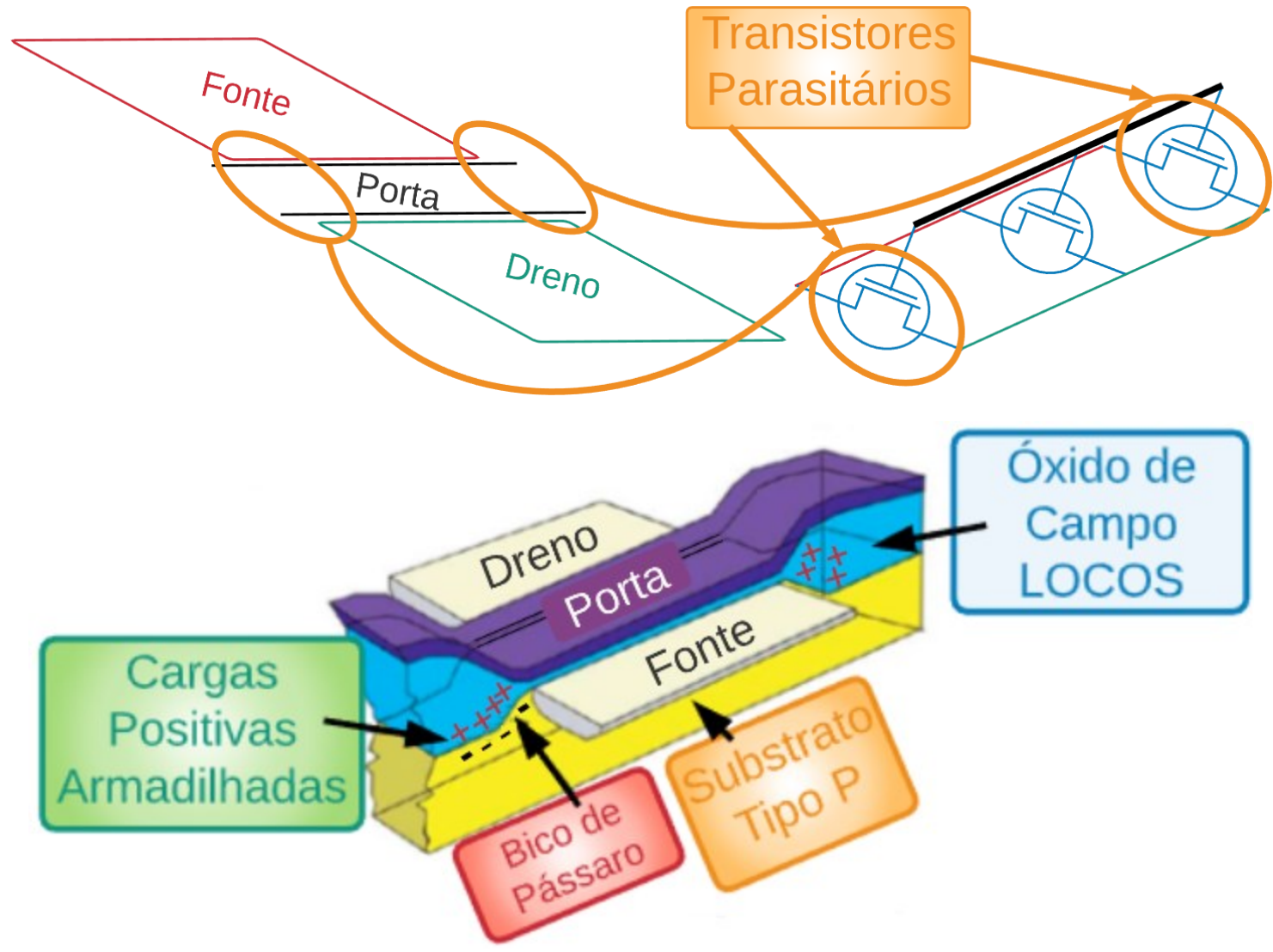




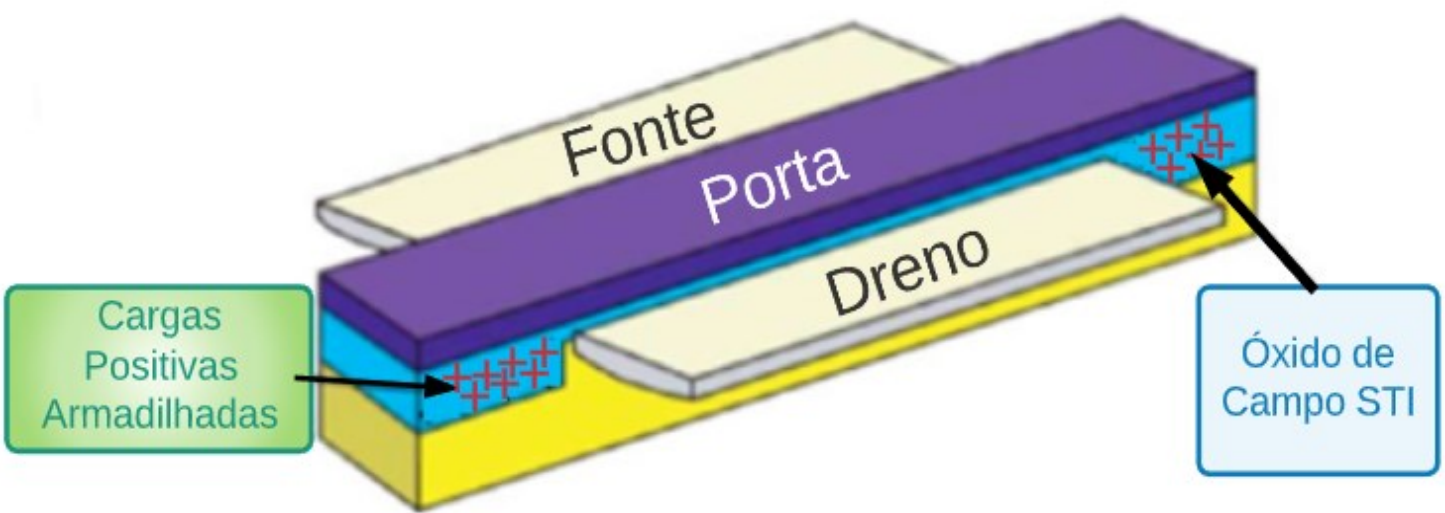

Fonte: Autor "adaptado de" [11], 2008, p. 1841.

Na Figura 40 são apresentadas as estruturas LOCOS e STI para MOSFETs. Como pode ser observado na Figura 40, essas regiões de bico de pássaro nas extremidades do canal funcionam como transistores paralelos ao dispositivo principal [11]. A exposição do MOSFET às radiações ionizantes aumenta a influência desses transistores parasitários, podendo causar um aumento da corrente de fuga entre as regiões de dreno e fonte. $\mathrm{O}$ aumento da corrente de fuga, por consequência, resulta num maior consumo de energia elétrica quando o MOSFET está desligado [11].

Deve-se observar que a intensidade do acúmulo de cargas no óxido depende do campo elétrico vertical aplicado ao MOSFET (campo elétrico proporcionado em função da tensão aplicada entre os terminais da porta e fonte), do processo de fabricação do dispositivo e da espessura do óxido de porta do MOSFET [11].

Além disso, a geração de armadilhas na interface é tipicamente um efeito menos efetivo que o acúmulo de cargas no óxido, e os mecanismos para sua ocorrência ainda são estudados. A quantidade de armadilhas geradas na interface $\mathrm{Si} / \mathrm{SiO}_{2}$ de um MOSFET dependerá de fatores como a dose total absorvida, o campo elétrico vertical aplicado, a espessura do óxido de porta e o material de porta do MOSFET [5], [11].

\subsubsection{Influência da TID nos Parâmetros dos MOSFETs}

As cargas armadilhadas no óxido e na interface do MOSFET se mostram um grande problema no correto funcionamento desses dispositivos, já que além do aumento da corrente de fuga e desvio da tensão de limiar, também podem causar a degradação da mobilidade de portadores do canal [5], [11]. Serão apresentadas as influências diretas nos 
parâmetros da tensão de limiar, inclinação de sublimiar, transcondutância e corrente de fuga dos MOSFETs.

\subsubsection{Desvio da tensão de limiar}

É um dos efeitos mais importantes levando-se em consideração um projeto eletrônico, já que a tensão de limiar $\left(\mathrm{V}_{\mathrm{TH}}\right)$ é a tensão necessária para acionar o transistor [1], [50]. A alteração desta tensão pode fazer com que o MOSFET não funcione da maneira com que foi planejado num circuito ou até inutilizá-lo completamente [5], [11].

Com o aprisionamento de cargas no óxido de isolação $\left(\mathrm{SiO}_{2}\right)$, torna-se mais fácil atingir o limiar de inversão do substrato, ou seja, a tensão de limiar se torna menor para os nMOSFETs e mais negativa para os pMOSFETs [5], [11]. Num nível de extrema radiação, este efeito pode fazer com que nMOSFETs não possam ser desligados e pMOSFETs necessitem de uma tensão muito negativa para serem ligados [5], [11], [84]. A Figura 41 ilustra as variações das $\mathrm{V}_{\mathrm{THS}}$ em MOSFETs expostos às radiações ionizantes, quando influenciados principalmente pelas cargas positivas induzidas no óxido.

Figura 41 - Curvas de $\mathrm{I}_{\mathrm{DS}}$ em função de $\mathrm{V}_{\mathrm{GS}}$, indicando os valores das $\mathrm{V}_{\mathrm{THS}}$ quando influenciados principalmente pelas cargas positivas induzidas no óxido em MOSFETs submetidos às radiações ionizantes

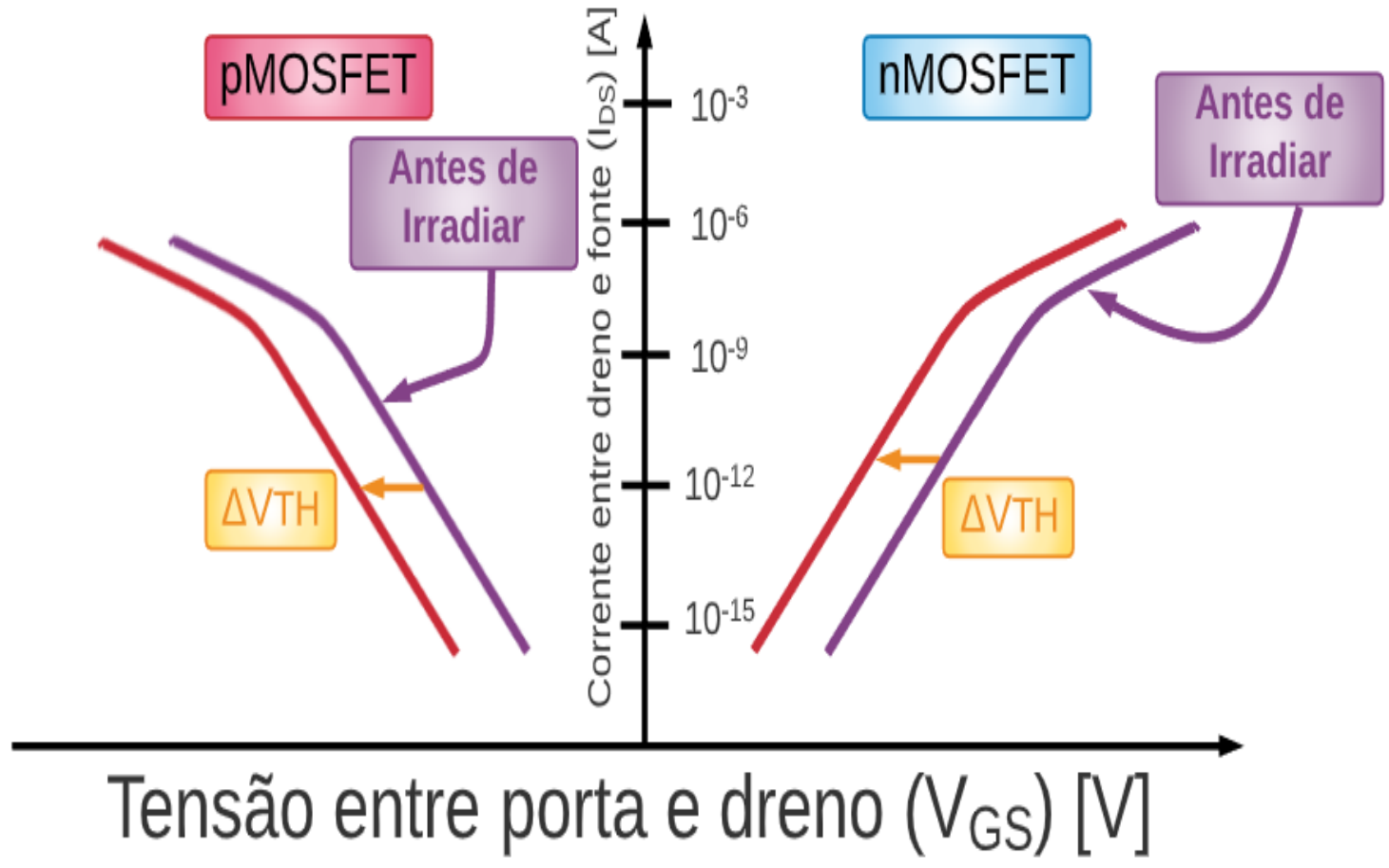

Fonte: Autor "adaptado de" [6], 2006, p. 3111. 
$\mathrm{Na}$ Figura 41, $\Delta \mathrm{V}_{\mathrm{TH}}$ representa a variação da $\mathrm{V}_{\mathrm{TH}}$ em função da influência das cargas positivas armadilhadas no óxido de porta, considerando os valores antes e depois do processo de irradiação [6].

\subsubsection{Redução da transcondutância}

As cargas armadilhadas na interface $\mathrm{Si} / \mathrm{SiO}_{2}$ do MOSFET diminuem a mobilidade dos portadores no canal. Isso ocasiona a redução na condutância do canal e na transcondutância do MOSFET, que por sua vez resulta numa redução do ganho do dispositivo [5], [96], [97].

A queda na velocidade dos portadores acaba aumentando o tempo de trânsito, levando a uma redução direta na velocidade do dispositivo [5], [96], [97].

\subsubsection{Aumento da inclinação de sublimiar}

As cargas armadilhadas na interface tendem a alargar a curva característica na região de sublimiar. Dessa forma, são necessárias maiores variações de tensão entre a porta e a fonte para atingir as mesmas variações de corrente elétrica entre dreno e fonte da situação denominada de pré-irradiação [5], [96], [97]. A Figura 42 ilustra como o armadilhamento de cargas na interface $\mathrm{Si} / \mathrm{SiO}_{2}$ afeta as inclinações de sublimiar ( $\mathrm{SSs}$ ) e também pode-se verificar um aumento em módulo da tensão de limiar. 
Figura 42 - Curvas de IDs em função de $\mathrm{V}_{\mathrm{GS}}$, indicando as variações das SSs e $\Delta V_{T H} S$ levando-se em conta o efeito do aprisionamento de cargas na interface $\mathrm{Si} / \mathrm{SiO}_{2}$ do MOSFET

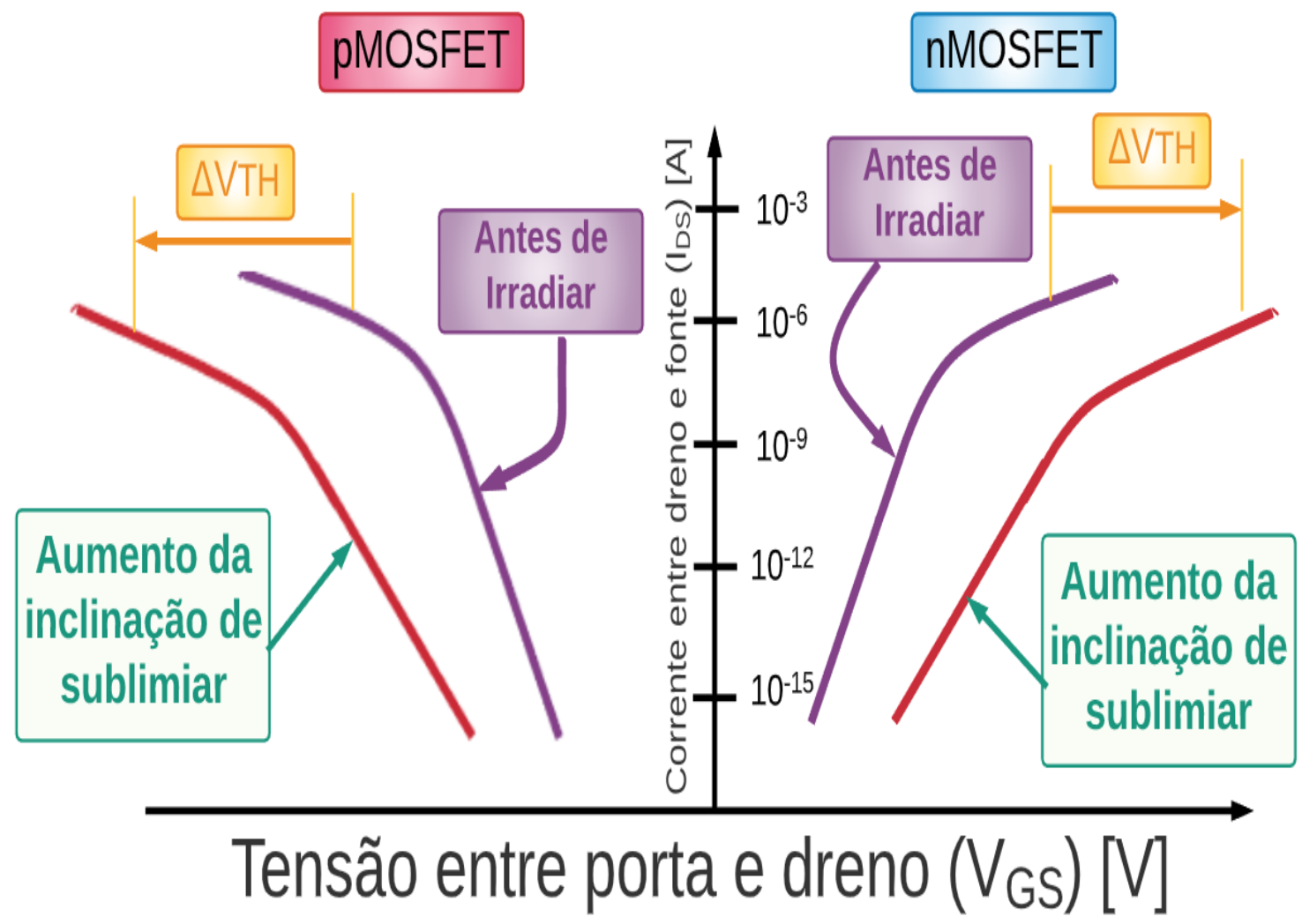

Fonte: Autor "adaptado de" [6], 2006, p. 3111.

\subsubsection{Aumento da corrente de fuga}

A corrente de fuga dos MOSFETs aumenta tanto pelo aprisionamento de cargas no óxido, como pela geração de armadilhas na interface. Além disso, há também o problema dos transistores parasitários [5], [96], [97]. A radiação ionizante é capaz de aumentar a influência dos transistores parasitários das regiões de bico de pássaro [5], [96], [97]. Esse aumento de corrente de fuga pode levar à elevada dissipação de potência e falhas funcionais em CIs [5], [96], [97].

O acúmulo de cargas nas camadas isolantes entre os transistores ou nas regiões de bico de pássaro, torna o problema dos transistores parasitários ainda mais grave. Isso porque há a formação de transistores parasitários que podem formar caminhos de condução fora de controle entre dreno e fonte do mesmo MOSFET, ou até mesmo entre MOSFETs diferentes [5], [96], [97]. 
Dessa forma foram apresentados os principais conceitos fundamentais necessários sobre os MOSFETs, alguns de seus parâmetros, conceitos estatísticos utilizados na realização do estudo da variabilidade dos nMOSFET do tipo Diamante, do tipo Octogonal e os seus respectivos convencionais equivalentes em ambientes de radiação ionizante do tipo raios-X, um estudo das principais características dos MOSFET de leiaute de porta hexagonal (MOSFET Diamante) e octogonal (MOSFET Octo) e alguns dos principais efeitos das radiações ionizantes em MOSFETs, necessários para o desenvolvimento e entendimento desta tese de doutorado. 


\section{MATERIAIS E MÉTODOS}

Este capítulo apresenta todos os procedimentos experimentais empregados tanto para as caracterizações elétricas dos MOSFETs utilizados no desenvolvimento deste trabalho, assim como para aplicação das doses de radiações ionizantes de raios-X.

Além disso, neste capítulo é apresentado também como os nMOSFETs foram manufaturados e como os equipamentos de raios- $\mathrm{X}$ e de medidas foram utilizados para a condução de todos os experimentos.

\subsection{PROJETO E FABRICAÇÃO DOS NMOSFETS UTILIZADOS NESTE TRABALHO}

Foram projetados circuitos integrados (CIs) CMOS pelo grupo de pesquisa do Centro Universitário FEI, utilizando-se os nMOSFETs do tipo Diamante (DnM), Octogonal (OnM) e convencional ( $\mathrm{CnM})$, com diferentes comprimentos de canais. Devese ressaltar que os chips utilizados para o desenvolvimento dos procedimentos experimentais deste trabalho são de tecnologia de Silício-Germânio com dimensão mínima de $130 \mathrm{~nm}$.

O leiaute do circuito integrado (CI) utilizado para a realização deste estudo comparativo estatístico experimental entre os DnMs, OnMs e CnMs em ambiente de radiação ionizante de raios-X, está ilustrado na Figura 43. 
Figura 43 - Leiaute do CI utilizado para a realização deste estudo comparativo experimental entre os DnMs, OnMs e CnMs, que foi fabricado com tecnologia de fabricação de CIs CMOS de Silício-Germânio de $130 \mathrm{~nm}$

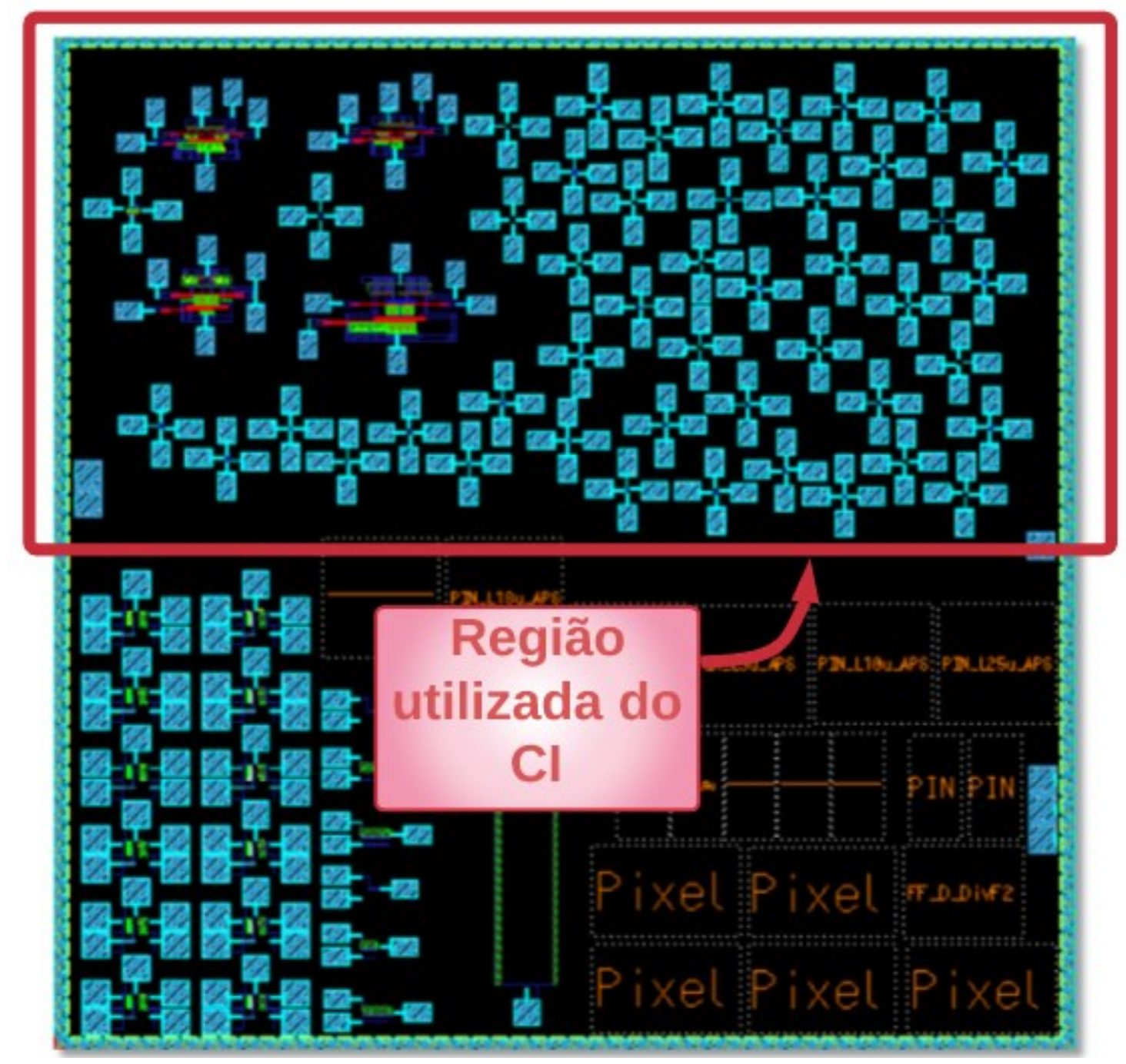

Fonte: Autor.

Na Tabela 2 são apresentadas as características dimensionais dos nMOSFETs de porta hexagonal, octogonal e retangular de $\mathrm{SiGe}$ que foram utilizados no desenvolvimento deste trabalho. 
Tabela 2 - Características dimensionais dos DnMs, OnMs e CnMs de SiGe utilizados nos estudos experimentais.

\begin{tabular}{|c|c|c|c|c|c|c|c|c|}
\hline & & $\begin{array}{c}\mathrm{W} \\
(\mu \mathrm{m})\end{array}$ & b $(\mu m)$ & $\mathrm{B}(\boldsymbol{\mu m})$ & $\begin{array}{c}\mathrm{Ag} \\
(\mu \mathrm{m})^{2}\end{array}$ & $\begin{array}{l}\text { Lgeo } \\
(\mu \mathrm{m})\end{array}$ & W/L & $\begin{array}{c}\text { Lef } \\
(\mu \mathrm{m})\end{array}$ \\
\hline \multirow{2}{*}{ DnM } & T5 & 0,56 & 0,2 & 0,88 & 0,3024 & 0,54 & 1,04 & 0,46 \\
\hline & T9 & 0,56 & 0,2 & 0,88 & 0,3024 & 0,54 & 1,04 & 0,46 \\
\hline \multirow{2}{*}{ OnM } & $\mathrm{T} 8$ & 1,52 & 0,69 & 1,49 & 1,94 & 1,29 & 1,18 & 1,22 \\
\hline & T37 & 0,7 & 0,4 & 0,91 & 0,51 & 0,78 & 0,9 & 0,74 \\
\hline \multirow{2}{*}{$\mathrm{CnM}$} & T6 & 0,4 & - & - & 0,064 & 0,16 & 2,5 & 0,16 \\
\hline & T17 & 0,8 & - & - & 0,128 & 0,16 & 5,0 & 0,16 \\
\hline
\end{tabular}

De acordo com os dados apresentados na Tabela 2, os valores de L obtidos para os DnMs foram calculados por meio da equação (32) e para os OnMs foram calculados por meio da equação (34). Os valores de $\mathrm{L}_{\mathrm{ef}}$ obtidos para os DnMs foram calculados por meio da equação (31) e para os OnMs foram calculados por meio da equação (36).

Além disso, deve-se ressaltar que os dispositivos de leiaute de porta hexagonal possuem ângulo $\alpha$ igual a $90^{\circ}$, enquanto os dispositivos de leiaute de porta octogonal possuem ângulo $\alpha$ igual a $90^{\circ}$ e fator de corte c igual a $50 \%$. O ângulo $\alpha$ é limitado a $90^{\circ}$ nesta tecnologia impedindo estudos com diferentes ângulos $\alpha$. Vale ressaltar que, outros estudos previamente desenvolvidos apontaram uma significativa tolerância à TID dos DnMs de $90^{\circ}$ [46].

Os leiautes dos nMOSFETs utilizados no desenvolvimento deste trabalho podem ser vistos na Figura 44. 
Figura 44 - Leiautes dos nMOSFETs utilizados no desenvolvimento deste trabalho: (a) leiaute do T5 e T9, (b) leiaute do T8, (c) leiaute do T37, (d) leiaute do T6 e (e) leiaute do T17

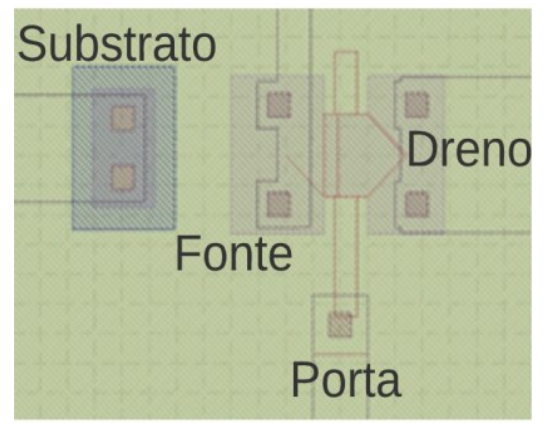

(a)

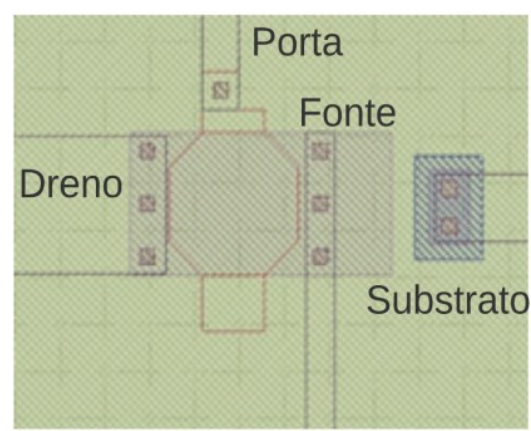

(b)

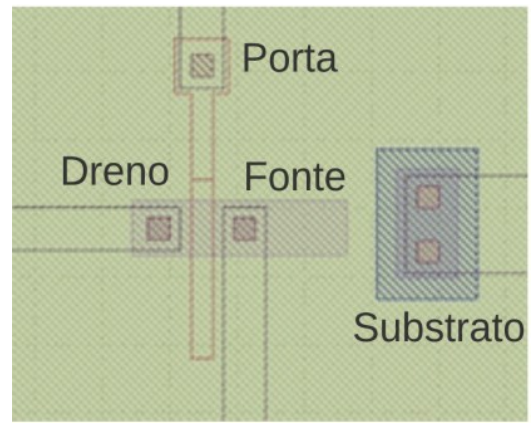

(d)

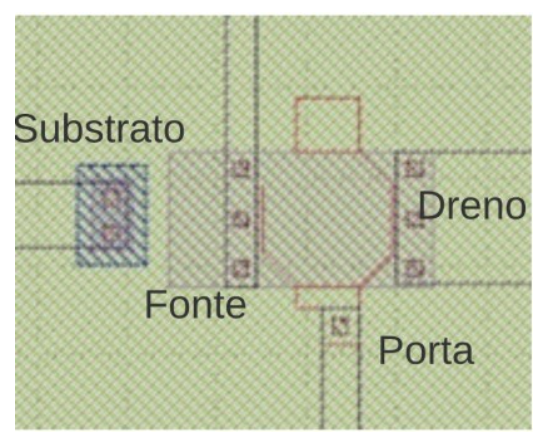

(c)

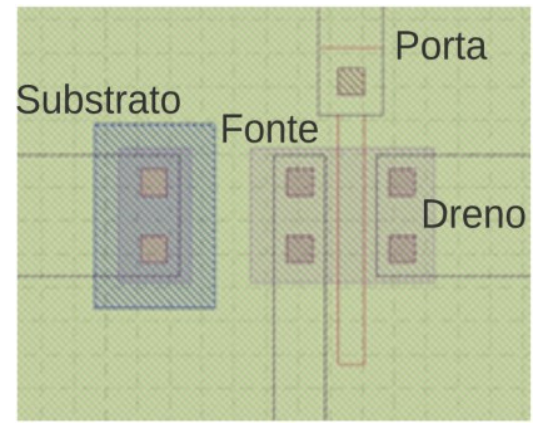

(e)

Fonte: Autor.

Além disso, embora as larguras dos canais dos OnMs e CnMs sejam diferentes entre si, os principais parâmetros elétricos estudados nesta tese, isto é, $\mathrm{V}_{\mathrm{TH}}$ e $\mathrm{SS}$ apresentam modelos matemáticos os quais não dependem da largura do canal do dispositivo [1]. Neste trabalho, a variabilidade é estudada em relação aos parâmetros $\mathrm{V}_{\mathrm{TH}}$ e SS para DnMs, OnMs e CnMs. Esses dois parâmetros matematicamente não dependem das dimensões do dispositivo e, portanto, a análise da $\mathrm{V}_{\mathrm{TH}}$ e SS pode ser realizada.

Ademais, a inclinação de sublimiar (SS) é considerada como uma característica do processo de fabricação de ICs CMOS que é capaz de medir a qualidade da interface 
entre o óxido de silício $\left(\mathrm{SiO}_{2}\right)$ e o filme de silício da região do canal do MOSFET [1], [48]. Assim, em relação ao mesmo processo de fabricação de CIs CMOS, é possível afirmar que esses dispositivos devem possuir as mesmas SSs, sendo que este parâmetro também independe das dimensões dos MOSFETs [1], [48].

É importante destacar que esses dispositivos com diferentes dimensões foram escolhidos propositalmente a fim de proporcionar uma situação de estudo de pior caso, isto é, permitindo aumentar ainda mais os efeitos aleatórios das variações do processo de fabricação dos CIs CMOS para o estudo do descasamento entre dispositivos.

Outra característica a ser destacada, refere-se ao fato de que as dimensões dos MOSFETs convencionais (áreas de porta: $0,064 \mu \mathrm{m}^{2}$ e $0,128 \mu \mathrm{m}^{2}$ ) são menores do que as dos MOSFETs de porta hexagonal (área de porta: $0,3 \mu \mathrm{m}^{2}$, pelo menos 2 vezes maior que a maior área de porta de um $\mathrm{CnM}$ ) e de porta octogonal (áreas de porta: 1,94 $\mu \mathrm{m}^{2}$ pelo menos 15 vezes maior que a maior área de porta de um $\mathrm{CnM}$ e $0,51 \mu \mathrm{m}^{2}$, quase 4 vezes maior que a maior área de porta de um $\mathrm{CnM}$ ) para realizar este estudo, pois é possível afirmar que erros aleatórios globais gerados durante o processo de fabricação dos chips, tendem a afetar ainda mais os dispositivos com dimensões maiores, pela própria característica dos erros aleatórios globais [99]. Assim, podemos considerar este trabalho como um estudo de pior caso para a variabilidade dos DnMs e OnMs [99].

Foram utilizados nesse estudo $11 \mathrm{CIs}$, onde 6 destes CIs foram encapsulados para execução de um estudo com os nMOSFETs polarizados enquanto estes estavam sob a influência das radiações ionizantes por raios-X. Deve-se ressaltar que o processo de encapsulamento foi realizado pelo Centro de Tecnologia da Informação Renato Archer (CTI), com apoio do projeto CITAR (Circuitos Integrados Tolerantes a Radiação - Projeto FINEP/CTI número 01.12.0224.00). A Figura 45 ilustra o esquema de ligações entre os dispositivos e os terminais do encapsulamento. 
Figura 45 - Esquema de ligações dos CIs no encapsulamento
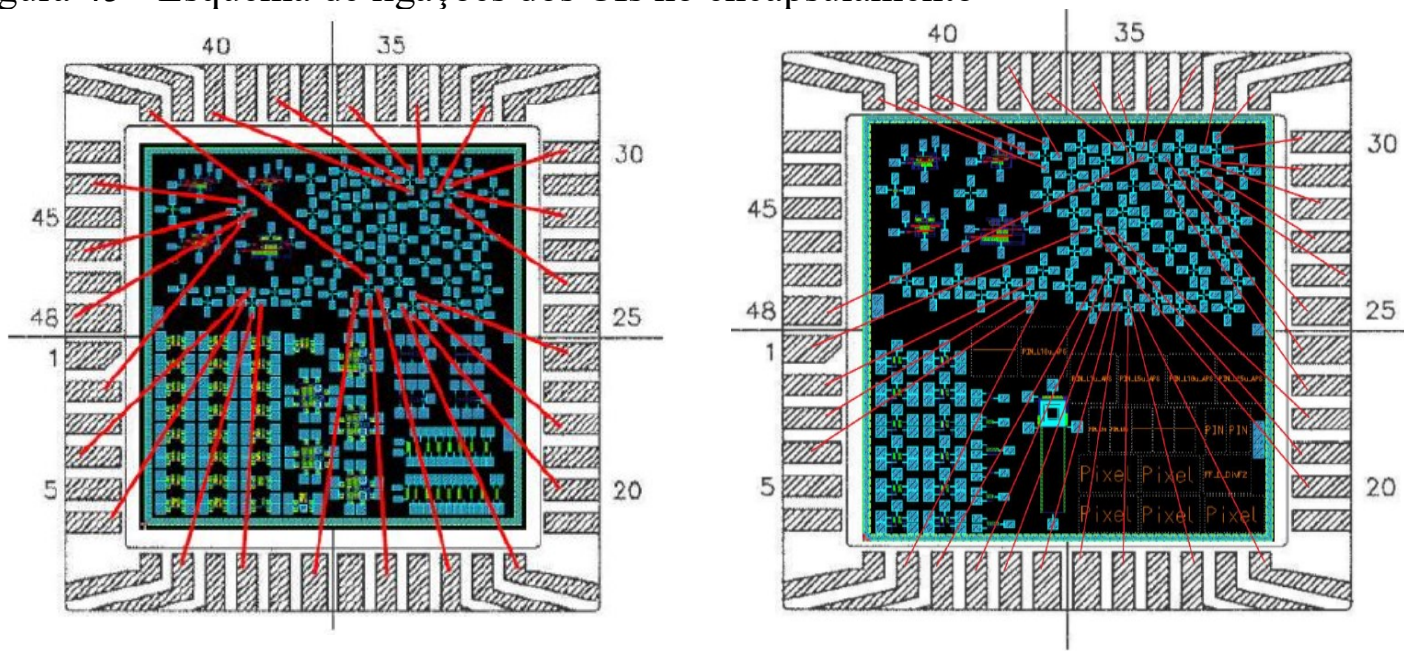

Fonte: Autor.

$\mathrm{Na}$ Figura 45, as ligações nos pads dos dispositivos são indicadas por meio de linhas vermelhas, sendo que há transistores nestes chips que foram utilizados em outros trabalhos. No encapsulamento há uma janela que pode ser aberta permitindo que o chip seja exposto diretamente às radiações ionizantes por raios-X. Deve-se ressaltar que esta janela sempre ficou fechada, para eliminar influência da luz ambiente, durante as caracterizações elétricas. Durante a aplicação da radiação ionizante por raios-X, esta janela sempre ficou aberta.

\subsection{EQUIPAMENTOS UTILIZADOS NO DESENVOLVIMENTO DO TRABALHO}

Todos os equipamentos utilizados para o desenvolvimento dos experimentos desta tese de doutorado se encontram nas dependências do Centro Universitário da FEI. Os principais equipamentos utilizados durante os procedimentos do estudo experimental serão apresentados nesta seção.

\subsubsection{Aparelho de caracterização Keithley 4200 - SCS}

O aparelho de caracterização Keithley 4200 é um analisador de parâmetros modular que é capaz de realizar a caracterização elétrica de materiais e dispositivos eletrônicos semicondutores. Este aparelho utiliza um sistema operacional integrado baseado no Windows. Além disso, verifica-se que o software do equipamento fornece ao 
usuário uma interface para configuração dos testes de caracterização elétrica a serem realizados para um determinado objetivo [100]. A Figura 46 é uma foto do equipamento Keithley 4200-SCS.

Figura 46 - Foto do sistema de caracterização elétrica de dispositivos semicondutores "Keithley 4200-SCS"

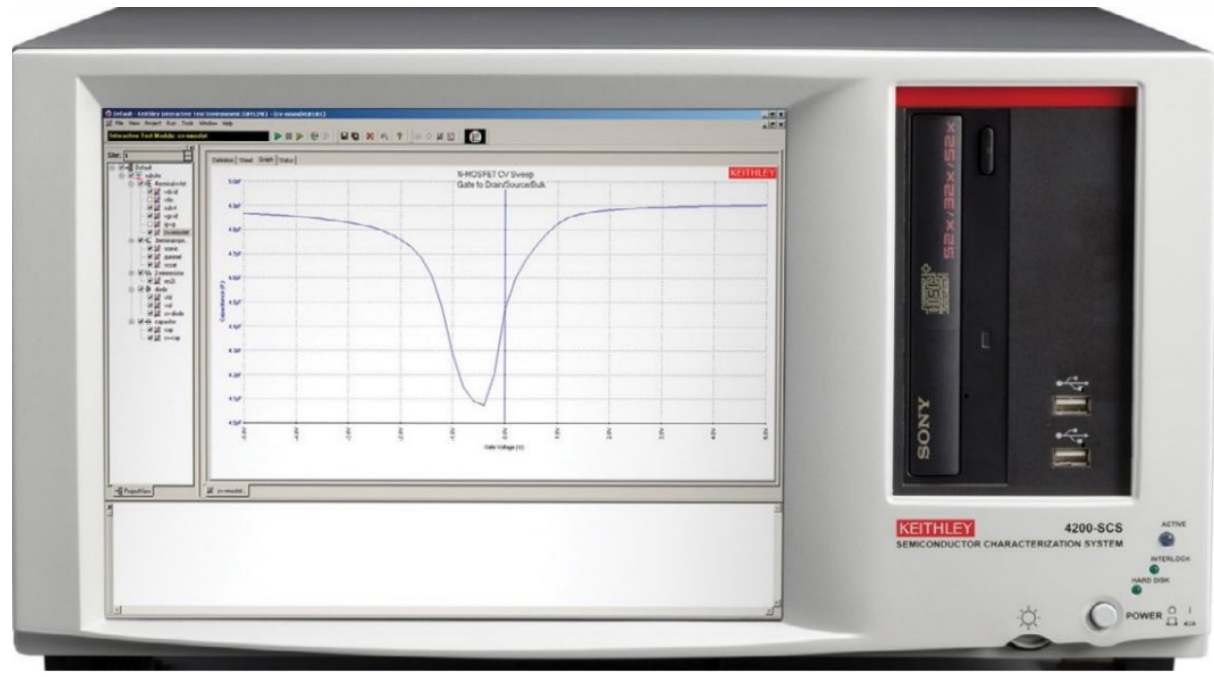

Fonte: Autor "adaptado de" [100].

Deve-se ressaltar que a resolução de medidas do Keithley 4200-SCS alcançada é de $0,2 \mu \mathrm{V}$ para tensões elétricas e de $100 \mathrm{fA}$ para correntes elétricas [100].

\subsubsection{Fonte de alimentação Keithley 2636B}

O aparelho eletrônico Keithley 2636B é um instrumento de caracterização com muitas tecnologias integradas em 2 canais, como fonte de alimentação de elevada precisão, fonte de corrente e gerador de pulso [101].

Pode-se observar que esse equipamento que é mais portátil em comparação com o modelo 4200-SCS descrito anteriormente, não tem um sistema operacional embarcado, sendo necessário, portanto, a instalação de seus softwares e drivers em um computador para sua adequada utilização [101]. A Figura 47 apresenta a foto do equipamento Keithley 2636B. 
Figura 47 - Foto da fonte de alimentação "Keithley 2636B"

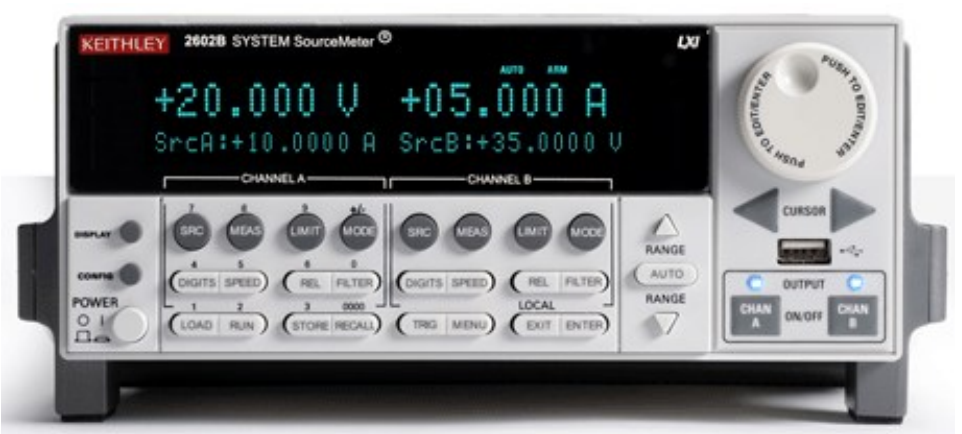

Fonte: Autor "adaptado de" [101].

Além disso, o instrumento de medidas Keithley 2636B tem resolução de medida de $0,1 \mathrm{fA}$ para correntes elétricas e $10 \mathrm{mV}$ para tensões elétricas [101].

\subsubsection{Difratômetro de raios-X Shimadzu XRD-6100}

Os ensaios de radiação de efeitos ionizantes de raios-X nos MOSFETs utilizados para o desenvolvimento desta tese foram realizados utilizando o difratômetro de raios-X Shimadzu XRD-6100, conforme ilustrado na Figura 48 [102].

Figura 48 - Foto do difratômetro de raios-X Shimadzu XRD-6100

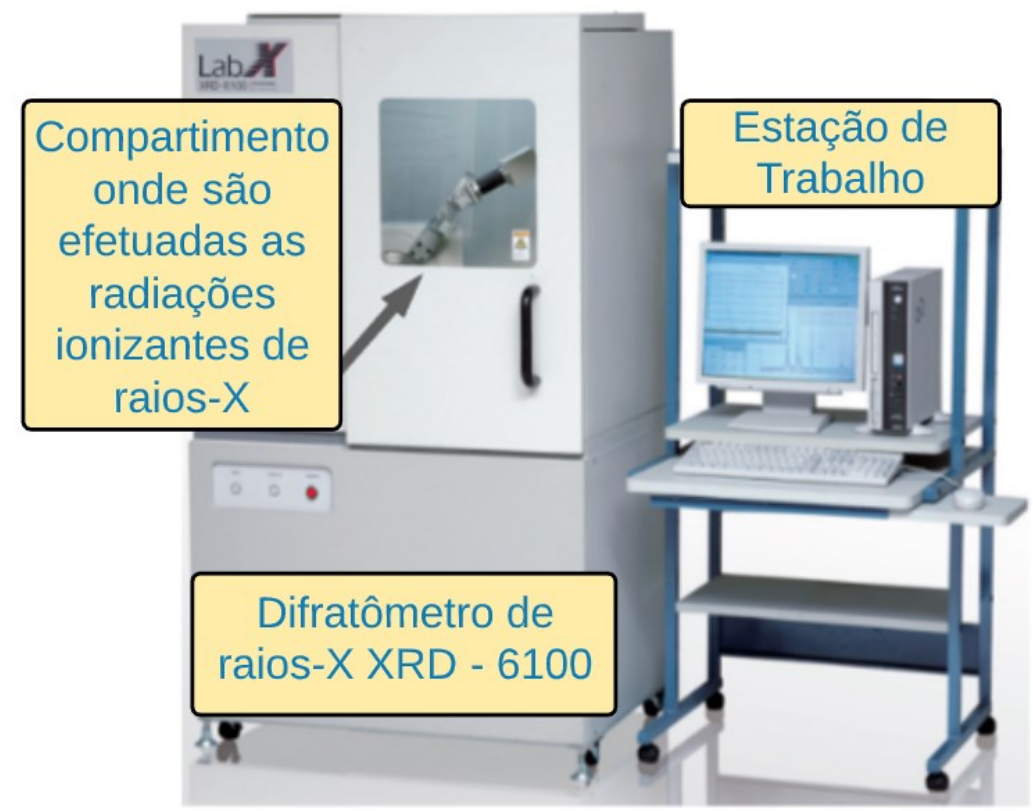

Fonte: Autor "adaptado de" [102]. 
O XRD-6100 é um equipamento que permite a realização de processos de irradiação ionizante de raios- $\mathrm{X}$, sendo que o seu gerador de raios-X apresenta uma tensão elétrica máxima de $60 \mathrm{kV}$ e uma corrente elétrica máxima de $80 \mathrm{~mA}$. A parametrização do difratômetro é realizada por meio de um computador, enquanto o chip a ser irradiado deve ser acondicionado dentro do compartimento.

\subsection{PROCEDIMENTOS EXPERIMENTAIS}

Para a caracterização elétrica e as posteriores radiações ionizantes por raios- $\mathrm{X}$ dos nMOSFETs de porta hexagonal, octogonal e retangular, foram seguidas etapas e metodologias.

As análises comparativas experimentais dos efeitos da TID nos nMOSFETs foram realizadas em quatro condições de polarização desses dispositivos, sendo elas:

a) não polarizado (Floating) durante o procedimento das radiações ionizantes por raios-X (nos T5, T9, T8, T37, T6 e T17);

b) polarizado no modo On (On-state) durante o procedimento de radiações ionizantes por raios-X (nos T8, T37, T6 e T17);

c) polarizado no modo $O f f($ Off-state) durante o procedimento de radiações ionizantes por raios-X (nos T5, T9, T8, T37, T6 e T17);

d) polarizado no modo Analog durante o procedimento de radiações ionizantes por raios-X (nos T5, T9, T8, T37, T6 e T17).

Em seções seguintes serão apresentadas as principais diferenças entre as formas de polarização dos nMOSFETs e como elas podem influenciar estes dispositivos durante a aplicação das radiações ionizantes de raios-X.

Estas medidas experimentais serviram de base para calcular o valor médio, desvio-padrão e variância de cada um dos parâmetros elétricos e figuras de mérito, antes e depois de aplicadas as doses das radiações ionizantes de raios-X. Vale ressaltar que os resultados experimentais obtidos dos nMOSFETs com geometria de porta retangular 
serviram como base de comparação para os demais transistores que foram avaliados neste trabalho.

Visando a caracterização elétrica dos nMOSFETs em condições de não termos a influência da TID (condição de "Pré-rad"), assim como em ambientes de radiações ionizantes de raios-X sem qualquer polarização nesses dispositivos, foram utilizados chips que não foram encapsulados. Para as demais polarizações aplicadas nestes dispositivos durante as radiações ionizantes por raios-X (e também na condição de "Prérad"), foram utilizados chips que foram encapsulados.

Após a obtenção das curvas características de todos os nMOSFETs, foi então realizado um procedimento de irradiação por raios-X em um chip para uma certa dose ionizante acumulada decidida previamente, baseando-se em referências bibliográficas (da ordem de Mrad para o estudo em Floating e da ordem de krad para os estudos em Onstate, Off-state e Analog) [46], [47]. Logo em seguida ao término do processo de irradiação, as curvas características dos nMOSFETs do chip irradiado foram novamente levantadas. Esse processo de se irradiar e caracterizar um mesmo chip seguiu até que um dos nMOSFETs parasse de funcionar como deveria.

Com estas curvas obtidas de forma experimental, foi possível realizar a comparação e desenvolver um estudo estatístico valendo-se dos principais parâmetros elétricos e figuras de mérito em condições de pré-radiação e sobre os efeitos da TID entre o nMOSFET Diamante, Octo e o seu convencional equivalente, considerando-se as mesmas condições de polarização.

\subsubsection{Caracterização elétrica dos dispositivos não encapsulados}

A caracterização elétrica dos dispositivos não encapsulados nas duas condições consideradas (pré-radiação e pós-radiação) foi realizada com o equipamento Keithley 4200-SCS e um microprovador Cascade Microtech, equipamentos que fazem parte do Laboratório de Microeletrônica do Centro Universitário FEI. Todos os nMOSFETs foram caracterizados em temperatura controlada de $20{ }^{\circ} \mathrm{C}$, sem polarização e numa cabine sem incidência de luz. A Figura 49 apresenta fotos do microprovador preparado para realizar as caracterizações elétricas dos dispositivos desse estudo. 
Figura 49 - Fotos do microprovador Cascade Microtech com uma placa de teste utilizada para a caracterização elétrica dos nMOSFETs: (a) Sistema completo e (b) ampliação do local onde a placa de teste é colocada para efetuar sua caracterização elétrica

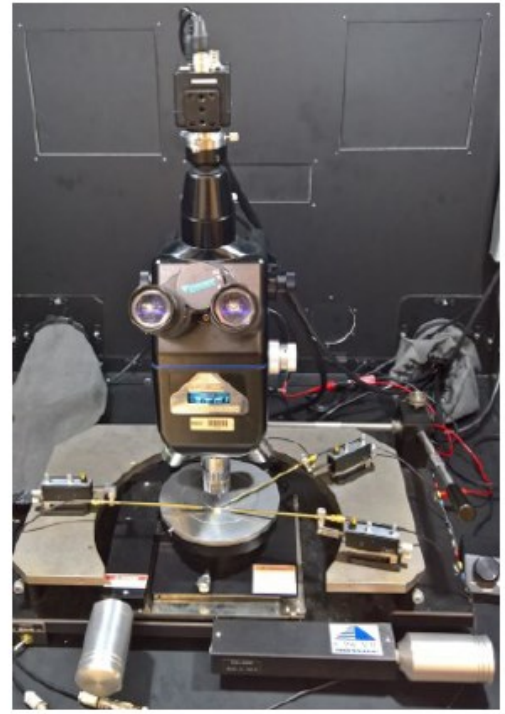

(a)

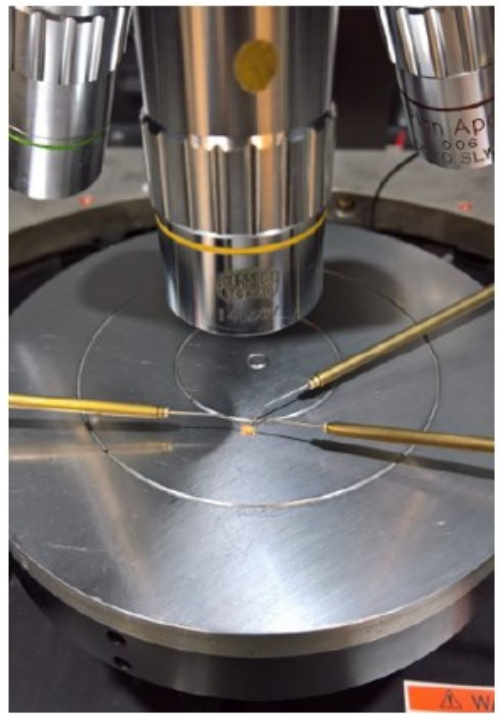

(b)

Fonte: Autor.

As caracterizações elétricas foram desenvolvidas pela obtenção de curvas características dos dispositivos, sendo elas:

- $\mathrm{I}_{\mathrm{DS}}$ em função de $\mathrm{V}_{\mathrm{GS}}$ para obtenção da $\mathrm{V}_{\mathrm{TH}}$, com $\mathrm{V}_{\mathrm{GS}}$ variando de $0 \mathrm{~V}$ a $1,2 \mathrm{~V}$ e $\mathrm{V}_{\mathrm{DS}}$ de $50 \mathrm{mV}$;

- $\mathrm{I}_{\mathrm{DS}}$ em função de $\mathrm{V}_{\mathrm{GS}}$ com $\mathrm{V}_{\mathrm{GS}}$ de $-0,5 \mathrm{~V}$ a $1,2 \mathrm{~V}$ e diferentes valores de $\mathrm{VDS}$;

- IDS em função de $\mathrm{V}_{D S}$ com $\mathrm{V}_{\mathrm{DS}}$ variando de $0 \mathrm{~V}$ a $1,2 \mathrm{~V}$ e diferentes valores de $V_{\mathrm{GS}}$.

\subsubsection{Caracterização elétrica dos dispositivos encapsulados}

Os dispositivos encapsulados foram caracterizados por meio do sistema Keithley 2636B e com auxílio de um aparelho de teste da Keithley (fixture modelo LR:8028). Com o Keithley LR:8028 é possível fixar o encapsulamento e realizar a conexão entre os pinos desejados com os cabos de testes que são ligados ao Keithley 2636B. A Figura 50 apresenta uma foto desse conjunto que foi utilizado para realizar a caracterização elétrica dos chips encapsulados. 
Figura 50 - Conjunto de equipamentos utilizados para a caracterização elétrica (Keithley 2636B e Keithley LR:8028) dos nMOSFETs estudados

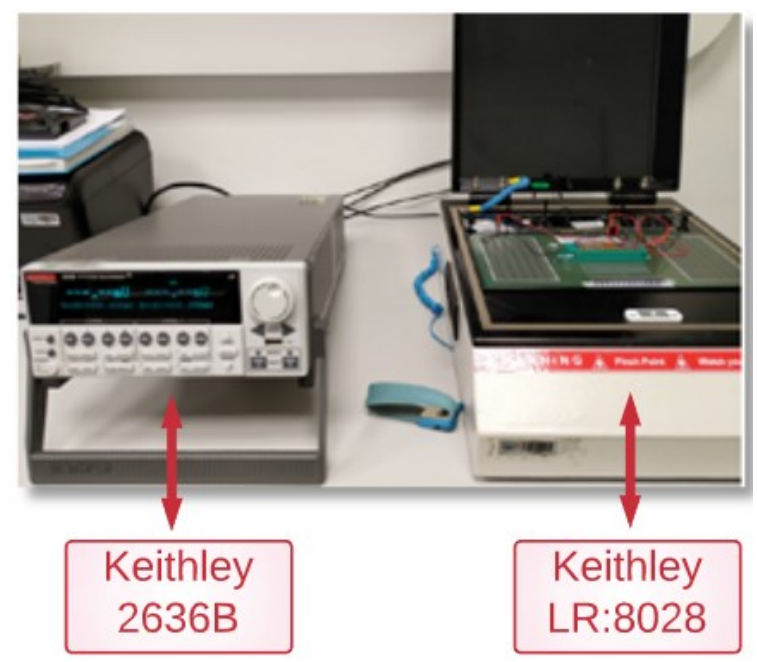

Fonte: Autor.

Deve-se ressaltar que as mesmas curvas que foram obtidas para o estudo dos MOSFETs não encapsulados, foram também obtidas para os nMOSFETs encapsulados.

Estes equipamentos citados se encontram disponíveis no Laboratório de Efeitos da Radiação Ionizante (LERI) do Centro Universitário da FEI.

\subsection{PROCESSO DE IRRADIAÇÃO POR RAIOS-X DOS DISPOSITIVOS}

O processo de irradiação por raios-X de todos os dispositivos, encapsulados ou não encapsulados, foi realizado por meio do difratômetro de raios-X Shimadzu XRD6100. As taxas de dose para aplicar as radiações ionizantes de raios-X foram definidas de forma experimental, considerando-se a distância entre o feixe e o sensor utilizado (câmara de ionização do tipo cilíndrica), a corrente elétrica do gerador de raios-X e a tensão do gerador de raios-X. Com tais valores de taxas de dose, foram definidos os tempos de exposição às radiações por raios-X, a fim de alcançar a TID desejada em cada procedimento. A título de exemplo, se a taxa de dose é de $250 \mathrm{krad} / \mathrm{h}$, o dispositivo deve ser exposto por $2 \mathrm{~h}$ para que ele alcance uma TID de $500 \mathrm{krad}$, conforme pode ser visualizado na Tabela 3.

Assim, pode-se afirmar que a única diferença no processo de irradiação por raios$\mathrm{X}$ dos chips encapsulados para os não encapsulados, é que para realizar o processo de polarização para os chips encapsulados, é necessária a ligação de uma fonte de tensão externa nos modos de polarização desejados em cada procedimento (On-state, Off-state 
e Analog). Então, cabe ressaltar que os dies não encapsulados podem ser comparáveis aos CIs no estado Floating.

A Tabela 3 ilustra as correntes elétricas utilizadas no gerador de raios-X, as tensões utilizadas no gerador de raios-X, as distâncias entre a saída do feixe de raios-X e os chips, a taxa de dose e os tempos médios entre o fim do procedimento de irradiação e o início das caracterizações elétricas dos nMOSFETs estudados, para os dispositivos desencapsulados e encapsulados.

Tabela 3 - Condições adotadas para efetuar a configuração do difratômetro para a aplicação das radiações ionizantes de raios-X nas amostras

\begin{tabular}{|c|c|c|}
\hline $\begin{array}{c}\text { Corrente elétrica do gerador de raios X do } \\
\text { difratômetro }\end{array}$ & $\begin{array}{c}\text { Dispositivos } \\
\text { Desencapsulados }\end{array}$ & $\begin{array}{c}\text { Dispositivos } \\
\text { Encapsulados }\end{array}$ \\
\hline $\begin{array}{c}\text { Tensão do gerador de raios X do } \\
\text { diffratômetro }\end{array}$ & $40 \mathrm{~mA}$ & $20 \mathrm{kV}$ \\
\hline raistância do chip para a saída do feixe de & $2,5 \mathrm{~cm}$ & $26 \mathrm{~cm}$ \\
\hline $\begin{array}{c}\text { Taxa de dose escolhida } \\
\text { Tempo médio entre o fím da radiação e } \mathbf{0}\end{array}$ & Cerca de 14 & $\begin{array}{c}\text { Cerca de } 1 \\
\text { minuto }\end{array}$ \\
\hline início da caracterização elétrica & minutos & $70,22 \mathrm{krad} / \mathrm{h}$ \\
\hline
\end{tabular}

A diferença medida no tempo médio entre o fim da irradiação de raios-X e o início das caracterizações elétricas para os dispositivos encapsulados e os não encapsulados se dá pelo fato de que era necessário levar as amostras não encapsuladas de um laboratório para outro (do laboratório de Efeitos da Radiação Ionizante até o Laboratório de Microeletrônica) ao fim dos procedimentos de irradiação ionizantes de raios-X. Desta forma, é importante ressaltar que preocupou-se em não promover um annealing nas amostras radiadas entre as radiações ionizantes de raios-X e a realização das caracterizações elétricas. Ademais, pode-se afirmar que somente as armadilhas de meia vida curta é que decaem neste intervalo de tempo apresentado na Tabela 3 [5], [6].

A Figura 51 ilustra os diferentes modos de polarização dos nMOSFETs a serem estudados quando eles são submetidos às radiações ionizantes de raios-X. 
Figura 51 - Representação elétrica dos modos de polarização dos nMOSFETs a serem estudados durante a realização do processo de radiação de raios-X. (a) On-state, (b) Offstate, (c) Analog

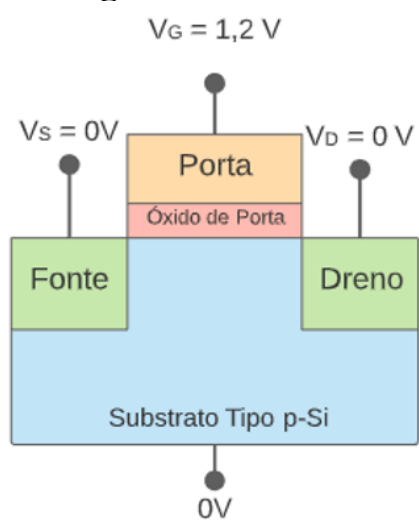

(a)

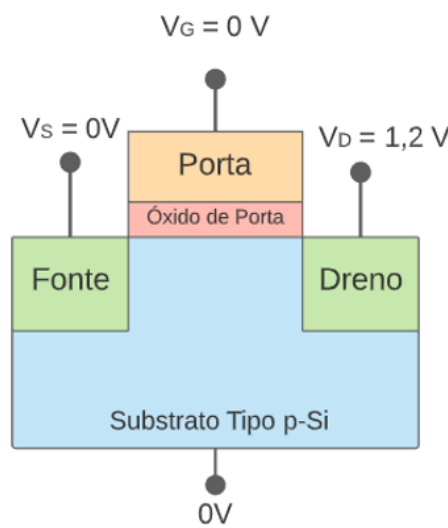

(b)

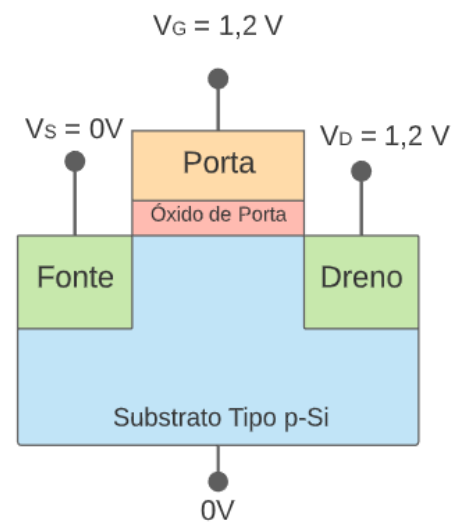

(c)

Fonte: Autor.

Partindo do estudo e análise de normas e procedimentos de teste do padrão militar dos Estados Unidos da América (Military Test Guideline, MIL-STD-883L), foram definidos esses três modos de polarização dos nMOSFETs durante o procedimento da radiação ionizantes de raios-X, que visou adaptar a norma MIL-STD-883L para o desenvolvimento dos testes realizados em laboratório [103]. Em conjunto com os testes sem polarização (Floating), esses três modos (On-state na Figura 51.a, Off-state na Figura 51.b e Analog na Figura 51.c), permitem qualificar os nMOSFETs para aplicações de CIs CMOS operando em ambientes sujeitos às radiações ionizantes.

A condição passiva (Floating), é aquela quando o nMOSFET está com todos os seus terminais desconectados (ou flutuando), enquanto exposto às radiações ionizantes. Esse procedimento não tem a influência dos campos elétricos na região de canal do MOSFET gerados pelos potenciais elétricos aplicados em seus terminais. Deve-se ressaltar também que os pares elétrons-lacunas que escapam do processo de 
recombinação inicial dividido pelo número total dos pares elétrons-lacunas gerados referem-se ao rendimento de carga fracionada ou a fração dos portadores de cargas gerados por ionização, que não se recombinam inicialmente. Esses sofrem a influência do campo elétrico resultante no óxido [6]. Os estudos dos efeitos da TID quando o MOSFET não está polarizado durante a radiação ionizante são importantes para analisar o comportamento de dispositivos de reposição em missões espaciais. Assim, pode-se afirmar que dispositivos de reposição (ou de redundância) permanecem desligados até que, numa eventual falha de um outro dispositivo, eles possam substituir o dispositivo com mau funcionamento [104].

A condição de estado ligado (On-state), é dada pela aplicação de $\mathrm{V}_{\mathrm{DD}}(1,2 \mathrm{~V})$ ao terminal da porta e $0 \mathrm{~V}$ nos demais terminais, enquanto o nMOSFET é exposto às radiações ionizantes. No modo de polarização On-state há a presença de um campo elétrico vertical na região de canal do nMOSFET que é capaz de aumentar os efeitos das radiações ionizantes de raios- $\mathrm{X}$ no dispositivo em estudo em comparação aos efeitos vistos na condição passiva (Floating). Nesse modo de polarização, o nMOSFET opera como "chave fechada", sendo uma importante condição de operação digital estudada [105], [106].

A condição de estado desligado (Off-state), é a configuração do MOSFET exposto às radiações ionizantes de raios-X quando há a aplicação de $\mathrm{V}_{\mathrm{DD}}(1,2 \mathrm{~V})$ ao terminal de dreno e $0 \mathrm{~V}$ aos demais terminais. Essa configuração gera um campo elétrico longitudinal na região de canal pela polarização entre dreno e fonte, e é capaz de potencializar os efeitos da TID nos dispositivos. Nesse modo de polarização o MOSFET opera como "chave aberta", sendo outra importante condição de operação digital estudada [105], [106].

Por fim, a quarta condição de polarização dos nMOSFETs é denominada como a condição de estado analógico (Analog), quando $\mathrm{V}_{\mathrm{DD}}(1,2 \mathrm{~V})$ é aplicado aos terminais de porta e de dreno do MOSFET, e fonte e substrato são polarizados com $0 \mathrm{~V}$. Por consequência dessa polarização, há a influência dos campos elétricos vertical e longitudinal ao mesmo tempo na região de canal do MOSFET, potencializando os efeitos das radiações ionizantes de raios-X no dispositivo. Nesta condição de estado analógico, o campo elétrico vertical é maior na região de canal, próximo ao terminal de dreno, e menor quanto mais se aproxima do terminal de fonte. Nesse modo de polarização, o nMOSFET opera na região de saturação, como normalmente é utilizado em aplicações de CIs CMOS analógicas [105], [106]. 
Neste capítulo foram apresentados todos os procedimentos experimentais empregados tanto para as caracterizações elétricas dos MOSFETs utilizados no desenvolvimento deste trabalho, assim como para aplicação das doses de radiações ionizantes de raios- $\mathrm{X}$.

Ademais, também foram apresentados como os nMOSFETs foram manufaturados e como os equipamentos de raios-X e de medidas foram utilizados para a condução de todos os experimentos realizados para o desenvolvimento desta tese de doutorado. 


\section{ANÁLISE DE RESULTADOS}

Nesta seção são apresentados os resultados experimentais realizados com o objetivo de se estudar e quantificar estatisticamente os efeitos das radiações ionizantes de raios-X nos principais parâmetros dos nMOSFETs com geometrias de porta hexagonal, octogonal e retangular nas 4 diferentes condições de polarização (Floating, On-state, Offstate e Analog).

Deve-se ressaltar que todos os experimentos realizados foram obtidos em ambientes controlados, visando a reduzir ao máximo as possíveis interferências proporcionadas pelas variações de temperaturas no comportamento elétrico dos chips utilizados.

\subsection{ANÁLISE COMPARATIVA EXPERIMENTAL ESTATÍSTICA DOS} EFEITOS DA TID ENTRE NMOSFETS DE PORTA HEXAGONAL, OCTOGONAL E RETANGULAR, SEM QUE OS DISPOSITIVOS ESTIVESSEM POLARIZADOS DURANTE OS PROCEDIMENTOS DAS RADIAÇÕES IONIZANTES DE RAIOS-X

Para análise dos efeitos da TID nos MOSFETs de porta hexagonal $(\mathrm{DnM})$, octogonal $(\mathrm{OnM})$ e retangular $(\mathrm{CnM})$ quando submetidos às radiações ionizantes por raios-X na condição sem polarização elétrica durante $o$ procedimento das radiações ionizantes de raios-X (Floating), foram utilizados 28 dispositivos em 5 chips diferentes. A Figura 52 ilustra a quantidade de amostras utilizadas para desenvolver este estudo. 
Figura 52 - Quantidade de nMOSFETs de porta hexagonal, octogonal e retangular utilizados para o desenvolvimento do estudo dos efeitos da TID, na condição sem polarização elétrica durante o procedimento das radiações ionizantes de raios-X

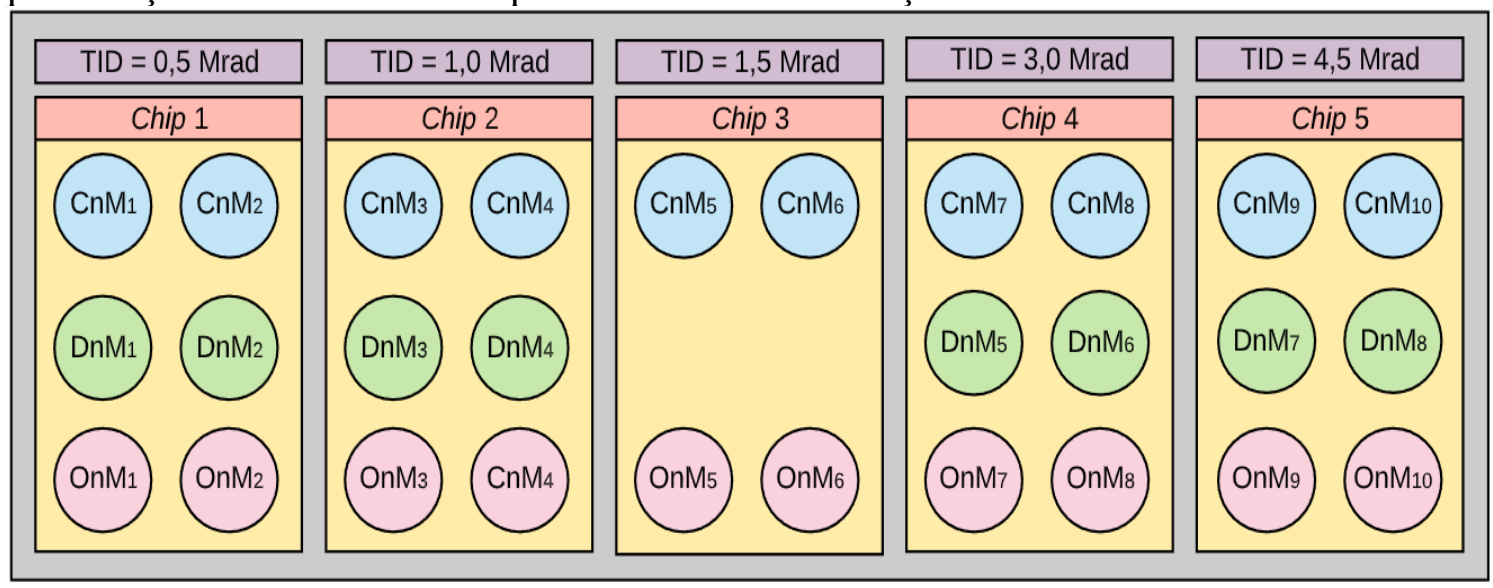

Fonte: Autor.

De acordo com a Fig. 52, 2 DnMs, 2 OnMs e 2 CnMs foram investigados para cada chip $\left(\right.$ Chip $_{\mathrm{i}}=1, \ldots, 5$; o índice “" é utilizado para determinar o número do chip). Portanto, o estudo foi realizado com uma quantidade total de $28 \mathrm{nMOSFETs}\left(\mathrm{DnM}_{\mathrm{j}}={ }_{1}\right.$, $\ldots, 8, \mathrm{OnM}_{\mathrm{j}}=1, \ldots, 10 \mathrm{e} \mathrm{CnM}_{\mathrm{j}}=1, \ldots, 10$; o índice “ $\mathrm{j}$ ” é utilizado para determinar o número do nMOSFET). Deve-se ressaltar que não foram utilizados 2 DnMs no chip 3, pois estes não estavam funcionando apropriadamente desde a condição de pré-radiação. Desta forma optou-se por não utilizar estes dispositivos no desenvolvimento do estudo.

Além disso, pode-se observar que cada chip foi caracterizado na condição de préradiação e exposto a uma dose única, isto é, as doses de radiação ionizantes por raios-X foram divididas em três doses de 0,5 Mrad e duas de 1,5 Mrad. Portanto, pode-se afirmar que o chip 1 recebeu uma dose de 0,5 Mrad, o chip 2 recebeu uma dose de 1,0 Mrad, o chip 3 recebeu uma dose de 1,5 Mrad, o chip 4 recebeu uma dose de 3,0 Mrad e o chip 5 recebeu uma dose de 4,5 Mrad.

Com o principal objetivo de se levar em consideração todas as possibilidades potenciais de variações aleatórias do processo de fabricação e também do procedimento utilizado para realizar as radiações ionizantes de raios-X (erros locais e erros globais), optou-se por utilizar 5 CIs diferentes (cada um contendo 2 DnMs, 2 OnMs e 2 CnMs).

A Figura 53 apresenta o procedimento para a realização do estudo da variabilidade que mede o descasamento (por meio da utilização da figura de mérito estatística denominada de coeficiente de variação) entre os parâmetros elétricos extraídos dos nMOSFETs dos tipos Diamante, Octogonal e dos convencionais equivalentes. Deve-se 
ressaltar que as caracterizações elétricas dos parâmetros foram efetuadas após a aplicação de cada dose.

Figura 53 - Ilustração do procedimento para a realização do estudo estatístico da variabilidade que mede o descasamento entre os parâmetros elétricos extraídos dos nMOSFETs dos tipos Diamante, Octogonal e dos convencionais equivalentes

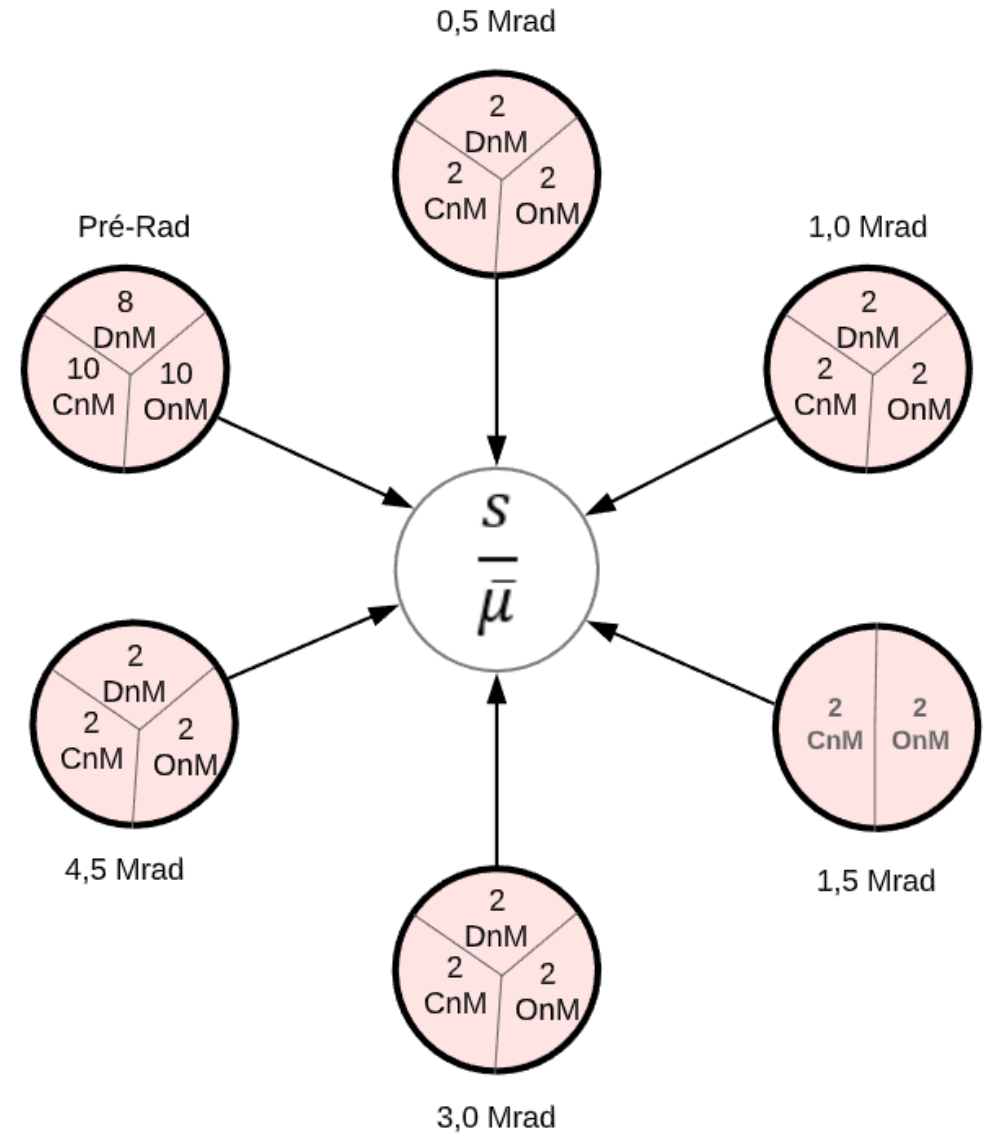

Fonte: Autor.

Na Figura 53, "s" representa os desvios-padrão dos parâmetros elétricos que são extraídos das amostras dos nMOSFETs dos tipos Diamante, Octogonal e dos convencionais equivalentes e $\bar{\mu}$ representa as médias dos parâmetros elétricos que são extraídos das amostras desses dispositivos.

Ressalta-se que o desenvolvimento do estudo dos DnMs, OnMs e CnMs quando submetidos às radiações ionizantes por raios-X na condição sem polarização elétrica durante o procedimento das radiações ionizantes de raios- $\mathrm{X}$ trata de um dos possíveis estudos que podem ser realizados para analisar o comportamento de dispositivos eletrônicos ou peças de reposição (dispositivos de substituição ou dispositivos de redundância) sob os efeitos da TID. Normalmente, esses dispositivos não são polarizados 
durante as missões espaciais e são usados apenas se algum equipamento apresentar algum problema de funcionamento [104].

Inicialmente iremos efetuar a análise do coeficiente de variação em função das TIDs estudadas neste trabalho dos parâmetros $\mathrm{V}_{\mathrm{THS}}$ e SSs extraídas experimentalmente dos DnMs, OnMs e CnMs, para posteriormente apresentarmos um gráfico radar que irá ilustrar o coeficiente de variação dos parâmetros $\mathrm{I}_{\mathrm{DSsat}} /(\mathrm{W} / \mathrm{L}), \operatorname{gm}_{\mathrm{MAX}} /(\mathrm{W} / \mathrm{L})$, $\operatorname{gmmaX}_{\mathrm{MAS}} / \mathrm{I}_{\mathrm{DSat}}, \mathrm{R}_{\mathrm{DSon}} /(\mathrm{L} / \mathrm{W}), \mathrm{g}_{\mathrm{D}} /(\mathrm{W} / \mathrm{L}), \mathrm{V}_{\mathrm{EA}} / \mathrm{L}, \mathrm{f}_{\mathrm{T}} /(\mathrm{W} / \mathrm{L}), \mathrm{Av}_{\mathrm{v}}, \mathrm{I}_{\mathrm{ON}} /(\mathrm{W} / \mathrm{L}), \mathrm{I}_{\mathrm{OFF}} /(\mathrm{W} / \mathrm{L})$, IoN/IOFF e I IEAK/(W/L) extraídos experimentalmente dos DnMs, OnMs e CnMs, em função das TIDs estudadas neste trabalho.

\subsubsection{Análise do Coeficiente de Variação da Tensão de Limiar ( $\left.V_{T H}\right)$ em Função das TIDs Estudadas}

Para extrair as $\mathrm{V}_{\mathrm{TH}} \mathrm{S}$ dos dispositivos DnMs, OnMs e CnMs utilizou-se a segunda derivada da curva $\mathrm{I}_{\mathrm{DS}}$ em função de $\mathrm{V}_{\mathrm{GS}}$, considerando-se $\mathrm{V}_{\mathrm{DS}}$ igual a $50 \mathrm{mV}$.

A Figura 54 ilustra o coeficiente de variação pré e pós-irradiações das $\mathrm{V}_{\mathrm{TH}} \mathrm{S}$ extraídas experimentalmente dos DnMs, OnMs e CnMs, calculado pela razão entre o desvio-padrão e o valor médio, em função da TID. O coeficiente de variação das $\mathrm{V}_{\mathrm{THS}}$ na condição de dose zero leva em consideração todos os 28 dispositivos $\left(\operatorname{DnM}_{\mathrm{j}}={ }_{1}, \ldots, 8\right.$, $\left.\mathrm{OnM}_{\mathrm{j}}={ }_{1}, \ldots, 10 \mathrm{e} \mathrm{CnM}_{\mathrm{j}}={ }_{1}, \ldots, 10\right)$, enquanto nas condições de pós-irradiação foram utilizados apenas 2 DnMs, 2 OnMs e 2 CnMs para cada TID aplicada (Chip $1 /$ TID = 0,5 Mrad: $\operatorname{DnM}_{\mathrm{j}}={ }_{1}, 2, \mathrm{OnM}_{\mathrm{j}}={ }_{1,}{ }_{2}$ e $\mathrm{CnM}_{\mathrm{j}}={ }_{1}, 2 ;$ Chip $2 / \mathrm{TID}=1,0 \mathrm{Mrad}: \mathrm{DnM}_{\mathrm{j}}={ }_{3},{ }_{4}, \mathrm{OnM}_{\mathrm{j}}$ $={ }_{3,4}$ e $\mathrm{CnM}_{\mathrm{j}}={ }_{3}, 4$; Chip $3 / \mathrm{TID}=1,5 \mathrm{Mrad}_{\mathrm{O}} \mathrm{OnM}_{\mathrm{j}}=5,6 \mathrm{e} \mathrm{CnMj}=5,6$; Chip 4 / TID =

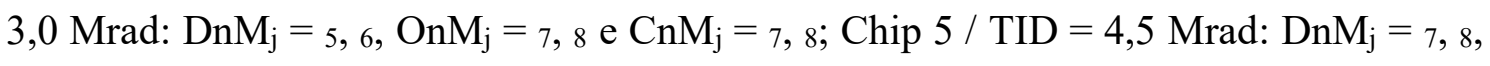
$\mathrm{OnM}_{\mathrm{j}}=9,10$ e $\mathrm{CnM}_{\mathrm{j}}=9,10$ ). 
Figura 54 - Gráfico que relaciona o coeficiente de variação na condição de pré e pósirradiação das $\mathrm{V}_{\mathrm{TH}} \mathrm{S}$ extraídas experimentalmente dos DnMs, OnMs e CnMs em função da TID, para $\mathrm{V}_{\mathrm{DS}}$ igual a $50 \mathrm{mV}$

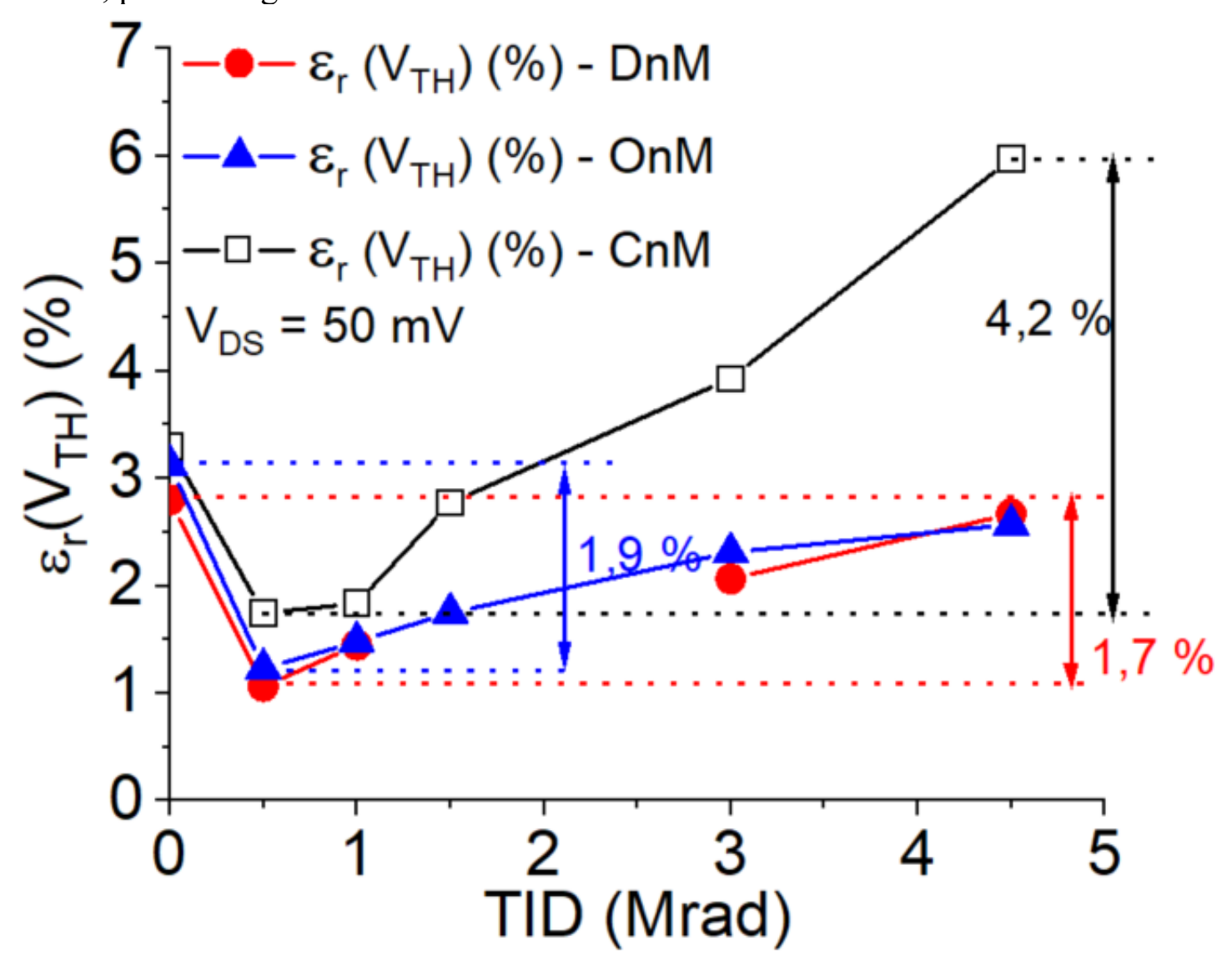

Fonte: Autor

Em relação à Figura 54, para a condição de pré-irradiação (TID igual a 0 rad), observa-se que os coeficientes de variação da tensão limiar $\left(\mathrm{V}_{\mathrm{TH}}\right)$ para 8 DnMs, 10 OnMs e $10 \mathrm{CnMs}$ são praticamente iguais (diferença percentual de 0,5\%). Isso ocorre porque a $\mathrm{V}_{\mathrm{TH}}$ dos DnMs é aproximadamente igual a $340 \mathrm{mV}$, a $\mathrm{V}_{\mathrm{TH}}$ dos OnMs é aproximadamente igual a $310 \mathrm{mV}$ e a $\mathrm{V}_{\mathrm{TH}}$ do CnMs é aproximadamente igual a $410 \mathrm{mV}$ e os desvios-padrão dessas amostras são praticamente os mesmos $(9,5 \mathrm{mV}$ para os DnMs, 9,6 mV para os OnMs e 13,6 mV para os $\mathrm{CnMs}$ ). Isso é esperado, porque esses dispositivos são implementados na mesma tecnologia de CMOS CIs.

No entanto, à medida que a TID aumenta, aumentam as diferenças percentuais dos coeficientes de variação (descasamento de dispositivos) dos dispositivos DnMs, OnMs e CnMs. Verifica-se que para a primeira TID de 0,5 Mrad, os coeficientes de variação dos três dispositivos diminuem. Uma possível justificativa para este comportamento está no fato de que para a análise dos coeficientes de variação calculados para as TIDs diferentes da condição de pré-radiação, existem somente 2 amostras para a 
determinação dos desvios-padrão e valores médios das $\mathrm{V}_{\mathrm{THS}} \mathrm{d}$ dos DnMs, OnMs e CnMs, fazendo com que exista uma redução dos desvios-padrão e, por consequência, do valor do coeficiente de variação. Ademais, uma outra possível justificativa para este comportamento se encontra no fato de que para taxas menores de TIDs, há um balanceamento de cargas no óxido e na interface ocorrendo de forma concomitante, portanto, para a TID de 0,5 Mrad é possível observar que há um deslocamento dos valores médios das $\mathrm{V}_{\text {THS }}$ para a direita, mostrando que há mais cargas positivas na interface $\mathrm{SiO}_{2}$ / Silício $(\mathrm{Si})$ do que no óxido de porta $\left(\mathrm{SiO}_{2}\right)$, devido à radiação ionizante de raios-X nos MOSFETs.

Além disso, a partir de 0,5 Mrad, verifica-se que os coeficientes de variação das $\mathrm{V}_{\mathrm{THS}}$ dos DnMs e OnMs são mantidos praticamente constantes, devido fundamentalmente ao DEPAMBBRE que suprimem os MOSFETs parasitários nas regiões de bico de pássaro (Bird's Beak Region, BBRs), enquanto o coeficiente de variação dos CnMs aumenta ( $\mathrm{V}_{\mathrm{TH}}$ deslocando para a esquerda, mostrando que há mais cargas positivas no óxido de porta $\left(\mathrm{SiO}_{2}\right)$ do que na interface $\mathrm{SiO}_{2} /$ Silício $\left.(\mathrm{Si})\right)$ devido à radiação ionizante de raios-X nos MOSFETs parasitas localizados nas BBRs dos CnMs, conforme a TID aumenta. Assim, os DnMs e OnMs apresentam uma tolerância à TID de raios-X maior a partir de 1 Mrad do que as encontradas nas amostras de CnMs (OnMs: 1,75 \% e CnMs: 3,8 \% para uma TID de 1,5 Mrad; DnMs: 2,0 \%, OnMs: 2,3 \% e CnMs: 4,0 \% para uma TID de 3 Mrad; DnMs: 2,7 \%, OnMs: 2,6 \% e CnMs: 6,0 \% para uma TID de 4,5 Mrad).

Desta maneira, a diferença percentual máxima entre o coeficiente de variação das $\mathrm{V}_{\mathrm{THS}}$ dos DnMs é de $1,7 \%$, dos OnMs é de $1,9 \%$ enquanto dos CnMs é de 4,2\%. Isso pode ser justificado porque o desvio-padrão das $\mathrm{V}_{\mathrm{THS}}$ referentes aos DnMs é de 3,5 mV para uma TID de 0,5 Mrad e o valor médio das $\mathrm{V}_{\mathrm{THS}}$ referentes aos DnMs é igual a 0,332 $\mathrm{V}$, resultando em um coeficiente de variação de 1,06 \%. Para a condição de pré-radiação, o desvio-padrão das $\mathrm{V}_{\mathrm{THS}}$ referentes aos DnMs é de 9,5 $\mathrm{mV}$ e o valor médio das $\mathrm{V}_{\mathrm{THS}}$ referentes aos DnMs é igual a $0,339 \mathrm{~V}$, resultando em um coeficiente de variação de 2,8 \%. Portanto, a diferença entre esses dois coeficientes de variação resulta em aproximadamente $1,7 \%$.

Ademais, o desvio-padrão das $\mathrm{V}_{\mathrm{THS}}$ referentes aos OnMs é de 3,5 $\mathrm{mV}$ para uma TID de 0,5 Mrad e o valor médio das $\mathrm{V}_{\mathrm{THS}}$ referentes aos OnMs é igual a 0,287 V, resultando em um coeficiente de variação de 1,23\%. Para a condição de pré-radiação, o desvio-padrão das $\mathrm{V}_{\mathrm{TH}} \mathrm{S}$ referentes aos OnMs é de 9,6 mV e o valor médio das $\mathrm{V}_{\mathrm{THS}}$ 
referentes aos OnMs é igual a 0,309 V, resultando em um coeficiente de variação de $3,13 \%$. Portanto, a diferença entre esses dois coeficientes de variação resulta em aproximadamente $1,9 \%$.

Com base na Figura 54, em relação ao estudo estatístico que utiliza a figura de mérito denominada de coeficiente de variação do parâmetro $\mathrm{V}_{\mathrm{TH}}$, podemos concluir que eles apresentam praticamente a mesma tolerância à radiação ionizante de raios-X (diferença de 2,5\%, levando-se em consideração a diferença percentual, máxima e mínima, dos coeficientes de variação dos DnMs, que é igual a 1,7 \% e a diferença percentual, também máxima e mínima, dos coeficientes de variação dos CnMs, que é igual a $4,2 \%)$.

Uma possível maneira para poder afirmar se há diferença estatística entre as porcentagens apresentadas, é por meio da aplicação dos testes estatísticos ANOVA e Tukey. Assim, mesmo que percentualmente os valores sejam próximos, os resultados destes testes estatísticos permitiriam confirmar, em função de um nível de confiança (nível de acerto) utilizado para a aplicação destes testes estatísticos, se estes valores são estatisticamente diferentes ou equivalentes entre si.

\subsubsection{Análise do Coeficiente de Variação da Inclinação de Sublimiar (SS) em Função das TIDs Estudadas}

A Figura 55 ilustra o coeficiente de variação pré e pós-irradiação das SSs extraídas experimentalmente dos DnMs, OnMs e CnMs, calculado pela razão entre o desvio-padrão e o valor médio, em função da TID. O coeficiente de variação das SSs na condição de dose zero leva em consideração todos os 28 dispositivos $\left(\mathrm{DnM}_{\mathrm{j}}={ }_{1}, \ldots, 8, \mathrm{OnM}_{\mathrm{j}}={ }_{1}, \ldots, 10\right.$ e $\left.\mathrm{CnM}_{\mathrm{j}}={ }_{1}, \ldots, 10\right)$, enquanto nas condições de pós-irradiação usamos apenas 2 DnMs, 2 OnMs e 2 CnMs para cada TID aplicada (Chip 1: $\mathrm{DnM}_{\mathrm{j}}={ }_{1,2}, \mathrm{OnM}_{\mathrm{j}}={ }_{1,2}$ e $\mathrm{CnM}_{\mathrm{j}}={ }_{1}, 2$; Chip 2: $\mathrm{DnM}_{\mathrm{j}}={ }_{3},{ }_{4}, \mathrm{OnM}_{\mathrm{j}}={ }_{3},{ }_{4}$ e $\mathrm{CnM}_{\mathrm{j}}={ }_{3}, 4$; Chip 3: $\mathrm{OnM}_{\mathrm{j}}={ }_{5,}, \mathrm{e} \mathrm{CnM}_{\mathrm{j}}={ }_{5}, 6$; Chip 4: $\mathrm{DnM}_{\mathrm{j}}=$ 5, 6, OnM $={ }_{7,8}$ e $\mathrm{CnM}_{\mathrm{j}}=$ 7, 8; Chip 5: $\mathrm{DnM}_{\mathrm{j}}={ }_{7,8}, \mathrm{OnM}_{\mathrm{j}}=9,10$ e $\mathrm{CnM}_{\mathrm{j}}=9,{ }_{10}$ ). 
Figura 55 - Gráfico que relaciona o coeficiente de variação na condição de pré e pósirradiação das SSs extraídas experimentalmente dos DnMs, OnMs e CnMs em função da $\mathrm{TID}$, para $\mathrm{V}_{\mathrm{DS}}$ igual a $50 \mathrm{mV}$

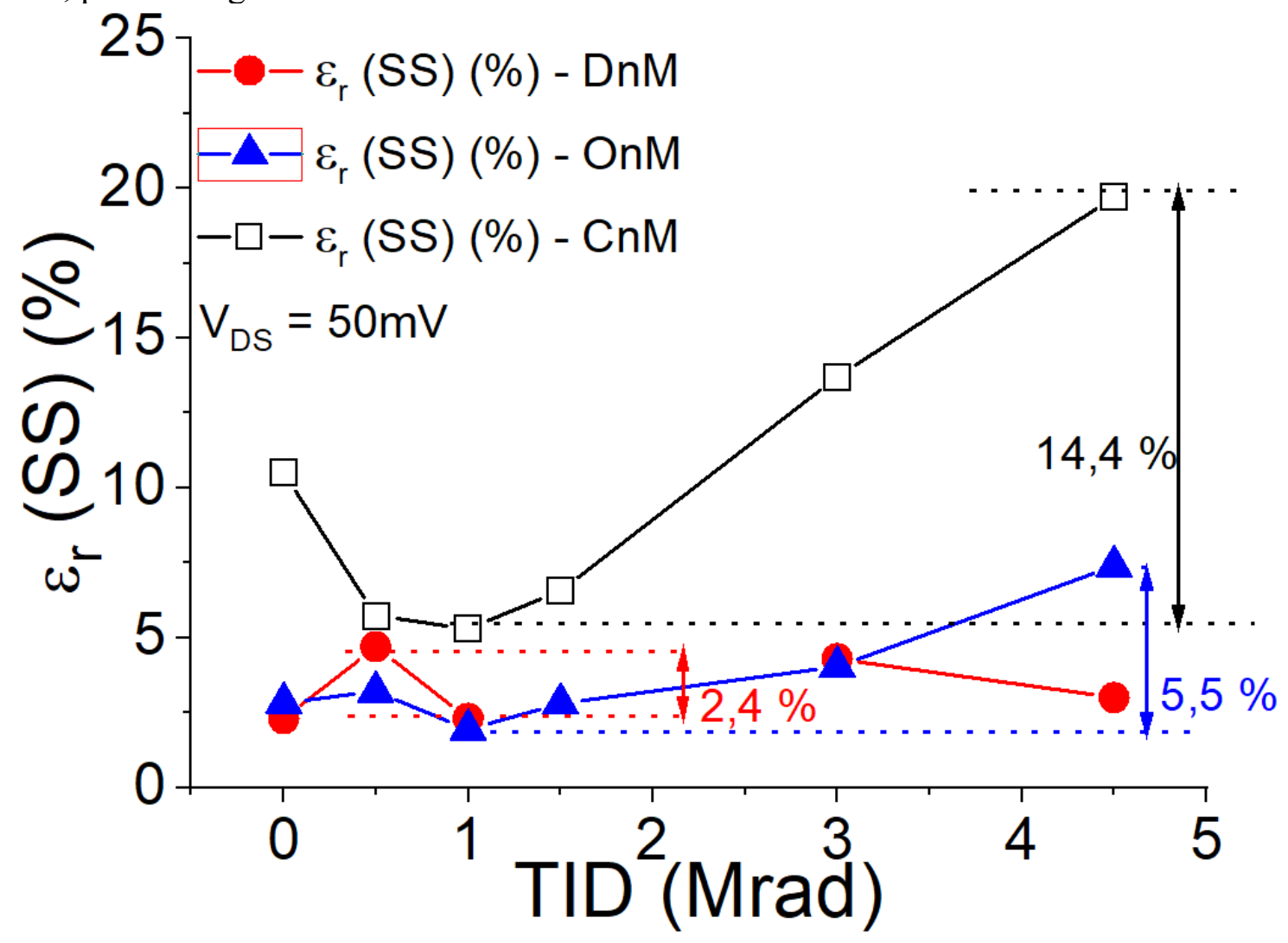

Fonte: Autor.

Em relação à Figura 55, valendo-se das condições de pré-irradiação, o coeficiente de variação relacionado ao parâmetro SS de uma amostra de 8 DnMs é igual a 2,3 \%, já o coeficiente de variação da SS de uma amostra de 10 OnMs é igual a 2,8 \%, enquanto o coeficiente de variação da SS de uma amostra de $10 \mathrm{CnMs}$ é $10,5 \%$. Isso ocorre porque, embora o valor médio da SS dos DnMs (89,6 mV / dec.) e o valor médio da SS dos OnMs (85,8 $\mathrm{mV} /$ dec.) seja menor que o valor médio da $\mathrm{SS}$ dos CnMs (95,9 mV/ dec.), os desvios-padrão das SSs referentes aos DnMs e OnMs (2,1 mV / dec. para os DnMs e 2,43 $\mathrm{mV} /$ dec. para os OnMs) são menores do que o observado nos CnMs (10,1 mV / dec.). Isso pode ser explicado em função do DEPAMBBRE, que encurva as linhas de campo elétrico longitudinal resultantes (RLEF) nos BBRs dos DnMs e OnMs, suprimindo os MOSFETs parasitários localizados nos BBRs dos DnMs e OnMs.

Deve-se ressaltar que à medida que a TID aumenta, observam-se variações entre as diferenças percentuais dos coeficientes de variação (descasamento de dispositivos) dos dispositivos DnMs, OnMs e CnMs. Verifica-se que para a primeira TID de 0,5 Mrad, o 
coeficiente de variação dos $\mathrm{CnMs}$ reduz. Uma possível justificativa para este comportamento está no fato de que para o cálculo dos coeficientes de variação para as TIDs diferentes da condição de pré-radiação, existem somente 2 amostras para a determinação dos desvios-padrão e valores médios das SSs dos DnMs, OnMs e CnMs, fazendo com que exista uma redução dos desvios-padrão e, por consequência, do valor do coeficiente de variação da SS dos CnMs. Além disso, uma outra possível justificativa para esta variação, se encontra no fato de que para taxas menores de TIDs, há um balanceamento de cargas no óxido e na interface ocorrendo de forma concomitante nos CnMs, portanto, para a TID de 0,5 Mrad é possível observar que há mais cargas positivas no óxido de porta $\left(\mathrm{SiO}_{2}\right)$ do que na interface $\mathrm{SiO}_{2} /$ Silício $(\mathrm{Si})$ dos $\mathrm{CnMs}$ devido à radiação ionizante dos raios-X.

Além disso, à medida que a TID aumenta, as diferenças entre os coeficientes de variação relacionados às SSs dos DnMs e dos OnMs em comparação ao coeficiente de variação relacionado à $\mathrm{SS}$ dos CnMs aumentam significativamente a partir de 3,0 Mrad (4,3 \% para os DnMs, 4,03\% para os OnMs e 13,7\% para os CnMs, resultando em uma diferença percentual de $9,4 \%$ quando se compara os coeficientes de variação dos DnMs e dos CnMs e em uma diferença percentual de 9,7\% quando se compara os coeficientes de variação dos OnMs e dos CnMs) até 4,5 $\mathrm{Mrad}$ (3,0 \% \% para os DnMs, 7,4 \% para os OnMs e 19,7 \% para os CnMs, resultando em uma diferença percentual de 16,7 \% quando se compara os coeficientes de variação dos DnMs e dos CnMs e em uma diferença percentual de 12,3 \% quando se compara os coeficientes de variação dos OnMs e dos $\mathrm{CnMs}$ ). Isso ocorre porque os coeficientes de variação relacionados aos parâmetros SSs dos DnMs e dos OnMs são mantidos praticamente constantes (máxima diferença percentual de 2,4\% para os DnMs e 5,5\% para os OnMs) devido ao DEPAMBBRE, enquanto as cargas positivas induzidas na interface com os BBRs dos CnMs devido à radiação ionizante dos raios-X continuam a aumentar (máxima diferença percentual de $14,4 \%$ para os CnMs), quando a TID aumenta.

Ademais, a diferença máxima entre o coeficiente de variação da SS (descasamento de dispositivos) dos DnMs é igual a 2,4\% (para 1 Mrad da TID: 2,3\% e para 0,5 Mrad da TID: 4,7\%), para os OnMs é igual a 5,5\% (para 1 Mrad da TID: 1,9\% e para 4,5 Mrad da TID: 7,4 \%) enquanto para os CnMs é de 14,4 \% (para 1 Mrad da TID: 5,3\% e para 4,5 Mrad da TID: 19,7 \%). Estes resultados mostram que os DnMs e os OnMs são mais tolerantes à radiação ionizante de raios- $\mathrm{X}$ do que os $\mathrm{CnMs}$. 
A Figura 56 ilustra os valores das $\mathrm{V}_{\mathrm{TH}}$ em função das $\mathrm{SSs}$ extraídas experimentalmente dos DnMs, OnMs e nos CnM para as diferentes TIDs aplicadas, para os dispositivos irradiados na condição de polarização Floating.

Figura 56 - Gráfico que relaciona os valores das $\mathrm{V}_{\mathrm{THS}}$ em função das SSs extraídas experimentalmente dos DnMs, OnMs e CnMs em função das TIDs aplicadas, para os dispositivos irradiados na condição de polarização Floating, para $\mathrm{V}_{\mathrm{DS}}$ igual a $50 \mathrm{mV}$

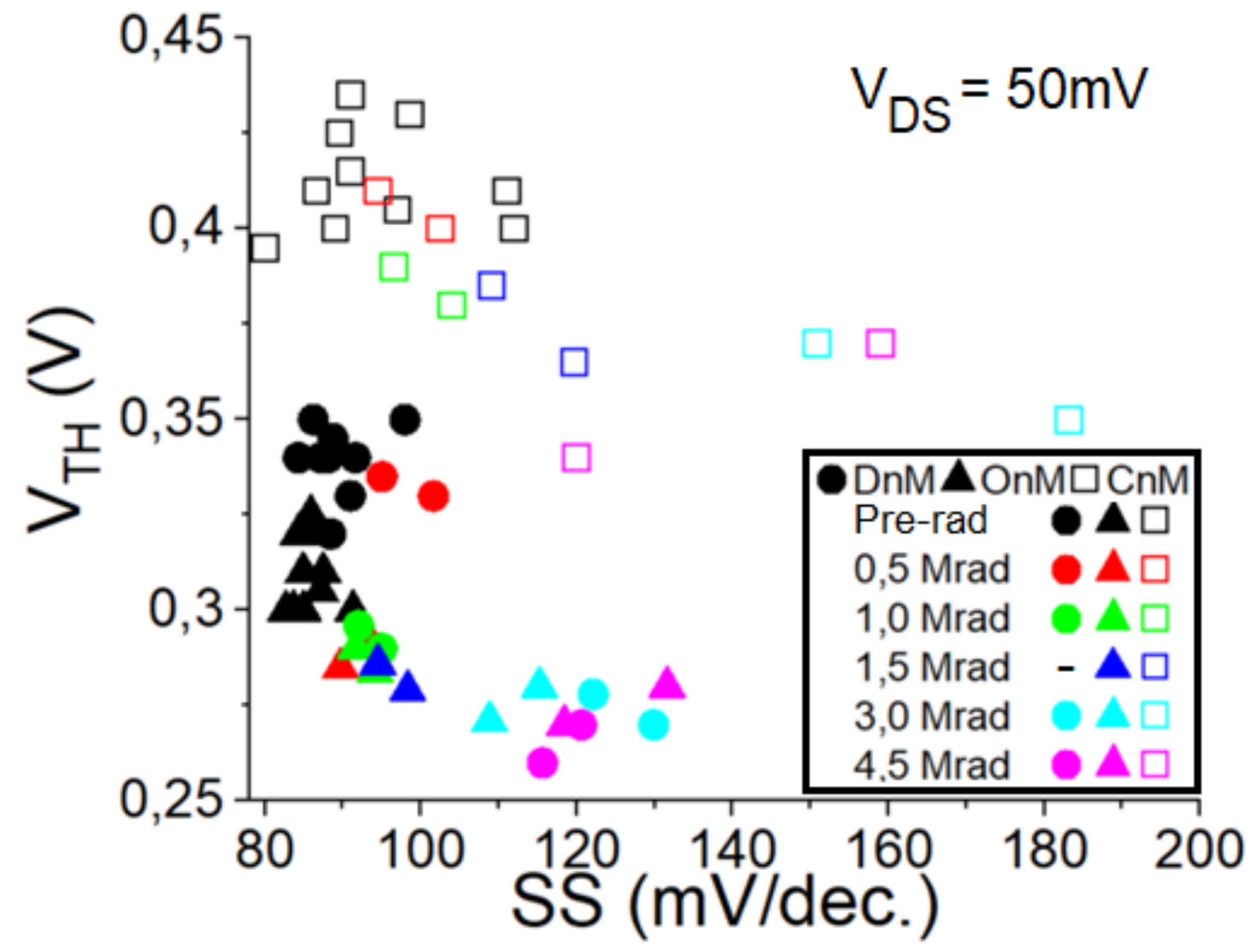

Fonte: Autor.

A partir da Figura 56, podemos ver que os comportamentos das $\mathrm{V}_{\mathrm{TH}} \mathrm{S}$ e das $\mathrm{SSs}$ exibidos nas Figuras 54 e 55 podem ser justificados pelas alterações nos valores médios e desvios-padrão das $\mathrm{V}_{\mathrm{THS}}$ e das SSs extraídas experimentalmente dos DnMs, OnMs e CnMs, à medida que a TID aumenta. Em relação à $\mathrm{V}_{T H}$ dos três tipos de dispositivos, verifica-se que os valores diminuem porque um maior número de cargas positivas são induzidas no óxido de porta em comparação com as encontradas na interface composta por $\mathrm{SiO}_{2}$ e a região do canal.

Em relação às SSs dos dispositivos, podemos observar que elas aumentam para os três tipos de dispositivos, à medida que a TID aumenta. Isso pode ser explicado pelo maior número de cargas positivas induzidas pelas radiações ionizantes de raios-X na 
interface composta pela $\mathrm{SiO}_{2}$ e a região do canal, conforme aumenta a TID. No entanto, podemos ver que os DnMs e os OnMs foram os dispositivos menos afetados, graças ao DEPAMBBRE presente em suas estruturas.

Além disso, na condição de pré-irradiação, observamos em relação à $\mathrm{V}_{\mathrm{TH}}$, que o desvio-padrão dos DnMs é 30,1 \% menor (9,5 mV) em comparação ao desvio-padrão dos CnMs (13,6 mV) e o desvio-padrão dos OnMs é 29,4 \% menor (9,6 mV) que o dos CnMs $(13,6 \mathrm{mV})$. A Tabela 4 resume os valores dos desvios-padrão em relação às $\mathrm{V}_{\mathrm{THS}}$ extraídas experimentalmente dos dispositivos DnMs, OnMs e CnMs em função das TIDs estudadas, na condição sem polarização elétrica durante o procedimento das radiações ionizantes de raios-X.

Tabela 4 - Valores dos desvios-padrão em relação às $V_{T H S}$ extraídas experimentalmente dos dispositivos DnMs, OnMs e CnMs em função das TIDs estudadas, na condição sem polarização elétrica durante o procedimento das radiações ionizantes de raios-X

\begin{tabular}{|c|c|c|c|c|c|c|c|}
\hline $\begin{array}{c}\boldsymbol{S}_{\boldsymbol{V}_{T H}} \\
(\mathbf{m V} \mathbf{)}\end{array}$ & $\begin{array}{c}\text { Pré- } \\
\text { Rad }\end{array}$ & $\begin{array}{c}\mathbf{0 , 5} \\
\text { Mrad }\end{array}$ & $\begin{array}{c}\mathbf{1 , 0} \\
\text { Mrad }\end{array}$ & $\begin{array}{c}\mathbf{1 , 5} \\
\text { Mrad }\end{array}$ & $\begin{array}{c}\mathbf{3 , 0} \\
\text { Mrad }\end{array}$ & $\begin{array}{c}\mathbf{4 , 5} \\
\text { Mrad }\end{array}$ & $\begin{array}{c}\text { Máxima } \\
\text { Diferença }\end{array}$ \\
\hline $\mathbf{D n M}$ & 9,5 & 3,5 & 4,2 & - & 5,6 & 7,1 & 6,0 \\
\hline $\mathbf{O n M}$ & 9,6 & 3,5 & 4,2 & 4,9 & 2,3 & 2,6 & 7,3 \\
\hline $\mathbf{C n M}$ & 13,6 & 7,1 & 7,1 & 14,1 & 14,2 & 21,2 & 14,1 \\
\hline
\end{tabular}

A Figura 57 apresenta os dados plotados em um gráfico dos desvios-padrão em relação às $\mathrm{V}_{\mathrm{TH}}$ extraídas experimentalmente dos dispositivos DnMs, OnMs e CnMs em função das TIDs estudadas, que estão apresentados na Tabela 4. 
Figura 57 - Valores dos desvios-padrão em relação às $\mathrm{V}_{\mathrm{TH}} \mathrm{S}$ extraídas experimentalmente dos dispositivos DnMs, OnMs e CnMs em função das TIDs estudadas, na condição sem polarização elétrica durante o procedimento das radiações ionizantes de raios-X

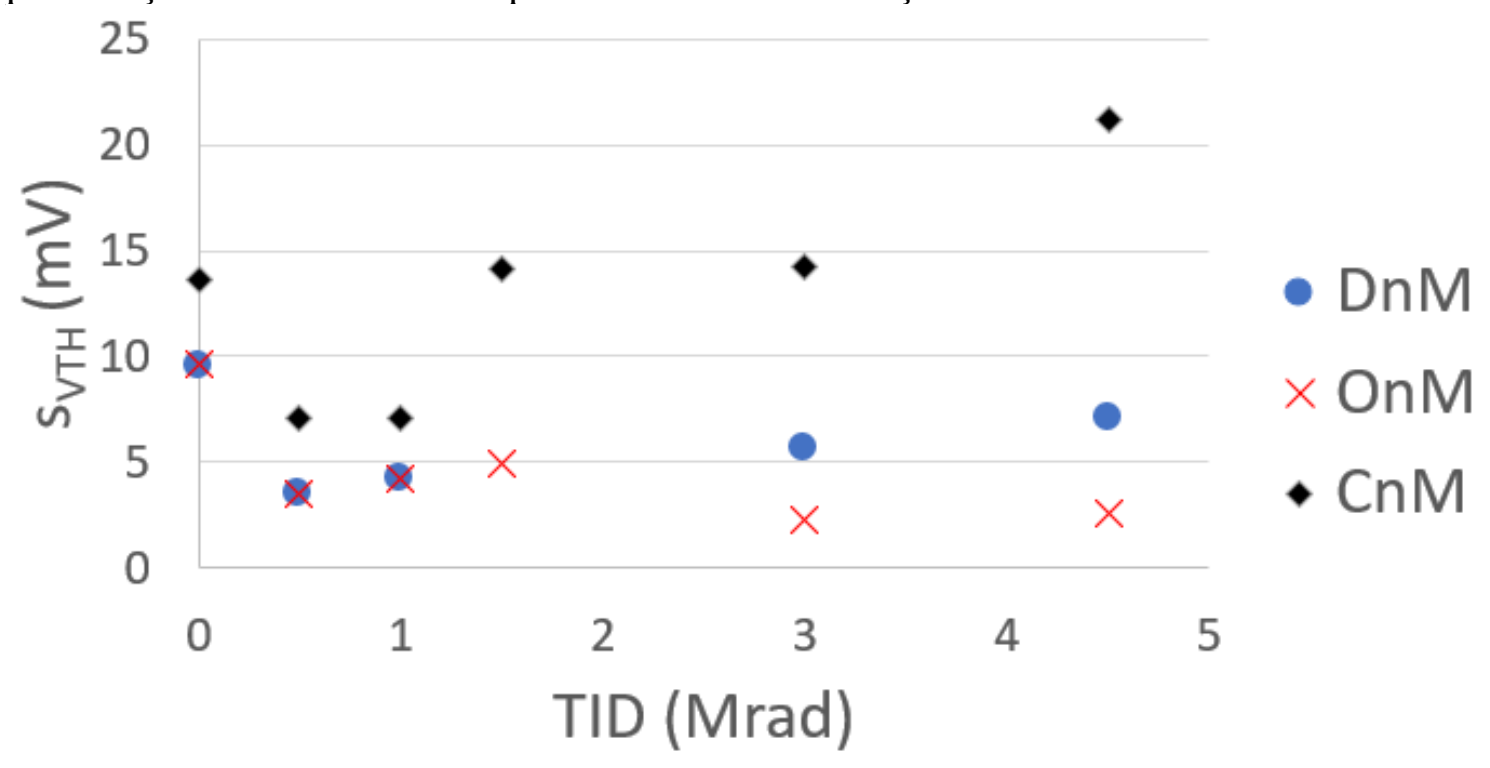

Analisando-se os resultados apresentados na Tabela 4 e na Figura 57, pode-se afirmar que o maior desvio-padrão em relação às $\mathrm{V}_{\mathrm{THS}} \mathrm{d}$ dos DnMs é para a condição de pré-irradiação $(9,5 \mathrm{mV})$, para os OnMs também é para a condição de pré-irradiação $(9,6$ $\mathrm{mV}$ ) e para os CnMs, o maior desvio-padrão é encontrado para a TID de 4,5 $\operatorname{Mrad}(21,2$ $\mathrm{mV})$. Já o menor desvio-padrão encontrado para os DnMs $(3,5 \mathrm{mV})$ ocorre para a TID de 0,5 Mrad, para os OnMs (2,3 mV) ocorre para a TID de 3,0 Mrad e para os CnMs (7,1 $\mathrm{mV}$ ) ocorre para as TIDs de 0,5 Mrad e 1,0 Mrad. Pode-se observar também que o dispositivo que apresentou a menor diferença entre os desvios-padrão, para as diferentes TIDs aplicadas, foi o DnM, com uma diferença máxima de $6,0 \mathrm{mV}$.

Deve-se ressaltar que a diminuição dos desvios-padrão quando se analisa a condição de pré-irradiação em comparação às TIDs de 0,5 Mrad e 1,0 Mrad, deve-se fundamentalmente à quantidade menor de amostras analisadas nas TIDs de 0,5 Mrad e 1,0 Mrad, fazendo com que os desvios-padrão tendam a diminuir nestas TIDs iniciais. Posteriormente, com o aumento das TIDs nas amostras, pode-se verificar um aumento significativo dos desvios-padrão, devido às radiações ionizantes de raios-X.

A Tabela 5 apresenta os valores dos desvios-padrão em relação às SSs extraídas experimentalmente dos dispositivos DnMs, OnMs e CnMs em função das TIDs estudadas, na condição sem polarização elétrica durante o procedimento das radiações ionizantes de raios-X. 
Tabela 5 - Valores dos desvios-padrão em relação às SSs extraídas experimentalmente dos dispositivos DnMs, OnMs e CnMs em função das TIDs estudadas, na condição sem polarização elétrica durante o procedimento das radiações ionizantes de raios-X

\begin{tabular}{|c|c|c|c|c|c|c|c|}
\hline $\begin{array}{c}\boldsymbol{S}_{\text {SS }} \\
(\mathbf{m} \text { V/déc. })\end{array}$ & $\begin{array}{c}\text { Pré- } \\
\text { Rad }\end{array}$ & $\begin{array}{c}\mathbf{0 , 5} \\
\text { Mrad }\end{array}$ & $\begin{array}{c}\mathbf{1 , 0} \\
\text { Mrad }\end{array}$ & $\begin{array}{c}\mathbf{1 , 5} \\
\text { Mrad }\end{array}$ & $\begin{array}{c}\mathbf{3 , 0} \\
\text { Mrad }\end{array}$ & $\begin{array}{c}\mathbf{4 , 5} \\
\text { Mrad }\end{array}$ & $\begin{array}{c}\text { Máxima } \\
\text { Diferença }\end{array}$ \\
\hline $\mathbf{D n M}$ & 2,1 & 4,7 & 2,1 & - & 5,5 & 3,5 & 3,4 \\
\hline $\mathbf{O n M}$ & 2,4 & 2,9 & 1,8 & 2,7 & 4,5 & 9,3 & 7,5 \\
\hline $\mathbf{C n M}$ & 10,1 & 5,6 & 5,3 & 7,5 & 22,8 & 27,6 & 22,3 \\
\hline
\end{tabular}

A Figura 58 apresenta os dados plotados em um gráfico dos desvios-padrão em relação às SSs extraídas experimentalmente dos dispositivos DnMs, OnMs e CnMs em função das TIDs estudadas, que estão apresentados na Tabela 5.

Figura 58 - Valores dos desvios-padrão em relação às SSs extraídas experimentalmente dos dispositivos DnMs, OnMs e CnMs em função das TIDs estudadas, na condição sem polarização elétrica durante o procedimento das radiações ionizantes de raios-X

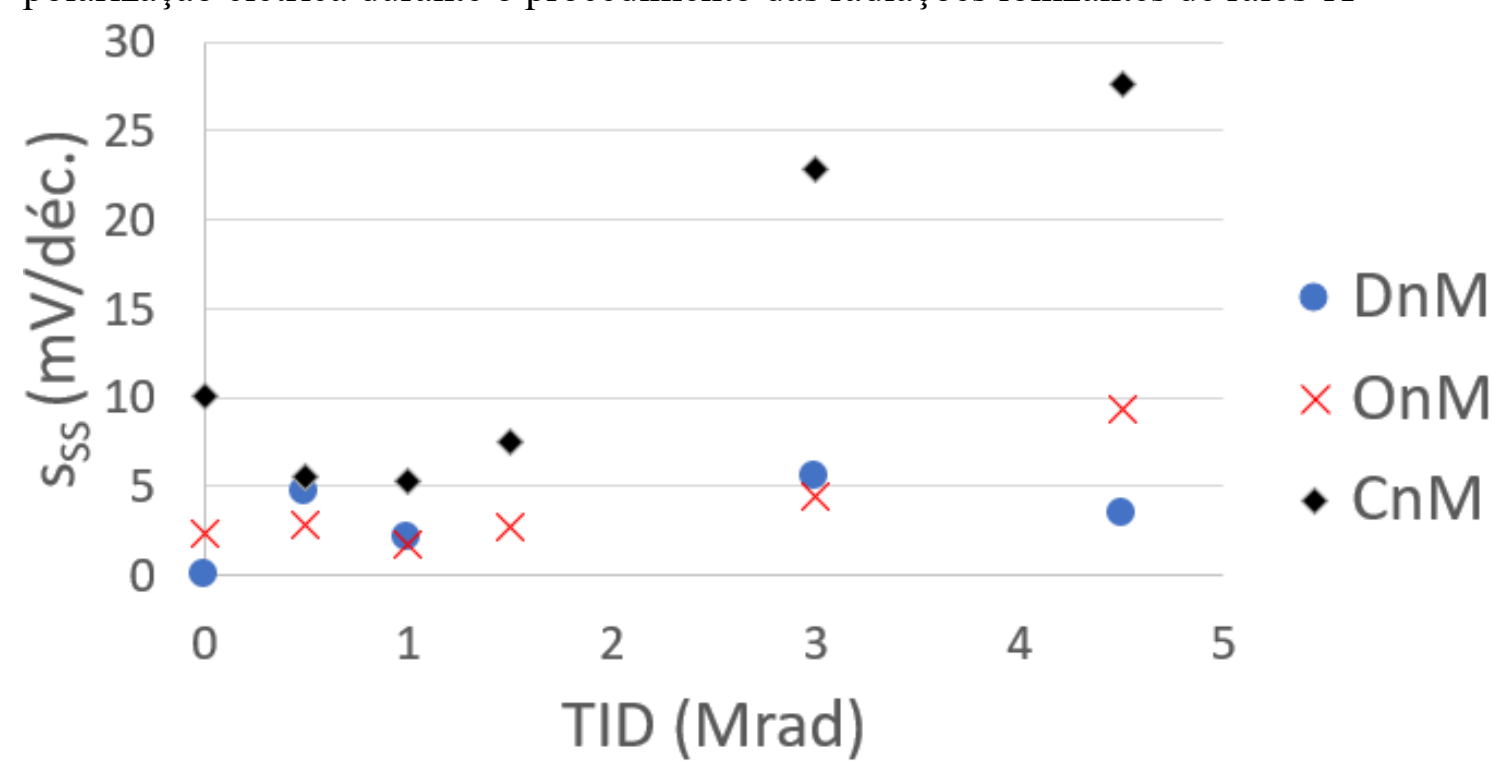

Analisando-se os resultados apresentados na Tabela 5 e na Figura 58, observa-se que o desvio-padrão das SSs em relação aos DnMs não muda praticamente (diferença máxima de 3,4 mV / dec.), enquanto que o desvio-padrão das SSs em relação aos CnMs varia de forma significativa (diferença máxima de $22,3 \mathrm{mV} /$ dec.), conforme a TID 
aumenta. Já o comportamento do desvio-padrão das SSs em relação aos OnMs apresentase intermediário entre o comportamento observado para os DnMs e os CnMs (diferença máxima de 7,5 mV/ dec.) em função do efeito DEPAMBBRE existente.

Assim, os resultados experimentais indicam que os DnMs e os OnMs apresentam uma tolerância à TID mais alta do que aqueles medidos nos dispositivos CnMs e, portanto, o estilo de leiaute de porta do tipo hexagonal e octogonal para nMOSFETs podem ser considerados como possíveis alternativas para melhorar a tolerância de MOSFETs às radiações ionizantes de raios-X.

\subsubsection{Estudo do coeficiente de variação entre a tensão de limiar e a inclinação de sublimiar}

Com base nas análises desenvolvidas nas Figuras 54 e 55, podem-se também calcular três figuras de mérito (FMs) diferentes:

I- $\quad \mathrm{O}$ erro relativo dos coeficientes de variação das $\mathrm{V}_{\mathrm{THS}}$ e SSs extraídas experimentalmente dos DnMs e dos OnMs irradiados (2 amostras para cada TID) em relação aos observados para os CnMs irradiados $\left(\varepsilon_{\mathrm{r} 1}\right.$ para a análise com os DnMs e $\varepsilon_{\mathrm{r} 2}$ para a análise com os OnMs, valendo-se de 2 amostras para cada TID);

II- $\quad$ O erro relativo dos coeficientes de variação $\varepsilon_{\mathrm{r} 3}$ e $\varepsilon_{\mathrm{r} 4}$ é referente às $\mathrm{V}_{\mathrm{TH}}$ e às SSs dos DnMs e OnMs irradiados, respectivamente ( 2 amostras para cada TID) em relação às suas condições pré-irradiadas;

III- Além disso, o cálculo do erro relativo do coeficiente de variação $\varepsilon_{\mathrm{r} 5}$ diz respeito aos coeficientes de variação das $\mathrm{V}_{\mathrm{THS}}$ e SSs dos CnMs irradiados (2 amostras para cada TID) em relação aos CnMs pré-irradiados.

A Tabela 6 apresenta os valores calculados para os erros relativos descritos como $\varepsilon_{\mathrm{r} 1}, \varepsilon_{\mathrm{r} 2}, \varepsilon_{\mathrm{r} 3}, \varepsilon_{\mathrm{r} 4}$ e $\varepsilon_{\mathrm{r} 5}$, respectivamente. 
Tabela 6 - Valores dos erros relativos calculados e descritos como $\varepsilon_{\mathrm{r} 1}, \varepsilon_{\mathrm{r} 2}, \varepsilon_{\mathrm{r} 3}, \varepsilon_{\mathrm{r} 4}$ e $\varepsilon_{\mathrm{r} 5}$ em função das TIDs estudadas

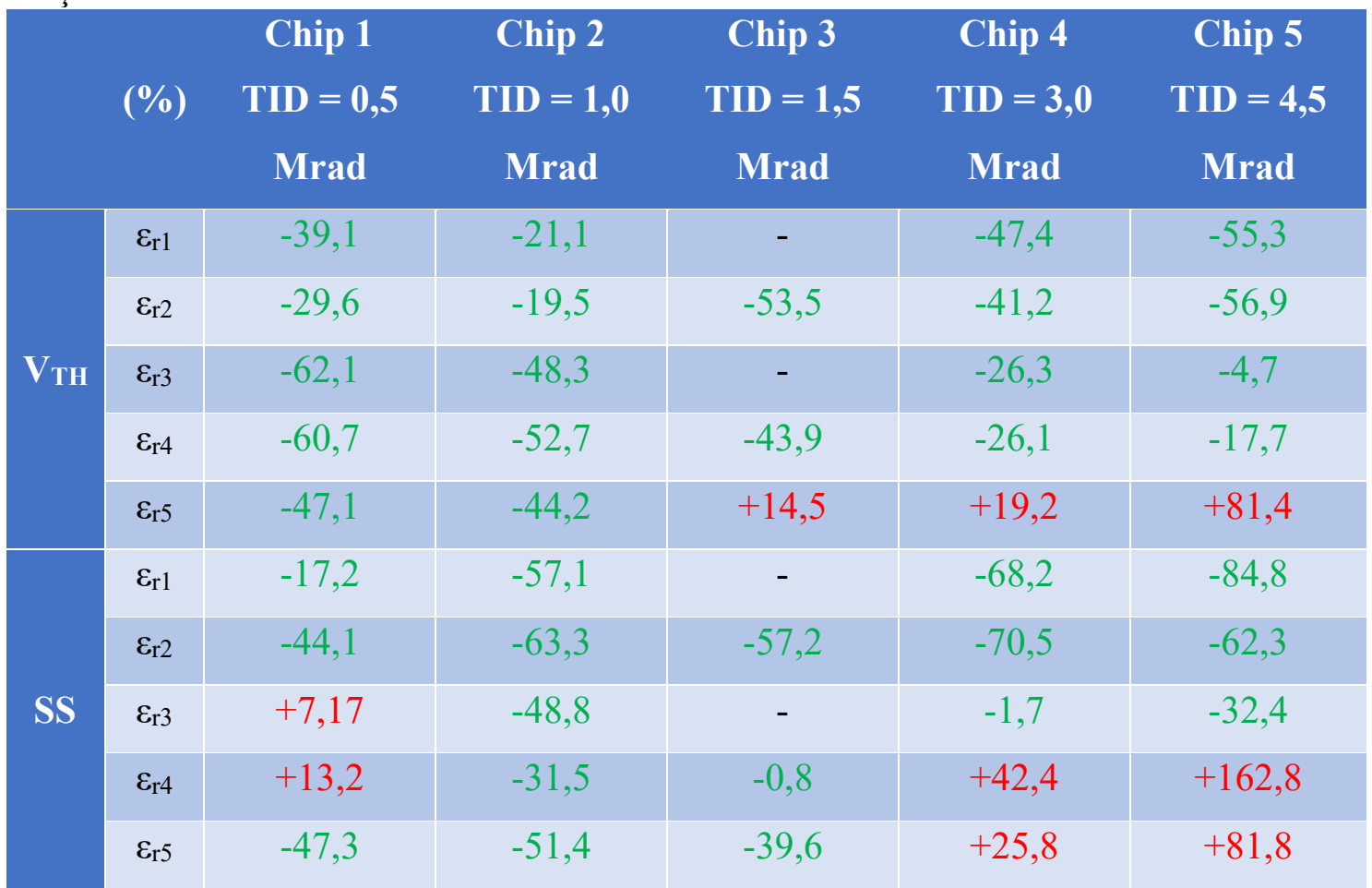

Com base na Tabela 6 , os $\varepsilon_{\mathrm{r} 1} \mathrm{~s}$ e $\varepsilon_{\mathrm{r} 2} \mathrm{~s}$ indicam que para as $\mathrm{V}_{\mathrm{TH}} \mathrm{s}$ e SSs, o erro relativo dos coeficientes de variação dos DnMs e OnMs irradiados são sempre menores ( $\mathrm{V}_{\mathrm{TH}}$ : 40,7\% em média e SS: -56,8\% em média para os DnMs e $\mathrm{V}_{\mathrm{TH}}$ :-40,1\% em média e SS: $59,5 \%$ em média para os OnMs) do que aqueles medidos para os $\mathrm{CnMs}$, devido fundamentalmente ao DEPAMBBRE presente nos DnMs e OnMs. Portanto, é possível afirmar por meio destes resultados que os DnMs e os OnMs apresentam um casamento entre dispositivos melhor em comparação com os CnMs para todas as TIDs consideradas neste trabalho. Assim, pode-se concluir que o a geometria de leiaute de porta do tipo Diamante e Octogonal podem ser considerados como uma técnica alternativa de Hardness-By-Design (HBD) para implementar MOSFETs com o propósito de aumentar o casamento entre dispositivos, com foco em aplicações de circuitos integrados CMOS nas áreas de aviação, espaciais e médicas.

Além disso, quando se analisam as figuras de mérito $\varepsilon_{\mathrm{r} 3}$ e $\varepsilon_{\mathrm{r} 4}$ em relação ao parâmetro $\mathrm{V}_{\mathrm{TH}}$ (casamento entre dispositivos), pode-se verificar que os coeficientes de variação dos DnMs e OnMs irradiados são sempre menores do que os coeficientes de variação dos dispositivos que não sofreram o processo degradação devido à irradiação ionizante de raios-X (condição de pré-irradiação para os dispositivos DnMs e OnMs) e 
reduzem à medida que a TID aumenta (-35,3\% em média para os DnMs e -40,2\% para os OnMs), ou seja, o erro relativo do coeficiente de variação $\varepsilon_{\mathrm{r} 3}$ e $\varepsilon_{\mathrm{r} 4}$ devem ser ainda mais próximos de zero para uma TID superior a 4,5 Mrad, pois que as áreas de porta dos OnMs são maiores em comparação às áreas dos DnMs. Uma possível justificativa para este comportamento observado, refere-se a diferença entre os efeitos das cargas sobre o óxido de porta (que faz com que a $\mathrm{V}_{\mathrm{TH}}$ seja reduzida) devido à radiação ionizante que está sendo compensada pelos efeitos do cargas na interface de $\mathrm{SiO}_{2}$ e no filme de silício (que faz com que a $\mathrm{V}_{\mathrm{TH}}$ aumente) e, portanto, há uma tendência para a $\mathrm{V}_{\mathrm{TH}}$ retornar à condição de pré-irradiação. No entanto, embora o $\varepsilon_{\mathrm{r} 5}$ referente à análise da $\mathrm{V}_{\mathrm{TH}}$ para os dispositivos CnMs sigam as mesmas tendências observadas para as $\mathrm{V}_{\mathrm{TH}} \mathrm{S}$ dos DnMs e OnMs até 1 Mrad, eles aumentam significativamente além de $1 \mathrm{Mrad}$, ou seja, não tendem a retornar aos valores pré-irradiação (+ 4,7\% em média), como vimos para os DnMs e OnMs.

Além disso, para a análise do parâmetro SS, quando se efetua o cálculo de $\varepsilon_{\mathrm{r} 3}$ para os DnMs, pode-se observar que os erros relativos dos coeficientes de variação dos DnMs irradiados são praticamente sempre inferiores (-18,9 \% em média, com a exceção da TID igual a 0,5 Mrad, onde se observa que o erro relativo calculado é igual a $+7,17 \%$ ) aos dos dispositivos pré-irradiados (com uma variação máxima de 2,4\%, em relação à Figura 55) e diminuem com o aumento da TID, em comparação com as observadas para os CnMs (com variação máxima de 14,4\%, em relação à Figura 55). Ademais, quando se efetua o cálculo de $\varepsilon_{\mathrm{r} 4}$ para os OnMs, pode-se observar que os erros relativos dos coeficientes de variação dos OnMs irradiados são superiores para as TIDs de 1,0 Mrad e 1,5 Mrad (para a TID igual a $0,5 \mathrm{Mrad}$, o erro relativo calculado é igual a $+13,2 \%$, para a TID igual a 3,0 Mrad, o erro relativo calculado é igual a $+42,4 \%$ e para a TID igual a 4,5 Mrad, o erro relativo calculado é igual a $+162,8 \%$ ) aos dos dispositivos pré-irradiados (com uma variação máxima de 5,5\%, em relação à Figura 55) e aumentam com o aumento da TID. Portanto, pode-se verificar que os DnMs apresentam um melhor casamento de dispositivos, no que diz respeito à $\mathrm{V}_{\mathrm{TH}}$ e à $\mathrm{SS}$ (variação máxima de $1,8 \%$ para a $\mathrm{V}_{\mathrm{TH}} \mathrm{e}$ 2,4 \% para a SS), sendo que os OnMs também apresentam um resultado bastante satisfatório em relação ao casamento entre dispositivos no que diz respeito à $\mathrm{V}_{\mathrm{TH}} \mathrm{e}$ à $\mathrm{SS}$ (variação máxima de 1,9 \% para a $\mathrm{V}_{\mathrm{TH}}$ e 5,5 \% para a SS), após a exposição aos raios-X em relação à condição de pré-irradiação, além disso ressalta-se que os DnMs obtiveram menores erros devido ao fato de que as áreas de porta dos OnMs serem maiores em comparação às áreas dos DnMs. 


\subsubsection{Gráficos do tipo radar para a análise dos parâmetros IDSsat/(W/L), $\operatorname{gm}_{M A x} /(W / L), g_{M A X} / I_{D S s a t}, R_{D S o n} /(L / W), g_{D} /(W / L), V_{E A} / L, f_{T} /(W / L), A v, I_{o N} /(W / L)$, IOFF/(W/L), Ion/IOFF e ILEAK/(W/L)}

Nesta seção serão apresentados os gráficos do tipo radar dos coeficientes de variação calculados em função dos parâmetros $\mathrm{I}_{\mathrm{DSsat}} /(\mathrm{W} / \mathrm{L}), \operatorname{gm}_{\mathrm{MAX}} /(\mathrm{W} / \mathrm{L}), \mathrm{gm}_{\mathrm{MAX}} / \mathrm{I}_{\mathrm{DSsat}}$, $\mathrm{R}_{\mathrm{DSon}} /(\mathrm{L} / \mathrm{W}), \mathrm{g}_{\mathrm{D}} /(\mathrm{W} / \mathrm{L}), \quad \mathrm{V}_{\mathrm{EA}} / \mathrm{L}, \mathrm{f}_{\mathrm{T}} /(\mathrm{W} / \mathrm{L}), \mathrm{A}_{\mathrm{V}}, \mathrm{I}_{\mathrm{ON}} /(\mathrm{W} / \mathrm{L}), \mathrm{I}_{\mathrm{OFF}} /(\mathrm{W} / \mathrm{L}), \mathrm{I}_{\mathrm{ON}} / \mathrm{I}_{\mathrm{OFF}} \mathrm{e}$ ILEAK/(W/L), extraídos experimentalmente dos dispositivos DnMs, OnMs e CnMs.

Deve-se ressaltar que o parâmetro $\mathrm{I}_{\mathrm{DSsat}} /(\mathrm{W} / \mathrm{L})$ foi extraído por meio de uma curva $\mathrm{I}_{D S}$ em função de $\mathrm{V}_{\mathrm{DS}}$ com uma polarização de $\mathrm{V}_{\mathrm{GS}}$ igual a $0,8 \mathrm{~V}$ e $\mathrm{VDS}$ igual a $1 \mathrm{~V}$, para

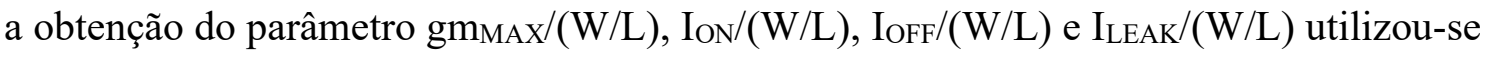
uma curva $I_{D S}$ em função de $V_{G S}$ com uma polarização de $V_{D S}$ igual a $0,5 \mathrm{~V}$, para a obtenção dos parâmetros $\mathrm{R}_{\mathrm{DSon}} /(\mathrm{L} / \mathrm{W})$ e $\mathrm{V}_{\mathrm{EA}} / \mathrm{L}$ utilizou-se uma curva $\mathrm{I}_{\mathrm{DS}}$ em função de $\mathrm{V}_{\mathrm{DS}}$ com uma polarização de $\mathrm{V}_{\mathrm{GS}}$ igual a $0,8 \mathrm{~V}$.

A Figura 59 apresenta 6 gráficos do tipo radar no qual estão apresentados os coeficientes de variação dos parâmetros $\mathrm{I}_{\mathrm{DSsa}} /(\mathrm{W} / \mathrm{L}), \mathrm{gm}_{\mathrm{MAX}} /(\mathrm{W} / \mathrm{L}), \mathrm{gm}_{\max } / \mathrm{I}_{\mathrm{DSsat}}$, $\mathrm{R}_{\mathrm{DSon}} /(\mathrm{L} / \mathrm{W}), \mathrm{g}_{\mathrm{D}} /(\mathrm{W} / \mathrm{L}), \mathrm{V}_{\mathrm{EA}} / \mathrm{L}, \mathrm{f}_{\mathrm{T}} /(\mathrm{W} / \mathrm{L}), \mathrm{A}_{\mathrm{V}}, \mathrm{I}_{\mathrm{ON}} /(\mathrm{W} / \mathrm{L}), \mathrm{I}_{\mathrm{OFF}} /(\mathrm{W} / \mathrm{L}), \mathrm{I}_{\mathrm{ON}} / \mathrm{I}_{\mathrm{OFF}} \mathrm{e}$ $\mathrm{I}_{\mathrm{LEAK}} /(\mathrm{W} / \mathrm{L})$ extraídos experimentalmente dos dispositivos DnMs, OnMs e CnMs para cada um das TIDs estudadas neste trabalho, isto é, na condição pré-irradiação (Figura 59.a), 0,5 Mrad (Figura 59.b), 1,0 Mrad (Figura 59.c), 1,5 Mrad (Figura 59.d), 3,0 Mrad (Figura 59.e) e 4,5 Mrad (Figura 59.f). Por meio destes gráficos, deve-se observar que o melhor desempenho é ficar perto da origem de cada eixo. Desta forma, menor será o coeficiente de variação para o parâmetro elétrico analisado. 
Figura 59 - Coeficientes de variação dos parâmetros $\mathrm{I}_{\mathrm{DSsat}} /(\mathrm{W} / \mathrm{L}), \operatorname{gm}_{\mathrm{MAX}} /(\mathrm{W} / \mathrm{L})$, $\mathrm{gm}_{\mathrm{MAX}} / \mathrm{I}_{\mathrm{DSsa}}, \mathrm{R}_{\mathrm{DSon}} /(\mathrm{L} / \mathrm{W}), \mathrm{g}_{\mathrm{D}} /(\mathrm{W} / \mathrm{L}), \mathrm{V}_{\mathrm{EA}} / \mathrm{L}, \mathrm{f}_{\mathrm{T}} /(\mathrm{W} / \mathrm{L}), \mathrm{A}_{\mathrm{V}}, \mathrm{I}_{\mathrm{ON}} /(\mathrm{W} / \mathrm{L}), \mathrm{I}_{\mathrm{OFF}} /(\mathrm{W} / \mathrm{L})$, $\mathrm{I}_{\mathrm{ON}} / \mathrm{I}_{\mathrm{OFF}}$ e $\mathrm{I}_{\mathrm{LEAK}} /(\mathrm{W} / \mathrm{L})$ extraídos experimentalmente dos DnMs, OnMs e CnMs, para as condições de pré-irradiação (a), 0,5 $\operatorname{Mrad}(\mathrm{b}), 1,0 \mathrm{Mrad}$ (c), 1,5 $\operatorname{Mrad}(\mathrm{d})$, 3,0 $\operatorname{Mrad}(\mathrm{e}) \mathrm{e}$ 4,5 $\operatorname{Mrad}(\mathrm{f})$.

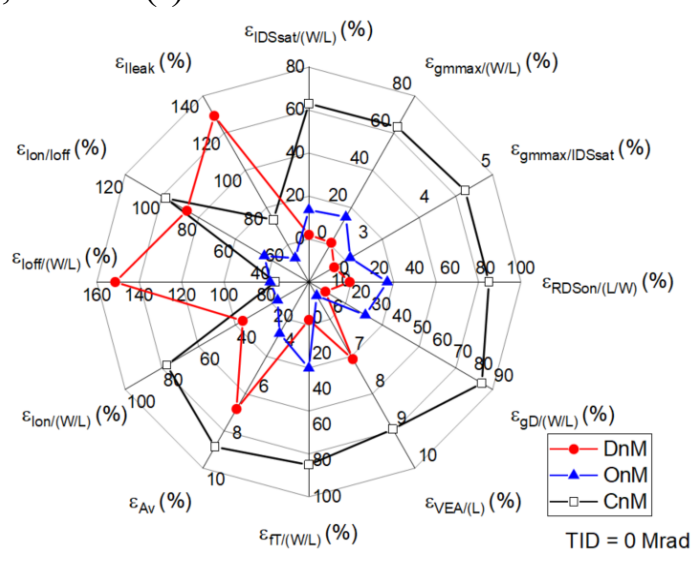

(a)

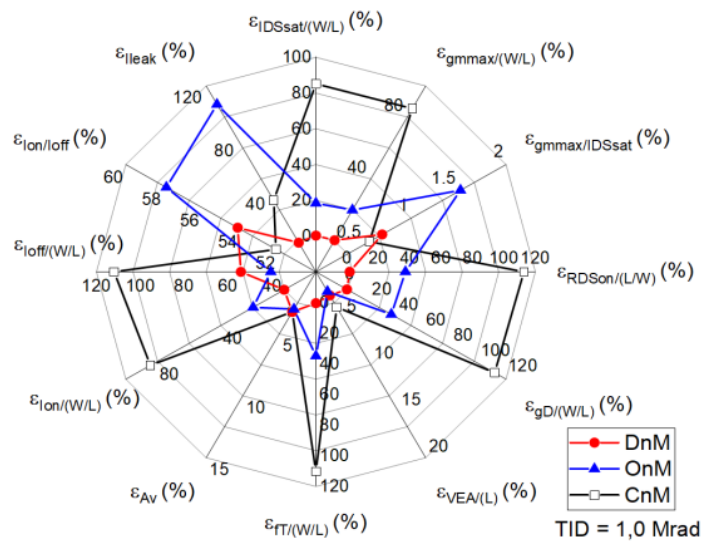

(c)

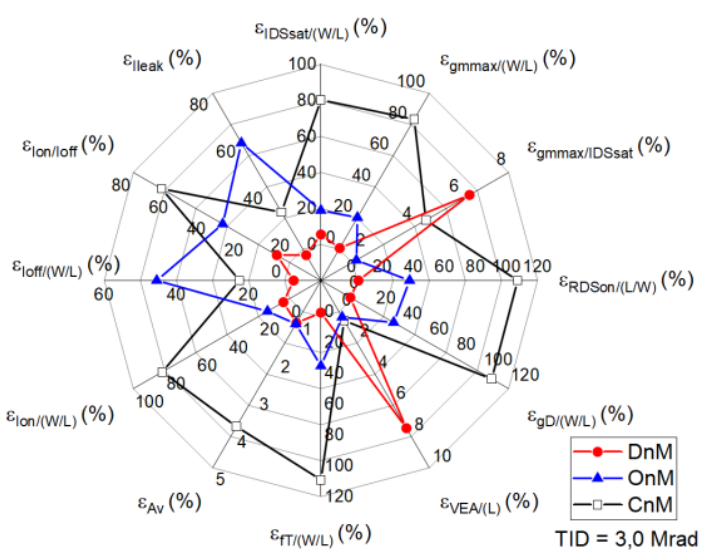

(e)

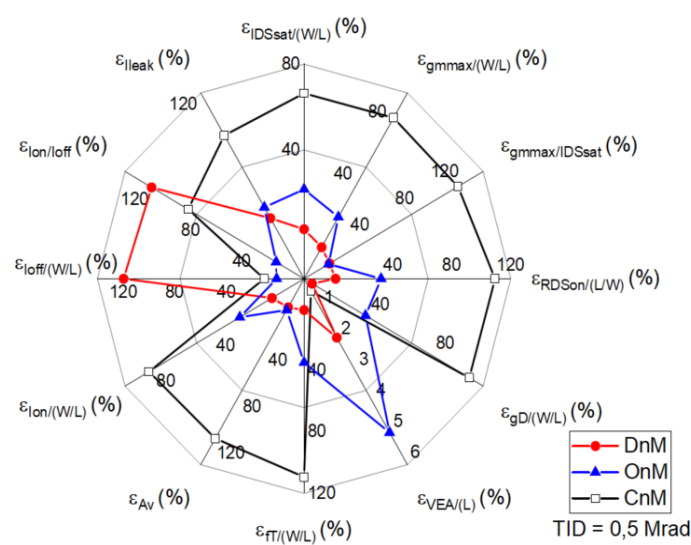

(b)

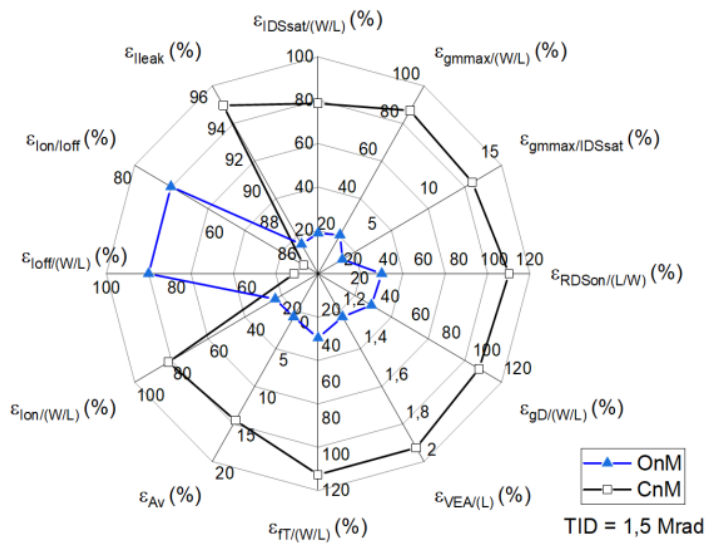

(d)

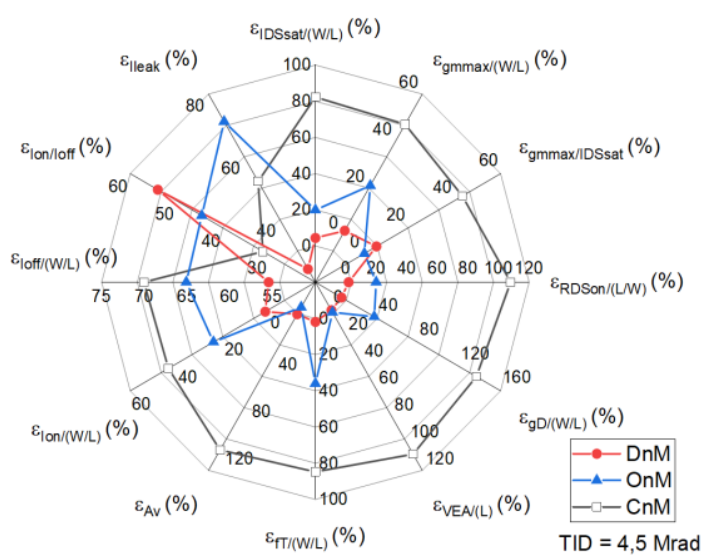

(f)

Fonte: Autor 
A Tabela 7 ilustra todos os coeficientes de variação dos parâmetros $\mathrm{I}_{\mathrm{DSsat}} /(\mathrm{W} / \mathrm{L})$, $\operatorname{gm}_{\operatorname{MAX}} /(\mathrm{W} / \mathrm{L}), \mathrm{gm}_{\mathrm{MAX}} / \mathrm{I}_{\mathrm{DSsa}}, \mathrm{R}_{\mathrm{DSon}} /(\mathrm{L} / \mathrm{W}), \mathrm{g}_{\mathrm{D}} /(\mathrm{W} / \mathrm{L}), \mathrm{V}_{\mathrm{EA}} / \mathrm{L}, \mathrm{f}_{\mathrm{T}} /(\mathrm{W} / \mathrm{L}), \mathrm{A}_{\mathrm{V}}, \mathrm{I}_{\mathrm{ON}} /(\mathrm{W} / \mathrm{L})$, $\mathrm{I}_{\mathrm{OFF}} /(\mathrm{W} / \mathrm{L}), \mathrm{I}_{\mathrm{ON}} / \mathrm{I}_{\mathrm{OFF}}$ e $\mathrm{I}_{\mathrm{LEAK}} /(\mathrm{W} / \mathrm{L})$ extraídos experimentalmente dos CnMs, para cada uma das TIDs estudadas neste trabalho, com os terminais em condição de Floating.

Tabela 7 - Coeficientes de variação dos parâmetros $\mathrm{I}_{\mathrm{DSsa}} /(\mathrm{W} / \mathrm{L}), \operatorname{gm}_{\mathrm{MAX}} /(\mathrm{W} / \mathrm{L})$, $\mathrm{gm}_{\mathrm{MAX}} / \mathrm{I}_{\mathrm{DSsat}}, \mathrm{R}_{\mathrm{DSon}} /(\mathrm{L} / \mathrm{W}), \mathrm{g}_{\mathrm{D}} /(\mathrm{W} / \mathrm{L}), \mathrm{V}_{\mathrm{EA}} / \mathrm{L}, \mathrm{f}_{\mathrm{T}} /(\mathrm{W} / \mathrm{L}), \mathrm{Av}_{\mathrm{v}}, \mathrm{I}_{\mathrm{ON}} /(\mathrm{W} / \mathrm{L}), \mathrm{I}_{\mathrm{OFF}} /(\mathrm{W} / \mathrm{L})$, ION/IOFF e I IEAK $/(\mathrm{W} / \mathrm{L})$ extraídos experimentalmente dos CnMs, para cada uma das TIDs estudadas

\begin{tabular}{|c|c|c|c|c|c|c|}
\hline CnM & $\begin{array}{l}\text { Pre - } \\
\text { Rad }\end{array}$ & $\begin{array}{c}0,5 \\
\text { Mrad }\end{array}$ & $\begin{array}{c}1,0 \\
\text { Mrad }\end{array}$ & $\begin{array}{c}1,5 \\
\text { Mrad }\end{array}$ & $\begin{array}{c}\mathbf{3 , 0} \\
\text { Mrad }\end{array}$ & $\begin{array}{c}4,5 \\
\text { Mrad }\end{array}$ \\
\hline IDSsat(W/L) & 0,63 & 0,66 & 0,85 & 0,79 & 0,80 & 0,82 \\
\hline $\operatorname{gmax}_{\operatorname{Max}} /(\mathrm{W} / \mathrm{L})$ & 0,63 & 0,84 & 0,85 & 0,87 & 0,83 & 0,47 \\
\hline gm $_{\text {MAX }} / \mathbf{I D S s a t}$ & 0,05 & 1,18 & 0,01 & 0,13 & 0,04 & 0,44 \\
\hline $\mathbf{R}_{\text {DSon }} /(\mathbf{L} / \mathbf{W})$ & 0,82 & 1,09 & 1,13 & 1,08 & 1,07 & 1,08 \\
\hline $\mathrm{g}_{\mathrm{D}} /(\mathrm{W} / \mathrm{L})$ & 0,85 & 1,07 & 1,12 & 1,05 & 1,07 & 1,36 \\
\hline $\mathbf{V}_{\mathrm{EA}} / \mathbf{L}$ & 0,09 & 0,004 & 0,04 & 0,02 & 0,01 & 1,08 \\
\hline$f_{\mathrm{T}} /(\mathrm{W} / \mathrm{L})$ & 0,82 & 1,09 & 1,10 & 1,11 & 1,09 & 0,84 \\
\hline $\mathbf{A}_{\mathbf{v}}$ & 0,09 & 1,17 & 0,03 & 0,15 & 0,04 & 1,23 \\
\hline$I_{o n} /(\mathbf{W} / L)$ & 0,77 & 0,84 & 0,85 & 0,82 & 0,81 & 0,44 \\
\hline$I_{\text {off }} /(W / L)$ & 0,76 & 0,11 & 1,12 & 0,47 & 0,23 & 0,70 \\
\hline $\mathbf{I}_{\text {on }} / \mathbf{I}_{\text {off }}$ & 0,98 & 0,91 & 0,52 & 0,43 & 0,65 & 0,31 \\
\hline ILEAK/(W/L) & 0,73 & 1,06 & 0,34 & 0,95 & 0,29 & 0,52 \\
\hline
\end{tabular}

A Tabela 8 ilustra todos os coeficientes de variação dos parâmetros $\mathrm{I}_{\mathrm{DSsat}} /(\mathrm{W} / \mathrm{L})$, $\operatorname{gm}_{\operatorname{MAX}} /(\mathrm{W} / \mathrm{L}), \mathrm{gm}_{\mathrm{MAX}} / \mathrm{I}_{\mathrm{DSsat}}, \mathrm{R}_{\mathrm{DSon}} /(\mathrm{L} / \mathrm{W}), \mathrm{g}_{\mathrm{D}} /(\mathrm{W} / \mathrm{L}), \mathrm{V}_{\mathrm{EA}} / \mathrm{L}, \mathrm{f}_{\mathrm{T}} /(\mathrm{W} / \mathrm{L}), \mathrm{Av}_{\mathrm{v}}, \mathrm{I}_{\mathrm{ON}} /(\mathrm{W} / \mathrm{L})$, $\mathrm{I}_{\mathrm{OFF}} /(\mathrm{W} / \mathrm{L})$, I $\mathrm{ON} / \mathrm{I}_{\mathrm{OFF}}$ e I IEAK/(W/L) extraídos experimentalmente dos DnMs, para cada uma das TIDs estudadas neste trabalho, com os terminais em condição de Floating. 
Tabela 8 - Coeficientes de variação dos parâmetros $\mathrm{I}_{\mathrm{DSsa}} /(\mathrm{W} / \mathrm{L}), \operatorname{gm}_{\mathrm{MAX}} /(\mathrm{W} / \mathrm{L})$, $\mathrm{gm}_{\mathrm{MAX}} / \mathrm{I}_{\mathrm{DSsa}}, \mathrm{R}_{\mathrm{DSon}} /(\mathrm{L} / \mathrm{W}), \mathrm{g}_{\mathrm{D}} /(\mathrm{W} / \mathrm{L}), \mathrm{V}_{\mathrm{EA}} / \mathrm{L}, \mathrm{f}_{\mathrm{T}} /(\mathrm{W} / \mathrm{L}), \mathrm{A}_{\mathrm{V}}, \mathrm{I}_{\mathrm{ON}} /(\mathrm{W} / \mathrm{L}), \mathrm{I}_{\mathrm{OFF}} /(\mathrm{W} / \mathrm{L})$, $\mathrm{I}_{\mathrm{ON}} / \mathrm{I}_{\mathrm{OFF}}$ e $\mathrm{I}_{\mathrm{LEAK}} /(\mathrm{W} / \mathrm{L})$ extraídos experimentalmente dos DnMs, para cada uma das TIDs estudadas

\begin{tabular}{|c|c|c|c|c|c|c|}
\hline DnM & $\begin{array}{l}\text { Pre - } \\
\text { Rad }\end{array}$ & $\begin{array}{c}0,5 \\
\text { Mrad }\end{array}$ & $\begin{array}{c}1,0 \\
\text { Mrad }\end{array}$ & $\begin{array}{c}1,5 \\
\text { Mrad }\end{array}$ & $\begin{array}{c}3,0 \\
\text { Mrad }\end{array}$ & $\begin{array}{c}4,5 \\
\text { Mrad }\end{array}$ \\
\hline IDSsat/(W/L) & 0,02 & 0,03 & 0,003 & - & 0,06 & 0,04 \\
\hline $\operatorname{gmmax}_{\text {(W/L) }}$ & 0,01 & 0,003 & 0,004 & - & 0,01 & 0,02 \\
\hline gmMAX/IDSsat $_{\text {Max }}$ & 0,02 & 0,03 & 0,01 & - & 0,06 & 0,06 \\
\hline $\mathbf{R}_{\text {DSon }} /(\mathrm{L} / \mathrm{W})$ & 0,03 & 0,01 & 0,02 & - & 0,04 & 0,02 \\
\hline $\mathrm{gD}_{\mathrm{D}} /(\mathrm{W} / \mathrm{L})$ & 0,08 & 0,05 & 0,03 & - & 0,02 & 0,05 \\
\hline $\mathbf{V E A}_{\mathbf{E A}} / \mathbf{L}$ & 0,07 & 0,02 & 0,03 & - & 0,07 & 0,01 \\
\hline $\mathbf{f}_{\mathrm{T}} /(\mathbf{W} / \mathbf{L})$ & 0,01 & 0,003 & 0,004 & - & 0,01 & 0,02 \\
\hline $\mathbf{A}_{\mathbf{v}}$ & 0,07 & 0,05 & 0,03 & - & 0,01 & 0,07 \\
\hline$I_{o n} /(W / L)$ & 0,36 & 0,02 & 0,001 & - & 0,04 & 0,02 \\
\hline$I_{o f f} /(W / L)$ & 1,51 & 1,20 & 0,54 & - & 0,08 & 0,55 \\
\hline $\mathbf{I}_{\mathrm{on}} / \mathbf{I}_{\mathrm{off}}$ & 0,86 & 1,19 & 0,54 & - & 0,04 & 0,54 \\
\hline $\mathrm{ILEAK}_{\text {LW/L) }}$ & 1,29 & 0,80 & 0,02 & - & 0,11 & 0,24 \\
\hline
\end{tabular}

A Tabela 9 ilustra todos os coeficientes de variação dos parâmetros IDssat $/(\mathrm{W} / \mathrm{L})$, $\operatorname{gm}_{\mathrm{MAX}} /(\mathrm{W} / \mathrm{L}), \mathrm{gm}_{\mathrm{MAX}} / \mathrm{I}_{\mathrm{DSsat}}, \mathrm{R}_{\mathrm{DSon}} /(\mathrm{L} / \mathrm{W}), \mathrm{g}_{\mathrm{D}} /(\mathrm{W} / \mathrm{L}), \mathrm{V}_{\mathrm{EA}} / \mathrm{L}, \mathrm{f}_{\mathrm{T}} /(\mathrm{W} / \mathrm{L}), \mathrm{A}_{\mathrm{V}}, \mathrm{I}_{\mathrm{ON}} /(\mathrm{W} / \mathrm{L})$, $\mathrm{I}_{\mathrm{OFF}} /(\mathrm{W} / \mathrm{L}), \mathrm{I}_{\mathrm{ON}} / \mathrm{I}_{\mathrm{OFF}}$ e $\mathrm{I}_{\mathrm{LEAK}} /(\mathrm{W} / \mathrm{L})$ extraídos experimentalmente dos OnMs, para cada uma das TIDs estudadas neste trabalho, com os terminais em condição de Floating. 
Tabela 9 - Coeficientes de variação dos parâmetros $\mathrm{I}_{\mathrm{DSsa}} /(\mathrm{W} / \mathrm{L}), \operatorname{gm}_{\mathrm{MAX}} /(\mathrm{W} / \mathrm{L})$, $\mathrm{gm}_{\mathrm{MAX}} / \mathrm{I}_{\mathrm{DSsa}}, \mathrm{R}_{\mathrm{DSon}} /(\mathrm{L} / \mathrm{W}), \mathrm{g}_{\mathrm{D}} /(\mathrm{W} / \mathrm{L}), \mathrm{V}_{\mathrm{EA}} / \mathrm{L}, \mathrm{f}_{\mathrm{T}} /(\mathrm{W} / \mathrm{L}), \mathrm{A}_{\mathrm{V}}, \mathrm{I}_{\mathrm{ON}} /(\mathrm{W} / \mathrm{L}), \mathrm{I}_{\mathrm{OFF}} /(\mathrm{W} / \mathrm{L})$, $\mathrm{I}_{\mathrm{ON}} / \mathrm{I}_{\mathrm{OFF}}$ e $\mathrm{I}_{\mathrm{LEAK}} /(\mathrm{W} / \mathrm{L})$ extraídos experimentalmente dos OnMs, para cada uma das TIDs estudadas

\begin{tabular}{|c|c|c|c|c|c|c|}
\hline OnM & $\begin{array}{c}\text { Pre - } \\
\text { Rad }\end{array}$ & $\begin{array}{c}\mathbf{0 , 5} \\
\text { Mrad }\end{array}$ & $\begin{array}{c}1,0 \\
\text { Mrad }\end{array}$ & $\begin{array}{c}1,5 \\
\text { Mrad }\end{array}$ & $\begin{array}{c}3,0 \\
\text { Mrad }\end{array}$ & $\begin{array}{c}4,5 \\
\text { Mrad }\end{array}$ \\
\hline IDSsat/(W/L) & 0,11 & 0,17 & 0,14 & 0,14 & 0,15 & 0,16 \\
\hline $\operatorname{gmmax}_{\operatorname{ma}}(\mathrm{W} / \mathrm{L})$ & 0,13 & 0,15 & 0,16 & 0,16 & 0,16 & 0,17 \\
\hline gmMAx/IDSsat & 0,03 & 0,02 & 0,02 & 0,02 & 0,02 & 0,01 \\
\hline RdDon/(L/W) & 0,24 & 0,32 & 0,37 & 0,36 & 0,37 & 0,38 \\
\hline $\mathrm{g}_{\mathrm{D}} /(\mathrm{W} / \mathrm{L})$ & 0,27 & 0,37 & 0,35 & 0,34 & 0,34 & 0,37 \\
\hline $\mathbf{V}_{\mathrm{EA}} / \mathrm{L}$ & 0,05 & 0,01 & 0,02 & 0,01 & 0,003 & 0,02 \\
\hline$f_{T} /(W / L)$ & 0,28 & 0,34 & 0,35 & 0,36 & 0,35 & 0,36 \\
\hline $\mathbf{A}_{\mathbf{v}}$ & 0,04 & 0,03 & 0,01 & 0,01 & 0,01 & 0,01 \\
\hline $\mathrm{I}_{\mathrm{on}} /(\mathrm{W} / \mathrm{L})$ & 0,17 & 0,23 & 0,20 & 0,23 & 0,14 & 0,24 \\
\hline$I_{\text {off }} /(W / L)$ & 0,78 & 0,01 & 0,41 & 0,88 & 0,45 & 0,65 \\
\hline $\mathbf{I}_{\text {on }} / \mathbf{I}_{\text {off }}$ & 0,44 & 0,22 & 0,58 & 0,72 & 0,32 & 0,45 \\
\hline $\mathbf{I L E A K}_{\text {/W/L) }}$ & 0,53 & 0,83 & 1,06 & 0,86 & 0,59 & 0,71 \\
\hline
\end{tabular}

A Tabela 10 apresenta os valores médios dos coeficientes de variação dos parâmetros $\mathrm{I}_{\mathrm{DSsat}} /(\mathrm{W} / \mathrm{L}), \mathrm{gm}_{\mathrm{MAX}} /(\mathrm{W} / \mathrm{L}), \mathrm{gm}_{\mathrm{MAX}} / \mathrm{I}_{\mathrm{DSsat}}, \mathrm{R}_{\mathrm{DSon}} /(\mathrm{L} / \mathrm{W}), \mathrm{g}_{\mathrm{D}} /(\mathrm{W} / \mathrm{L}), \mathrm{V}_{\mathrm{EA}} / \mathrm{L}$, $\mathrm{f}_{\mathrm{T}} /(\mathrm{W} / \mathrm{L}), \mathrm{A}_{\mathrm{V}}, \mathrm{I}_{\mathrm{ON}} /(\mathrm{W} / \mathrm{L}), \mathrm{I}_{\mathrm{OFF}} /(\mathrm{W} / \mathrm{L}), \mathrm{I}_{\mathrm{ON}} / \mathrm{I}_{\mathrm{OFF}}$ e I $\mathrm{I}_{\mathrm{LEAK}} /(\mathrm{W} / \mathrm{L})$ extraídos experimentalmente dos CnMs, DnMs e OnMs, para cada uma das TIDs estudadas neste trabalho. 
Tabela 10 - Valores médios dos coeficientes de variação dos parâmetros $\mathrm{I}_{\mathrm{DSsat}} /(\mathrm{W} / \mathrm{L})$, $\mathrm{gm}_{\mathrm{MAX}} /(\mathrm{W} / \mathrm{L}), \mathrm{gm}_{\mathrm{MAX}} / \mathrm{I}_{\mathrm{DSsat}}, \mathrm{R}_{\mathrm{DSon}} /(\mathrm{L} / \mathrm{W}), \mathrm{g}_{\mathrm{D}} /(\mathrm{W} / \mathrm{L}), \mathrm{V}_{\mathrm{EA}} / \mathrm{L}, \mathrm{f}_{\mathrm{T}} /(\mathrm{W} / \mathrm{L}), \mathrm{A}_{\mathrm{V}}, \mathrm{I}_{\mathrm{ON}} /(\mathrm{W} / \mathrm{L})$, $\mathrm{I}_{\mathrm{OFF}} /(\mathrm{W} / \mathrm{L}), \mathrm{I}_{\mathrm{ON}} / \mathrm{I}_{\mathrm{OFF}}$ e $\mathrm{I}_{\mathrm{LEAK}} /(\mathrm{W} / \mathrm{L})$ extraídos experimentalmente dos CnMs, DnMs e OnMs, para cada uma das TIDs estudadas neste trabalho.

\begin{tabular}{|c|c|c|c|c|c|}
\hline & CnMs & DnMs & OnMs & $\begin{array}{c}\text { Melhor } \\
\text { Caso }\end{array}$ & Pior Caso \\
\hline IDSsat/(W/L) & 0,76 & 0,03 & 0,15 & DnM & $\mathrm{CnM}$ \\
\hline $\operatorname{gm}_{\operatorname{Max}} /(\mathrm{W} / \mathrm{L})$ & 0,75 & 0,01 & 0,16 & DnM & $\mathrm{CnM}$ \\
\hline $\operatorname{gmMAX}_{\text {MDSsat }}$ & 0,31 & 0,04 & 0,02 & OnM & $\mathrm{CnM}$ \\
\hline RDSon/(L/W) & 1,05 & 0,02 & 0,34 & DnM & $\mathrm{CnM}$ \\
\hline $\mathrm{g}_{\mathrm{D}} /(\mathrm{W} / \mathrm{L})$ & 1,09 & 0,05 & 0,34 & DnM & $\mathrm{CnM}$ \\
\hline $\mathbf{V}_{\mathbf{E A}} / \mathbf{L}$ & 0,21 & 0,04 & 0,02 & OnM & $\mathrm{CnM}$ \\
\hline $\mathbf{f} /(\mathbf{W} / L)$ & 1,01 & 0,01 & 0,34 & DnM & $\mathrm{CnM}$ \\
\hline$A_{v}$ & 0,45 & 0,05 & 0,02 & OnM & $\mathrm{CnM}$ \\
\hline$I_{o n} /(W / L)$ & 0,75 & 0,09 & 0,20 & DnM & $\mathrm{CnM}$ \\
\hline$I_{\text {off }} /(W / L)$ & 0,56 & 0,78 & 0,53 & OnM & DnM \\
\hline $\mathbf{I}_{\text {on }} / \mathbf{I}_{\text {off }}$ & 0,63 & 0,63 & 0,45 & OnM & $\mathrm{CnM} / \mathrm{DnM}$ \\
\hline ILEAK/(W/L) & 0,65 & 0,49 & 0,76 & DnM & OnM \\
\hline
\end{tabular}

Da Tabela 10, ao efetuar a comparação dos coeficientes de variação dos CnMs, DnMs e OnMs, pode-se concluir que quanto menor for o valor do coeficiente de variação, maior será a robustez deste dispositivo aos efeitos das radiações ionizantes de raios-X, isto é, menor será a variabilidade da variação paramétrica (menor dispersão das variações das grandezas medidas). Desta forma, verifica-se que somente em relação aos parâmetros I IFF/(W/L), ION/ IOFF e I IEAK/(W/L) os DnMs e OnMs apresentam um maior descasamento médio entre dispositivos em comparação aos $\mathrm{CnMs}$, que mesmo em detrimento à atuação do DEPAMBBRE, pode-se justificar este comportamento devido às áreas de porta dos OnMs e DnMs serem muito maiores em comparação aos CnMs. Ademais, verifica-se que no caso dos DnMs houve um annealing maior entre as medidas para as TIDs de $1 \mathrm{Mrad}$ e $3 \mathrm{Mrad}$. Este comportamento pode ser justificado em função do maior perímetro da região de junção entre porta e dreno do leiaute de porta octogonal e hexagonal quando 
comparado ao MOSFET convencional equivalente. Além disso, este comportamento também pode ser justificado em função do efeito LCE existente nos DnMs e OnMs, quando comparado aos CnMs.

Em relação ao parâmetro $\mathrm{I}_{\mathrm{DSsat}} /(\mathrm{W} / \mathrm{L})$, verifica-se que os valores médios dos coeficientes de variação dos DnMs e OnMs são menores em comparação aos obtidos para os CnMs (96,1\% em relação ao DnM e 80,3\% em relação ao OnM). Isso ocorre devido aos efeitos LCE e PAMDLE que potencializam o campo elétrico longitudinal nas estruturas dos DnMs e OnMs, aumentando, portanto, o valor médio das I $\mathrm{DSsat} /(\mathrm{W} / \mathrm{L})$.

Quando se observa o comportamento das transcondutâncias máximas normalizadas pela razão de aspecto, verifica-se que os valores médios dos coeficientes de variação dos DnMs e OnMs são também bastante menores em comparação aos obtidos para os CnMs (98,6\% em relação ao DnM e 78,6\% em relação ao OnM). Pode-se explicar este comportamento devido ao DEPAMBBRE presentes nas estruturas dos DnMs e OnMs, que reduzem de forma significativa o efeito dos transistores parasitários presentes nas regiões de bico de pássaro presentes nestes dispositivos.

Por meio dos resultados obtidos em relação aos parâmetros gm MAX $_{\mathrm{DSSat}}$ dos DnMs, OnMs e CnMs, é possível observar que os DnMs e OnMs apresentam melhores resultados no regime de inversão forte em relação aos resultados obtidos nos CnMs. Os DnMs e OnMs apresentam valores médios menores dos coeficientes de variação, em relação a gm $\mathrm{MAX}_{\mathrm{D}} / \mathrm{I}_{\mathrm{DSsat}}$, que dos CnMs (87,1\% em relação aos DnMs e 93,5\% em relação aos OnMs).

Em relação à resistência de estado ligado normalizado em relação ao inverso da razão de aspecto (L/W), observa-se que os DnMs e OnMs apresentam valores médios dos coeficientes de variação menores em cerca de $98,1 \%$ e $67,6 \%$, respectivamente, que dos CnMs. Este resultado pode ser explicado como consequência dos efeitos PAMDLE e LCE presentes nas estruturas dos DnMs e OnMs. Por apresentarem menores resistências de estado ligado, os DnMs e OnMs tendem a apresentar melhores velocidades de chaveamento e menores potências dissipadas em comparação com os CnMs, considerando-se a mesma área de porta, mesma largura de canal e mesmas condições de polarização.

Ademais, as tensões Early normalizadas em relação à "L" nos DnMs e OnMs apresentam valores médios dos coeficientes de variação menores em cerca de $80,9 \%$ e 90,5\%, respectivamente, que dos CnMs. Essa degradação da tensão Early pode ser 
compreendida em função do menor comprimento efetivo de canal dos CnMs quando comparado com os DnMs e OnMs.

Os DnMs e OnMs apresentaram valores médios dos coeficientes de variação do ganho de $A_{V}$ (na inversão forte) de 88,9\% e 95,5\%, respectivamente, menores que dos CnMs. Este comportamento pode ser explicado devido aos excelentes desempenhos apresentados dos DnMs e OnMs nas análises dos parâmetros gm $\mathrm{MAX}_{\mathrm{X}} / \mathrm{I}_{\mathrm{DSsat}}$ no regime de inversão forte e da tensão Early normalizada em relação à "L".

Em relação às gD normalizadas em relação à (W/L) (na inversão forte), os DnMs e OnMs apresentaram valores médios dos coeficientes de variação menores que dos CnMs em cerca de $95,4 \%$ e $68,8 \%$, respectivamente. Este comportamento pode ser explicado devido aos desempenhos apresentados dos DnMs e OnMs nas análises dos parâmetros $\mathrm{I}_{\mathrm{DSsat}} /(\mathrm{W} / \mathrm{L})$ e da tensão Early normalizada em relação à "L".

Além disso, verifica-se que os DnMs e OnMs ainda apresentaram valores médios dos coeficientes de variação das $f_{T} s$ normalizadas em relação à (W/L) menores que 99\% e 66,3\%, respectivamente, em comparação aos resultados obtidos com os CnMs. Pode-se verificar que a frequência de ganho de tensão unitário dos DnMs e OnMs sofrem influência devido aos efeitos LCE e PAMDLE presentes nas suas estruturas, que permitem potencializar os seus campos elétricos longitudinais.

Ao se analisarem os gráficos apresentados na Figura 59, pode-se verificar que para a condição pré-irradiação, os parâmetros extraídos de CnMs sempre apresentam um maior coeficiente de variação em comparação aos DnMs e OnMs, à exceção dos parâmetros $\mathrm{I}_{\mathrm{LEAK}} /(\mathrm{W} / \mathrm{L})$ e $\mathrm{I}_{\mathrm{OFF}} /(\mathrm{W} / \mathrm{L})$ para os dispositivos DnMs. Isto ocorre pois que o desvio-padrão encontrado para estes dois parâmetros em relação à DnMs são os maiores em comparação aos CnMs e OnMs.

Na Figura 59, para a TID igual a 0,5 Mrad, os dispositivos DnMs apresentam um maior coeficiente de variação para os parâmetros $\mathrm{I}_{\mathrm{OFF}} /(\mathrm{W} / \mathrm{L})$ e ION/IOFF $\left(\varepsilon_{\mathrm{IOFF} /(\mathrm{W} / \mathrm{L}): 119,7}\right.$ \% e $\varepsilon_{\text {ION/IOFF }}: 119,2$ \%) em comparação aos CnMs ( $\varepsilon_{\operatorname{IOFF} /(\mathrm{W} / \mathrm{L})}: 10,9$ \% e $\varepsilon_{\mathrm{ION} / \mathrm{IOFF}}: 90,6$ \%) e OnMs $\left(\varepsilon_{\mathrm{IOFF} /(\mathrm{W} / \mathrm{L})}: 1,24 \%\right.$ e $\left.\varepsilon_{\mathrm{ION} / \mathrm{IOFF}}: 21,8 \%\right)$. Uma possível justificativa para este comportamento está no fato de que os desvios-padrão encontrados para estes dois parâmetros, em relação à DnMs, serem os maiores. Para os demais parâmetros (com exceção para o parâmetro $\mathrm{V}_{\mathrm{EA}} /(\mathrm{L})$, onde se verifica que os coeficientes de variação dos DnMs, OnMs e CnMs são praticamente equivalentes, isto é: DnMs: 1,8 \%; OnMs: 4,9 \%; CnMs: 0,4 \%), verifica-se que os coeficientes de variação dos CnMs são sempre superiores em comparação aos calculados para os dispositivos DnMs e OnMs. 
Para a TID igual a 1,0 Mrad, os dispositivos OnMs apresentam um maior coeficiente de variação para os parâmetros $\mathrm{I}_{\mathrm{LEAK}} /(\mathrm{W} / \mathrm{L})$ e $\mathrm{I}_{\mathrm{ON}} / \mathrm{I}_{\mathrm{OFF}}\left(\varepsilon_{\mathrm{ILEAK}} / \mathrm{W} / \mathrm{L}\right): 106,1$ \% e $\varepsilon_{\text {ION/IOFF }}: 57,8 \%$ ) em comparação aos CnMs ( $\varepsilon_{\text {ILEAK/(W/L) }}: 33,9 \%$ e $\varepsilon_{\text {ION/IOFF }}: 52,1 \%$ ) e DnMs $\left(\varepsilon_{\mathrm{ILEAK} /(\mathrm{W} / \mathrm{L})}: 2,02 \%\right.$ e $\left.\varepsilon_{\mathrm{ION} / \mathrm{IOFF}}: 54,1 \%\right)$. Isto ocorre pois o desvio-padrão encontrado para estes dois parâmetros em relação à OnMs são os maiores em comparação aos CnMs e DnMs. Para o parâmetro gm MAX $_{\text {DSsat, }}$ observa-se que os coeficientes de variação dos DnMs, OnMs e CnMs são praticamente equivalentes, isto é: DnMs: 0,69 \%; OnMs: 1,5 \%; CnMs: 0,56 \%. Para os demais parâmetros verifica-se que os coeficientes de variação dos CnMs são sempre superiores em comparação aos calculados para os dispositivos DnMs e OnMs.

Para a TID igual a 1,5 Mrad, observa-se que não há o cálculo dos coeficientes de variação para os dispositivos DnMs, isto ocorre pois que estes não estavam funcionando apropriadamente mesmo para a condição de pré-irradiação, assim optou-se por não utilizar os dados destes dispositivos para esta TID analisada. Os dispositivos OnMs apresentam um maior coeficiente de variação para os parâmetros $\mathrm{I}_{\mathrm{OFF}} /(\mathrm{W} / \mathrm{L})$ e $\mathrm{I}_{\mathrm{ON}} / \mathrm{I}_{\mathrm{OFF}}$ ( $\left.\varepsilon_{\mathrm{IOFF} /(\mathrm{W} / \mathrm{L})}: 88,1 \%, \varepsilon_{\mathrm{ION} / \mathrm{IOFF}}: 72,1 \%\right)$ em comparação aos $\mathrm{CnMs}\left(\varepsilon_{\mathrm{IOFF} /(\mathrm{W} / \mathrm{L})}: 46,8\right.$ \% e EION/IOFF: 43,1 \%). Isto ocorre pois o desvio-padrão encontrado para estes dois parâmetros em relação à OnMs são os maiores em comparação aos CnMs. Para os demais parâmetros verifica-se que os coeficientes de variação dos CnMs são sempre superiores em comparação aos calculados para os dispositivos OnMs.

Para a TID igual a 3,0 Mrad, os dispositivos OnMs apresentam um maior coeficiente de variação para os parâmetros $\mathrm{I}_{\mathrm{LEAK}} /(\mathrm{W} / \mathrm{L})$ e $\mathrm{I}_{\mathrm{OFF}} /(\mathrm{W} / \mathrm{L})\left(\varepsilon_{\mathrm{ILEAK} /(\mathrm{W} / \mathrm{L})}: 58,7\right.$ \%,

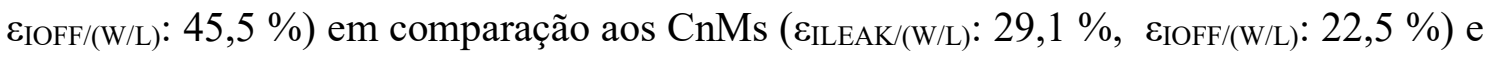
DnMs $\left(\varepsilon_{\mathrm{ILEAK} /(\mathrm{W} / \mathrm{L})}: 10,8 \%, \varepsilon_{\mathrm{IOFF} /(\mathrm{W} / \mathrm{L})}:\right.$ 7,56 \%). Isto pode ser justificado estatisticamente pois o desvio-padrão encontrado para estes dois parâmetros em relação à OnMs são os maiores em comparação aos CnMs e DnMs. Para os DnMs, verifica-se que os coeficientes de variação para os parâmetros gm $\mathrm{MAX}_{\mathrm{A}} / \mathrm{I}_{\mathrm{DSsat}} \mathrm{e} \mathrm{V}_{\mathrm{EA}}$ são superiores em comparação aos coeficientes de variação extraídos para os dispositivos CnM e OnM, porém os valores são muito próximos entre si e em uma escala que não alcança nem a 10\%. Para os demais parâmetros verifica-se que os coeficientes de variação dos CnMs são sempre superiores em comparação aos calculados para os dispositivos DnMs e OnMs.

Por fim, para uma TID igual a 4,5 Mrad, verifica-se que os DnMs apresentam um maior coeficiente de variação para o parâmetro ION/ IOFF $(54,1 \%)$ e os OnMs apresentam um maior coeficiente de variação para o parâmetro $\mathrm{I}_{\text {ILEAK/(W/L) }}(71,2 \%)$. Para os demais 
parâmetros analisados, verifica-se que os CnMs sempre apresentaram um maior coeficiente de variação em comparação aos coeficientes de variação extraídos dos DnMs e OnMs. Uma possível explicação para este comportamento observado refere-se ao maior perímetro da região de junção entre porta e dreno do leiaute de porta octogonal e hexagonal quando comparado ao de seu MOSFET convencional equivalente. Ademais, este comportamento também pode ser explicado em função da existência do efeito LCE nos DnMs e OnMs quando comparado aos CnMs.

\subsection{ANÁLISE COMPARATIVA EXPERIMENTAL ESTATÍSTICA DOS EFEITOS DA TID ENTRE UM MOSFET DE PORTA OCTOGONAL E RETANGULAR, POLARIZADOS NO MODO ON-STATE DURANTE OS PROCEDIMENTOS DAS RADIAÇÕES IONIZANTES DE RAIOS-X}

Para análise dos efeitos da TID nos nMOSFETs de porta octogonal (OnM) e retangular $(\mathrm{CnM})$ quando submetidos às radiações ionizantes por raios-X e valendo-se da aplicação de $\mathrm{V}_{\mathrm{DD}}(1,2 \mathrm{~V})$ ao terminal da porta e $0 \mathrm{~V}$ nos demais terminais dos MOSFETs durante o procedimento das radiações ionizantes (On-state), foram utilizados 4 dispositivos (2 OnMs e 2 CnMs) em 1 chip. A Figura 60 ilustra o procedimento para a realização do estudo do casamento entre dispositivos (por meio da utilização do coeficiente de variação) entre os parâmetros elétricos extraídos experimentalmente dos OnMs e CnMs. 
Figura 60 - Ilustração do procedimento para a realização do estudo do casamento entre os parâmetros elétricos extraídos experimentalmente dos OnMs e CnMs

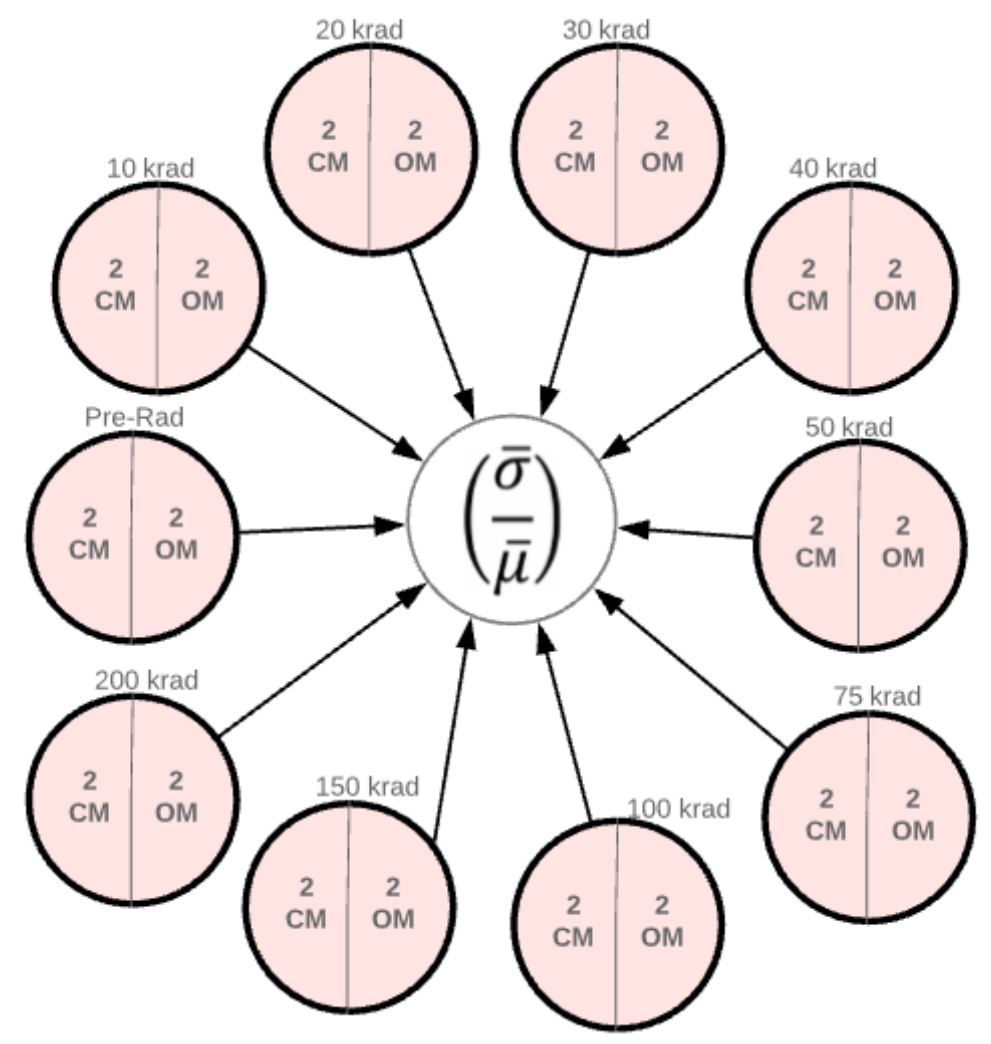

Fonte: Autor.

De acordo com a Figura 60, foram investigados 2 OnMs e 2 CnMs provenientes de um mesmo CI. Portanto, o estudo foi realizado com uma quantidade total de 4 MOSFETs (2 OnM e $2 \mathrm{CnM}$ ). Os valores de Ws e Ls dos CnMs são iguais a 0,4 $\mu \mathrm{m}$ e $0,16 \mu \mathrm{m}$ e dos CnMs são iguais a $0,8 \mu \mathrm{m}$ e $0,16 \mu \mathrm{m}$, respectivamente. Os valores de $\mathrm{W}$, b, B, ângulo alfa $(\alpha)$ e o fator de corte (c) para os OnMs são iguais a 1,52 $\mu \mathrm{m}, 0,69 \mu \mathrm{m}$, $1,49 \mu \mathrm{m}, 90^{\circ}$ e $50 \%$ e também $0,7 \mu \mathrm{m}, 0,4 \mu \mathrm{m}, 0,91 \mu \mathrm{m}, 90^{\circ}$ e $50 \%$, respectivamente.

Além disso, o chip foi exposto às seguintes doses: $10 \mathrm{krad}, 20 \mathrm{krad}, 30 \mathrm{krad}, 40$ $\mathrm{krad}, 50 \mathrm{krad}, 75 \mathrm{krad}, 100 \mathrm{krad}, 150 \mathrm{krad}$ e $200 \mathrm{krad}$. A taxa de dose escolhida para a realização deste estudo foi definida pelo mínimo permitido pelo radiador de raios-X (70 $\mathrm{krad} / \mathrm{h}$ ), a fim de compreender o comportamento desses dispositivos em uma menor taxa de dose e um maior número de pontos medidos para a TID de radiações ionizantes de raios-X.

Os parâmetros elétricos foram obtidos a partir das curvas da corrente de dreno $\left(\mathrm{I}_{\mathrm{DS}}\right)$ em função da tensão de porta $\left(\mathrm{V}_{\mathrm{GS}}\right)$, com a tensão de dreno $\left(\mathrm{V}_{\mathrm{DS}}\right)$ de $50 \mathrm{mV}$ para 
obter os valores da tensão de limiar $\left(\mathrm{V}_{\mathrm{TH}}\right)$ e da inclinação de sublimiar (SS). Os dispositivos CnMs pararam de funcionar adequadamente para uma TID de $300 \mathrm{krad} \mathrm{e}$, consequentemente, essa dose foi considerada como a máxima utilizada neste estudo.

Iremos efetuar a análise do coeficiente de variação em função das TIDs estudadas neste trabalho dos parâmetros $\mathrm{V}_{\mathrm{TH}}$ e $\mathrm{SS}$ extraídas experimentalmente dos dispositivos OnMs e CnMs.

\subsubsection{Análise do Coeficiente de Variação da Tensão de Limiar ( $\left.V_{T H}\right)$ em Função das TIDs Estudadas}

Para se efetuar a extração do parâmetro $\mathrm{V}_{\mathrm{TH}}$ dos dispositivos OnMs e CnMs, utilizou-se a segunda derivada da curva $\mathrm{I}_{\mathrm{DS}}$ em função de $\mathrm{V}_{\mathrm{GS}}$, considerando $\mathrm{V}_{\mathrm{DS}}$ igual a $50 \mathrm{mV}$.

A Figura 61 ilustra os coeficientes de variação nas condições de pré e pósirradiação das $\mathrm{V}_{\mathrm{THS}}$ extraídas experimentalmente dos OnMs e CnMs, em função da TID estudada. Os coeficientes de variação das $\mathrm{V}_{\mathrm{TH}} \mathrm{S}$ na condição de dose zero levam em consideração 2 CnMs e 2 OnMs, enquanto nas condições de pós-irradiação usamos estes mesmos 2 CnMs e 2 OnMs, utilizados na condição de pré-irradiação para cada TID aplicada (ou seja, $10 \mathrm{krad}, 20 \mathrm{krad}, 30 \mathrm{krad}, 40 \mathrm{krad}, 50 \mathrm{krad}, 75 \mathrm{krad}, 100 \mathrm{krad}, 150 \mathrm{krad}$ e $200 \mathrm{krad}$ ), isto é, 10 pontos de medição a partir da condição de pré-radiação até a TID de $200 \mathrm{krad}$. 
Figura 61 - Os coeficientes de variação pré e pós-irradiação das $\mathrm{V}_{\mathrm{TH}} \mathrm{S}$ dos OnMs e CnMs em função da TID estudada, para $\mathrm{V}_{\mathrm{DS}}$ igual a $50 \mathrm{mV}$

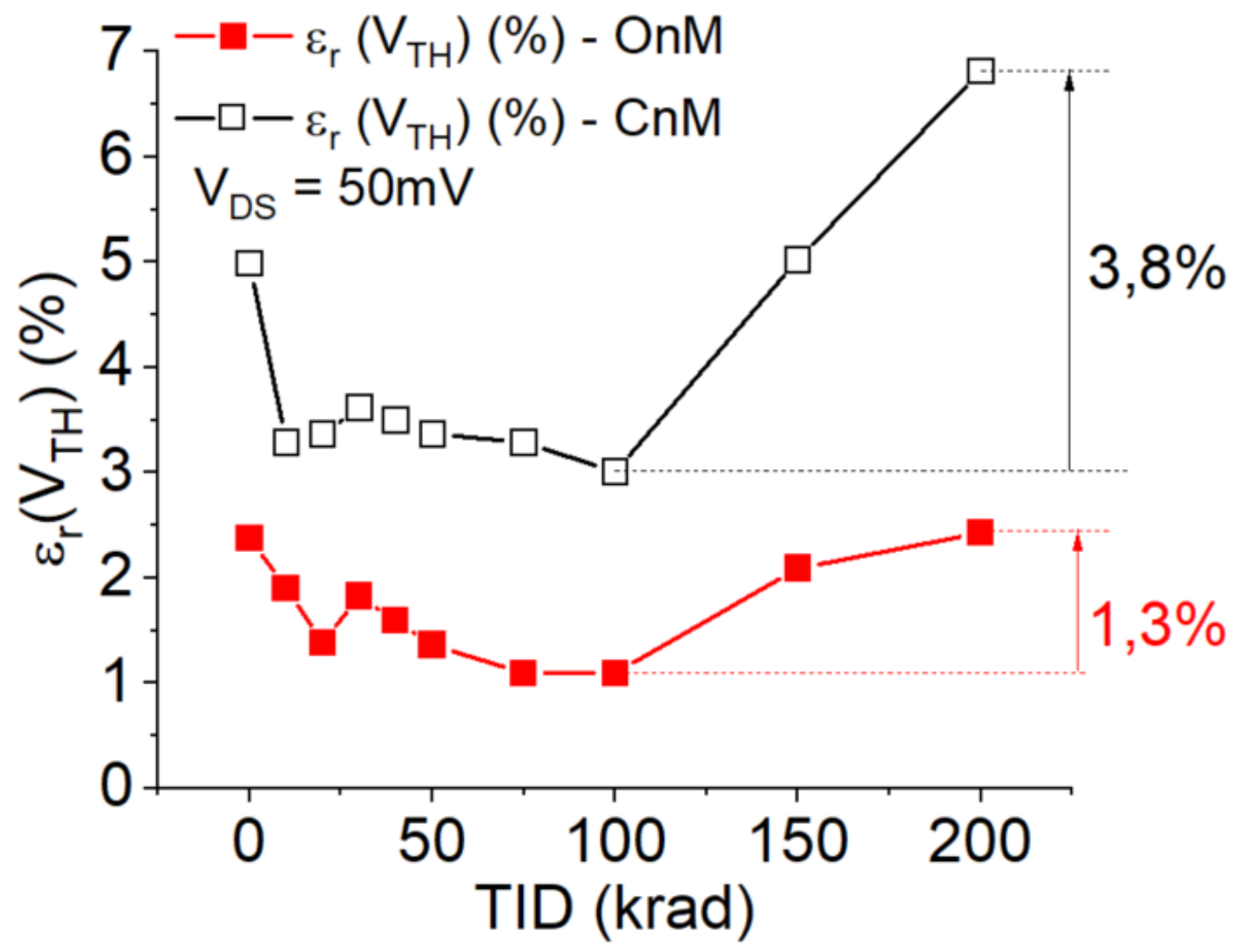

Fonte: Autor.

Em relação à Figura 61, para a condição inicial, observa-se que os coeficientes de variação da tensão limiar $\left(\mathrm{V}_{\mathrm{TH}}\right)$ para 2 OnMs é igual a 2,4 \% e para $2 \mathrm{CnMs}$ é igual a 5,0 \%. Isso ocorre porque o valor médio das $\mathrm{V}_{\mathrm{THS}}$ dos dispositivos OnMs é aproximadamente igual a $320 \mathrm{mV}$ e os desvios-padrão dessas amostras são iguais a 7,6 mV, enquanto a média das $\mathrm{V}_{\mathrm{THS}}$ dos dispositivos CnMs é aproximadamente igual a $420 \mathrm{mV}$ e os desviospadrão dessas amostras são iguais a $21,2 \mathrm{mV}$.

No entanto, à medida que a TID aumenta, as diferenças dos coeficientes de variação (casamento entre dispositivos) dos OnMs e CnMs aumentam, porém de formas distintas entre si. Isso ocorre porque os coeficientes de variação das $\mathrm{V}_{\mathrm{TH}} \mathrm{S}$ dos OnMs são mantidos praticamente constantes devido principalmente à atuação do DEPAMBBRE que suprime os MOSFETs parasitas nos BBRs, enquanto os erros relativos dos CnMs aumentam, isto é, não somente há um aumento dos valores médios dos valores das $\mathrm{V}_{\mathrm{TH}} \mathrm{S}$, mas também um aumento significativo dos desvios-padrão das $\mathrm{V}_{\mathrm{THS}}$ dos $\mathrm{CnMs}$ ( $\mathrm{V}_{\mathrm{TH}}$ mudando para a direita de forma mais pronunciada a partir de $100 \mathrm{krad}$, mostrando que 
há mais cargas positivas na interface $\mathrm{SiO}_{2} /$ Silício $(\mathrm{Si})$ do que no óxido de porta $\left.\left(\mathrm{SiO}_{2}\right)\right)$ devido à condição On-state dos dispositivos CnMs e também da radiação ionizante de raios-X, conforme a TID aumenta.

Assim, pode-se observar que os OnMs apresentam uma tolerância da TID de raios-X mais alta de $100 \mathrm{krad}$ até $200 \mathrm{krad}$ do que os observados nos CnMs (OnMs: 1,1\% e CnMs: 3,0 \% para uma TID de $100 \mathrm{krad}$; OnMs: 2,1 \% e CnMs: 5,0 \% para uma TID de $150 \mathrm{krad}$; OnMs: 2,5 \% e CnMs: 6,8 \% para uma TID de $200 \mathrm{krad}$ ). Além disso, a diferença máxima entre os coeficientes de variação das $\mathrm{V}_{\mathrm{THS}}$ dos CnMs é de 3,8\%, enquanto a dos OnMs é de apenas 1,3\% (diferença percentual de 2,5\%), e, portanto, pode-se concluir que os OnMs apresentam praticamente a mesma tolerância da TID de raios-X do que a obtida nos CnMs.

\subsubsection{Análise do Coeficiente de Variação da Inclinação de Sublimiar (SS) em} Função das TIDs Estudadas

A Figura 62 ilustra os coeficientes de variação nas condições de pré-irradiação e pós-irradiação das inclinações de sublimiar (SSs) extraídas experimentalmente dos OnMs e CnMs, em função da TID. Os coeficientes de variação das SSs na condição de dose zero levam em consideração $2 \mathrm{CnMs}$ e 2 OnMs, enquanto nas condições de pós-irradiação usamos estes mesmos 2 CnMs e 2 OnMs utilizados na condição de pré-irradiação para cada TID aplicada $(10 \mathrm{krad}, 20 \mathrm{krad}, 30 \mathrm{krad}, 40 \mathrm{krad}, 50 \mathrm{krad}, 75 \mathrm{krad}, 100 \mathrm{krad}, 150$ krad e $200 \mathrm{krad}$ ), isto é, 10 pontos de medição a partir da condição de pré-irradiação até a TID de $200 \mathrm{krad}$. 
Figura 62 - Os coeficientes de variação pré e pós-irradiação das SSs dos OnMs e CnMs em função da TID estudada, para $\mathrm{V}_{\mathrm{DS}}$ igual a $50 \mathrm{mV}$

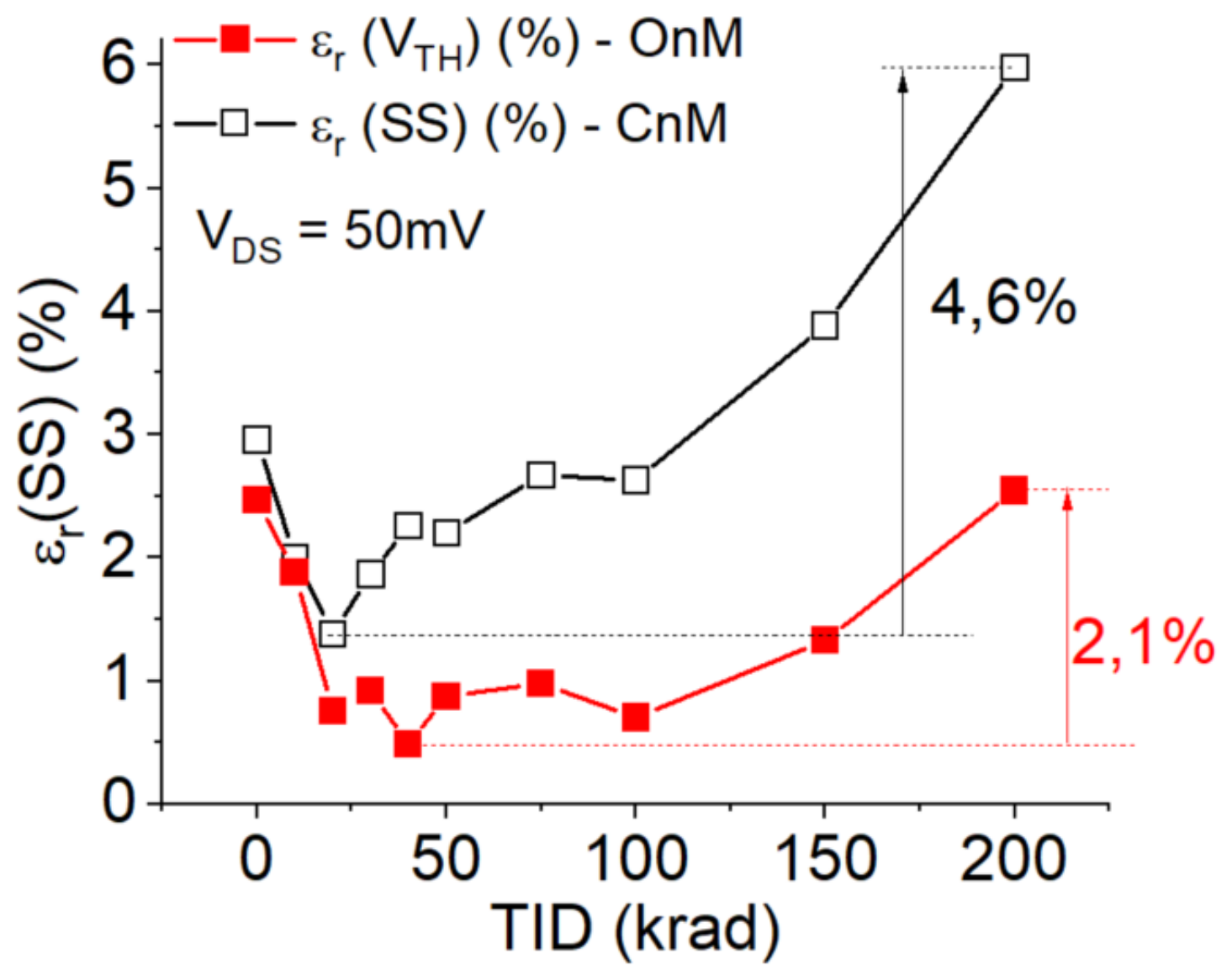

Fonte: Autor.

Analisando-se a Figura 62, em relação às condições de pré-irradiação, o coeficiente de variação das SSs (casamento entre dispositivos) de uma amostra de 2 OnMs é igual a 2,5\%, enquanto o coeficiente de variação das SSs da amostra de 2 CnMs é de 3 \%. Isso ocorre porque embora o valor médio das SSs dos OnMs $(87,3 \mathrm{mV} / \mathrm{dec}$.) seja menor do que o valor médio das SSs dos CnMs (91,3 mV / dec.), o desvio-padrão das SSs dos OnMs (2,15 mV / dec.) é menor do que o observado nos CnMs (2,7 mV / dec.).

Além disso, à medida que a TID aumenta, as diferenças entre os coeficientes de variação dos parâmetros SSs em relação aos dispositivos OnMs e CnMs aumentam significativamente de $30 \mathrm{krad}(0,95 \%$ : 0,91\% para os OnMs e 1,86\% para os CnMs) até $250 \mathrm{krad}(3,44 \%: 2,54 \%$ para os OnMs e 5,98\% para os CnMs). Isso é explicado principalmente pelo DEPAMBBRE, que encurva as linhas RLEF nos BBRs dos OnMs, reduzindo o funcionamento dos MOSFETs parasitas. Portanto, as cargas positivas induzidas na interface dos BBRs pela radiação ionizante de raios-X influenciam menos a 
qualidade de parte da interface de Silício / Óxido de Silício $\left(\mathrm{Si} / \mathrm{SiO}_{2}\right)$ dos OnMs, ao contrário do que está acontecendo na interface $\mathrm{Si} / \mathrm{SiO}_{2}$ com os BBRs dos CnMs.

Ademais, a diferença máxima entre os coeficientes de variação das SSs (casamento entre dispositivos) dos CnMs é 4,6 \% (para $20 \mathrm{krad}$ da TID: 1,38\% e para $200 \mathrm{krad}$ da TID: 5,98 \%), enquanto para os OnMs é igual a 2,1\% (para $40 \mathrm{krad}$ da TID: 0,44\% e para $200 \mathrm{krad}$ da TID: 2,54\%). Esses resultados indicam que os OnMs apresentam praticamente a mesma tolerância à radiação ionizante de raios-X que os $\mathrm{CnMs}$ equivalentes.

A Figura 63 ilustra a $\mathrm{V}_{\mathrm{TH}}$ como uma função da SS para as diferentes TIDs aplicadas nos OnMs e nos CnMs (2 amostras de cada), para os dispositivos irradiados na condição de polarização On-state, para $\mathrm{V}_{\mathrm{DS}}$ igual a $50 \mathrm{mV}$.

Figura 63 - Gráfico que relaciona os valores das $\mathrm{V}_{\mathrm{THS}}$ em função das SSs extraídas experimentalmente dos OnMs e CnMs em função das TIDs aplicadas, para os dispositivos irradiados na condição de polarização On-state, para $V_{D s}$ igual a $50 \mathrm{mV}$

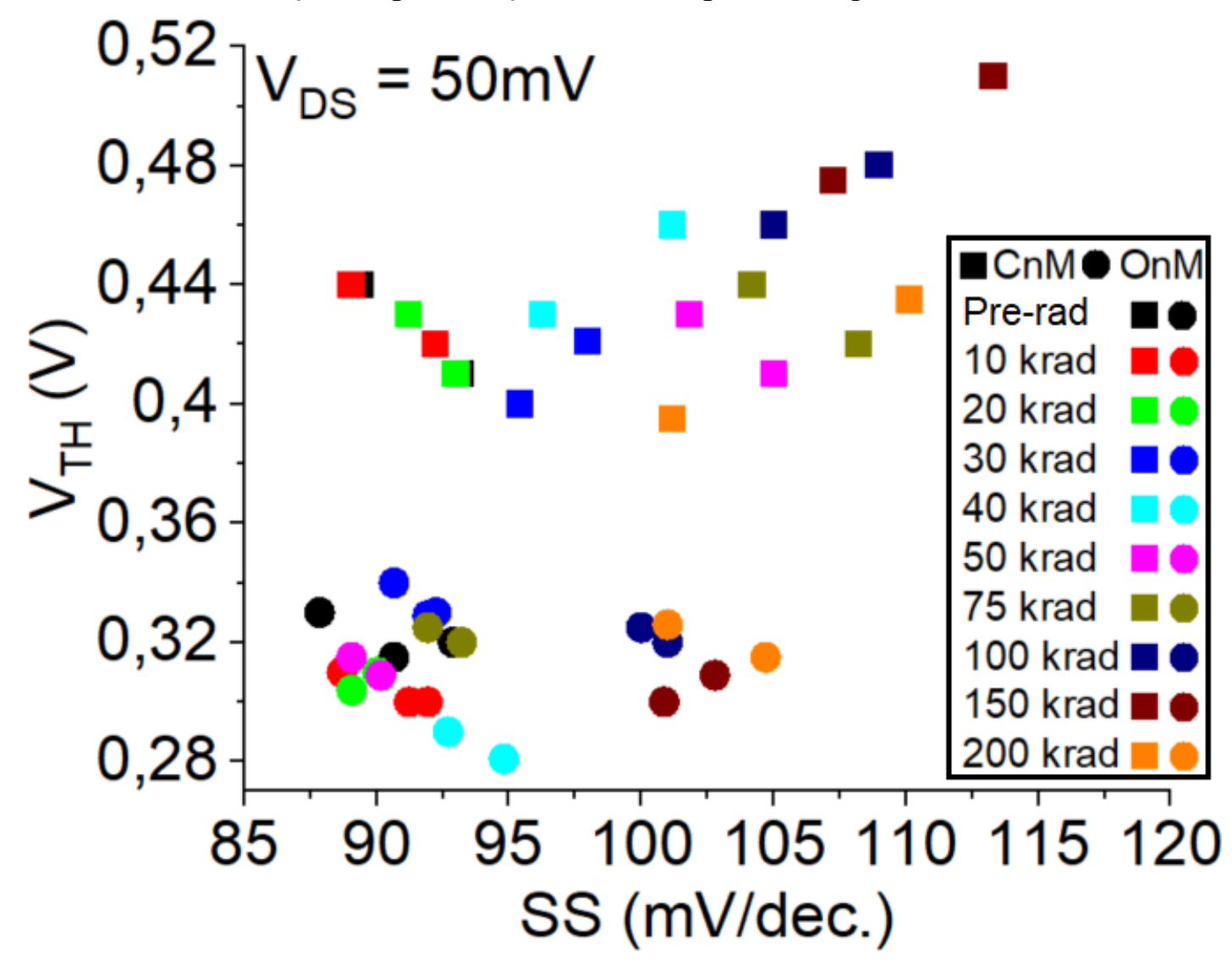

Fonte: Autor. 
Analisando-se a Figura 63, pode-se observar que as SSs obtidas dos dispositivos OnMs apresentam um espalhamento menor do que as observadas nos CnMs. As diferenças máximas para as $\mathrm{V}_{\mathrm{THS}}$ e as SSs dos CnMs, em relação a todas as TIDs, são iguais a $0,12 \mathrm{~V}$ e $24,3 \mathrm{mV} /$ dec., respectivamente, e as diferenças máximas para as $\mathrm{V}_{\mathrm{TH}} \mathrm{S}$ e as SSs dos OnMs, para todas as TIDs, são iguais a 0,06 V e 16,8 mV/ dec. A Tabela 11 resume os valores dos desvios-padrão das $\mathrm{V}_{\mathrm{TH}} \mathrm{S}$ extraídas experimentalmente dos dispositivos OnMs e CnMs em função das TIDs estudadas.

Tabela 11 - Valores dos desvios-padrão das $\mathrm{V}_{\mathrm{TH}} \mathrm{S}$ extraídas experimentalmente dos dispositivos OnMs e CnMs em função das TIDs estudadas

\begin{tabular}{|c|c|c|c|c|c|c|}
\hline $\begin{array}{l}S_{V_{T H}} \\
(\mathrm{mV})\end{array}$ & Pré-Rad & $10 \mathrm{krad}$ & $20 \mathrm{krad}$ & $30 \mathrm{krad}$ & $40 \mathrm{krad}$ & $50 \mathrm{krad}$ \\
\hline OnM & 7,6 & 7,1 & 4,2 & 7,1 & 6,4 & 4,2 \\
\hline CnM & 21,2 & 14,1 & 14,2 & 14,8 & 21,2 & 14,1 \\
\hline $\begin{array}{l}S_{V_{T H}} \\
(\mathrm{mV})\end{array}$ & $75 \mathrm{krad}$ & $100 \mathrm{krad}$ & $150 \mathrm{krad}$ & $200 \mathrm{krad}$ & $\begin{array}{l}\text { Máxima } \\
\text { Diferença }\end{array}$ & \\
\hline OnM & 3,5 & 3,6 & 6,4 & 7,9 & 3,7 & \\
\hline $\mathrm{CnM}$ & 14,2 & 14,2 & 24,7 & 28,3 & 14,2 & \\
\hline
\end{tabular}

A Figura 64 apresenta os dados plotados em um gráfico dos desvios-padrão em relação às $\mathrm{V}_{\mathrm{TH}}$ s extraídas experimentalmente dos dispositivos DnMs, OnMs e CnMs em função das TIDs estudadas que estão apresentados na Tabela 11. 
Figura 64 - Valores dos desvios-padrão em relação às $V_{T H}$ extraídas experimentalmente dos dispositivos DnMs, OnMs e CnMs em função das TIDs estudadas, na condição de polarização On-State, durante o procedimento das radiações ionizantes de raios-X

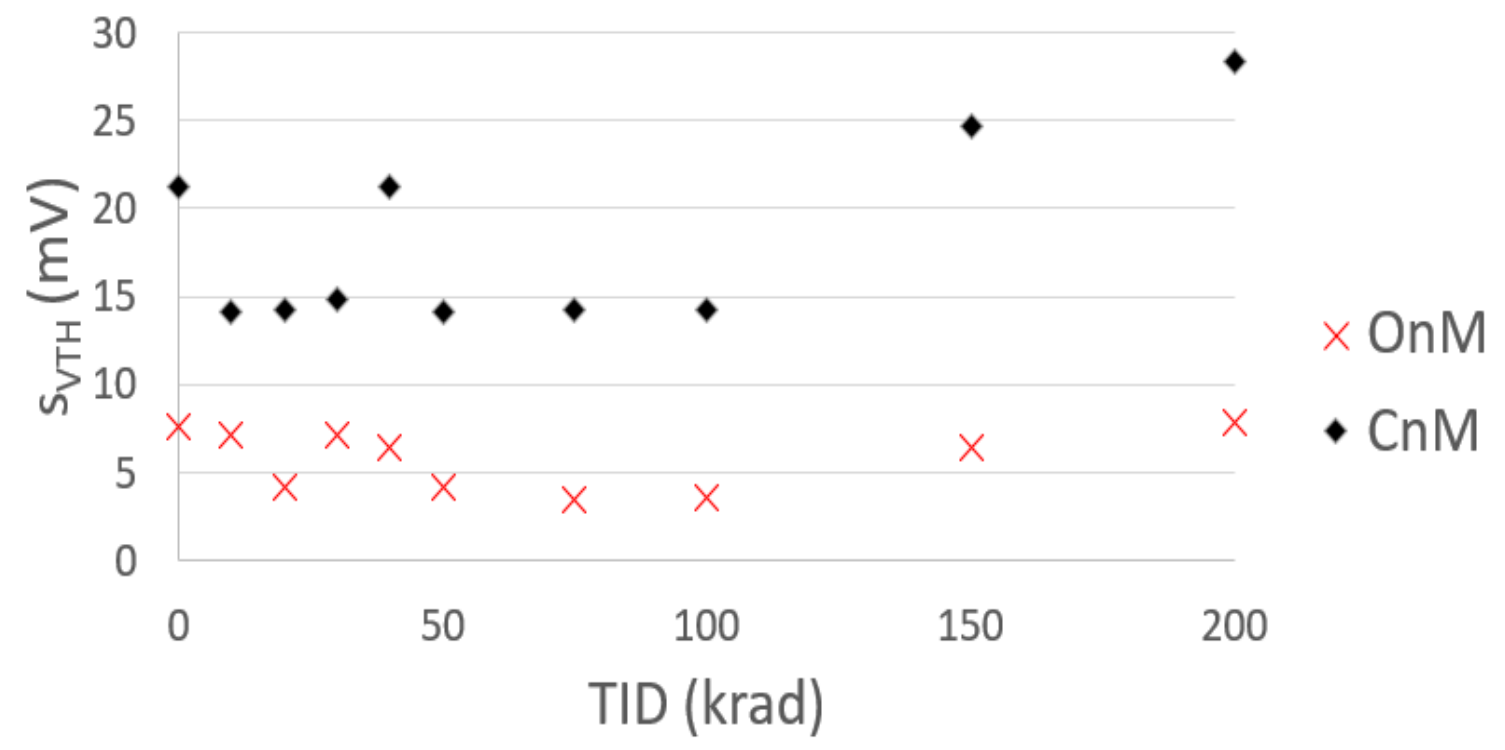

Analisando-se os resultados apresentados na Tabela 11 e na Figura 64, pode-se afirmar que o maior desvio-padrão em relação às $\mathrm{V}_{\mathrm{THS}}$ dos OnMs é para uma TID de 200 krad $(7,9 \mathrm{mV})$ e para os CnMs o maior desvio-padrão é encontrado para a TID de 200 krad (28,3 mV). Já o menor desvio-padrão encontrado, em relação às $\mathrm{V}_{\mathrm{TH}} \mathrm{S}$, para os OnMs $(4,2 \mathrm{mV})$ ocorre para a TID de $20 \mathrm{krad}$ e para os CnMs $(14,1 \mathrm{mV})$ ocorre para a TID de $10 \mathrm{krad}$. Pode-se observar também que o dispositivo que apresentou menor diferença entre os desvios-padrão foi o OnM, com uma diferença máxima de $3,7 \mathrm{mV}$.

A Tabela 12 resume os valores dos desvios-padrão das SSs dos dispositivos OnMs e CnMs em função das TIDs estudadas.

Tabela 12 - Valores dos desvios-padrão das SSs extraídas experimentalmente dos dispositivos OnMs e CnMs em função das TIDs estudadas

\begin{tabular}{|c|c|c|c|c|c|c|}
\hline $\begin{array}{c}S_{S S} \\
(\mathrm{mV} / \mathrm{déc} .)\end{array}$ & Pré-Rad & $10 \mathrm{krad}$ & $20 \mathrm{krad}$ & $30 \mathrm{krad}$ & $40 \mathrm{krad}$ & $50 \mathrm{krad}$ \\
\hline OnM & 2,15 & 0,5 & 0,7 & 0,2 & 1,5 & 0,8 \\
\hline $\mathrm{CnM}$ & 2,7 & 2,3 & 1,3 & 1,8 & 3,5 & 2,3 \\
\hline $\begin{array}{c}S_{S S} \\
(\mathrm{mV} / \mathrm{déc} .)\end{array}$ & $75 \mathrm{krad}$ & $100 \mathrm{krad}$ & $150 \mathrm{krad}$ & $200 \mathrm{krad}$ & $\begin{array}{l}\text { Máxima } \\
\text { Diferença }\end{array}$ & \\
\hline OnM & 0,9 & 0,7 & 1,4 & 2,6 & 2,4 & \\
\hline $\mathrm{CnM}$ & 2,8 & 2,9 & 4,3 & 6,3 & 5,0 & \\
\hline
\end{tabular}


A Figura 65 apresenta os dados plotados em um gráfico dos desvios-padrão em relação às SSs extraídas experimentalmente dos dispositivos DnMs, OnMs e CnMs em função das TIDs estudadas que estão apresentados na Tabela 12.

Figura 65 - Valores dos desvios-padrão em relação às SSs extraídas experimentalmente dos dispositivos DnMs, OnMs e CnMs em função das TIDs estudadas, na condição de polarização On-State, durante o procedimento das radiações ionizantes de raios-X

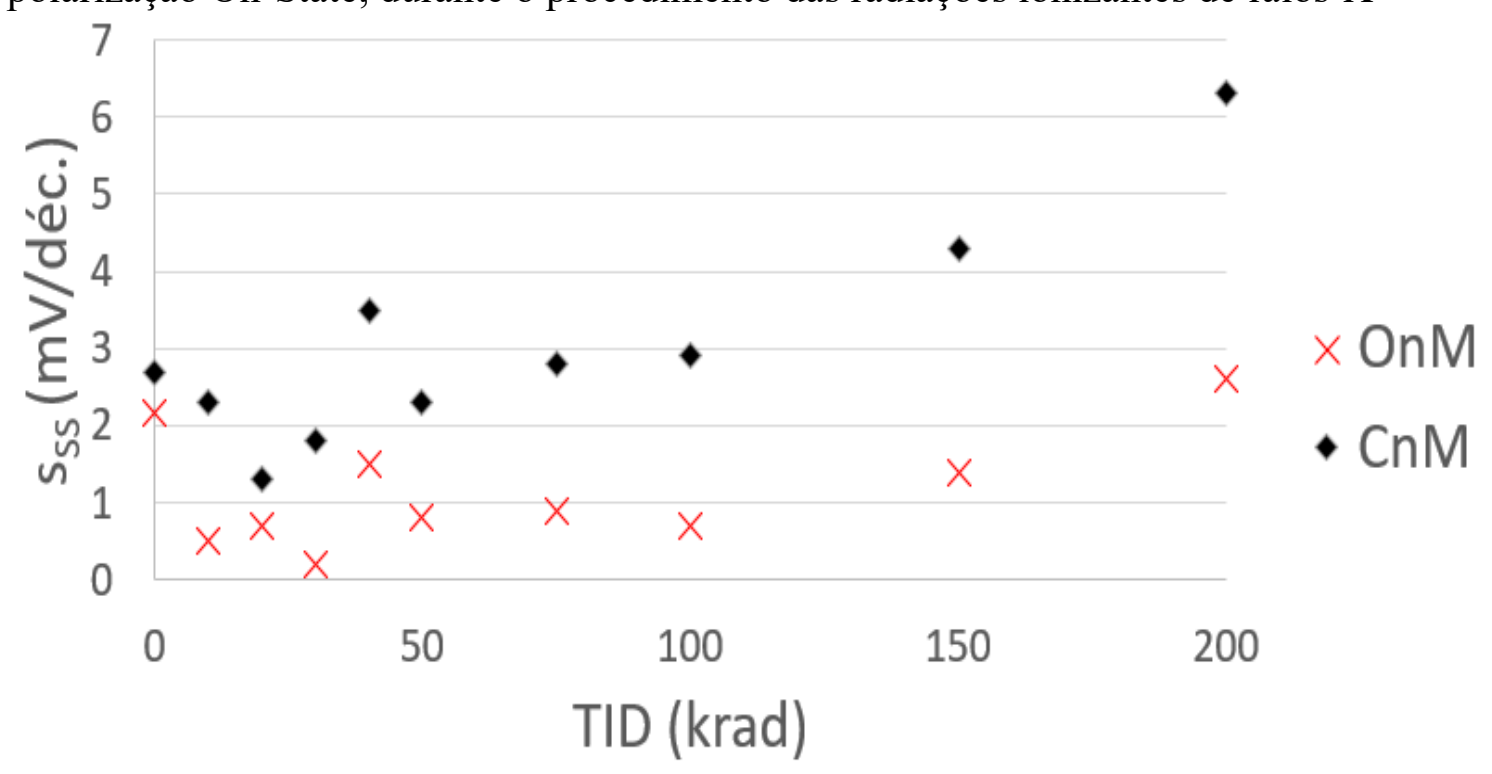

Analisando-se os resultados apresentados na Tabela 12 e na Figura 65, observase que o desvio-padrão das SSs em relação aos OnMs não muda praticamente (diferença máxima de 2,4 mV / dec.), enquanto que o desvio-padrão das SSs em relação aos CnMs aumenta (diferença máxima de 5,0 $\mathrm{mV} /$ dec.), conforme a TID aumenta.

Assim, os resultados experimentais indicam que os OnMs apresentam uma tolerância à TID de raios-X mais alta do que aqueles obtidos nos CnMs e, portanto, o estilo de leiaute Octo para MOSFETs pode ser considerado uma abordagem alternativa para melhorar a robustez à TID de raios-X. Comprovando estudos previamente realizados [46], por meio do estudo estatístico do descasamento entre os MOSFETs, devido à exposição de radiações ionizantes do tipo raios-X.

\subsubsection{Estudo do coeficiente de variação entre a tensão de limiar e a inclinação de sublimiar}

Com base nas Figuras 61 e 62, pode-se calcular três diferentes figuras de mérito (FMs): 
I- $\quad$ O erro relativo do coeficiente de variação da $V_{T H}$ e da SS extraídas experimentalmente dos OnMs irradiados ( 2 amostras para cada TID) em relação aos observados para os $\mathrm{CnMs}$ irradiados $\left(\varepsilon_{\mathrm{r} 1}\right)$ (2 amostras para cada TID), portanto analisando 4 amostras;

II- $\quad$ O erro relativo do coeficiente de variação da $\mathrm{V}_{\mathrm{TH}}$ e da SS dos OnMs irradiados ( 2 amostras para cada TID) em relação ao seu coeficiente de variação pré-irradiado $\left(\varepsilon_{\mathrm{r} 2}\right)$ de um total de 2 amostras;

III- $\quad$ O erro relativo do coeficiente de variação da $\mathrm{V}_{\mathrm{TH}}$ e da $\mathrm{SS}$ dos CnMs irradiados ( 2 amostras para cada TID) em relação aos encontrados nos CnMs pré-irradiados $\left(\varepsilon_{\mathrm{r} 3}\right)$ de um total de 2 amostras.

A Tabela 13 resume os valores encontrados para $\varepsilon_{\mathrm{r} 1}, \varepsilon_{\mathrm{r} 2}$ e $\varepsilon_{\mathrm{r} 3}$, respectivamente.

Tabela 13 - Valores dos erros relativos calculados e descritos como $\varepsilon_{\mathrm{r} 1}, \varepsilon_{\mathrm{r} 2}$ e $\varepsilon_{\mathrm{r} 3}$ em função das TIDs estudadas

\begin{tabular}{|c|c|c|c|c|c|c|c|c|c|c|}
\hline & \multicolumn{2}{|c|}{$\mathrm{TID}=10 \mathrm{krad}$} & \multicolumn{2}{|c|}{$\mathrm{TID}=20 \mathrm{krad}$} & \multicolumn{2}{|c|}{$\mathrm{TID}=30 \mathrm{krad}$} & \multicolumn{2}{|c|}{$\mathrm{TID}=40 \mathrm{krad}$} & \multicolumn{2}{|c|}{$\mathrm{TID}=50 \mathrm{krad}$} \\
\hline$(\%)$ & $\mathrm{V}_{\mathrm{TH}}$ & SS & $\mathrm{V}_{\mathrm{TH}}$ & SS & $\mathrm{V}_{\mathrm{TH}}$ & SS & $\mathrm{V}_{\mathrm{TH}}$ & SS & $\mathrm{V}_{\mathrm{TH}}$ & SS \\
\hline$\varepsilon_{\mathbf{r} 1}$ & $-42,13$ & $-24,16$ & $-58,96$ & $-45,14$ & $-49,5$ & $-50,76$ & $-53,24$ & $-54,56$ & $-59,62$ & $-60,21$ \\
\hline$\varepsilon_{12}$ & $-19,84$ & $-23,67$ & $-41,8$ & $-69,24$ & $-23,07$ & $-62,76$ & $-6,12$ & $-35,44$ & $-42,73$ & $-64,46$ \\
\hline$\varepsilon_{r 3}$ & $-34,11$ & $-16,16$ & $-32,54$ & $-53,29$ & $-27,53$ & $-36,99$ & $-4,49$ & $+18,36$ & $-32,54$ & $-25,6$ \\
\hline & TID $=$ & $5 \mathrm{krad}$ & $\mathbf{T I D}=$ & Dokrad & $\mathrm{TID}=$ & 50 krad & TID $=?$ & $0 \mathrm{krad}$ & & \\
\hline$(\%)$ & $\mathrm{V}_{\mathrm{TH}}$ & SS & $\mathrm{V}_{\mathrm{TH}}$ & SS & $\mathrm{V}_{\mathrm{TH}}$ & SS & $\mathrm{V}_{\mathrm{TH}}$ & SS & & \\
\hline$\varepsilon_{r 1}$ & $-66,67$ & $-63,38$ & $-63,57$ & $-73,25$ & $-58,41$ & $-65,86$ & $-64,39$ & $-57,48$ & & \\
\hline$\varepsilon_{12}$ & $-53,83$ & $-60,33$ & $-53,83$ & $-71,45$ & $-11,98$ & $-46,19$ & $+2,21$ & $+3,2$ & & \\
\hline$\varepsilon_{\mathrm{r} 3}$ & $-34,11$ & $-9,77$ & $-39,72$ & $-11,12$ & $+0,68$ & $+31,32$ & $+36,55$ & $+102,2$ & & \\
\hline
\end{tabular}

Com base nos dados ilustrados na Tabela 13, os $\varepsilon_{\mathrm{r} 1 \mathrm{~s}}$ indicam que os erros relativos dos coeficientes de variação das $\mathrm{V}_{\mathrm{THS}}$ e das SSs extraídas experimentalmente dos OnMs irradiados são sempre menores ( $\mathrm{V}_{\mathrm{TH}}:-57,4 \%$ em média; $\mathrm{SS}:-54,9 \%$ em média) do que 
aqueles obtidos para os CnMs, graças ao DEPAMBBRE presente nos OnMs. Portanto, os OnMs apresentam um casamento entre dispositivos melhor em comparação com os CnMs para todas as TIDs consideradas neste trabalho.

Além disso, o $\varepsilon_{\mathrm{r} 2}$ indica que os erros relativos do coeficiente de variação (casamento entre dispositivos) dos OnMs relacionados ao parâmetro $\mathrm{V}_{\mathrm{TH}}$ irradiados são sempre menores (com exceção da $\mathrm{V}_{\mathrm{TH}}$ calculada para a condição da TID de $200 \mathrm{krad}$ ) do que os erros relativos dos coeficientes de variação dos dispositivos originais e reduzem à medida que a TID aumenta (-27,9 \% em média), ou seja, a $\mathrm{V}_{\mathrm{TH}}$ dos OnMs tende para retornar ao valor pré-irradiação. No entanto, embora o $\varepsilon_{\mathrm{r} 3}$ referente ao parâmetro $\mathrm{V}_{\mathrm{TH}}$ extraída dos CnMs siga as mesmas tendências da $\mathrm{V}_{\mathrm{TH}}$ dos OnMs até $100 \mathrm{krad}$, eles aumentam significativamente além de $150 \mathrm{krad}$, ou seja, não tendem a retornar aos valores pré-irradiação (- 18,6\% em média), como visto para os OnMs.

Adicionalmente, em relação ao erro relativo $\varepsilon_{\mathrm{r} 2}$ do parâmetro SS calculado para os OnMs (-47,8 \% em média), observa-se que os erros relativos dos OnMs irradiados são praticamente sempre menores que os erros relativos das condições de pré-irradiação (com exceção do erro relativo das SSs calculadas para a condição da TID de $200 \mathrm{krad}$ ) e reduzem à medida que a TID aumenta, em contraste com os observados para os CnMs, para a condição da TID de $150 \mathrm{krad}$ e $200 \mathrm{krad}$. No entanto, não obstante os $\varepsilon_{\mathrm{r} 3} \mathrm{~S}$ calculados referentes às SSs extraídas dos CnMs seguem as mesmas tendências dos erros relativos das SSs dos OnMs até 100 krad (com exceção do erro relativo das SSs calculadas para a condição da TID de $40 \mathrm{krad}$ ), eles aumentam significativamente acima de $150 \mathrm{krad}$, ou seja, não tendem a retornar aos valores pré-irradiação $(+0,11 \%$ em média), após a exposição aos raios-X em comparação com as condições pré-irradiação.

Assim, pode-se concluir que o estilo de leiaute do tipo Octo pode ser considerado como uma técnica alternativa de Hardness-By-Design (HBD) para implementar MOSFETs para aumentar de forma importante o casamento entre dispositivos, com foco em aplicações de circuitos integrados CMOS nas áreas de aviação, espaciais e médicas. 
4.3 ESTUDO ESTATÍSTICO DOS EFEITOS DA TID ENTRE UM MOSFET DE PORTA HEXAGONAL, OCTOGONAL E RETANGULAR POLARIZADOS NO MODO ANALOG DURANTE OS PROCEDIMENTOS DAS RADIAÇÕES IONIZANTES DE RAIOS-X

O objetivo deste estudo é verificar estatisticamente, por meio das aplicações dos testes ANOVA e de Tukey, se os valores médios das amostras das $\mathrm{V}_{\mathrm{TH}} \mathrm{S}$ e SSs extraídas experimentalmente dos DnMs, OnMs e CnMs durante as aplicações das radiações ionizantes do tipo raios-X, valendo-se de uma polarização no modo Analog são estatisticamente equivalentes entre si. Desta forma, é possível afirmar, em função de um nível de significância de 5\% (portanto um nível de acerto de 95\%) escolhido para a aplicação dos testes ANOVA e de Tukey, qual dispositivo apresentou uma maior variabilidade no comportamento dos parâmetros $\mathrm{V}_{\mathrm{TH}}$ e SS, isto é, indicando, portanto, uma menor robustez às TIDs aplicadas.

Para análise dos efeitos da TID nos nMOSFETs de porta hexagonal (DnM), octogonal $(\mathrm{OnM})$ e retangular $(\mathrm{CnM})$ quando submetidos às radiações ionizantes por raios-X e valendo-se da aplicação de $\mathrm{V}_{\mathrm{DD}}(1,2 \mathrm{~V})$ ao terminal da porta e ao terminal de dreno e $0 \mathrm{~V}$ nos demais terminais dos MOSFETs durante a aplicação das radiações ionizantes de raios-X (modo Analog), foram utilizados 4 dispositivos (2 DnMs, 1 OnM e $1 \mathrm{CnM}$ ) em 1 chip. A Figura 66 ilustra o procedimento para a obtenção das amostras das $\mathrm{V}_{\mathrm{TH}} \mathrm{S}$ e das SSs extraídas experimentalmente dos DnMs, OnM e CnM durante as aplicações das radiações ionizantes do tipo raios-X, valendo-se de uma polarização no modo Analog. 
Figura 66 - Procedimento para a obtenção das amostras das $\mathrm{V}_{\mathrm{TH}}$ e das SS extraídas experimentalmente dos DnMs, OnM e CnM durante as aplicações das radiações ionizantes do tipo raios-X, valendo-se de uma polarização no modo Analog

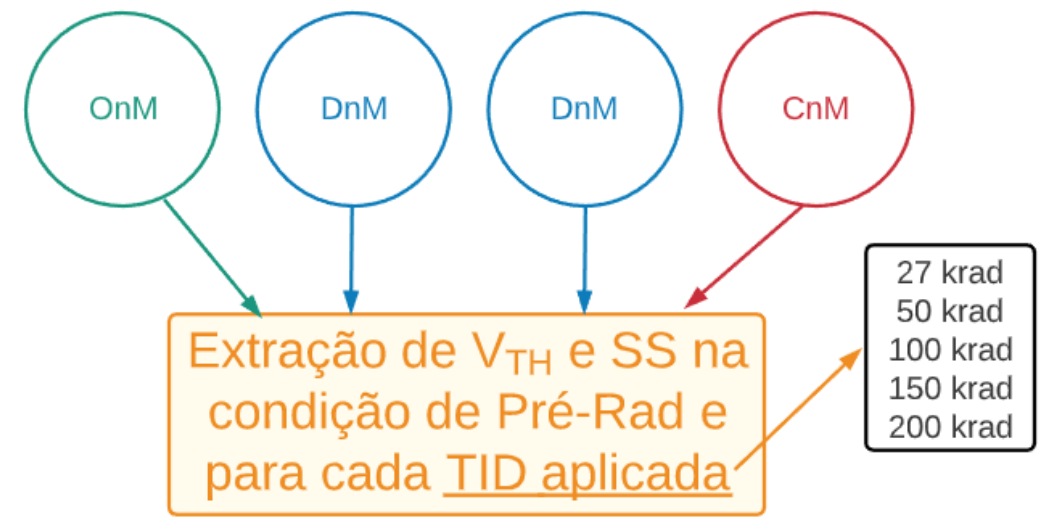

Fonte: Autor.

De acordo com a Figura 66, foram investigados 2 DnMs, 1 OnM e $1 \mathrm{CnM}$ provenientes de um mesmo CI. Pode-se observar que para um grau de confiança de $90 \%$ e para um erro máximo aceitável de $10 \%$ do parâmetro que se deseja estudar (por exemplo, a $\mathrm{V}_{\mathrm{TH}}$ ou a SS), verifica-se que a quantidade de amostras calculadas fica em cerca de 2 a 3 nMOSFETs [67]. Portanto, o estudo foi realizado com uma quantidade total de 4 MOSFETs (2 DnMs, 1 OnM e $1 \mathrm{CnM}$ ). Os valores de W e L do CnM são iguais a $0,8 \mu \mathrm{m}$ e $0,16 \mu \mathrm{m}$. Os valores de $\mathrm{W}, \mathrm{b}, \mathrm{B}$, ângulo alfa $(\alpha)$ e o fator de corte (c) para o OnM são iguais a $1,52 \mu \mathrm{m}, 0,69 \mu \mathrm{m}, 1,49 \mu \mathrm{m}, 90^{\circ}$ e $50 \%$. Os valores de $\mathrm{W}, \mathrm{b}, \mathrm{B}$, ângulo alfa $(\alpha)$ para os dois DnMs são iguais a $0,56 \mu \mathrm{m}, 0,2 \mu \mathrm{m}, 0,88 \mu \mathrm{m}, 90^{\circ}$, respectivamente.

Além disso, de acordo com a Figura 66, o chip foi exposto com as seguintes doses: $27 \mathrm{krad}, 50 \mathrm{krad}, 100 \mathrm{krad}, 150 \mathrm{krad}$ e $200 \mathrm{krad}$. A taxa de dose escolhida para a realização deste estudo foi definida pelo mínimo permitido pelo radiador de raios-X (70 $\mathrm{krad} / \mathrm{h}$ ), a fim de compreender o comportamento desses dispositivos em uma menor taxa de dose e um maior número de pontos medidos para a TID de radiações ionizantes de raios-X.

Os parâmetros elétricos foram obtidos a partir das curvas de corrente de dreno (IDS) em função da tensão de porta $\left(\mathrm{V}_{\mathrm{GS}}\right)$, com tensão de dreno $\left(\mathrm{V}_{\mathrm{DS}}\right)$ de $50 \mathrm{mV}$ para obter os valores da tensão de limiar $\left(\mathrm{V}_{\mathrm{TH}}\right)$ e da inclinação de sublimiar (SS). Um dispositivo CnM e outro DnM pararam de funcionar para uma TID de $200 \mathrm{krad}$ e, consequentemente, essa dose foi considerada como a máxima utilizada neste estudo.

A Figura 67 ilustra um diagrama de blocos do procedimento realizado para a aplicação dos testes estatísticos ANOVA e de Tukey das amostras das $\mathrm{V}_{\mathrm{THS}}$ e das SSs 
extraídas experimentalmente dos DnMs, OnM e CnM durante as aplicações das radiações ionizantes do tipo raios-X, valendo-se de uma polarização no modo Analog.

Figura 67 - Diagrama de blocos do procedimento realizado para a aplicação dos testes estatísticos ANOVA e de Tukey das amostras das $\mathrm{V}_{\mathrm{THS}}$ e das SSs extraídas dos DnMs, OnM e CnM considerando-se de uma polarização no modo Analog, durante o procedimento das radiações ionizantes de raios-X

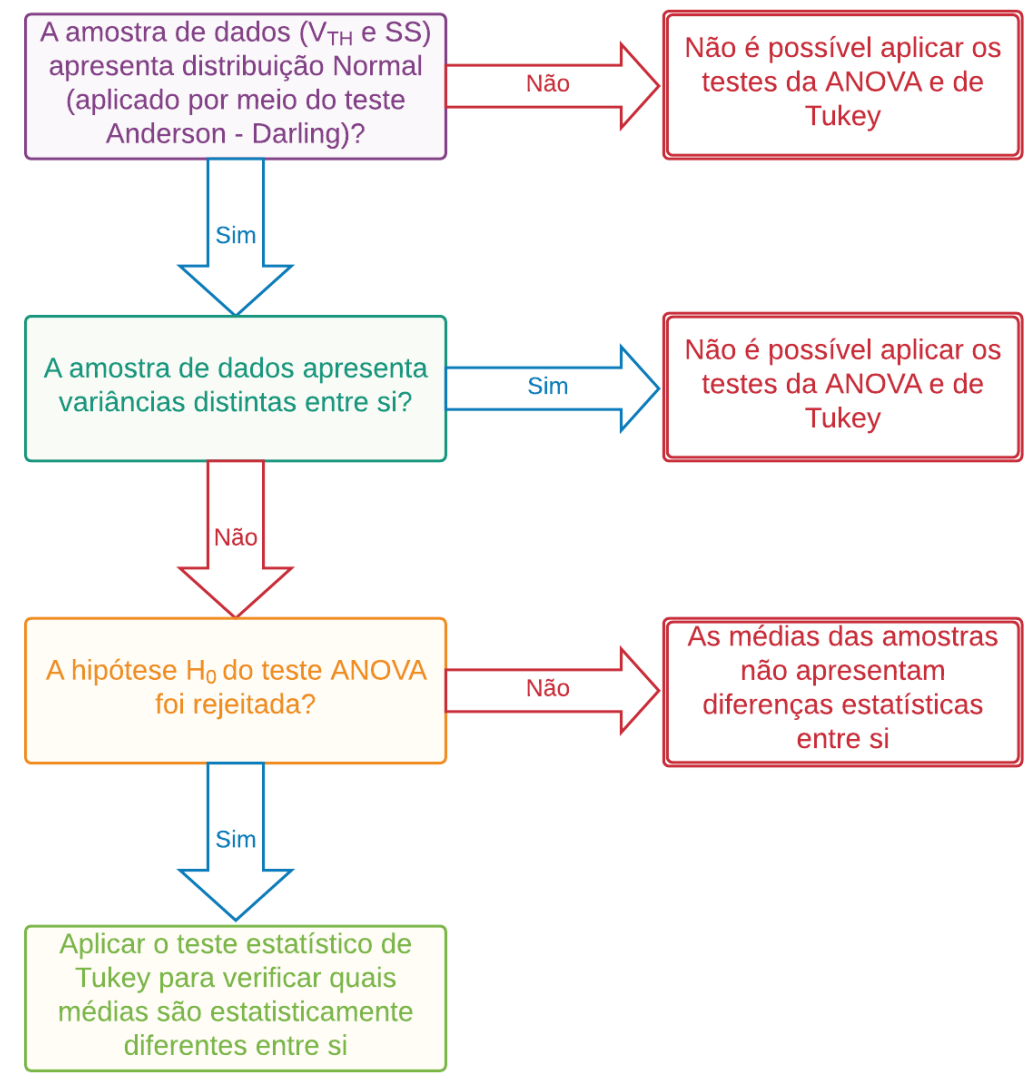

Fonte: Autor

Iremos efetuar um estudo estatístico que utiliza o teste de Anderson - Darling [61] para determinar se as amostras das $\mathrm{V}_{\mathrm{TH}}$ e das $\mathrm{SSs}$ extraídas experimentalmente dos DnMs, OnM e CnM durante as aplicações das radiações ionizantes do tipo raios-X, valendo-se de uma polarização no modo Analog apresentam uma distribuição normal de dados. Caso estas amostras tenham uma distribuição normal, deve-se aplicar outro teste estatístico à estas amostras com o objetivo de verificar se estas variâncias são estatisticamente equivalentes entre si.

Caso seja possível afirmar que as variâncias das amostras das $\mathrm{V}_{\mathrm{TH}} \mathrm{S}$ e SSs extraídas experimentalmente dos DnMs, OnM e CnM durante as aplicações das radiações 
ionizantes do tipo raios-X, valendo-se de uma polarização no modo Analog são estatisticamente equivalentes entre si, pode-se aplicar os testes ANOVA e de Tukey para determinar quais valores médios de $\mathrm{V}_{\mathrm{TH}}$ e $\mathrm{SS}$ destas amostras são estatisticamente diferentes entre si. Por meio da aplicação destes dois testes estatísticos é possível determinar, portanto, qual dispositivo apresentou uma maior variabilidade, isto é, uma menor robustez às TIDs aplicadas.

\subsubsection{Tensão de Limiar $\left(V_{T H}\right)$}

Para se efetuar a extração das $\mathrm{V}_{\mathrm{THS}}$ dos dispositivos DnMs, OnM e CnM utilizouse a segunda derivada da curva $\mathrm{I}_{\mathrm{DS}}$ em função de $\mathrm{V}_{\mathrm{GS}}$, considerando $\mathrm{V}_{\mathrm{DS}}$ igual a $50 \mathrm{mV}$.

Para a aplicação do teste ANOVA e Tukey entre as $\mathrm{V}_{\mathrm{TH}} \mathrm{S}$ extraídas experimentalmente dos DnMs, OnM e CnM, é necessário, antes, verificar se as amostras de dados utilizadas apresentam uma distribuição normal.

$\mathrm{O}$ teste utilizado para verificar se as amostras das $\mathrm{V}_{\mathrm{THS}}$ extraídas experimentalmente dos DnMs, OnM e CnM durante as aplicações das radiações ionizantes do tipo raios-X, valendo-se de uma polarização no modo Analog, apresentam uma distribuição normal é o de Anderson - Darling [61]. O nível de significância escolhido para a aplicação deste teste foi de 0,05 (o que significa dizer que este teste estatístico será realizado com uma precisão de acerto igual a $95 \%$ ). As hipóteses nula e alternativa para a aplicação do teste de Anderson - Darling são ilustradas na Figura 68.

Figura 68 - As hipóteses nula e alternativa levadas em conta para a aplicação do teste de Anderson - Darling nas amostras das $\mathrm{V}_{\mathrm{THS}}$ extraídas experimentalmente dos DnMs, OnM e CnM, considerando-se de uma polarização no modo Analog, durante o procedimento das radiações ionizantes de raios-X

$$
\left\{\begin{array}{l}
\mathrm{H}_{0} \text { : As amostras apresentam distribuição normal } \\
\mathrm{H}_{1} \text { : As amostras não apresentam distribuição normal }
\end{array}\right.
$$

Fonte: Autor.

A Tabela 14 resume os resultados dos valores de $\mathrm{p}$ do teste estatístico de Anderson - Darling das $\mathrm{V}_{\mathrm{TH}} \mathrm{S}$ extraídas experimentalmente dos DnMs, OnM e CnM. Se o valor de $\mathrm{p}$ for maior a 0,05 , conclui-se que a amostra em análise apresenta uma distribuição 
normal, caso contrário, deve-se concluir que a amostra não apresenta uma distribuição normal [61].

Tabela 14 - Valores de p do teste estatístico de Anderson - Darling das $\mathrm{V}_{\mathrm{TH}} \mathrm{S}$ extraídas experimentalmente dos DnMs, OnM e CnM, considerando-se de uma polarização no modo Analog, durante o procedimento das radiações ionizantes de raios-X

\begin{tabular}{|c|c|}
\hline nMOSFET & p \\
\hline DnM & 0,550 \\
\hline OnM & 0,366 \\
\hline CnM & 0,434 \\
\hline
\end{tabular}

Analisando-se os resultados do valor $\mathrm{p}$ apresentados na Tabela 14, pode-se observar que para todas as amostras das $\mathrm{V}_{\mathrm{TH}} \mathrm{S}$ em estudo, o valor de $\mathrm{p}$ encontra-se sempre superior a 0,05, e consequentemente, conclui-se que todas as amostras de dados apresentam uma distribuição normal, isto é, a $\mathrm{H}_{0}$ é aceita e $\mathrm{H}_{1}$ rejeitada [61]. Portanto, este resultado possibilita a aplicação dos testes estatísticos ANOVA e Tukey para a amostra que está sendo considerada neste trabalho.

O próximo passo é verificar se as variâncias das amostras das $\mathrm{V}_{\mathrm{THS}}$ extraídas experimentalmente dos DnMs, OnM e CnM, durante as aplicações das radiações ionizantes do tipo raio-X, valendo-se de uma polarização no modo Analog são estatisticamente equivalentes entre si. Para isto, um possível teste estatístico que pode ser utilizado para verificar se as amostras de dados apresentam variâncias estatisticamente equivalentes entre si é o teste para comparação de duas variâncias. O nível de significância escolhido para a aplicação deste teste foi de 0,05 (o que significa dizer que este teste estatístico será realizado com uma precisão de acerto igual a 95 \%). As hipóteses nula e alternativa para a aplicação do teste para comparação de duas variâncias são ilustradas na Figura 69. 
Figura 69 - Hipóteses nula e alternativa levadas em conta para a aplicação do teste para comparação de duas variâncias das amostras das $\mathrm{V}_{\mathrm{TH}} \mathrm{S}$ extraídas experimentalmente dos DnMs, OnM e CnM durante as aplicações das radiações ionizantes do tipo raios-X, valendo-se de uma polarização no modo Analog

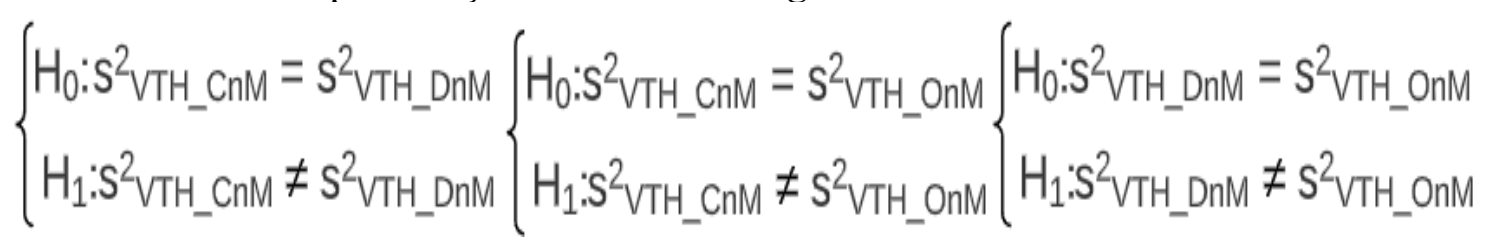

Fonte : Autor

Na Figura $69, s_{V T H \_C n M}^{2}, s_{V T H \_D n M}^{2}$ e $s_{V T H \_O n M}^{2}$ são as variâncias das $\mathrm{V}_{\mathrm{THS}}$ extraídas experimentalmente dos CnMs, DnMs e OnMs, respectivamente, durante as aplicações das radiações ionizantes do tipo raios-X, valendo-se de uma polarização no modo Analog.

A Tabela 15 resume os resultados dos valores de $\mathrm{p}$ do teste para comparação das variâncias das amostras das $\mathrm{V}_{\mathrm{TH}} \mathrm{S}$ extraídas experimentalmente dos DnMs, OnM e CnM, isto é, $s_{V_{T_{-}-} C n M}^{2}$ comparada com $s_{V_{T H_{-} D n M}}^{2}, s_{V_{T_{-}-} C n M}^{2}$ comparada com $s_{V_{T H_{-} O n M}}^{2} \mathrm{e}$ $S_{V_{T H_{-}} D n M}^{2}$ comparada com $s_{V_{T H_{-}} O n M}^{2}$. Se o valor de p for maior a 0,025 (pois que para este teste deve-se comparar se o valor de p é superior a $\alpha^{\prime} / 2$ ), conclui-se que as variâncias das amostras das $\mathrm{V}_{\mathrm{THS}}$ extraídas experimentalmente dos DnMs, OnM e CnM são estatisticamente equivalentes entre si, caso contrário, deve-se concluir que as variâncias das amostras das $\mathrm{V}_{\mathrm{TH}} \mathrm{S}$ não são estatisticamente equivalentes entre si, impossibilitando a aplicação dos testes estatísticos ANOVA e Tukey. Além disso, na Tabela 15 também é ilustrada a razão estimada entre as variâncias analisadas, isto é, $s_{V_{T_{-}} C n M^{2}}^{2} s_{V_{T H_{-}} D n M}^{2}$, $s_{V_{T H_{-}} C n M}^{2} / s_{V_{T H_{-} O n M}}^{2}$ e $s_{V_{T_{-}-} D n M}^{2} / s_{V_{T H} O}^{2}$ OnM . 
Tabela 15 - Valores de p do teste para comparação de duas variâncias das $\mathrm{V}_{\mathrm{TH}} \mathrm{S}$ extraídas experimentalmente dos DnMs, OnM e CnM considerando-se de uma polarização no modo Analog, durante o procedimento das radiações ionizantes de raios-X e razão estimada entre as variâncias analisadas.

\begin{tabular}{|c|c|c|}
\hline Comparação Efetuada & $\mathbf{p}$ & Razão Estimada \\
\hline$s_{V_{T H}-C n M}^{2} \operatorname{com} s_{V_{T H-} D n M}^{2}$ & 0,437 & 1,32 \\
\hline$s_{V_{T H_{-} C n M}}^{2} \operatorname{com} s_{V_{T H_{-}} \text {OnM }}^{2}$ & 0,557 & 1,31 \\
\hline$s_{V_{T H} D}^{2}{ }_{n M} \operatorname{com} s_{V_{T H} O_{n M}}^{2}$ & 0,93 & 0,99 \\
\hline
\end{tabular}

Analisando-se os resultados do valor $\mathrm{p}$ apresentados na Tabela 15, pode-se observar que todas as comparações das variâncias entre as amostras das $\mathrm{V}_{\mathrm{THS}}$ em estudo $\left(s_{V_{T H_{-}} C n M}^{2}\right.$ comparada com $s_{V_{T H_{-} D n M}}^{2}, s_{V_{T_{H}-} C n M}^{2}$ comparada com $s_{V_{T_{H}-} O n M}^{2}$ e $s_{V_{T_{H}-D n M}}^{2}$ comparada com $s_{V_{T_{-}} \mathrm{O} O M}^{2}$ ), o valor de p encontra-se sempre superior a 0,025 (pois que para aplicação deste teste estatístico de comparação entre duas variâncias, deve-se utilizar $0,05 / 2=0,025$ para o nível de significância), e consequentemente, conclui-se que todas as variâncias das amostras das $\mathrm{V}_{\mathrm{TH}} \mathrm{S}$ extraídas experimentalmente dos DnMs, OnM e CnM são estatisticamente equivalentes entre si, o que possibilita a aplicação dos testes estatísticos ANOVA e Tukey para a amostra que está sendo considerada.

Ademais, também pode-se verificar na Tabela 15 que a razão estimada das comparações entre as variâncias das amostras das $\mathrm{V}_{\mathrm{TH}} \mathrm{S}$ extraídas dos DnMs, OnM e CnM apresentam valores pequenos (inferiores a nove vezes), o que também possibilita a aplicação dos testes estatísticos ANOVA e Tukey para a amostra que está sendo considerada neste trabalho [66].

O próximo passo é aplicar o teste estatístico ANOVA com o objetivo de verificar se as médias das amostras das $\mathrm{V}_{\mathrm{THS}}$ extraídas experimentalmente dos DnMs, OnM e CnM são estatisticamente equivalentes ou diferentes entre si. O nível de significância escolhido para a aplicação deste teste foi de 0,05 (o que significa dizer que este teste estatístico será realizado com uma precisão de acerto igual a $95 \%$ ). As hipóteses nula e alternativa para a aplicação do Teste ANOVA são ilustradas na Figura 70. 
Figura 70 - As hipóteses nula e alternativa levadas em conta para a aplicação do Teste ANOVA aplicado nas médias das amostras das $\mathrm{V}_{\mathrm{THS}}$ extraídas experimentalmente dos DnMs, OnM e CnM durante as aplicações das radiações ionizantes do tipo raios-X, valendo-se de uma polarização no modo Analog

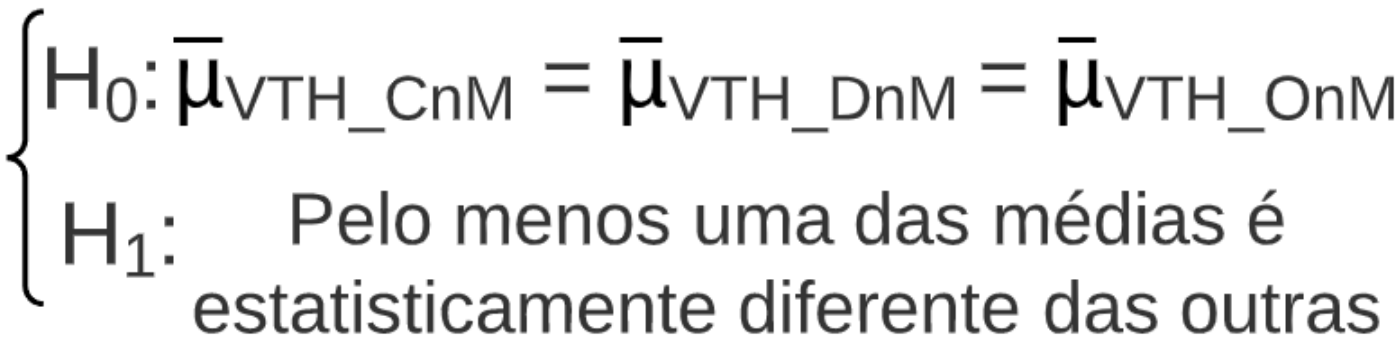

Fonte: Autor.

Na Figura $70, \bar{\mu}_{V T H_{-} C n M}, \bar{\mu}_{V T H_{-} D n M}$ e $\bar{\mu}_{V T H_{-} O n M}$ são os valores médios das $\mathrm{V}_{\mathrm{TH}} \mathrm{S}$ extraídas experimentalmente dos CnMs, DnMs e OnMs, respectivamente, durante as aplicações das radiações ionizantes do tipo raios-X, valendo-se de uma polarização no modo Analog.

A Tabela 16 ilustra o resultado do teste ANOVA das médias das $\mathrm{V}_{\mathrm{THS}}$ extraídas experimentalmente dos DnMs, OnM e CnM.

Tabela 16 - Resultado do teste ANOVA das médias das amostras das $\mathrm{V}_{\mathrm{TH}} \mathrm{S}$ extraídas experimentalmente dos DnMs, OnM e CnM considerando-se de uma polarização no modo Analog, durante o procedimento das radiações ionizantes de raios-X

\begin{tabular}{|c|c|c|}
\hline $\mathbf{p}$ & $\mathbf{F}_{\text {calculado }}$ & $\mathbf{F}_{\text {crítico }}$ \\
\hline 0,000 & 92,76 & 3,52 \\
\hline
\end{tabular}

Da Tabela 16, como o valor de pé menor que 0,05 e o valor de $F_{\text {calculado é maior }}$ que $\mathrm{F}_{\text {crítico }}\left(\mathrm{F}_{\mathrm{C}}\right)$, pode-se rejeitar $\mathrm{H}_{0}$, portanto pode-se afirmar que pelo menos uma das médias das $\mathrm{V}_{\mathrm{THS}}$ extraídas experimentalmente dos DnMs, OnM e CnM são estatisticamente diferentes entre si. Desta forma, para analisar qual média das $\mathrm{V}_{\mathrm{TH}} \mathrm{S}$ extraídas experimentalmente dos DnMs, OnM e CnM diferem entre si, deve-se aplicar o teste estatístico Tukey.

Para aplicar o teste de Tukey, devemos efetuar o cálculo de $\Delta$ ilustrado na equação (37). O valor de QME é fornecido pelo MINITAB 2020 e, para estas amostras estudadas, o valor de QME é igual a $0,166 \mathrm{mV}^{2}$. O valor de q é obtido na tabela de amplitude estudentizada q para um nível de significância de 0,05 e é igual a 3,5927, C' é o número de comparações a ser realizada, que é igual a 3 para este estudo [69], [70]. 


$$
\Delta=q \cdot \sqrt{\frac{Q M E}{C^{\prime}}}=3,5927 \cdot \sqrt{\frac{0,000166}{3}}=0,0267 \mathrm{~V}
$$

Além disso, para se concluir qual média das $\mathrm{V}_{\mathrm{TH}} \mathrm{S}$ extraídas experimentalmente dos DnMs, OnM e CnM diferem entre si, devemos levar em consideração a seguinte comparação $\left|\bar{\mu}_{l}-\bar{\mu}_{J}\right|>\Delta$. A Tabela 17 indica o resultado do teste estatístico de Tukey aplicado às médias das $\mathrm{V}_{\mathrm{TH}} \mathrm{S}$ extraídas experimentalmente dos DnMs, OnM e CnM, durante as aplicações das radiações ionizantes do tipo raios-X, valendo-se de uma polarização no modo Analog.

Tabela 17 - Resultado do teste estatístico de Tukey aplicado às médias das $\mathrm{V}_{\mathrm{TH}}$ extraídas experimentalmente dos DnMs, OnM e CnM considerando-se de uma polarização no modo Analog, durante o procedimento das radiações ionizantes de raios-X

\begin{tabular}{|c|c|c|c|c|}
\hline Amostras & $\begin{array}{c}\text { Média }\left(\bar{\mu}_{V_{T H}}\right) \\
(\mathbf{V})\end{array}$ & |Diferença de Médias $\mid(\mathbf{V})$ & $\Delta(\mathbf{V})$ \\
\hline CnM & 0,40500 & $\bar{\mu}_{\mathrm{V}_{\mathrm{TH}-\mathrm{DnM}}-\bar{\mu}_{\mathrm{V}_{\mathrm{TH}-} \mathrm{CnM}}}|0,09109|$ & 0,0267 \\
\hline DnM & 0,31391 & $\bar{\mu}_{\mathrm{V}_{\mathrm{TH}-} \mathrm{OnM}}-\bar{\mu}_{\mathrm{V}_{\mathrm{TH}-\mathrm{CnM}}}|0,08583|$ & 0,0267 \\
\hline OnM & 0,31917 & $\bar{\mu}_{\mathrm{V}_{\mathrm{TH}-\mathrm{OnM}}-\bar{\mu}_{\mathrm{V}_{\mathrm{TH}-} \mathrm{DnM}}}|0,00526|$ & 0,0267 \\
\hline
\end{tabular}

Por meio da análise dos resultados apresentados na Tabela 17, pode-se concluir que o valor médio da $\mathrm{V}_{\mathrm{TH}}$ extraída dos CnMs não é estatisticamente equivalente em comparação aos valores médios das $\mathrm{V}_{\mathrm{TH}} \mathrm{S}$ extraídas dos DnMs e OnMs. Isto pode ser afirmado pois que a diferença dos valores médios é maior em comparação ao parâmetro $\Delta$ para as comparações $\left(\bar{\mu}_{\mathrm{VTH}}-\mathrm{DnM}-\bar{\mu}_{\mathrm{VTH}}-\mathrm{CnM}\right)$ e $\left(\bar{\mu}_{\mathrm{VTH}}-\right.$ OnM $\left.-\bar{\mu}_{\mathrm{VTH}}-\mathrm{CnM}\right)$. Porém quando se efetua a diferença entre os valores médios $\left(\bar{\mu}_{\mathrm{VTH}}-\mathrm{OnM}-\bar{\mu}_{\mathrm{VTH}}\right.$ - DnM $)$, verificase que esta diferença é menor que o parâmetro $\Delta$, indicando que estes dois valores médios são estatisticamente equivalentes entre si. Isso permite afirmar que os valores médios das $\mathrm{V}_{\mathrm{THS}}$ extraídas experimentalmente dos DnMs e OnMs apresentam a mesma variabilidade ou o mesmo nível de robustez para as TIDs aplicadas nas amostras.

A Figura 71 ilustra o histograma das $\mathrm{V}_{\mathrm{TH}} \mathrm{S}$ extraídas experimentalmente dos DnMs, OnM e CnM durante as aplicações das radiações ionizantes do tipo raios-X, valendo-se de uma polarização no modo Analog. 
Figura 71 - Histograma da amostra de dados das $\mathrm{V}_{\mathrm{TH}} \mathrm{S}$ extraídas experimentalmente dos DnMs, OnM e CnM durante as aplicações das radiações ionizantes do tipo raios-X, valendo-se de uma polarização no modo Analog

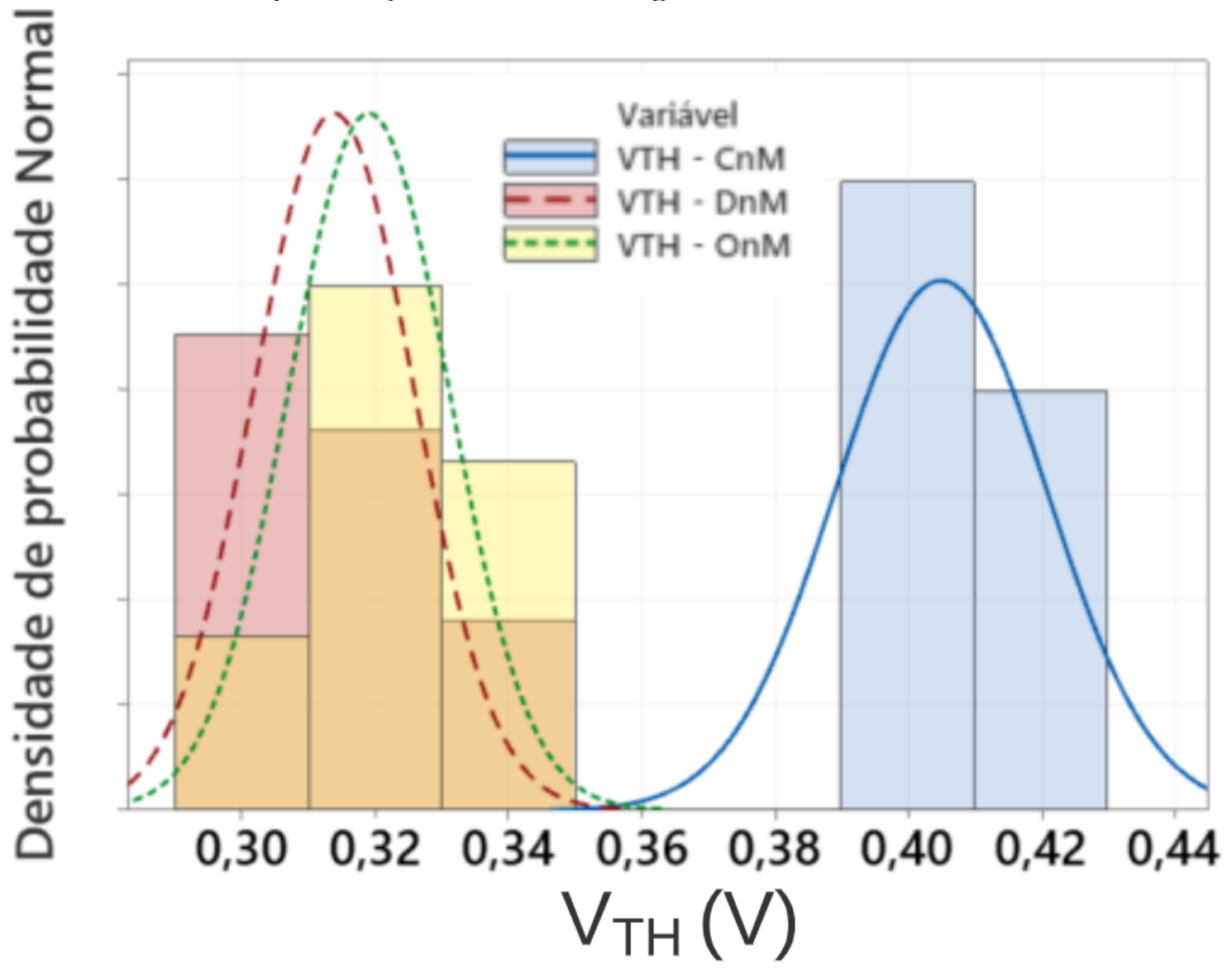

Fonte: Autor.

Outra maneira de verificar o efeito do desvio-padrão nas amostras das $\mathrm{V}_{\mathrm{THS}}$ extraídas experimentalmente dos DnMs, OnM e CnM valendo-se de todas as TIDs aplicadas nos nMOSFETs, é por meio do gráfico dos valores máximos e mínimos e dos valores médios das $\mathrm{V}_{\mathrm{TH}}$ s extraídas experimentalmente dos DnMs, OnM e CnM durante as aplicações das radiações ionizantes do tipo raios-X, valendo-se de uma polarização no modo Analog, ilustrado na Figura 72. 
Figura 72 - Gráfico dos intervalos máximos e mínimos e dos valores médios das $\mathrm{V}_{\mathrm{THS}}$ extraídas experimentalmente dos DnMs, OnM e CnM durante as aplicações das radiações ionizantes do tipo raios-X, valendo-se de uma polarização no modo Analog

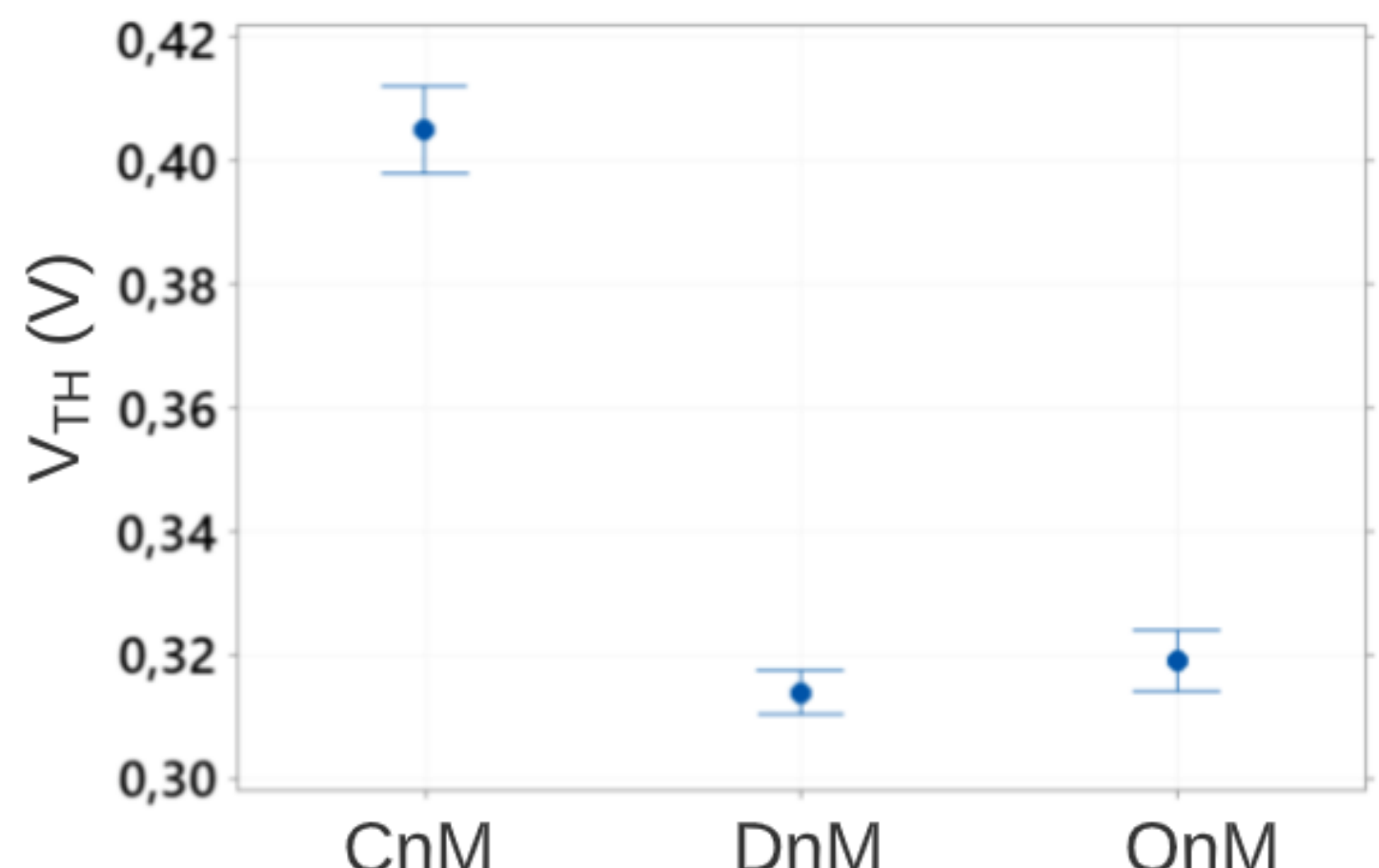

Fonte: Autor

Com base nos dados ilustrados na Tabela 17 e nas Figura 71 e 72, pode-se concluir que a amostra de dados das $\mathrm{V}_{\mathrm{THS}}$ extraídas dos CnMs apresenta um desvio-padrão maior $(0,01581 \mathrm{~V})$ e portanto, uma maior variabilidade em ambientes de radiação ionizantes do tipo raios-X quando se efetua a comparação com os desvios-padrão das $\mathrm{V}_{\mathrm{THS}}$ extraídas dos DnMs e OnMs (0,01200 V para os DnMs e 0,01251 V para os OnMs). Esta afirmação pode ser comprovada, para um nível de significância de 5\% (portanto um nível de acerto de $95 \%$ ) e este comportamento pode ser justificado graças aos efeito DEPAMBBRE presente nos DnMs e OnMs. Portanto, os DnMs e OnMs apresentam menores variabilidades e, assim, maior robustez em ambientes de radiação ionizantes do tipo raios$\mathrm{X}$, quando polarizados no modo Analog e, portanto, um casamento entre dispositivos melhor em comparação com os CnMs para todas as TIDs consideradas neste estudo. 


\subsubsection{Inclinação de Sublimiar (SS)}

Para a aplicação do teste ANOVA e Tukey entre as SSs extraídas experimentalmente dos DnMs, OnM e CnM durante as aplicações das radiações ionizantes do tipo raios-X, valendo-se de uma polarização no modo Analog, é necessário verificar se as amostras de dados utilizadas apresentam uma distribuição normal.

O teste estatístico utilizado para verificar se as amostras das SSs extraídas experimentalmente dos DnMs, OnM e CnM durante as aplicações das radiações ionizantes do tipo raios-X, valendo-se de uma polarização no modo Analog apresentam uma distribuição normal é o de Anderson - Darling [61]. O nível de significância escolhido para a aplicação deste teste foi de 0,05 (o que significa dizer que este teste estatístico será realizado com uma precisão de acerto igual a 95 \%) [61]. As hipóteses nula e alternativa para a aplicação do teste de Anderson - Darling são ilustradas por meio da Figura 73.

Figura 73 - As hipóteses nula e alternativa levadas em conta para a aplicação do teste de Anderson - Darling nas amostras das SSs extraídas experimentalmente dos DnMs, OnM e CnM durante as aplicações das radiações ionizantes do tipo raios-X, valendo-se de uma polarização no modo Analog

\section{$\left\{\begin{array}{l}\mathrm{H}_{0}: \text { As amostras apresentam distribuição normal } \\ \mathrm{H}_{1} \text { : As amostras não apresentam distribuição normal }\end{array}\right.$}

Fonte: Autor.

A Tabela 18 resume os resultados dos valores de $\mathrm{p}$ do teste estatístico de Anderson - Darling das SSs extraídas experimentalmente dos DnMs, OnM e CnM durante as aplicações das radiações ionizantes do tipo raios-X valendo-se de uma polarização no modo Analog. Se o valor de p for maior a 0,05, conclui-se que a amostra em análise apresenta uma distribuição normal, caso contrário, deve-se concluir que a amostra não apresenta uma distribuição normal, impossibilitando a aplicação dos testes estatísticos ANOVA e Tukey. 
Tabela 18 - Valores de p do teste estatístico de Anderson - Darling das SSs extraídas experimentalmente dos DnMs, OnM e CnM considerando-se de uma polarização no modo Analog, durante o procedimento das radiações ionizantes de raios-X

\begin{tabular}{|cc|}
\hline nMOSFET & p \\
\hline DnM & 0,547 \\
\hline OnM & 0,798 \\
\hline CnM & 0,056 \\
\hline
\end{tabular}

Analisando-se os resultados do valor $\mathrm{p}$ apresentados na Tabela 18, pode-se observar que para todas as amostras das SSs em estudo, o valor de p encontra-se sempre superior a 0,05, e consequentemente, conclui-se que todas as amostras de dados apresentam uma distribuição normal, isto é, a $\mathrm{H}_{0}$ é aceita e $\mathrm{H}_{1}$ rejeitada (hipóteses apresentadas na Figura 73). Portanto, este resultado possibilita a aplicação dos testes estatísticos ANOVA e Tukey para a amostra que está sendo considerada.

O próximo passo é verificar se as variâncias das SSs extraídas experimentalmente dos DnMs, OnM e CnM durante as aplicações das radiações ionizantes do tipo raios-X, valendo-se de uma polarização no modo Analog são estatisticamente equivalentes entre si. Para isto, o teste utilizado para verificar se as amostras de dados apresentam variâncias estatisticamente equivalentes entre si é o teste para comparação de duas variâncias. $\mathrm{O}$ nível de significância escolhido para a aplicação deste teste foi de 0,05 (o que significa dizer que este teste estatístico será realizado com uma precisão de acerto igual a $95 \%$ ). As hipóteses nula e alternativa levadas em conta para a aplicação do teste para comparação de duas variâncias são ilustradas na Figura 74.

Figura 74 - Hipóteses nula e alternativa levadas em conta para a aplicação do teste para comparação de duas variâncias das SSs extraídas experimentalmente dos DnMs, OnM e $\mathrm{CnM}$ durante as aplicações das radiações ionizantes do tipo raios-X, valendo-se de uma polarização no modo Analog

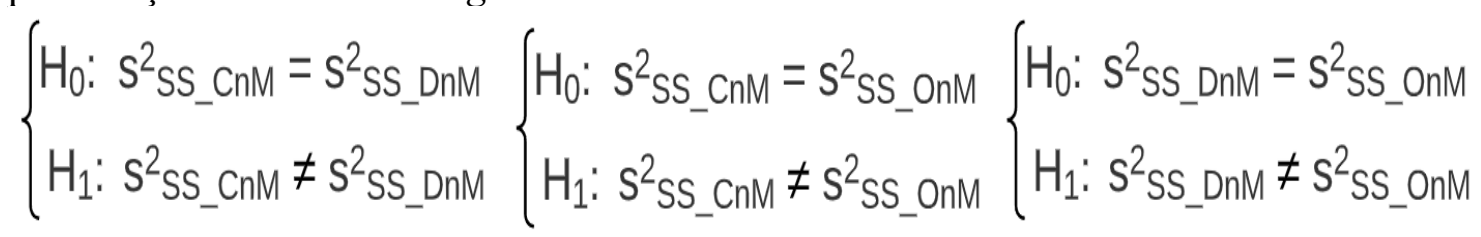


$\mathrm{Na}$ Figura $74, s_{S S_{-} C n M}^{2}, s_{S S_{-} D n M}^{2}$ e $s_{S S_{-} O n M}^{2}$ são as variâncias das SSs extraídas experimentalmente dos CnMs, DnMs e OnMs, respectivamente, durante as aplicações das radiações ionizantes do tipo raios-X, valendo-se de uma polarização no modo Analog.

A Tabela 19 resume os resultados dos valores de $\mathrm{p}$ do teste para a comparação das variâncias das amostras das SSs extraídas experimentalmente dos DnMs, OnM e CnM durante as aplicações das radiações ionizantes do tipo raio-X, valendo-se de uma polarização no modo Analog, isto é, $\mathrm{s}^{2}{ }_{\mathrm{SS}} \mathrm{CnM}$ comparada com $\mathrm{s}^{2} \mathrm{SS}$ _DnM, $\mathrm{s}^{2} \mathrm{SS}$ CnM

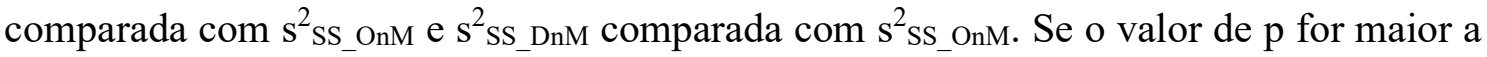
0,025 (pois que para este teste deve-se comparar se o valor de $\mathrm{p}$ é superior a $\alpha^{\prime} / 2$ ), conclui-se que as variâncias das SSs extraídas experimentalmente dos DnMs, OnM e CnM são estatisticamente equivalentes entre si, caso contrário, deve-se concluir que as variâncias das SSs não são estatisticamente equivalentes entre si, impossibilitando a aplicação dos testes estatísticos ANOVA e Tukey. Além disso, na Tabela 19 também é ilustrada a razão estimada entre as variâncias analisadas, isto é, $s_{S S_{-} C n M}^{2} / s_{S S_{-} D n M}^{2}$, $s_{S S_{-} C n M}^{2} / s_{S S_{-} O n M}^{2}$ e $s_{S S_{-} D n M}^{2} / s_{S S_{-} O n M}^{2}$.

Tabela 19 - Valores de p do teste para comparação de duas variâncias das SSs extraídas experimentalmente dos DnMs, OnM e CnM considerando-se de uma polarização no modo Analog durante o procedimento das radiações ionizantes de raios-X, e a razão estimada entre as variâncias analisadas.

\begin{tabular}{|c|c|c|}
\hline Comparação Efetuada & $\mathbf{p}$ & Razão Estimada \\
\hline 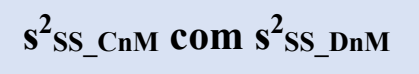 & 0,001 & 4,01 \\
\hline 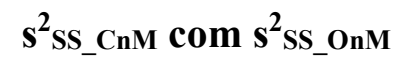 & 0,001 & 6,03 \\
\hline $\mathbf{s}^{2}$ SS_DnM Com $\mathbf{s}^{2}$ SS_OnM & 0,989 & 0,97 \\
\hline
\end{tabular}

Analisando-se os resultados do valor $\mathrm{p}$ apresentados na Tabela 19, pode-se observar que as comparações das variâncias entre as amostras das SSs, isto é, s $^{2}$ SS_CnM com s s $^{2}$ SS_DnM e s ${ }^{2}$ SS_CnM Com s ${ }^{2}$ SS_OnM, o valor de p encontra-se inferior a 0,025. Entretanto sabe-se que é possível ainda aplicar o teste ANOVA para situações nas quais a razão estimada entre as variâncias é inferior a nove vezes [66]. Dessa forma, o teste ANOVA ainda será aplicado em função da máxima razão estimada calculada pelo MINITAB 2020 ser igual a 6,03 . 
Para a comparação entre $\mathrm{s}^{2}$ SS_DnM com $\mathrm{s}^{2}$ SS_OnM, verifica-se que o valor de $\mathrm{p}$ é superior a 0,025 o que possibilita a aplicação dos testes estatísticos ANOVA e Tukey para a comparação que está sendo considerada.

O próximo passo é aplicar o teste estatístico ANOVA com o objetivo de verificar se as médias das amostras das SSs extraídas experimentalmente dos DnMs, OnM e CnM durante as aplicações das radiações ionizantes do tipo raios-X, valendo-se de uma polarização no modo Analog são estatisticamente equivalentes ou diferentes entre si. O nível de significância escolhido para a aplicação deste teste foi de 0,05 (o que significa dizer que este teste estatístico será realizado com uma precisão de acerto igual a $95 \%$ ). As hipóteses nula e alternativa levadas em conta para a aplicação do Teste ANOVA são ilustradas na Figura 75.

Figura 75 - As hipóteses nula e alternativa levadas em conta para a aplicação do teste ANOVA nos valores médios das SSs extraídas experimentalmente dos DnMs, OnM e $\mathrm{CnM}$ durante as aplicações das radiações ionizantes do tipo raios-X, valendo-se de uma polarização no modo Analog

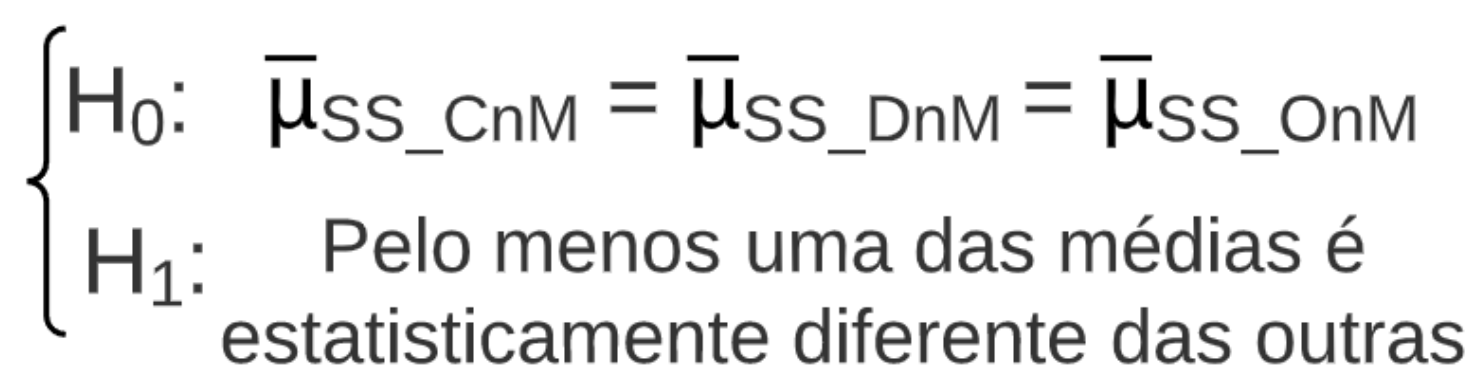

Fonte: Autor.

Na Figura $75, \bar{\mu}_{S S_{-} C n M}, \bar{\mu}_{S S_{-} D n M}$ e $\bar{\mu}_{S S_{-} O n M}$ são os valores médios das SSs extraídas experimentalmente dos CnMs, DnMs e OnMs, respectivamente, durante as aplicações das radiações ionizantes do tipo raios-X, valendo-se de uma polarização no modo Analog.

A Tabela 20 ilustra o resultado do teste ANOVA das médias das amostras das SSs extraídas experimentalmente dos DnMs, OnM e CnM considerando-se de uma polarização no modo Analog, durante o procedimento das radiações ionizantes de raios$\mathrm{X}$. 
Tabela 20 - Resultado do teste ANOVA das médias das SSs extraídas experimentalmente dos DnMs, OnM e CnM considerando-se de uma polarização no modo Analog durante o procedimento das radiações ionizantes de raios-X

\begin{tabular}{|c|c|c|}
\hline $\mathbf{p}$ & $\mathbf{F}_{\text {calculado }}$ & F crítico \\
\hline 0,002 & 9,28 & 3,52 \\
\hline
\end{tabular}

Como o valor de $\mathrm{p}$ é menor que 0,05 e o valor de $\mathrm{F}_{\text {calculado }}$ é maior que $\mathrm{F}_{\text {crítico }}\left(\mathrm{F}_{\mathrm{C}}\right)$, pode-se rejeitar $\mathrm{H}_{0}$, portanto pode-se afirmar que pelo menos uma das médias das SSs extraídas experimentalmente dos DnMs, OnM e CnM são estatisticamente diferentes entre si. Desta forma, para analisar qual média das SSs extraídas experimentalmente dos DnMs, OnM e CnM diferem entre si, deve-se aplicar o teste estatístico Tukey.

Para se aplicar o teste estatístico Tukey, devemos efetuar o cálculo de $\Delta$ ilustrado na equação (38). O valor de QME é fornecido pelo MINITAB 2020 e, para estas amostras estudadas tem o valor igual a $255,4(\mathrm{mV} / \mathrm{dec} .)^{2}$. O valor de q é obtido na tabela de amplitude estudentizada q e para um nível de significância de 0,05 , é igual a 3,5927, C' é o número de comparações a ser realizada que é igual a 3 para este estudo [69], [70].

$$
\Delta=q \cdot \sqrt{\frac{Q M E}{C^{\prime}}}=3,5927 \cdot \sqrt{\frac{255,4}{3}}=33,14 \frac{\mathrm{mV}}{\text { déc. }}
$$

Além disso, para se concluir qual valor médio das SSs extraídas experimentalmente dos DnMs, OnM e CnM diferem entre si, devemos levar em consideração a seguinte comparação $\left|\bar{y}_{l}-\bar{y}_{J}\right|>\Delta$. A Tabela 21 indica o resultado do teste estatístico de Tukey nos valores médios das SSs extraídas experimentalmente dos DnMs, OnM e CnM durante as aplicações das radiações ionizantes do tipo raios-X, valendo-se de uma polarização no modo Analog. 
Tabela 21 - Resultado do teste estatístico de Tukey nos valores médios das SSs extraídas experimentalmente dos DnMs, OnM e CnM considerando-se de uma polarização no modo Analog, durante o procedimento das radiações ionizantes de raios-X

\begin{tabular}{|c|c|cc|c|}
\hline A mostras & $\begin{array}{r}\text { Média }\left(\bar{\mu}_{S S}\right) \\
(\mathbf{m} \text { V/déc. })\end{array}$ & |Diferença de Médias $\mid(\mathbf{m V} /$ déc. $)$ & $\begin{array}{c}\Delta \\
(\mathrm{mV} / \text { déc. })\end{array}$ \\
\hline CnM & 139,40 & $\bar{\mu}_{S S_{-} \text {DnM }}-\bar{\mu}_{S S_{-} \mathrm{CnM}}$ & $|33,5|$ & 33,14 \\
\hline DnM & 105,90 & $\bar{\mu}_{S S_{-} \text {OnM }}-\bar{\mu}_{S S_{-} \mathrm{CnM}}$ & $|37,16|$ & 33,14 \\
\hline OnM & 102,24 & $\bar{\mu}_{S S_{-} \text {OnM }}-\bar{\mu}_{S S_{-} \text {DnM }}$ & $|3,66|$ & 33,14 \\
\hline
\end{tabular}

Por meio da análise dos resultados apresentados na Tabela 21, pode-se concluir que o valor médio das SSs extraídas dos $\mathrm{CnMs}$ não é estatisticamente equivalente em comparação aos valores médios das SSs extraídas dos DnMs e OnMs. Isto pode ser afirmado, pois que a diferença dos valores médios entre duas amostras é maior em comparação ao parâmetro $\Delta$ para as comparações $\left(\bar{\mu}_{\text {SS_DnM }}-\bar{\mu}_{\text {SS_CnM }_{-}}\right)$e $\left(\bar{\mu}_{\text {SS_OnM }}-\right.$ $\left.\bar{\mu}_{\text {SS_CnM }}\right)$. Porém quando se efetua a diferença entre os valores médios ( $\bar{\mu}_{\text {SS_onM }}-$ $\bar{\mu}_{\text {SS_DnM }}$ ), verifica-se que esta diferença é menor que o parâmetro $\Delta$, indicando que estes dois valores médios são estatisticamente equivalentes entre si. Isso permite afirmar que os valores médios das SSs extraídas experimentalmente dos DnMs e OnMs apresentam as mesmas variabilidades ou o mesmo nível de robustez para as TIDs aplicadas nas amostras, para um nível de acerto de 95\%.

A Figura 76 ilustra o histograma das SSs extraídas experimentalmente dos DnMs, OnM e CnM durante as aplicações das radiações ionizantes do tipo raios-X, valendo-se de uma polarização no modo Analog. 
Figura 76 - Histograma das SSs extraídas experimentalmente dos DnMs, OnM e CnM durante as aplicações das radiações ionizantes do tipo raios-X, valendo-se de uma polarização no modo Analog

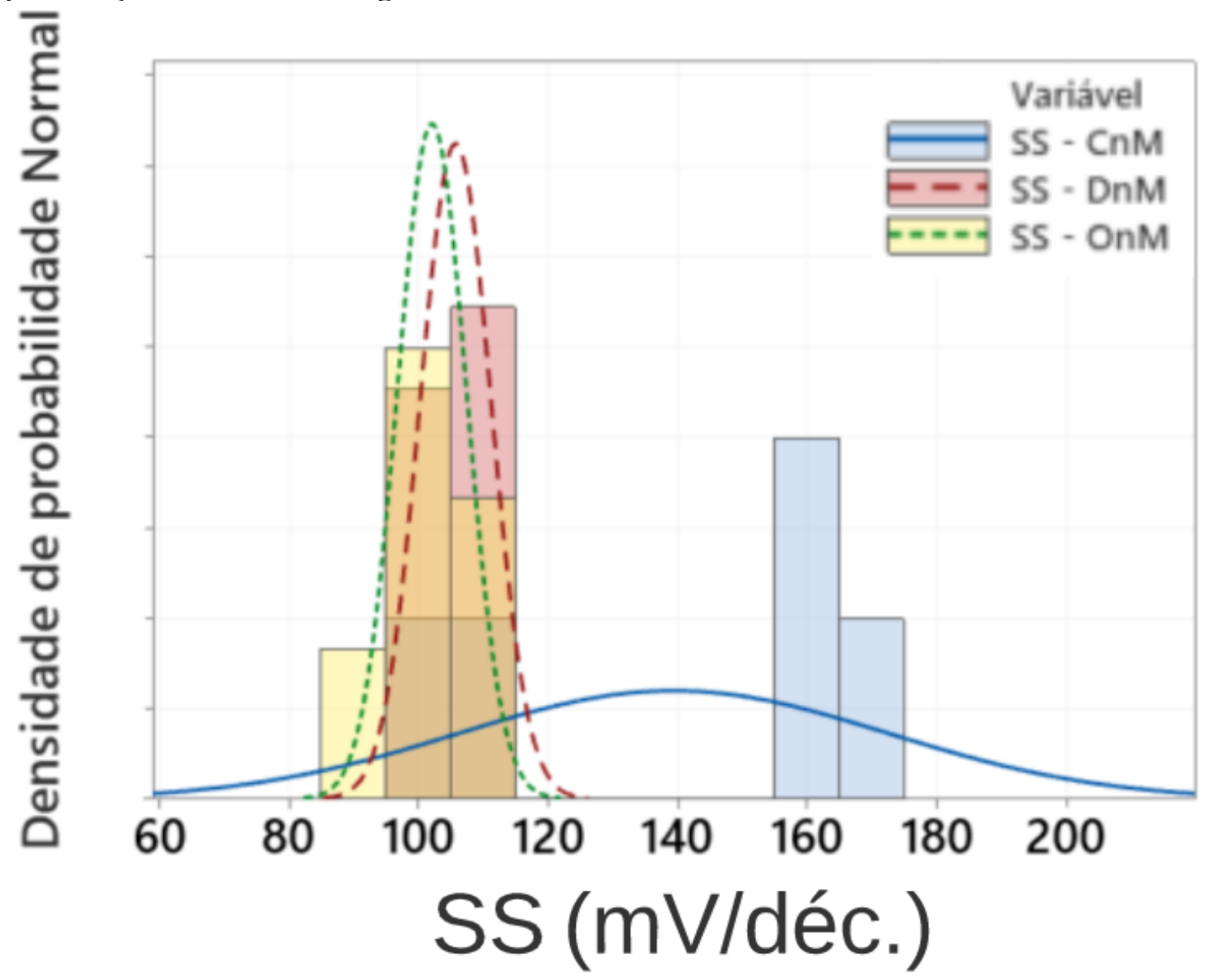

Fonte: Autor.

Por meio da análise da Figura 76, pode-se observar um comportamento estatisticamente equivalente entre os valores médios das SS dos DnMs e OnMs, todavia verifica-se um comportamento significativamente diferente dos valores médios das SSs dos CnMs, durante as aplicações das radiações ionizantes do tipo raios-X.

Outra maneira de analisar o efeito do desvio-padrão nas amostras das SSs é por meio do gráfico dos intervalos máximos e mínimos e dos valores médios das SSs extraídas experimentalmente dos DnMs, OnM e CnM durante as aplicações das radiações ionizantes do tipo raios-X, valendo-se de uma polarização no modo Analog, ilustrado na Figura 77. 
Figura 77 - Gráfico dos intervalos máximos e mínimos e dos valores médios das SSs extraídas experimentalmente dos DnMs, OnM e CnM durante as aplicações das radiações ionizantes do tipo raios-X, valendo-se de uma polarização no modo Analog

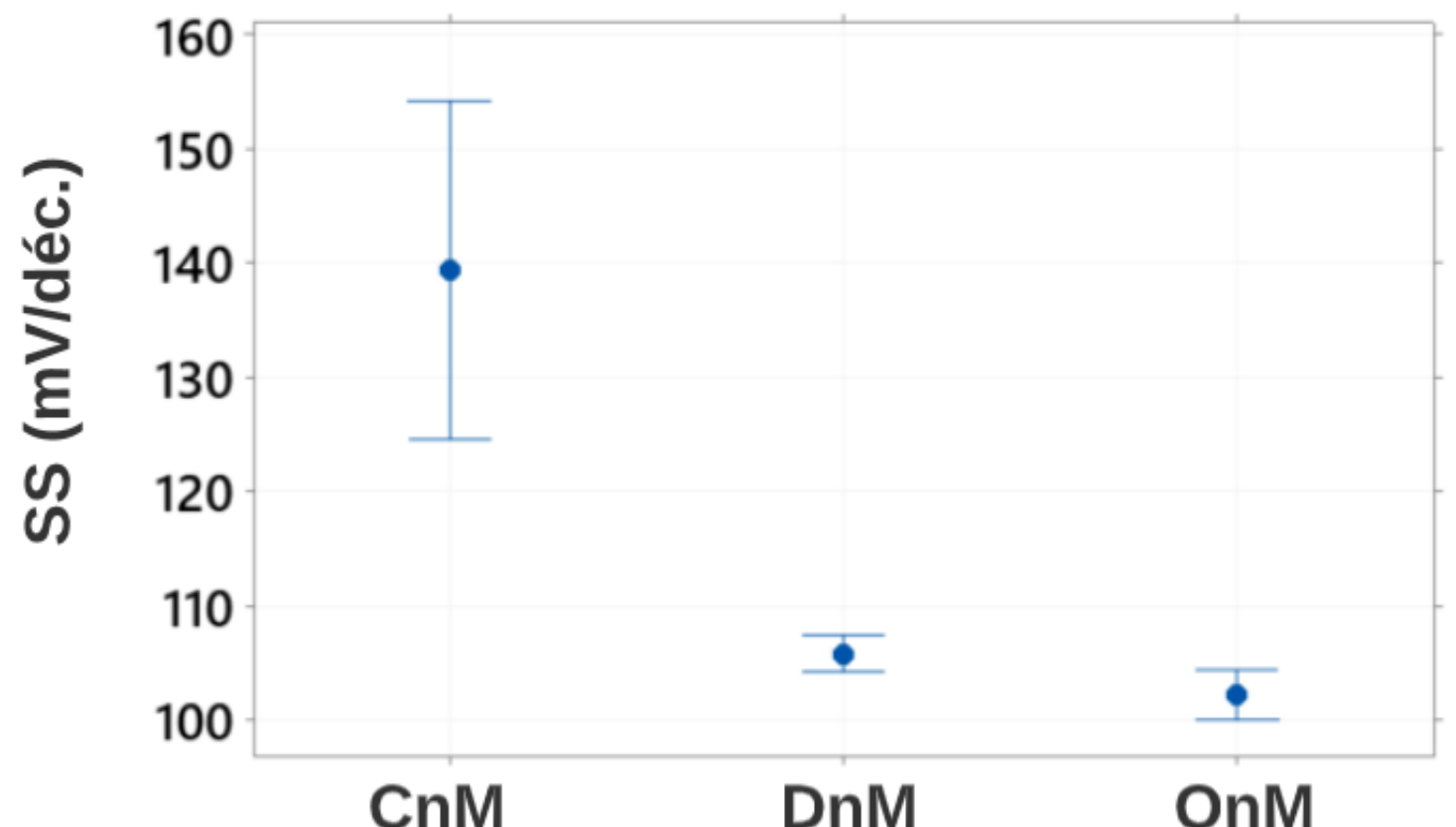

Fonte: Autor

Por meio dos resultados apresentados na Tabela 21 e nas Figura 76 e 77, pode-se concluir que a amostra de dados das SSs extraídas dos CnMs apresentam um desviopadrão significativamente maior $(33,20 \mathrm{mV} /$ déc.) e portanto, uma maior variabilidade em ambientes de radiação ionizantes do tipo raios-X quando se efetua a comparação com os desvios-padrão das SSs extraídas dos DnMs e OnMs (5,34 mV/déc. para os DnMs e 5,50 $\mathrm{mV} /$ déc. para os OnMs). Esta afirmação pode ser comprovada, para um nível de significância de 5\% (portanto um nível de acerto de 95\%) e este comportamento pode ser explicado graças ao DEPAMBBRE presente nos DnMs e OnMs. Portanto, os DnMs e OnMs apresentam menores variabilidades e uma maior robustez em ambientes de radiação ionizantes do tipo raios-X quando polarizados no modo Analog e, portanto, um melhor casamento entre dispositivos em comparação com os CnMs para todas as TIDs consideradas neste estudo. 
4.4 ESTUDO ESTATÍSTICO DOS EFEITOS DA TID ENTRE UM MOSFET DE PORTA HEXAGONAL, OCTOGONAL E RETANGULAR POLARIZADOS NO MODO OFF-STATE DURANTE OS PROCEDIMENTOS DAS RADIAÇÕES IONIZANTES DE RAIOS-X

O objetivo deste estudo é verificar estatisticamente, por meio dos testes ANOVA e de Tukey, se os valores médios das amostras das $\mathrm{V}_{\mathrm{THS}}$ e SSs extraídas experimentalmente dos DnMs, OnMs e CnMs durante as aplicações das radiações ionizantes do tipo raios-X, valendo-se de uma polarização no modo Off-state são estatisticamente equivalentes entre si. Desta forma, é possível afirmar, em função de um nível de significância de 5\% (portanto um nível de acerto de 95\%) escolhido para a aplicação dos testes ANOVA e de Tukey, qual dispositivo apresentou uma maior variabilidade, isto é, uma menor robustez às TIDs aplicadas.

Para análise dos efeitos da TID nos nMOSFETs de porta hexagonal (DnM), octogonal $(\mathrm{OnM})$ e retangular $(\mathrm{CnM})$ quando submetidos às radiações ionizantes por raios-X e valendo-se da aplicação de $\mathrm{V}_{\mathrm{DD}}(1,2 \mathrm{~V})$ ao terminal de dreno e $0 \mathrm{~V}$ nos demais terminais dos MOSFETs durante o procedimento das radiações ionizantes (Off-state), foram utilizados 4 dispositivos (2 DnMs, $1 \mathrm{OnM}$ e $1 \mathrm{CnM}$ ) em 1 chip. A Figura 78 ilustra o procedimento para a obtenção das amostras das $\mathrm{V}_{\mathrm{THS}}$ e SSs extraídas dos DnMs, OnM e CnM.

Figura 78 - Procedimento para a obtenção das amostras das $\mathrm{V}_{\mathrm{THS}}$ e SSs extraídas dos DnMs, OnM e CnM durante as aplicações das radiações ionizantes do tipo raios-X, valendo-se de uma polarização no modo Off-state

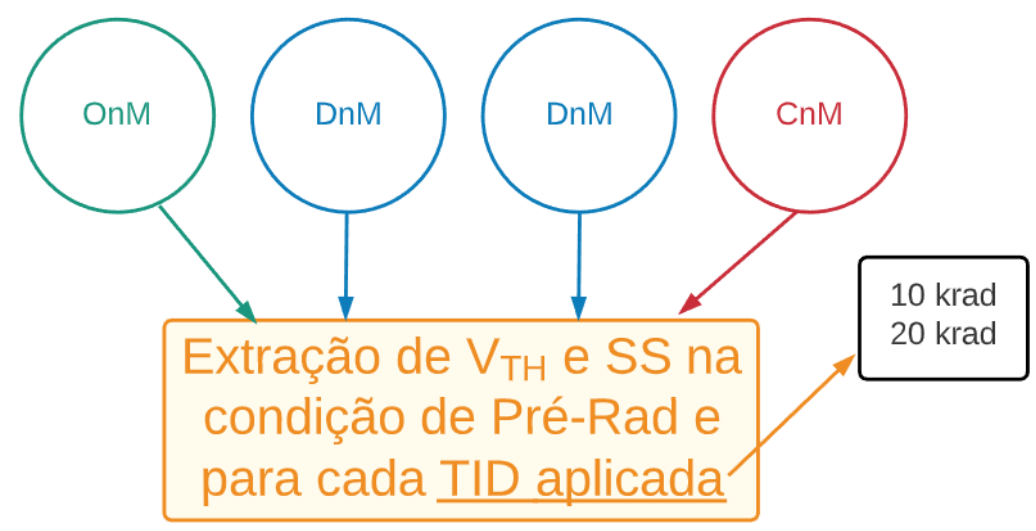

Fonte: Autor. 
De acordo com a Figura 78, foram investigados 2 DnMs, 1 OnM e 1 CnM provenientes de um mesmo CI. Portanto, o estudo foi realizado com uma quantidade total de 4 MOSFETs (2 DnMs, 1 OnM e $1 \mathrm{CnM}$ ). Os valores de W e L do CnM são iguais a $0,8 \mu \mathrm{m}$ e $0,16 \mu \mathrm{m}$. Os valores de $\mathrm{W}, \mathrm{b}, \mathrm{B}$, ângulo alfa $(\alpha)$ e o fator de corte (c) para o OnM são iguais a 1,52 $\mu \mathrm{m}, 0,69 \mu \mathrm{m}, 1,49 \mu \mathrm{m}, 90^{\circ}$ e $50 \%$. Os valores de $\mathrm{W}, \mathrm{b}, \mathrm{B}$, ângulo alfa $(\alpha)$ para os dois DnMs são iguais a $0,56 \mu \mathrm{m}, 0,2 \mu \mathrm{m}, 0,88 \mu \mathrm{m}, 90^{\circ}$.

Além disso, de acordo com o procedimento ilustrado na Figura 78, o CI foi exposto com as seguintes doses: $10 \mathrm{krad}$ e $20 \mathrm{krad}$. A taxa de dose escolhida para a realização deste estudo foi definida pelo mínimo permitido pelo radiador de raios X (70 $\mathrm{krad} / \mathrm{h}$ ), a fim de compreender o comportamento desses dispositivos em uma menor taxa de dose de radiações ionizantes de raios $\mathrm{X}$.

Os parâmetros elétricos foram obtidos a partir das curvas de corrente de dreno (I $\left.\mathrm{IS}_{\mathrm{D}}\right)$ em função da tensão de porta ( $\mathrm{V}_{\mathrm{GS}}$ ), com tensão de dreno ( $\left.\mathrm{V}_{\mathrm{DS}}\right)$ de $50 \mathrm{mV}$ para obter os valores da tensão de limiar ( $\left.\mathrm{V}_{\mathrm{TH}}\right)$ e da inclinação de sublimiar (SS). O dispositivo CnM parou de funcionar para uma TID de $40 \mathrm{krad} \mathrm{e}$, consequentemente, essa dose foi considerada como a máxima utilizada neste estudo.

A Figura 79 ilustra um diagrama de blocos que ilustra os procedimentos efetuados para a aplicação dos testes estatísticos ANOVA e de Tukey das VTHS e SSs extraídas experimentalmente dos DnMs, OnM e CnM durante as aplicações das radiações ionizantes do tipo raios-X, valendo-se de uma polarização no modo Off-state. 
Figura 79 - Diagrama de blocos para a aplicação dos testes estatísticos ANOVA e de Tukey das $\mathrm{V}_{\mathrm{THS}}$ e SSs extraídas experimentalmente dos DnMs, OnM e CnM durante as aplicações das radiações ionizantes do tipo raios-X, valendo-se de uma polarização no modo Off-state.

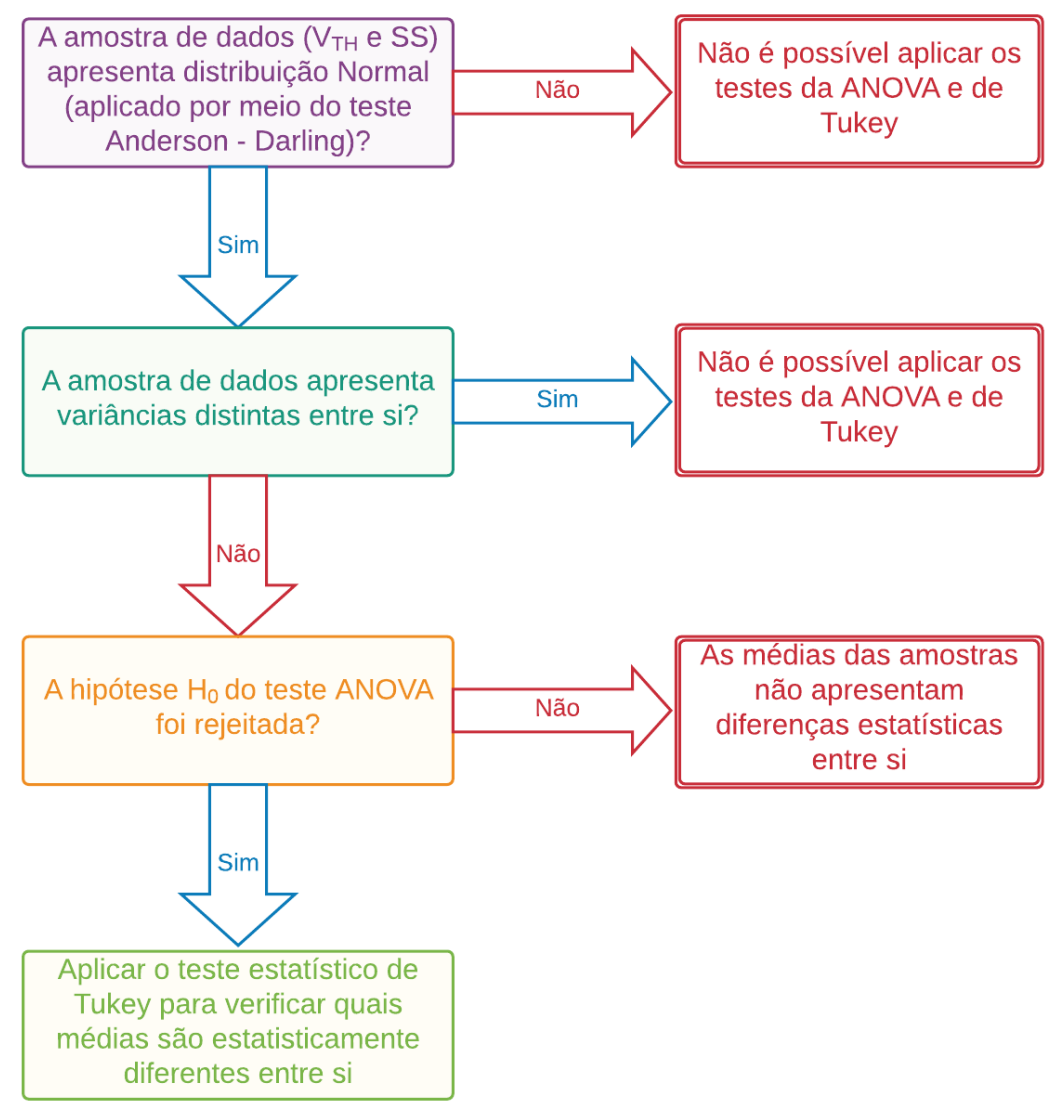

Fonte: Autor

Será efetuado um estudo estatístico que utiliza o teste de Anderson - Darling [61] para determinar se as amostras das $\mathrm{V}_{\mathrm{TH}}$ e SSs extraídas experimentalmente dos DnMs, OnM e CnM durante as aplicações das radiações ionizantes do tipo raios-X, valendo-se de uma polarização no modo Off-state apresentam uma distribuição normal de dados. Caso estas amostras tenham uma distribuição normal, deve-se aplicar outro teste estatístico à estas amostras para verificar se estas variâncias são estatisticamente equivalentes entre si.

Caso seja possível afirmar que as variâncias das amostras são estatisticamente equivalentes entre si, pode-se aplicar os testes ANOVA e de Tukey para determinar quais valores médios das amostras das $\mathrm{V}_{\mathrm{THS}}$ e das SSs extraídas experimentalmente dos DnMs, OnM e CnM durante as aplicações das radiações ionizantes do tipo raios-X, valendo-se 
de uma polarização no modo Off-state, variam entre si. Por meio da aplicação destes dois testes estatísticos é possível determinar, portanto, qual dispositivo apresentou uma maior variabilidade, isto é, uma menor robustez às TIDs aplicadas.

\subsubsection{Tensão de Limiar $\left(V_{T H}\right)$}

Para se efetuar a extração das $\mathrm{V}_{\mathrm{TH}}$ dos dispositivos DnMs, OnM e CnM utilizouse a segunda derivada da curva IDS em função de $\mathrm{V}_{\mathrm{GS}}$, considerando $\mathrm{V}_{\mathrm{DS}}$ igual a $50 \mathrm{mV}$.

Para a aplicação do teste ANOVA e Tukey entre as $\mathrm{V}_{\mathrm{THS}}$ extraídas experimentalmente dos DnMs, OnM e CnM durante as aplicações das radiações ionizantes do tipo raios-X, valendo-se de uma polarização no modo Off-state, é necessário antes, verificar se as amostras de dados utilizadas apresentam uma distribuição normal [61].

$\mathrm{O}$ teste utilizado para verificar se as amostras das $\mathrm{V}_{\mathrm{TH}} \mathrm{S}$ extraídas experimentalmente dos DnMs, OnM e CnM durante as aplicações das radiações ionizantes do tipo raios-X, valendo-se de uma polarização no modo Off-state, apresentam uma distribuição normal é o de Anderson - Darling [61]. O nível de significância escolhido para a aplicação deste teste foi de 0,05 (o que significa dizer que este teste estatístico será realizado com uma precisão de acerto igual a $95 \%$ ). As hipóteses nula e alternativa levadas em conta para a aplicação do teste de Anderson - Darling são ilustradas na Figura 80.

Figura 80 - As hipóteses nula e alternativa levadas em conta para a aplicação do teste de Anderson - Darling nas amostras das $\mathrm{V}_{\mathrm{THS}}$ extraídas experimentalmente dos DnMs, OnM e CnM durante as aplicações das radiações ionizantes do tipo raios-X, valendo-se de uma polarização no modo Off-state

\section{$\left\{\begin{array}{l}\mathrm{H}_{0}: \text { As amostras apresentam distribuição normal } \\ \mathrm{H}_{1} \text { : As amostras não apresentam distribuição normal }\end{array}\right.$}

Fonte: Autor.

A Tabela 22 resume os resultados dos valores de $\mathrm{p}$ do teste estatístico de Anderson - Darling das $\mathrm{V}_{\mathrm{TH}} \mathrm{S}$ extraídas experimentalmente dos DnMs, OnM e CnM considerandose de uma polarização no modo Off-state, durante o procedimento das radiações 
ionizantes de raios-X. Se o valor de $\mathrm{p}$ for maior a 0,05 , conclui-se que a amostra em análise apresenta uma distribuição normal, caso contrário, deve-se concluir que a amostra não apresenta uma distribuição normal.

Tabela 22 - Valores de p do teste estatístico de Anderson - Darling das $\mathrm{V}_{\mathrm{THS}}$ extraídas experimentalmente dos DnMs, OnM e CnM considerando-se de uma polarização no modo Off-state, durante o procedimento das radiações ionizantes de raios-X

\begin{tabular}{|c|c|}
\hline nMOSFET & p \\
\hline DnM & 0,953 \\
\hline OnM & 0,552 \\
\hline CnM & 0,605 \\
\hline
\end{tabular}

Analisando-se os resultados do valor $\mathrm{p}$ apresentados na Tabela 22, pode-se observar que para todas as amostras das $\mathrm{V}_{\mathrm{TH}}$ em estudo, o valor de $\mathrm{p}$ encontra-se sempre superior a 0,05 , e consequentemente, conclui-se que todas as amostras de dados apresentam uma distribuição normal, isto é, a $\mathrm{H}_{0}$ é aceita e $\mathrm{H}_{1}$ rejeitada. Portanto, este resultado possibilita a aplicação dos testes estatísticos ANOVA e Tukey para a amostra que está sendo considerada neste estudo.

$\mathrm{O}$ próximo passo é verificar se as variâncias das amostras das $\mathrm{V}_{\mathrm{THS}}$ extraídas experimentalmente dos DnMs, OnM e CnM durante as aplicações das radiações ionizantes do tipo raios-X, valendo-se de uma polarização no modo Off-state são estatisticamente equivalentes entre si. Para isto, o teste utilizado para verificar se as amostras de dados apresentam variâncias estatisticamente equivalentes entre si é o teste para comparação de duas variâncias. O nível de significância escolhido para a aplicação deste teste foi de 0,05 (o que significa dizer que este teste estatístico será realizado com uma precisão de acerto igual a 95 \%). As hipóteses nula e alternativa levadas em conta para a aplicação do teste para comparação de duas variâncias são ilustradas na Figura 81. 
Figura 81 - Hipóteses nula e alternativa levadas em conta para a aplicação do teste para comparação de duas variâncias das amostras das $\mathrm{V}_{\mathrm{TH}} \mathrm{S}$ extraídas experimentalmente dos DnMs, OnM e CnM durante as aplicações das radiações ionizantes do tipo raios-X, valendo-se de uma polarização no modo Off-state

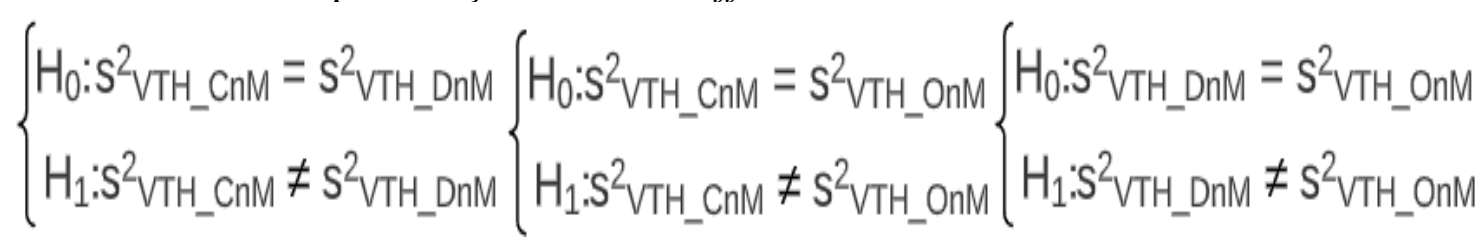

Fonte : Autor

A Tabela 23 resume os resultados dos valores de $p$ do teste para comparação das variâncias das $\mathrm{V}_{\mathrm{THS}}$ extraídas experimentalmente dos DnMs, OnM e CnM durante as aplicações das radiações ionizantes do tipo raios-X, valendo-se de uma polarização no modo Off-state, isto é, $s_{V_{T H_{-}} C n M}^{2}$ comparada com $s_{V_{T H} D n M}^{2}, s_{V_{T_{-}-} C n M}^{2}$ comparada com $S_{V_{T H_{-}} O n M}^{2}$ e $s_{V_{T_{-}} D n M}^{2}$ comparada com $s_{V_{T H_{-}} O n M}^{2}$. Se o valor de p for maior a 0,025 (pois que para este teste deve-se comparar se o valor de p é superior a $\alpha^{\prime} / 2$ ), conclui-se que as variâncias das amostras das $\mathrm{V}_{\mathrm{THS}}$ extraídas experimentalmente dos DnMs, OnM e CnM são estatisticamente equivalentes entre si, caso contrário, deve-se concluir que as variâncias das amostras das $\mathrm{V}_{\mathrm{THS}}$ não são estatisticamente equivalentes entre si, impossibilitando a aplicação dos testes estatísticos ANOVA e Tukey. Além disso, na Tabela 23 também é ilustrada a razão estimada entre as variâncias analisadas, isto é, $s_{V_{T H-} C n M}^{2} / s_{V_{T H-} D n M}^{2}, s_{V_{T H-} C n M}^{2} / s_{V_{T H-} O n M}^{2}$ e $s_{V_{T H \_} D n M}^{2} / s_{V_{T H} O n M}^{2}$.

Tabela 23 - Valores de $\mathrm{p}$ do teste para comparação de duas variâncias das $\mathrm{V}_{\mathrm{TH}} \mathrm{S}$ extraídas experimentalmente dos DnMs, OnM e CnM considerando-se de uma polarização no modo Off-state, durante o procedimento das radiações ionizantes de raios-X e razão estimada entre as variâncias analisadas.

\begin{tabular}{|c|c|c|}
\hline Comparação Efetuada & $\mathbf{p}$ & Razão Estimada \\
\hline$s_{V_{T_{-} H_{C} C n M}}^{2} \operatorname{com} s_{V_{T_{H}-D n M}}^{2}$ & 0,008 & 4,53 \\
\hline$s_{V_{T H_{-}} C n M}^{2} \operatorname{com} s_{V_{T H_{-}} \text {OnM }}^{2}$ & 0,076 & 5,02 \\
\hline$s_{V_{T_{-}-D n M}}^{2} \operatorname{com} s_{V_{T_{-}-O n M}}^{2}$ & 0,99 & 1,11 \\
\hline
\end{tabular}


Analisando-se os resultados do valor $\mathrm{p}$ apresentados na Tabela 23, pode-se observar que a comparação das variâncias entre as amostras das $\mathrm{V}_{\mathrm{THS}}$ em estudo $\left(s_{V_{T H} C n M}^{2}\right.$ comparada com $\left.s_{V_{T H} D n M}^{2}\right)$, o valor de p encontra-se inferior a 0,025 . Entretanto sabe-se que é possível ainda aplicar o teste ANOVA para situações nas quais a razão estimada é inferior a nove vezes quando se compara duas variâncias [66]. Dessa forma, o teste ANOVA ainda será aplicado em função da máxima razão estimada calculada pelo MINITAB 2020 ser igual a 4,53.

Ademais, pode-se observar que as comparações das variâncias entre as amostras das $\mathrm{V}_{\mathrm{THS}}$ em estudo $\left(s_{V_{T_{-}} \mathrm{CnM}}^{2}\right.$ comparada com $s_{V_{T H_{-} O n M}}^{2}$ e $s_{V_{T_{H_{-}} D n M}}^{2}$ comparada com $\left.S_{V_{T H}-}^{2}{ }_{\text {OnM }}\right)$, o valor de $\mathrm{p}$ encontra-se sempre superior a 0,025 , e consequentemente, conclui-se que todas as variâncias das amostras das $\mathrm{V}_{\mathrm{THS}}$ extraídas experimentalmente dos DnMs, OnM e CnM são estatisticamente equivalentes entre si, o que possibilita a aplicação dos testes estatísticos ANOVA e Tukey para a amostra que está sendo considerada por esse trabalho.

O próximo passo é aplicar o teste estatístico ANOVA com o objetivo de verificar se as médias das amostras das $\mathrm{V}_{\mathrm{TH}} \mathrm{S}$ extraídas experimentalmente dos DnMs, OnM e CnM durante as aplicações das radiações ionizantes do tipo raios-X valendo-se de uma polarização no modo Off-state são estatisticamente equivalentes ou diferentes entre si. $\mathrm{O}$ nível de significância escolhido para a aplicação deste teste foi de 0,05 (o que significa dizer que este teste estatístico será realizado com uma precisão de acerto igual a 95\%). As hipóteses nula e alternativa para a aplicação do Teste ANOVA são ilustradas na Figura 82.

Figura 82 - As hipóteses nula e alternativa levadas em conta para a aplicação do teste ANOVA aplicado nas médias das amostras das $\mathrm{V}_{\mathrm{TH}} \mathrm{S}$ extraídas experimentalmente dos DnMs, OnM e CnM durante as aplicações das radiações ionizantes do tipo raios-X, valendo-se de uma polarização no modo Offf-state

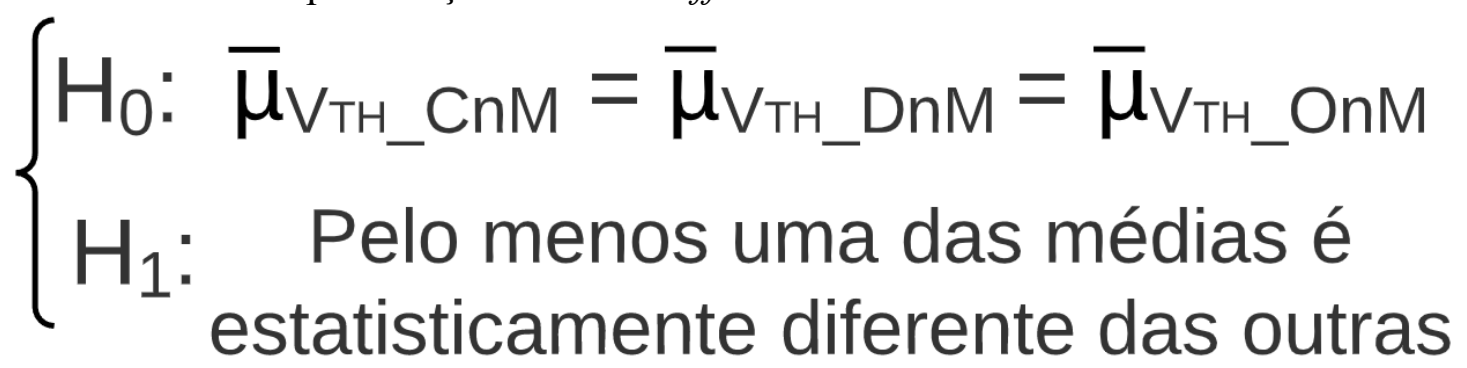

Fonte: Autor. 
A Tabela 24 ilustra o resultado do Teste ANOVA dos valores médios das $\mathrm{V}_{\mathrm{TH}} \mathrm{S}$ extraídas experimentalmente dos DnMs, OnM e CnM durante as aplicações das radiações ionizantes do tipo raios-X, valendo-se de uma polarização no modo Off-state.

Tabela 24 - Resultado do teste ANOVA dos valores médios das $\mathrm{V}_{\mathrm{THS}}$ extraídas experimentalmente dos DnMs, OnM e CnM considerando-se de uma polarização no modo Off-state, durante o procedimento das radiações ionizantes de raios-X

\begin{tabular}{|c|c|c|}
\hline $\mathbf{p}$ & $\mathbf{F}$ calculado & $\mathbf{F}_{\text {crítico }}$ \\
\hline 0,002 & 14,29 & 4,26 \\
\hline
\end{tabular}

Como o valor de $\mathrm{p}$ é menor que 0,05 e o valor de $\mathrm{F}_{\text {calculado }}$ é maior que $\mathrm{F}_{\text {crítico }}\left(\mathrm{F}_{\mathrm{C}}\right)$, pode-se rejeitar $\mathrm{H}_{0}$, portanto pode-se afirmar que pelo menos uma das médias das $\mathrm{V}_{\mathrm{TH}} \mathrm{S}$ extraídas experimentalmente dos DnMs, OnM e CnM são estatisticamente diferentes entre si. Desta forma, para analisar qual valor médio das $\mathrm{V}_{\mathrm{THS}}$ extraídas experimentalmente dos DnMs, OnM e CnM diferem entre si, deve-se aplicar o teste estatístico Tukey.

Para se aplicar o teste de Tukey, devemos efetuar o cálculo de $\Delta$ ilustrado na equação (39). O valor de QME é fornecido pelo MINITAB 2020 e, para estas amostras estudadas tem o valor igual a $0,537 \mathrm{mV}^{2}$. $\mathrm{O}$ valor de q é obtido na tabela de amplitude estudentizada q e para um nível de significância de 0,05 , é igual a 3,9485, C' é o número de comparações a ser realizada que é igual a 3 para este estudo [69], [70].

$$
\Delta=q \cdot \sqrt{\frac{Q M E}{C^{\prime}}}=3,9485 \cdot \sqrt{\frac{0,000537}{3}}=0,05283 \mathrm{~V}
$$

Além disso, para se concluir qual valor médio das $\mathrm{V}_{\mathrm{TH}} \mathrm{S}$ extraídas experimentalmente dos DnMs, OnM e CnM diferem entre si, devemos levar em consideração a seguinte comparação $\left|\overline{\mu_{l}}-\overline{\mu_{J}}\right|>\Delta$. A Tabela 25 indica o resultado do teste estatístico de Tukey nos valores médios das $\mathrm{V}_{\mathrm{TH}} \mathrm{S}$ extraídas experimentalmente dos DnMs, OnM e CnM durante as aplicações das radiações ionizantes do tipo raios-X, valendo-se de uma polarização no modo Off-state 
Tabela 25 - Resultado do teste estatístico de Tukey nas médias das $\mathrm{V}_{\mathrm{TH}} \mathrm{S}$ extraídas experimentalmente dos DnMs, OnM e CnM considerando-se de uma polarização no modo Off-state, durante o procedimento das radiações ionizantes de raios-X

\begin{tabular}{|c|c|c|c|c|}
\hline Amostras & $\begin{array}{c}\text { Média }\left(\bar{\mu}_{V_{T H}}\right) \\
(\mathbf{V})\end{array}$ & |Diferença de Médias $\mid(\mathbf{V})$ & $\Delta(\mathbf{V})$ \\
\hline CnM & 0,3763 & $\bar{\mu}_{\mathrm{V}_{\mathrm{TH}-\mathrm{DnM}}-\bar{\mu}_{\mathrm{V}_{\mathrm{TH}-} \mathrm{CnM}}}|0,0725|$ & 0,05283 \\
\hline DnM & 0,3038 & $\bar{\mu}_{\mathrm{V}_{\mathrm{TH}-\mathrm{OnM}}-\bar{\mu}_{\mathrm{V}_{\mathrm{TH}-} \mathrm{CnM}}}|0,0946|$ & 0,05283 \\
\hline OnM & 0,2817 & $\bar{\mu}_{\mathrm{V}_{\mathrm{TH}-} \mathrm{OnM}}-\bar{\mu}_{\mathrm{V}_{\mathrm{TH}} \mathrm{DnM}}$ & $|0,0221|$ & 0,05283 \\
\hline
\end{tabular}

Por meio da análise dos resultados apresentados na Tabela 25, pode-se concluir que o valor médio das $\mathrm{V}_{\mathrm{TH}} \mathrm{S}$ extraídas dos CnMs não é estatisticamente equivalente em comparação aos valores médios das $\mathrm{V}_{\mathrm{TH}} \mathrm{S}$ extraídas dos DnMs e OnMs. Isto pode ser afirmado pois que a diferença dos valores médios é maior em comparação ao parâmetro

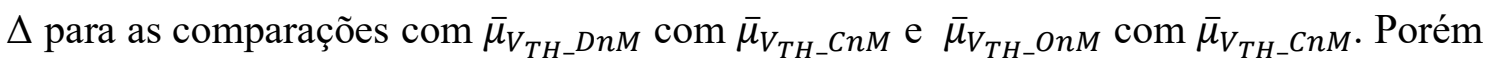
quando se efetua a diferença entre os valores médios das $\bar{\mu}_{\mathrm{VTH}}-\mathrm{OnM}-\bar{\mu}_{\mathrm{VTH}}$ - DnM verifica-se que esta diferença é menor que o parâmetro $\Delta$, indicando que estes dois valores médios são estatisticamente equivalentes entre si. Isso permite afirmar que os valores médios das $\mathrm{V}_{\mathrm{THS}}$ extraídas experimentalmente dos DnMs e OnMs apresentam as mesmas variabilidades ou o mesmo nível de robustez para as TIDs aplicadas nas amostras.

A Figura 83 ilustra o histograma da amostra de dados das $\mathrm{V}_{\mathrm{TH}} \mathrm{S}$ extraídas experimentalmente dos DnMs, OnM e CnM durante as aplicações das radiações ionizantes do tipo raios-X, valendo-se de uma polarização no modo Off-state. 
Figura 83 - Histograma da amostra de dados das $\mathrm{V}_{\mathrm{TH}} \mathrm{S}$ extraídas experimentalmente dos DnMs, OnM e CnM durante as aplicações das radiações ionizantes do tipo raios-X, valendo-se de uma polarização no modo Off-state

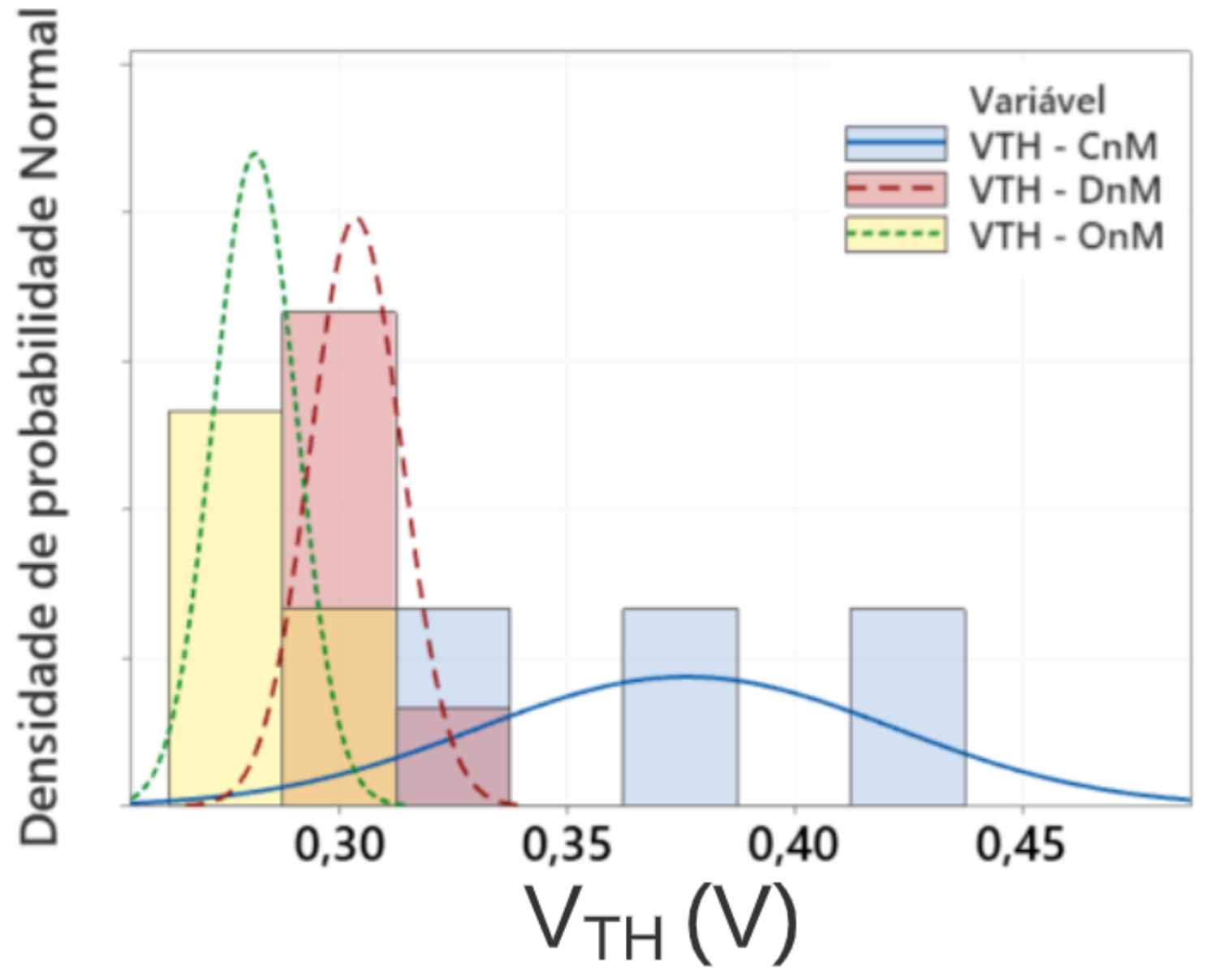

Fonte: Autor.

Outra forma de observar de forma quantitativa o efeito do desvio-padrão nas amostras das $\mathrm{V}_{\mathrm{THS}}$ extraídas experimentalmente dos DnMs, OnM e CnM é por meio do gráfico que ilustra os intervalos máximos e mínimos e dos valores médios das $\mathrm{V}_{\mathrm{TH}} \mathrm{S}$ extraídas experimentalmente dos DnMs, OnM e CnM durante as aplicações das radiações ionizantes do tipo raios-X, valendo-se de uma polarização no modo Off-state, ilustrado na Figura 84. 
Figura 84 - Gráfico dos intervalos máximos e mínimos e dos valores médios das $\mathrm{V}_{\mathrm{TH}} \mathrm{S}$ extraídas experimentalmente dos DnMs, OnM e CnM durante as aplicações das radiações ionizantes do tipo raios-X, valendo-se de uma polarização no modo Off-state

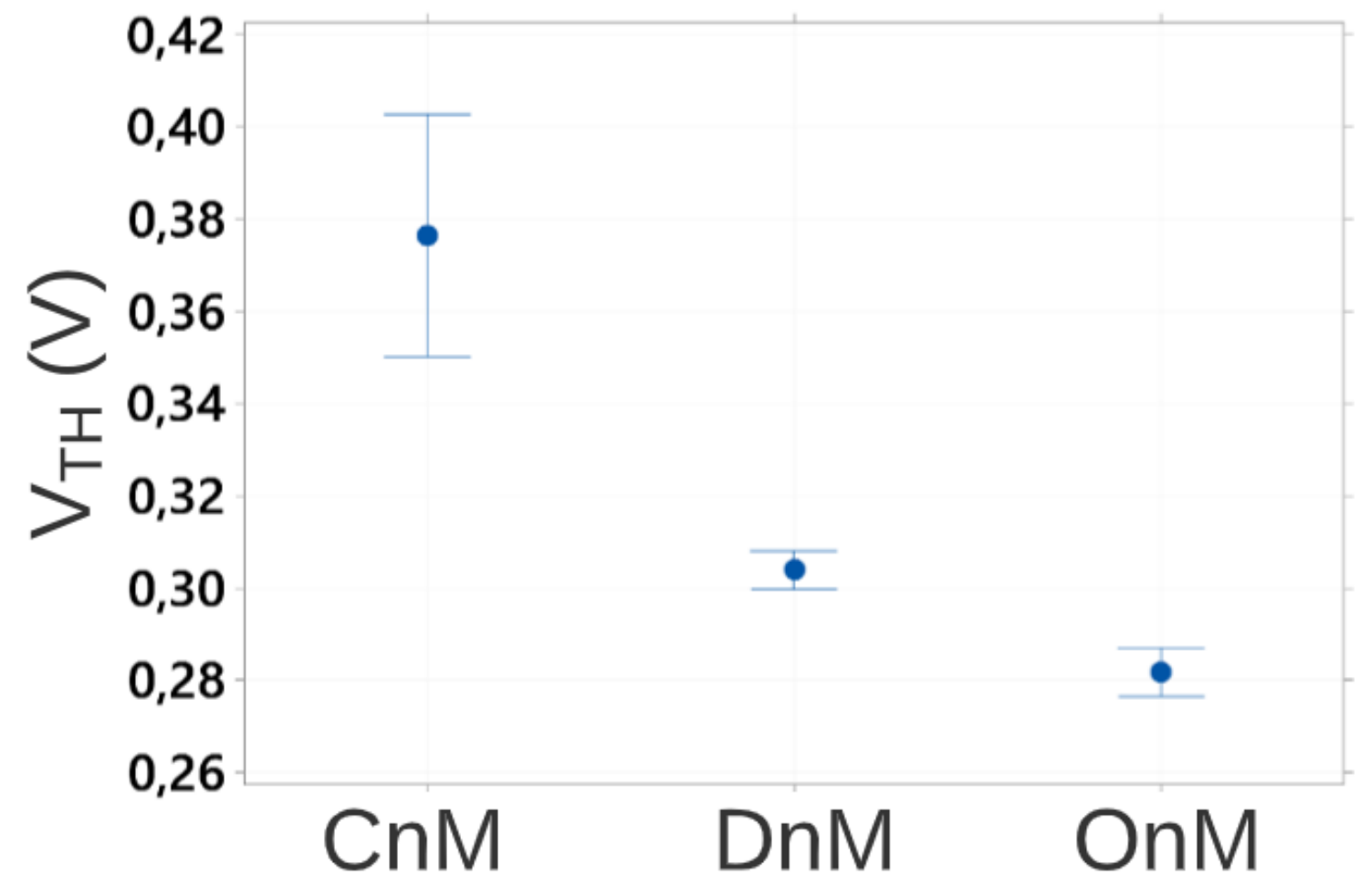

Fonte: Autor

Valendo-se dos dados ilustrados na Tabela 25 e nas Figuras 83 e 84, é possível observar que a amostra de dados das $\mathrm{V}_{\mathrm{THS}}$ extraídas dos CnMs apresentam um desviopadrão maior $(0,0456 \mathrm{~V})$ e portanto, uma tendência a ter uma maior variabilidade em ambientes de radiação ionizantes do tipo raios-X quando se efetua a comparação com os desvios-padrão das $\mathrm{V}_{\mathrm{TH}}$ extraídas dos DnMs e OnMs (0,0091 V para os DnMs e 0,0101 V para os OnMs). Esta afirmação pode ser realizada, para um nível de significância de 5\% (portanto um nível de acerto de 95\%) e este comportamento pode ser justificado, fundamentalmente, devido ao DEPAMBBRE atuando nos DnMs e OnMs. Dessa maneira, os DnMs e OnMs apresentam menores variabilidades e uma tendência a ter uma maior robustez em ambientes de radiação ionizantes do tipo raios-X, quando polarizados no modo Off-state e, portanto, um casamento entre dispositivos melhor em comparação com os CnMs para todas as TIDs consideradas neste estudo. 


\subsubsection{Inclinação de Sublimiar (SS)}

Para a aplicação do teste ANOVA e Tukey entre as SSs extraídas experimentalmente dos DnMs, OnM e CnM durante as aplicações das radiações ionizantes do tipo raios-X, valendo-se de uma polarização no modo Off-state, é necessário verificar se as amostras de dados utilizadas apresentam uma distribuição normal.

O teste estatístico utilizado para verificar se as amostras das SSs extraídas experimentalmente dos DnMs, OnM e CnM durante as aplicações das radiações ionizantes do tipo raios-X, valendo-se de uma polarização no modo Off-state apresentam uma distribuição normal é o de Anderson - Darling [61]. O nível de significância escolhido para a aplicação deste teste foi de 0,05 (o que significa dizer que este teste estatístico será realizado com uma precisão de acerto igual a $95 \%$ ). As hipóteses nula e alternativa levadas em conta para a aplicação do teste de Anderson - Darling são ilustradas na Figura 85.

Figura 85 - As hipóteses nula e alternativa levadas em conta para a aplicação do teste de Anderson - Darling nas amostras das SSs extraídas experimentalmente dos DnMs, OnM e CnM durante as aplicações das radiações ionizantes do tipo raios-X, valendo-se de uma polarização no modo Off-state

\section{$\left\{\begin{array}{l}\mathrm{H}_{0} \text { : As amostras apresentam distribuição normal } \\ \mathrm{H}_{1} \text { : As amostras não apresentam distribuição normal }\end{array}\right.$}

Fonte: Autor.

A Tabela 26 resume os resultados dos valores de p do teste estatístico de Anderson - Darling das SSs extraídas experimentalmente dos DnMs, OnM e CnM durante as aplicações das radiações ionizantes do tipo raios-X, valendo-se de uma polarização no modo Off-state. Se o valor de $\mathrm{p}$ for maior a 0,05 , conclui-se que a amostra em análise apresenta uma distribuição normal, caso contrário, deve-se concluir que a amostra não apresenta uma distribuição normal. 
Tabela 26 - Valores de p do teste estatístico de Anderson - Darling das SSs extraídas experimentalmente dos DnMs, OnM e CnM considerando-se de uma polarização no modo Off-state, durante o procedimento das radiações ionizantes de raios-X

\begin{tabular}{|cc|}
\hline nMOSFET & p \\
\hline DnM & 0,891 \\
\hline OnM & 0,069 \\
\hline CnM & 0,578 \\
\hline
\end{tabular}

Analisando-se os resultados do valor $\mathrm{p}$ apresentados na Tabela 26, pode-se observar que para todas as amostras das SSs em estudo, o valor de p encontra-se sempre superior a 0,05, e consequentemente, conclui-se que todas as amostras de dados apresentam uma distribuição normal, isto é, a $\mathrm{H}_{0}$ é aceita e $\mathrm{H}_{1}$ rejeitada. Portanto, este resultado possibilita a aplicação dos testes estatísticos ANOVA e Tukey para a amostra que está sendo considerada.

O próximo passo é verificar se as variâncias das amostras das SSs extraídas experimentalmente dos DnMs, OnM e CnM durante as aplicações das radiações ionizantes do tipo raio-X, valendo-se de uma polarização no modo Off-state são estatisticamente equivalentes entre si. Para isto, o teste utilizado para verificar se as amostras de dados apresentam variâncias estatisticamente equivalentes entre si é o teste para comparação de duas variâncias. O nível de significância escolhido para a aplicação deste teste foi de 0,05 (o que significa dizer que este teste estatístico será realizado com uma precisão de acerto igual a $95 \%$ ). As hipóteses nula e alternativa levadas em conta para a aplicação do teste para comparação de duas variâncias são ilustradas na Figura 86.

Figura 86 - Hipóteses nula e alternativa levadas em conta para a aplicação do teste para comparação de duas variâncias das amostras das SSs extraídas experimentalmente dos DnMs, OnM e CnM durante as aplicações das radiações ionizantes do tipo raios-X, valendo-se de uma polarização no modo Off-state

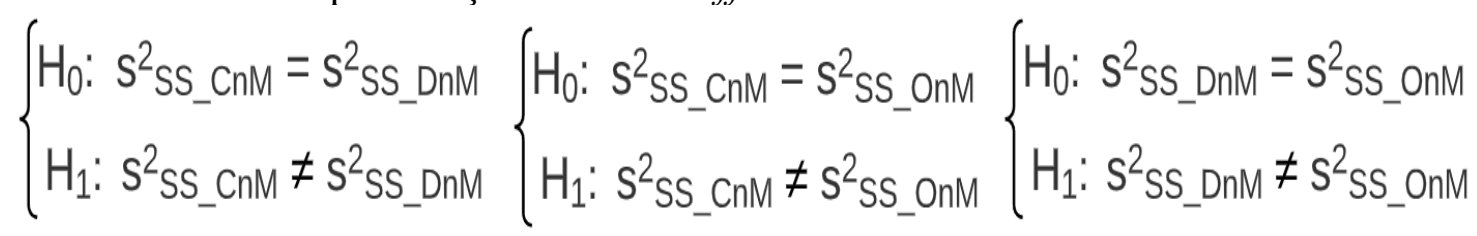


A Tabela 27 resume os resultados dos valores de $p$ do teste para comparação das variâncias das SSs extraídas experimentalmente dos DnMs, OnM e CnM durante as aplicações das radiações ionizantes do tipo raios-X, valendo-se de uma polarização no modo Off-state, isto é, $\mathrm{s}^{2} \mathrm{SS}$ _CnM comparada com $\mathrm{s}^{2} \mathrm{SS}$ _DnM, $\mathrm{s}^{2} \mathrm{SS}_{-} \mathrm{CnM}$ comparada com $\mathrm{s}^{2}$ SS_OnM e $\mathrm{s}^{2}$ SS_DnM comparada com $\mathrm{s}^{2}$ SS_OnM. Se o valor de $\mathrm{p}$ for maior a 0,025 (pois que para este teste deve-se comparar se o valor de $\mathrm{p}$ é superior a $\alpha^{\prime} / 2$ ), conclui-se que as variâncias das amostras das SSs extraídas experimentalmente dos DnMs, OnM e CnM são estatisticamente equivalentes entre si, caso contrário, deve-se concluir que as variâncias das amostras das SSs não são estatisticamente equivalentes entre si, impossibilitando a aplicação dos testes estatísticos ANOVA e Tukey. Além disso, na Tabela 27 também é ilustrada a razão estimada entre as variâncias analisadas, isto é, $s_{S S_{-} C n M}^{2} / s_{S S_{-} D n M}^{2}, s_{S S_{-} C n M}^{2} / s_{S S_{-} O n M}^{2}$ e $s_{S S_{-} D n M}^{2} / s_{S S_{-} O n M}^{2}$.

Tabela 27 - Valores de p do teste para comparação de duas variâncias das SSs extraídas experimentalmente dos DnMs, OnM e CnM considerando-se de uma polarização no modo Off-state durante o procedimento das radiações ionizantes de raios-X e razão estimada entre as variâncias analisadas.

\begin{tabular}{|c|c|c|}
\hline Comparação Efetuada & $\mathbf{p}$ & Razão Estimada \\
\hline $\mathrm{s}^{2}$ SS_CnM Com s $\mathrm{s}^{2}$ SS_DnM & 0,630 & 1,21 \\
\hline $\mathrm{s}^{2}$ SS_CnM com s $\mathrm{s}^{2}$ SS_OnM & 0,462 & 1,82 \\
\hline $\mathbf{s}^{2}{ }_{S S \_D n M}$ Com $\mathbf{s}^{2}$ SS_OnM & 0,667 & 1,50 \\
\hline
\end{tabular}

Analisando-se os resultados do valor $\mathrm{p}$ apresentados na Tabela 27, pode-se observar que todas as comparações das variâncias entre as amostras das SSs em estudo $\left(\mathrm{s}^{2}{ }_{\mathrm{SS}} \mathrm{CnM}\right.$ comparada com $\mathrm{s}_{\text {SS_DnM, }}^{2} \mathrm{~s}^{2} \mathrm{SS}_{-} \mathrm{CnM}$ comparada com $\mathrm{s}^{2}$ SS_OnM e $\mathrm{s}^{2}$ SS_DnM comparada com $s^{2}$ SS_OnM), o valor de $\mathrm{p}$ encontra-se sempre superior a 0,025, e consequentemente, conclui-se que todas as variâncias das amostras das SSs extraídas experimentalmente dos DnMs, OnM e CnM são estatisticamente equivalentes entre si, o que possibilita a aplicação dos testes estatísticos ANOVA e Tukey para a amostra que está sendo considerada por esse trabalho.

Ademais, também pode-se verificar na Tabela 27 que a razão estimada das comparações entre as variâncias das amostras das SSs extraídas dos DnMs, OnM e CnM 
apresentam valores pequenos (inferiores a nove vezes), o que também possibilita a aplicação dos testes estatísticos ANOVA e Tukey para a amostra que está sendo estudada [66].

O próximo passo é aplicar o teste estatístico ANOVA com o objetivo de verificar se as médias das SSs extraídas experimentalmente dos DnMs, OnM e CnM durante as aplicações das radiações ionizantes do tipo raios- $X$ valendo-se de uma polarização no modo Off-state são estatisticamente equivalentes ou diferentes entre si. O nível de significância escolhido para a aplicação deste teste foi de 0,05 (o que significa dizer que este teste estatístico será realizado com uma precisão de acerto igual a 95\%). As hipóteses nula e alternativa levadas em conta para a aplicação do teste ANOVA são ilustradas na Figura 87.

Figura 87 - As hipóteses nula e alternativa levadas em conta para a aplicação do teste ANOVA aplicado nas médias das amostras das SSs extraídas experimentalmente dos DnMs, OnM e CnM durante as aplicações das radiações ionizantes do tipo raios-X, valendo-se de uma polarização no modo Off-state

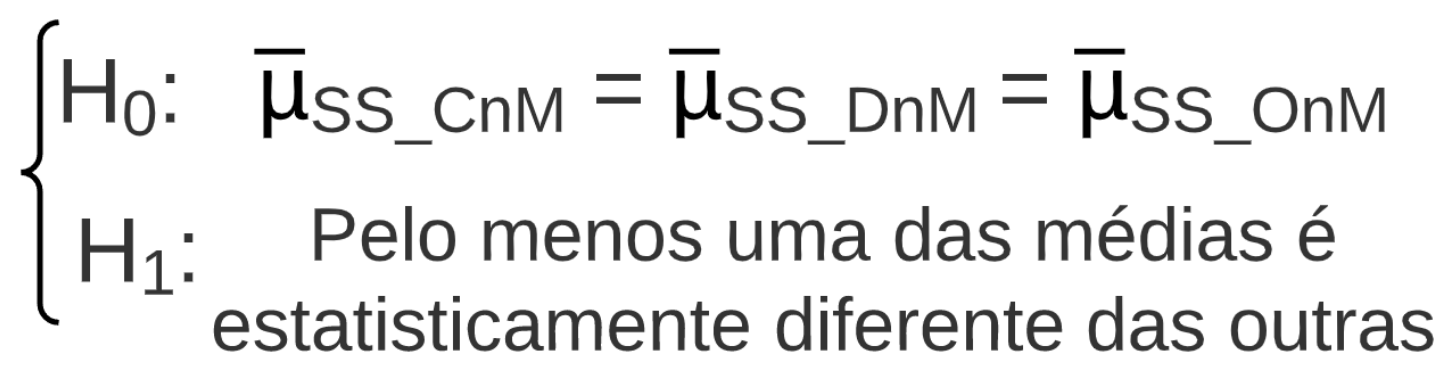

Fonte: Autor.

A Tabela 28 ilustra o resultado do teste ANOVA das médias das amostras das SSs extraídas experimentalmente dos DnMs, OnM e CnM durante as aplicações das radiações ionizantes do tipo raios-X, valendo-se de uma polarização no modo Off-state.

Tabela 28 - Resultado do teste ANOVA das médias das amostras das SSs extraídas experimentalmente dos DnMs, OnM e CnM considerando-se de uma polarização no modo Off-state, durante o procedimento das radiações ionizantes de raios-X

\begin{tabular}{|c|c|c|}
\hline $\mathbf{p}$ & $\mathbf{F}$ calculado & F crítico \\
\hline 0,004 & 11,23 & 4,26 \\
\hline
\end{tabular}

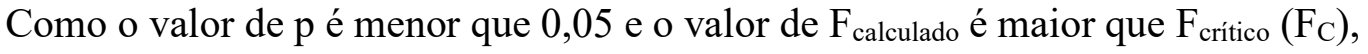
pode-se rejeitar $\mathrm{H}_{0}$, portanto pode-se afirmar que pelo menos uma das médias das SSs extraídas experimentalmente dos DnMs, OnM e CnM são estatisticamente diferentes 
entre si. Desta forma, para analisar qual média das SSs extraídas experimentalmente dos DnMs, OnM e CnM diferem entre si, deve-se aplicar o teste estatístico Tukey.

Para se aplicar o teste de Tukey, devemos efetuar o cálculo de $\Delta$ ilustrado na equação (40). O valor de QME é fornecido pelo MINITAB 2020 e, para estas amostras estudadas tem o valor igual a $12,52(\mathrm{mV} / \mathrm{dec} \text {. })^{2}$. O valor de q é obtido na tabela de amplitude estudentizada q e para um nível de significância de 0,05 , é igual a 3,9485, C' é o número de comparações a ser realizada que é igual a 3 para este estudo [69], [70].

$$
\Delta=q \cdot \sqrt{\frac{Q M E}{C^{\prime}}}=3,9485 \cdot \sqrt{\frac{12,52}{3}}=8,07 \frac{\mathrm{mV}}{\text { déc. }}
$$

Além disso, para se concluir qual média das SSs extraídas experimentalmente dos DnMs, OnM e CnM diferem entre si, devemos levar em consideração a seguinte comparação $\left|\bar{y}_{l}-\bar{y}_{J}\right|>\Delta$. A Tabela 29 indica o resultado do teste estatístico de Tukey nos valores médios das SSs extraídas experimentalmente dos DnMs, OnM e CnM durante as aplicações das radiações ionizantes do tipo raios-X, valendo-se de uma polarização no modo Off-state.

Tabela 29 - Resultado do teste estatístico de Tukey nos valores médios das SSs extraídas experimentalmente dos DnMs, OnM e CnM considerando-se de uma polarização no modo Off-state, durante o procedimento das radiações ionizantes de raios-X

\begin{tabular}{|c|c|c|c|c|}
\hline Amostras & $\begin{array}{c}\text { Média }\left(\bar{\mu}_{S S}\right) \\
(\mathrm{mV} / \text { déc. })\end{array}$ & \multicolumn{2}{|c|}{ |Diferença de Médias| (mV/déc.) } & $\begin{array}{c}\Delta \\
(\mathrm{mV} / \text { déc. })\end{array}$ \\
\hline $\mathrm{CnM}$ & 102,55 & $\bar{\mu}_{S S_{-} \mathrm{DnM}}-\bar{\mu}_{\mathrm{SS} \_\mathrm{CnM}}$ & $|11,58|$ & 8,07 \\
\hline DnM & 90,97 & $\bar{\mu}_{S S_{-} \mathrm{OnM}}-\bar{\mu}_{S S_{-} \mathrm{CnM}}$ & $|10,12|$ & 8,07 \\
\hline OnM & 92,43 & $\bar{\mu}_{S S_{-} \mathrm{OnnM}}-\bar{\mu}_{S S_{-} \mathrm{DnM}}$ & $|1,46|$ & 8,07 \\
\hline
\end{tabular}

Por meio da análise dos resultados apresentados na Tabela 29, pode-se concluir que o valor médio das SSs extraídas dos CnMs não é estatisticamente equivalente em comparação aos valores médios das SSs extraídas dos DnMs e OnMs. Isto pode ser afirmado pois que a diferença dos valores médios é maior em comparação ao parâmetro $\Delta$ para as comparações $\left(\bar{\mu}_{\text {SS_DnM }}-\bar{\mu}_{\text {SS_CnM }}\right)$ e $\left(\bar{\mu}_{\text {SS_OnM }}-\bar{\mu}_{\text {SS_CnM }}\right)$. Porém quando se efetua 
a diferença entre os valores médios $\left(\bar{\mu}_{\text {SS_OnM }}-\bar{\mu}_{\text {SS_DnM }}\right)$, verifica-se que esta diferença é menor que o parâmetro $\Delta$, indicando que estes dois valores médios são estatisticamente equivalentes entre si. Isso permite afirmar que os valores médios das SSs extraídas experimentalmente dos DnMs e OnMs apresentam as mesmas variabilidades ou o mesmo nível de robustez para as TIDs aplicadas nas amostras.

A Figura 88 ilustra o histograma das SSs extraídas experimentalmente dos DnMs, OnM e CnM durante as aplicações das radiações ionizantes do tipo raios-X, valendo-se de uma polarização no modo Off-state.

Figura 88 - Histograma da amostra de dados das SSs extraídas experimentalmente dos DnMs, OnM e CnM durante as aplicações das radiações ionizantes do tipo raios-X, valendo-se de uma polarização no modo Off-state

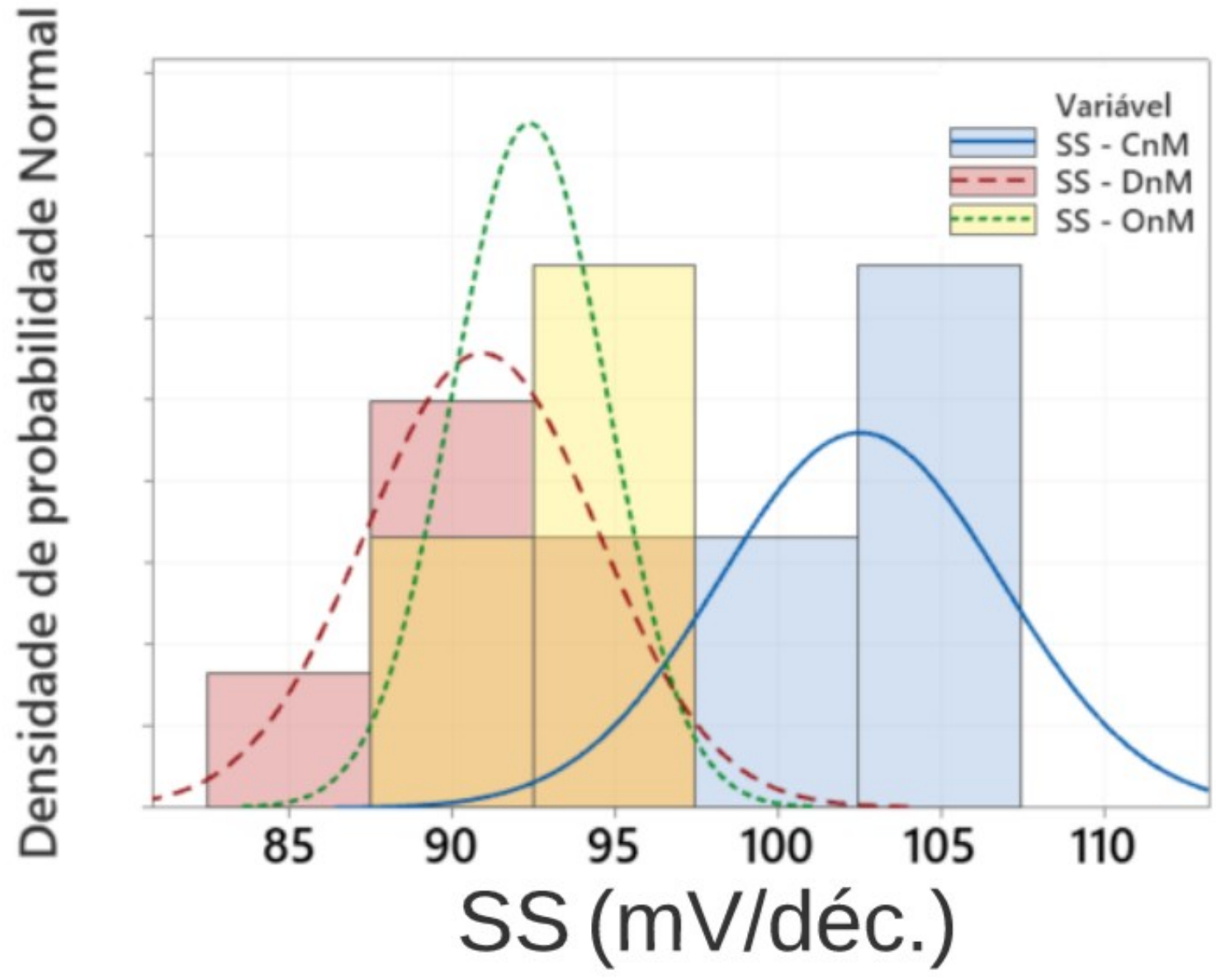

Fonte: Autor.

Outra maneira de verificar o efeito do desvio-padrão nas amostras das SSs extraídas experimentalmente dos DnMs, OnM e CnM é por meio do meio do gráfico dos intervalos máximos e mínimos e dos valores médios das SSs extraídas experimentalmente dos DnMs, OnM e $\mathrm{CnM}$ durante as aplicações das radiações 
ionizantes do tipo raios-X, valendo-se de uma polarização no modo Off-state, ilustrado na Figura 89.

Figura 89 - Gráfico dos intervalos máximos e mínimos e dos valores médios das SSs extraídas experimentalmente dos DnMs, OnM e CnM durante as aplicações das radiações ionizantes do tipo raios-X, valendo-se de uma polarização no modo Off-state

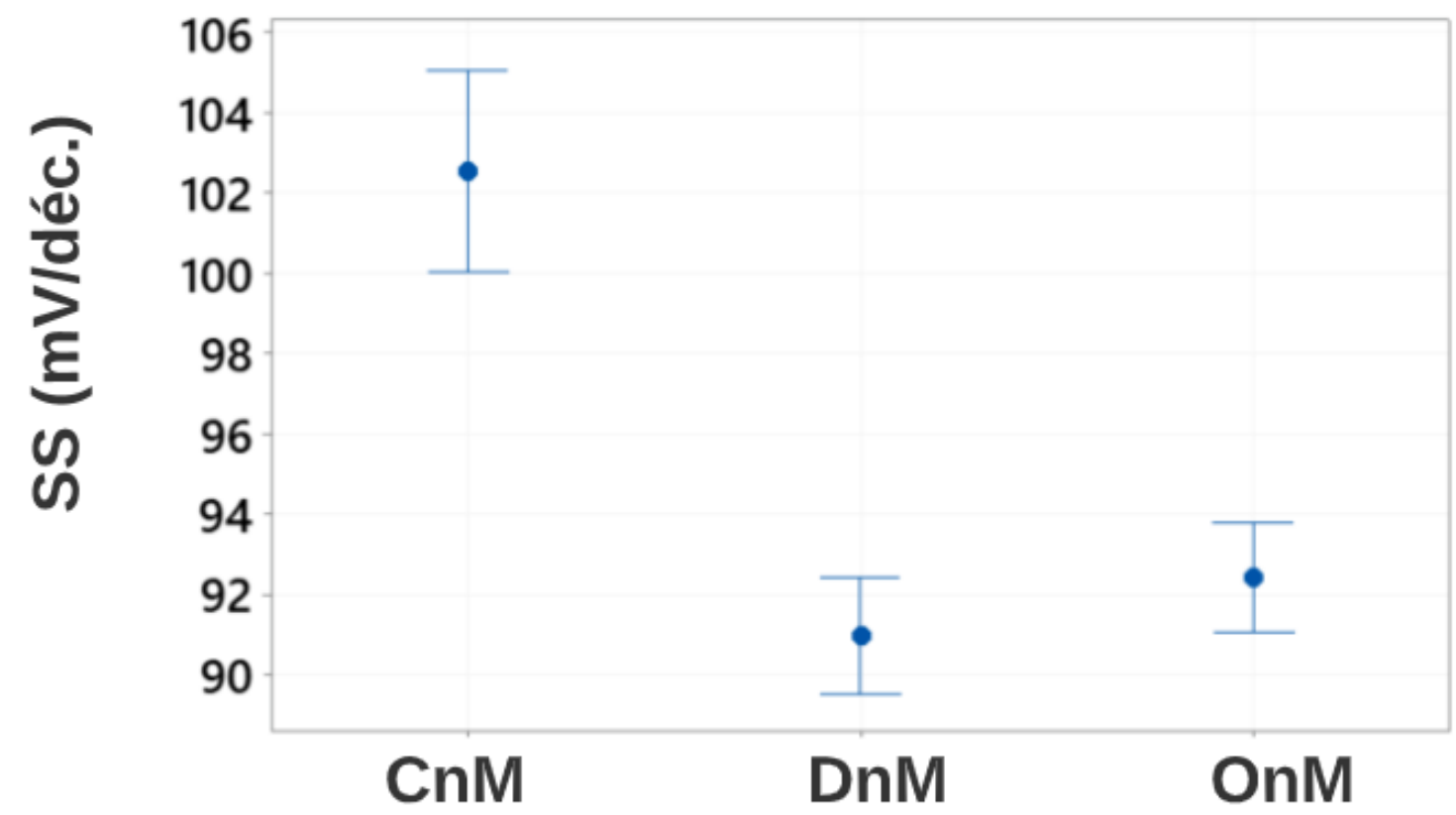

Fonte: Autor

Com base nos dados ilustrados na Tabela 29 e nas Figuras 88 e 89, pode-se concluir que a amostra de dados das SSs extraídas dos CnMs apresentam um desviopadrão maior (4,33 $\mathrm{mV} /$ déc.) e portanto, uma maior variabilidade em ambientes de radiação ionizantes do tipo raios-X quando se efetua a comparação com os desvios-padrão das SSs extraídas dos DnMs e OnMs (2,57 mV/déc. para os DnMs e 2,37 mV/déc. para os OnMs). Esta afirmação pode ser comprovada, para um nível de significância de 5\% (portanto um nível de acerto de 95\%) e este comportamento pode ser justificado graças ao DEPAMBBRE presente nos DnMs e OnMs. Portanto, os DnMs e OnMs apresentam uma menor variabilidade e maior robustez em ambientes de radiação ionizantes do tipo raios-X quando polarizados no modo Off-state e, portanto, um casamento entre dispositivos melhor em comparação com os CnMs para todas as TIDs consideradas neste estudo. 
Este trabalho consiste em um estudo experimental e estatístico acerca dos efeitos das radiações ionizantes sobre os nMOSFETs inovadores com sua geometria de porta hexagonal (DnMs) e octogonal (OnMs) em comparação aos seus respectivos convencionais (com porta retangular, $\mathrm{CnMs}$ ) equivalentes. Inicialmente, foi feita uma revisão teórica a respeito dos principais efeitos físicos existentes nos DnMs e OnMs denominados de LCE, PAMDLE e DEPAMBBRE e também das origens da radiação espacial e os seus principais efeitos nos MOSFETs.

Assim, o trabalho realizado teve como principal objetivo estudar a variabilidade e a robustez dos nMOSFETs de geometria de porta hexagonal, octogonal e retangular sob a ação de fonte de radiação ionizante por raios-X (tipo eletromagnética). Valendo-se de quatro diferentes estados de polarização destes nMOSFETs: Floating, On-state, Analog e Off-state. Para isto, utilizaram-se ferramentas estatísticas que permitiram mensurar a variabilidade de alguns parâmetros elétricos extraídos experimentalmente dos DnMs, OnMs e CnMs. Deve-se ressaltar que o estudo do casamento entre dispositivos foi desenvolvido por meio da utilização de dois métodos analíticos diferentes descritos a seguir: I: pelo cálculo do coeficiente de variabilidade para análise dos parâmetros elétricos extraídos dos DnMs, OnMs e CnMs sob a condição das polarizações Floating e On-State; II: por meio da aplicação dos testes estatísticos ANOVA e de Tukey para a análise dos parâmetros elétricos $\left(\mathrm{V}_{\mathrm{TH}}\right.$ e $\left.\mathrm{SS}\right)$ extraídos experimentalmente dos DnMs, OnMs e CnMs sob a condição das polarizações Analog e Off-State.

Para análise dos efeitos da TID nos MOSFETs de porta hexagonal (DnM), octogonal $(\mathrm{OnM})$ e retangular $(\mathrm{CnM})$ quando submetidos às radiações ionizantes por raios-X e sem que os dispositivos estivessem polarizados durante o procedimento das radiações ionizantes (Floating), foram utilizados 28 dispositivos em 5 chips diferentes. Desenvolveu-se primeiramente um estudo comparativo experimental do casamento entre os parâmetros elétricos das $\mathrm{V}_{\mathrm{THS}}$ e SSs extraídas experimentalmente dos DnMs, OnMs e CnMs em um ambiente de radiação ionizante de raios-X (TID compreendido na faixa de $500 \mathrm{krad}$ até 4,5 Mrad; 5 step-doses). Os resultados mostram que o estilo de leiaute Diamante (formato de porta hexagonal) para nMOSFETs com um ângulo de $\alpha$ de $90^{\circ}$ é capaz de reduzir o descasamento do dispositivo (para $\mathrm{V}_{\mathrm{TH}}$ : 40,7 \% e para SS: 56,8 \%) em comparação às encontradas nos CnMs. Isso ocorre devido ao impacto do LCE, PAMDLE e principalmente do DEPAMBBRE presentes nos nMOSFETs de porta hexagonal e 
octogonal. Este estudo foi desenvolvido valendo-se da utilização da figura de mérito estatística denominada de coeficiente de variação.

Valendo-se do estudo dos efeitos da TID nos nMOSFETs de porta octogonal $(\mathrm{OnM})$ e retangular $(\mathrm{CnM})$, levando-se em consideração que o OnM apresenta área de porta superior em comparação com a área de porta do CnM, o que faz com que o OnM apresente uma maior área de exposição à radiação ionizante por raios-X, o que pode levar à uma maior variação do comportamento dos parâmetros elétricos extraídos experimentalmente, e valendo-se da aplicação de $\mathrm{V}_{\mathrm{DD}}(1,2 \mathrm{~V})$ ao terminal da porta e $0 \mathrm{~V}$ nos demais terminais dos MOSFETs durante o procedimento das radiações ionizantes (On-state), foram utilizados 4 dispositivos em 1 chip e foi desenvolvido um estudo comparativo experimental do casamento entre os parâmetros elétricos das $\mathrm{V}_{\mathrm{TH}} \mathrm{S}$ e SSs extraídas experimentalmente dos OnMs e CnMs em um ambiente de radiação ionizante de raios-X (TID compreendido na faixa de $10 \mathrm{krad}$ até $200 \mathrm{krad} ; 5$ step-doses). Os resultados mostram que o OnM (forma de porta octogonal) para nMOSFETs com um ângulo $\alpha$ de $90^{\circ}$ e fator "c" de 50\% é capaz de aumentar o casamento entre dispositivos (para $\mathrm{V}_{\mathrm{TH}}:$ 57,4 \% e para SS: 54,9 \%) em comparação àqueles encontrados nos CnMs. Isso ocorre devido ao impacto dos efeitos LCE, PAMDLE e principalmente DEPAMBBRE presentes nos OnMs.

Para a realização do terceiro estudo, utilizou-se os testes estatísticos denominados de ANOVA e Tukey, para a análise dos efeitos da TID nos nMOSFETs de porta hexagonal $(\mathrm{DnM})$, octogonal $(\mathrm{OnM})$ e retangular $(\mathrm{CnM})$ quando submetidos às radiações ionizantes por raios-X e valendo-se da aplicação de $\mathrm{V}_{\mathrm{DD}}(1,2 \mathrm{~V})$ ao terminal da porta e ao terminal de dreno e $0 \mathrm{~V}$ nos demais terminais dos MOSFETs durante o procedimento das radiações ionizantes (modo Analog), foram utilizados 4 dispositivos (2 DnMs, 1 OnM e $1 \mathrm{CnM}$ ) em 1 chip e foi desenvolvido um estudo comparativo experimental que visa analisar a variabilidade estatística entre os parâmetros elétricos das $\mathrm{V}_{\mathrm{THS}}$ e SSs extraídas experimentalmente dos DnMs, OnMs e CnMs em um ambiente de radiação ionizante de raios-X (TID compreendida na faixa de $27 \mathrm{krad}$ até $200 \mathrm{krad} ; 5$ step-doses). Por meio da análise dos resultados obtidos, pode-se afirmar que os valores médios das $\mathrm{V}_{\mathrm{THS}}$ e SSs extraídas experimentalmente dos nMOSFETs de porta retangular diferem estatisticamente, com um nível de acerto de 95\%, das médias das $\mathrm{V}_{\mathrm{THS}}$ e SSs extraídas experimentalmente dos nMOSFETs de porta hexagonal e octogonal. Isso indica, portanto, que os $\mathrm{CnMs}$, quando irradiados com radiações ionizantes do tipo raios-X, apresentam uma maior variabilidade (desvio-padrão de $0,0158 \mathrm{~V}$ para a $\mathrm{V}_{\mathrm{TH}}$ e 33,2 $\mathrm{mV} /$ déc. para a 
SS) no seu funcionamento quando comparados com o comportamento dos DnMs e OnMs (DnMs: desvio-padrão de 0,012 V para a $\mathrm{V}_{\mathrm{TH}}$ e 5,34 mV/déc. para a SS; OnMs: desviopadrão de $0,0125 \mathrm{~V}$ para a $\mathrm{V}_{\mathrm{TH}}$ e 5,50 $\mathrm{mV} /$ déc. para a $\mathrm{SS}$ ). Isto permite afirmar, com um nível de acerto de 95\%, que os DnMs e OnMs apresentam um melhor casamento entre dispositivos em comparação aos CnMs, devido ao impacto dos efeitos LCE, PAMDLE e principalmente DEPAMBBRE presentes nos DnMs e OnMs.

No último estudo, foram utilizados os testes estatísticos denominados de ANOVA e Tukey, foram analisados os efeitos da TID nos nMOSFETs de porta hexagonal (DnM), octogonal $(\mathrm{OnM})$ e retangular $(\mathrm{CnM})$ quando submetidos às radiações ionizantes por raios-X e valendo-se da aplicação de $\mathrm{V}_{\mathrm{DD}}(1,2 \mathrm{~V})$ ao terminal de dreno e $0 \mathrm{~V}$ nos demais terminais dos MOSFETs durante o procedimento das radiações ionizantes de raios-X (Off-state), foram utilizados 4 dispositivos (2 DnMs, 1 OnM e $1 \mathrm{CnM}$ ) em 1 chip e foi desenvolvido um estudo comparativo experimental que visa estudar a variabilidade estatística entre os parâmetros elétricos das $\mathrm{V}_{\mathrm{TH}} \mathrm{S}$ e SSs extraídas experimentalmente dos DnMs, OnMs e CnMs em um ambiente de radiação ionizante de raios-X (TID a partir de $10 \mathrm{krad}$ até $20 \mathrm{krad}$ ). Por meio dos resultados obtidos da aplicação destes testes estatísticos, pode-se verificar que as médias das $\mathrm{V}_{\mathrm{TH}}$ e SS extraídas experimentalmente dos nMOSFETs de porta retangular diferem estatisticamente, com um nível de acerto de 95\%, das médias das $\mathrm{V}_{\mathrm{TH}}$ e SSs extraídas experimentalmente dos nMOSFETs de porta hexagonal e octogonal. Portanto, pode-se concluir que os $\mathrm{CnMs}$, quando irradiados com radiações ionizantes do tipo raios- $X$, apresentam uma maior variabilidade (desvio-padrão de $0,0456 \mathrm{~V}$ para a $\mathrm{V}_{\mathrm{TH}}$ e $4,33 \mathrm{mV} /$ déc. para a $\mathrm{SS}$ ) no seu funcionamento quando comparados com o comportamento dos DnMs e OnMs (DnMs: desvio-padrão de 0,009 $\mathrm{V}$ para a $\mathrm{V}_{\mathrm{TH}}$ e 2,57 mV/déc. para a SS; OnMs: desvio-padrão de 0,01 V para a $\mathrm{V}_{\mathrm{TH}} \mathrm{e}$ 2,37 $\mathrm{mV} /$ déc. para a SS). Isto permite afirmar, com um nível de confiança de 95\%, que os DnMs e OnMs apresentam um melhor casamento entre dispositivos em comparação aos CnMs em ambientes de radiação ionizante, devido ao impacto dos efeitos LCE, PAMDLE e principalmente DEPAMBBRE presentes nos DnMs e OnMs.

Desta forma, por meio da realização desses diferentes estudos, pode-se verificar, por meio da utilização de ferramentas estatísticas, a maior robustez e menor variabilidade dos nMOSFETs Diamante e Octo para aplicações em ambientes com radiações ionizantes quando comparados ao nMOSFET convencional, que apresentou sempre uma maior variabilidade nos parâmetros elétricos estudados e também deixou de funcionar antes que o DnM e OnM na maioria dos casos estudados. 
Portanto, valendo-se da polarização dos dispositivos no modo Floating e Analog nos dispositivos DnMs e OnMs em ambientes de radiação ionizantes de raios-X, verificase que os DnMs e OnMs são abordagens de leiautes que podem ser consideradas como técnicas alternativas de Hardness-By-Design (HBD) com o intuito de aumentar o casamento entre dispositivos de CIs CMOS espaciais, analógicos médicos e de radiofrequência $(\mathrm{RF})$.

Ademais, os resultados obtidos nos testes estatísticos desenvolvidos nesse estudo sugerem os nMOSFETs Diamante e Octo como uma alternativa de nMOSFETs para utilização em circuitos mistos para aplicações específicas (Application Specific Integrated Circuits, ASICs) e aplicações em áreas sujeitas às radiações ionizantes, como nas aplicações aeroespaciais. Sendo essa estrutura possível de ser aplicada apenas pela mudança do leiaute de porta, não gerando custos aos processos de fabricação já utilizados amplamente pela indústria.

Desta maneira, pesquisas em ambientes de radiações ionizantes quando os MOSFETs estão polarizados e estudos utilizando a mesma metodologia em um maior número de dispositivos, com dimensões diferentes das apresentadas neste estudo devem complementar os estudos dos efeitos da TID nesses leiautes, permitindo corroborar o presente estudo. Portanto, como trabalhos futuros decorrentes desse trabalho de tese de doutorado, pode-se sugerir:

- Estudar o comportamento elétrico dos DnM e OnM em função de outras fontes de radiações ionizantes como, por exemplo, Cobalto 60 ;

- Estudar o comportamento do pMOSFET com geometria de porta hexagonal e octogonal em função da TID;

- Desenvolver um modelo de regressão linear que permita analisar o comportamento da variabilidade dos parâmetros elétricos extraídos dos DnM, OnM e CnM em função das radiações ionizantes e em função da polarização aplicada nestes dispositivos.

No Apêndice A desta tese de doutorado, são apresentados os títulos dos artigos de revista publicados e também os trabalhos publicados em congressos durante o período do desenvolvimento deste trabalho. 


\section{REFERÊNCIAS}

[1] J. P. Colinge, Physics of Semiconductor Devices, Kluwer Academic Publishers, 2002.

[2] V. Sridhar, M. C. Padma e K. A. Radhakrishna Rao, Emerging Research in Electronics, Computer Science and Technology, Springer, 2018.

[3] Y. Tsividis e C. McAndrew, Operation and Modeling of the MOS Transistor, Oxford University Press, 2010.

[4] J. P. Colinge, FinFETs and Other Multi-Gate Transistors, Springer, 2007.

[5] A. H. Siedle e L. Adams, Handbook of Radiation Effects, New York: Oxford, 2002 .

[6] H. Barnaby, "Total-Ionizing-Dose Effects in Modern CMOS Technologies," IEEE Transactions on Nuclear Science, vol. 53, nº 6, pp. 3103 - 3121, 2006.

[7] J. P. Campbell, J. Qin, K. P. Cheung, L. Yu, J. S. Suehle, A. Oates e K. Sheng, "Random Telegraph Noise in Highly Scaled nMOSFETs," Random Telegraph Noise in Highly Scaled nMOSFETs, pp. 382 - 388, 26 - 3042009.

[8] M. Bagatin e S. Gerardin, Ionizing Radiation Effects in Electronics from Memories to Imagers, CRC Press, 2015.

[9] G. C. A. MESSENGER, "Summary Review of Displacement Damage from High Energy Radiation in Silicon Semiconductors and Semiconductors Device," The IEEE Transactions on Nuclear Science, vol. 39, n 3, pp. 468 - 473, 1992.

[10] Y. Taur, D. Buchanan, W. Chen, D. Frank, K. Ismail e S.-H. Lo, “CMOS scaling into the nanometer regime," Proceedings of the IEEE, vol. 85, n 4, pp. 486 - 504, 1997.

[11] J. R. Schwank, M. R. Shaneyfelt, D. M. Fleetwood, J. A. Felix, P. E. Dodd, P. Paillet e V. Ferlet-Cavrois, "Radiation Effects in MOS Oxides," IEEE Transactions on Nuclear Science, vol. 55, nº 4, pp. 1833-1853, Aug. 2008.

[12] R. Chau, S. Datta, M. Doczy, J. Kavalieros e M. Metz, "Gate dielectric scaling for high-performance CMOS: from $\mathrm{SiO} 2$ to high-K," Extended Abstracts of International Workshop on Gate Insulator (IEEE Cat. No.03EX765), 6 - 711 2003. 
[13] C. Zhao, M. Werner, S. Taylor, P. R. Chalker, R. J. Potter e J. Gaskell, "High-k dielectrics' radiation response to X-ray and $\gamma$-ray exposure," 16th IEEE International Symposium on the Physical and Failure Analysis of Integrated Circuits, 04092009.

[14] D. Hisamoto, W.-C. Lee e J. Kedzierski, "FinFET-A Self-Aligned Double-Gate MOSFET Scalable to $20 \mathrm{~nm}$," IEEE TRANSACTIONS ON ELECTRON DEVICES, vol. 47, nº 12, pp. 2320 - 2325, 2000.

K. J. Kuhn, "Considerations for Ultimate CMOS Scaling," IEEE Transactions on Electron Devices, vol. 59, nº 7, pp. 1813 - 1828, 16 May 2012.

[16] W. Snoeys, T. Gutierrez e G. Anelli, “A new NMOS layout structure for radiation tolerance," IEEE Transactions on Nuclear Science, vol. 49, n 4, pp. $1829-1833,2002$.

[17] J. P. Colinge, Silicon-On_Insulator Technology: Materials to VLSI, Boston: Kluwer Academic Publishers, 2004.

A. Vandooren, P. Francis, D. Flandre e J. Colinge, "Performance of /spl gamma/-irradiated gate-all-around SOI MOS OTA amplifiers," IEEE International SOI Conference Proceedings, pp. 62-63, 1997.

Y. X. Liu, T. Kamei, T. Matsukawa e K. Endo, "Experimental study of trigate SOI-FinFET flash memory," IEEE International SOI Conference (SOI), 1-4 102012.

[20] S. P. Gimenez, Layout Techniques for MOSFETs, Morgan \& Claypool Publishers, 2016.

[21] K. H. Cirne e S. P. Gimenez, "Estudo da Tensão Early em Função do Comprimento," Boletim Técnico da Faculdade de, p. 86, 2007.

[22] L. S. Sapage e S. P. Gimenez, "Estudo da Tensão Early em Função da Largura de,” Boletim Técnico da Faculdade de Tecnologia de São Paulo, p. 87, 2007.

[23] S. P. Gimenez, "The Wave SOI MOSFET: A New Accuracy Transistor Layout to Improve Drain Current and Reduce Die Area for Current Drivers Applications," ECS Transactions, vol. 19, nº 4, pp. 153-158, 2009. 
[24] R. N. Souza, M. A. G. Silveira e S. P. Gimenez, "Mitigating MOSFET Radiation Effects by Using the Wave Layout in Analog ICs Applications," Journal of Integrated Circuits and Systems, vol. 10, pp. 30-37, 2015.

[25] S. P. Gimenez, "Wave Transistor (S geometric shape): Novo Estrutrura de Leiaute que visa obter alta integracao, casamento entre dispositivos e reduzir os efeitos dos Efeitos das Descargas Eletrostáticas (ESD).”. Brasil Patente PI08026343, 07 082008 .

[26] S. P. Gimenez e D. M. Alati, "FISH SOI MOSFET: An Evolution of the Diamond SOI Transistor for Digital ICs Applications,” ECS Transactions, vol. 35, pp. 163 - 168, 2011.

[27] S. P. Gimenez, "FISH SOI MOSFET: Modeling, Characterization and Its Application to Improve the Performance of Analog ICs.," Journal of the Electrochemical Society, p. 159, 2011.

[28] S. P. Gimenez, "An Innovative Ellipsoidal Layout Style to Further Boost the Electrical Performance of MOSFETs," IEEE Electron Device Letters, vol. 36, $\mathrm{n}^{\circ}$ 7, pp. 705-707, 2015.

[29] M. M. Correia e S. P. Gimenez, "Boosting the electrical performance of MOSFET switches by applying Ellipsoidal layout style," SBMICRO, Bahia, 2015.

[30] S. P. Gimenez, "MOSFET do tipo Diamante". Brasil Patente PI0802745-5, 0708 2008 .

[31] S. P. Gimenez e D. M. Alati, "OCTO SOI MOSFET: An Evolution of the Diamond to Be Used in the Analog Integrated Circuits.," EUROSOI, 2011.

[32] S. P. Gimenez, "Diamond MOSFET: An innovative layout to improve performance of ICs.," Solid-State Electronics, pp. 1690 - 1699, 2010.

[33] D. M. Alati, S. P. Gimenez, M. A. G. Silveira, L. E. Seixas e W. Melo, "Experimental Comparative Study of the X-Ray Radiation Effects Between the Threshold Voltages of the Diamond and Conventional Layout Styles," EURO SOI, pp. 53-54, 2012.

[34] S. P. Gimenez, D. M. Alati, M. A. G. Silveira, W. Melo, L. E. Seixas, N. H. Medina, N. Added e M. Tabacnicks, "Improving The Protons Radiation- Robustness Of Integrated Circuits By Using The Diamond Layout Style," RADECS, 2012. 
[35] L. N. S. Fino e et al., "Experimental Study of the OCTO SOI nMOSFET to Improve Device Performance," EUROSOI, 2012.

[36] L. N. S. Fino e et al., "Improving Unit Voltage Gain Frequency of Integrated Circuits by Using OCTO Layout Style,” EUROSOI, Paris, 2013.

[37] L. N. S. Fino e et al., "Total ionizing dose effects on the digital performance of irradiated OCTO and conventional fully depleted SOI MOSFET," European Conference on Radiation and Its Effects on Components and Systems (RADECS), pp. 1-4, 2013.

[38] L. N. S. Fino e et al., "Improving the X-Ray Radiation Tolerance of the Analog ICs by Using OCTO Layout Style,” SBMICRO, Paraná, 2013.

[39] L. N. S. Fino e et al., "Boosting the Radiation Hardness and Higher Reestablishing Pre-Rad Conditions by Using OCTO Layou Style for MOSFETs," SBMICRO, Sergipe, Brazil, 2014.

[40] L. N. S. Fino, "Boosting the total ionizing dose tolerance of digital switches by using OCTO SOI MOSFET," Semiconductor Science and Technology,, vol. 30, $\mathrm{n}^{\mathrm{o}} 10,2015$.

[41] Y. Joly e et al., "Gate voltage matching investigation for low-power analog applications," IEEE Transac-tions on Electron Devices, vol. 60, n 3, pp. 1263 $1267,2013$.

[42] M. Pelgrom, A. Duinmaijer e A. Welbers, "Matching properties of MOS transistors," IEEE J. Solid-State Circuits, vol. 24, nº 5, pp. 1433-1439, 1989.

[43] H. Yang e et al., "Current mismatch due to local dopant fluctuations in MOSFET channel," IEEE Transactions on Electron Devices, vol. 50, nº 11, pp. 2248-2254, 2003.

[44] V. V. Peruzzi e et al., "Boosting the MOSFETs Matching by Using Diamond Layout Style," Journal of Integrated Circuits and Systems, vol. 12, nº 1, pp. 33 41, 2017.

[45] V. V. Peruzzi, “COMPARATIVE EXPERIMENTAL STUDY OF THE IMPROVED MOSFETS MATCHING BY USING THE HEXAGONAL LAYOUT STYLE," SBMicro, 2017.

[46] L. E. Seixas Júnior, Leiaute diamante par MOSFETS sob os efeitos das radiações ionizantes., São Bernardo do Campo: Centro Universitário FEI, 2017. 
[47] L. N. S. Fino, EFEITOS DAS RADIAÇÕES IONIZANTES DE RAIOS-X NO SOI nMOSFET COM GEOMETRIA DE PORTA OCTOGONAL, São Bernardo do Campo: Centro Universitário da FEI, 2017.

[48] S. M. SZE, Physics of semiconductor devices, New York: John Wiley, 1981.

[49] J. A. MARTINO, M. A. PAVANELlO e P. B. VERDONCK, Caracterização Elétrica de Tecnologia e Dispositivos MOS, Thomson, 2003.

[50] S. Sedra e A. S. Smith, Microelectronic circuits, Oxford: Oxford University, 2004.

[51] R. L. BOYLESTAD e L. NASHELSKY, Dispositivos eletrônicos e teoria de circuitos, São Paulo: Pearson Prentice-Hall, 2012.

[52] P. A. MORETTIN e W. O. BUSSAB, Estatística básica, São Paulo: Saraiva, 2004.

[53] R. LARSON e B. FARBER, Estatística Aplicada, São Paulo: Pearson Prentice Hall, 2010.

[54] M. N. MAGAlHAES e A. LIMA, Noções de Probabilidade e Estatística, São Paulo: EDUSP (Editora da Universidade de São Paulo), 6 ed., 2005.

[55] V. V. Peruzzi, ESTUDO COMPARATIVO EXPERIMENTAL ENTRE O CASAMENTO DO, São Bernardo do Campo, 2013.

[56] "Portal Action," Estatcamp - Consultoria Estatística e Qualidade, [Online]. Available: http://www.portalaction.com.br/probabilidades/63-distribuicao-quiquadrado. [Acesso em 0909 2020].

[57] M. M. ESPINOSA, C. C. JÚNIOR e F. A. R. LAHR, "Métodos Paramétricos e não-paramétricos para determinar o valor característico em resultados de ensaio de madeira," Scientia Forestalis, vol. 66, pp. 76-83, 2004.

[58] E. B. Kalil, "Princípios de técnica experimental com animais," ESALQ/USP, p. 210, 1977.

[59] C. H. Garcia, “Tabelas para classificação do coefici-ente de variação.," IPEF, pp. 12, (Cir-cular técnica, 171), 1989.

[60] D. Mohallem e et al., "Evaluation of the coeffi-cient of variation as a precision measure in experi-ments with broilers," Arq. Bras. Med. Vet. Zootec, vol. 60, n 2, pp. 449-453, 2008. 
[61] T. W. Anderson e D. A. Darling, "Asymptotic Theory of Certain "Goodness of Fit" Criteria Based on Stochastic Processes," The Annals of Mathematical Statistics, vol. 23, nº 2, pp. 193-212, 1952.

[62] M. M. ESPINOSA, C. C. JÚNIOR e F. A. R. LAHR, "Métodos Paramétricos e não - paramétricos para determinar o valor característico em resultados de ensaio de madeira," Scientia Forestalis, vol. 66, pp. 76-83, 2004.

[63] M. A. STEPHENS, “Asymptotic results for goodness of fit statistics with unkown parameters," Annals of statistics, vol. 4, pp. 357-369, 1976.

[64] Minitab Inc., (C) 2020 Minitab, LLC All rights reserved., 2020.

[65] A. B. Ara, A. V. Musetti e B. Schneiderman, Introdução à Estatística, São Paulo: Edgard Blucher LTDA, 2003.

[66] M. F. Triola, Introdução à Estatística, LTC, 2017.

[67] "edisciplinas," edisciplinas, S/A. [Online]. Available: https://edisciplinas.usp.br/pluginfile.php/3260534/mod_resource/content $/ 1 / \mathrm{T} \% \mathrm{C}$ 3\%B3pico_13.pdf. [Acesso em 0209 2020].

[68] J. W. Tukey, "SOME SELECTED QUICK AND EASY METHODS OF STATISTICAL ANALYSIS," SECTION OF MATHEMATICS AND ENGINEERING, 1953.

[69] S. Vieira, 0606 2016. [Online]. Available: http://soniavieira.blogspot.com/2016/06/paraproceder-ao-teste-de-tukey-e.html. [Acesso em 0909 2020].

[70] J. H. ZAR, BIOSTATISTICAL ANALYSIS, Prentice Hall; 4th Edition, 1998.

[71] R. Claser e S. P. Gimenez, "Implementação de Leiautes de MOSFETs Convencional e Diamante Utilizando o Software IC Station da Mentor Graphics," 17 . Simpósio Internacional de Iniciação Científica da Universidade de São Paulo (SIICUSP), 2009.

[72] D. M. Alati e S. P. Gimenez, "Estudo Comparativo entre o SOI nMOSFET Diamante e Convencional, Utilizando-se o Simulador Sentaurus Device da Synopsys," $17^{\circ}$. Simpósio Internacional de Iniciação Científica da Universidade de São Paulo (SIICUSP), p. v. 11, 2009. 
[73] D. M. Alati e S. P. Gimenez, "Comparative Experimental Study Between Diamond And Conventional MOSFET," 218th ECS Meeting, 2010, Las Vegas, NV. E14 E22 - SiGe, Ge, and Related Compounds: Materials, Processing, and Devices 4., 2010.

[74] S. P. Gimenez e M. Bellodi, "Diamond SOI MOSFET: A New Drain and Source/Channel Interface Layout to Improve Drain Current,” EURO SOI 2009, 2009, Gotemburgo. Fifth WorkShop of the Tematic Network on Silicon on Insulator Technology Devices and Circuits. Gotemburo, Suecia: NanoSIL Network of Excellence, pp. 87-88, 2009.

[75] S. P. Gimenez e et al., "A compact diamond MOSFET model accounting for the PAMDLE applicable down the $150 \mathrm{~nm}$ node," Electronics Letters, vol. 1, $\mathrm{n}^{\mathrm{o}} 50$, p. 1618-1620, 2014.

[76] S. P. Gimenez e D. M. Alati, "Electrical behavior of the diamond layout style for MOSFETs in X-rays ionizing radiation environments.," Microelectronic Engineering, vol. 148, pp. 85-90, 2015.

[77] R. VELAZCO, P. FOUILLAT e R. REIS, Radiation Effects on Embedded Systems, Dordrecht: Springer, 2007.

[78] H. D. YOUNG e R. A. FREEDMAN, Física IV: Ótica e Física Moderna, Pearson Education, 2004.

[79] P. DRESSENDORFER e T. MA, Ionizing radiation effects in MOS devices and, New York: John Wiley and Sons, 1989.

[80] T. J. O'GORMAN, "The effect of cosmic rays on the soft error rate of a DRAM at ground level," IEEE Trans. Electron Device, vol. 41, n 4, p. 553-557, 1994.

[81] A. E. PROFIO, Radiation Shielding and Dosimetry, New York: Wiley, 1979.

[82] P. E. DODD, "Basic Mechanisms for Single Event Effects," IEEE NSREC Short Course, vol. 1, nº 1, 1999.

[83] D. Baker, "Space Weather Effects in the Earth's Radiation Belts," Space Sci Rev, p. $60,2018$.

[84] C. CLAEYS e E. SIMOEN, Radiation effects in Advanced Semiconductor Materials and Devices, Berlin: Springer, 2002. 
[85] J. F. Ziegler e et al., "IBM experiments in soft fails in computer electronics," IBM J. RES. DEVELOP, vol. 40, nº 1, 1996.

[86] P. C. Anderson, F. J. Rich e S. Borisov, "Mapping the South Atlantic Anomaly continuously over 27 years," Journal of Atmospheric and Solar-Terrestrial Physics, vol. 177, pp. 237-246, 2018.

[87] E. STASSINOPOULOS e J. RAYMOND, “The Space Radiation Environment for Electronics," IEEE, p. 1423-1442, 1988.

[88] J. R. SROUR, C. J. MARSHALL e P. W. MARSHALL, "Review of Displacement Damage Effects in Silicon Devices," IEEE Trans. Nucl. Sci., vol. $50, n^{\circ} 3$, p. 653-670, 2003.

[89] F. WANG e V. D. AGRAWAL, "Single Event Upset: an embedded tutorial," IEEE International Conference on VLSI Design, p. 429-434, 2008.

[90] F. W. SEXTON e et al., "Single Event Gate Rupture in Thin Gate Oxides," IEEE Trans. Nucl. Sci., vol. 44, no 6, p. 2345-2352, 1997.

[91] C. S. GUENZER, E. A. WOLICKI e R. G. ALLAS, "Single Event Upset of Dynamic RMs by Neutrons and Protons," IEEE Trans. Nucl. Sci, vol. 26, n 6 , p. 5048-5052, 1979.

[92] M. P. BAZE e S. P. BUCHNER, “Attenuation of Single Event Induced Pulses in CMOS Combinational Logic," IEEE Trans. Nucl. Sci., vol. 44, n q6, p. 22172223, 1997.

[93] T. L. TURFLINGER, "Single Event Effects in Analog and Mixed signal integrated circuits," IEEE Trans. Nucl. Sci., vol. 43, nº 2, p. 594-602, 1996.

[94] University of Florida, "RSSC FUNDAMENTAL RADIATION CONCEPTS: RADIATION SAFETY SHORT COURS,” University of Florida, Florida, 2012.

[95] J. R. SCHWANK, "Basic Mechanisms of Radiation Effects in the Natural Space Environment," IEEE NSREC Short Course, 1994.

[96] R. D. SCHRIMPF, Radiation Effects in Microelectronics, Dordrecht: Springer, 2007.

[97] T. R. OLDHAM e F. B. MCLEAN, “Total Ionizing Dose Effects in MOS Oxides and Devices," IEEE Trans. Nucl. Sci., vol. 50, p. 483-499, 2003. 
[98] H. HUGHES e J. BENEDETTO, "Radiation effects and hardening of MOS technology," IEEE Transactions on Nuclear Science, vol. 50, nº 3, 2003.

[99] V. V. Peruzzi e et. al., "Using the Hexagonal Layout Style for MOSFETs to Boost the Device Matching in Ionizing Radiation Environments," Journal of Integrated Circuits and Systems, vol. 15, $\mathrm{n}^{\mathrm{o}}$ 2, pp. 1 - 5, 2020.

[100] KEITHLEY, 4200-SCS: Parameter Analyzer Technical Data, 2017.

[101] KEITHLEY, Models 2634B, 2635B, and 2636B System SourceMeter Instruments: Quick Start Guide., 2017.

[102] SHIMADZU, X-ray Diffractometer: XRD-6100. Manual, 2015.

[103] J. R. SCHWANK, M. R. SHANEYFELT e P. E. DODD, "Radiation Hardness Assurance Testing of Microelectronics Devices and Integrated Circuits Radiation Environments, Physical Mechanisms, and Foundations for Hardness Assurance," IEEE Transactions on Nuclear Science, vol. 60, n 3, pp. 2074-2100, 2013.

[104] F. W. SEXTON e J. SCHWANK, “Correlation of Radiation Effects in Transistors and Integrated Circuits," IEEE Transactions on Nuclear Science, vol. 32, n 6 , p. 3975-3981, 1985.

[105] Z. LIU e et. al., “Total Ionizing Dose Enhanced DIBL Effect,” IEEE Transaction Nuclear Science, vol. 58, $\mathrm{n}^{\circ}$ 3, p. 1324-1331, 2011.

[106] J. SCHWANK e et.al., "Correlation Between Co-60 and x-ray radiation-induced charge buildup in silicon-on-insulator buried oxides," IEEE Transaction on Nuclear Science, vol. 47, no 6, p. 2175-2182, 2000. 


\section{APÊNDICE A - PUBLICAÇÕES}

Artigos publicados em revista:

1. PERUZZI, V. V. ; CRUZ, W. S. ; Gabriel Augusto da Silva ; Simoen, Eddy ; Claeys, Cor ; GIMENEZ, S. P. . Using the Octagonal Layout Style for MOSFETs to boost the Device Matching in Ionizing Radiation Environments. IEEE TRANSACTIONS ON DEVICE AND MATERIALS RELIABILITY, v. 1, p. $1-6,2020$.

2. PERUZZI, V. V. ; CRUZ, W. S. ; Gabriel Augusto da Silva ; Simoen, Eddy ; Claeys, Cor; GIMENEZ, S. P. . Using the Hexagonal Layout Style for MOSFETs to boost the Device Matching in Ionizing Radiation Environments. JICS. JOURNAL OF INTEGRATED CIRCUITS AND SYSTEMS, v. 1, p. 1-5, 2020.

3. PERUZZI, V. V. ; Christian Renaux ; FLANDRE, Denis ; GIMENEZ, S. P. . Boosting the MOSFETs Matching by Using Diamond Layout Style. JICS. JOURNAL OF INTEGRATED CIRCUITS AND SYSTEMS, v. 12, p. 33-41, 2017.

\section{Trabalhos apresentados em congressos:}

1. PERUZZI, V. V. ; GIMENEZ, S. P. . Boosting the MOSFETs Matching by Using Diamond Layout Style. In: SBMicro 2016, 2016, Belo Horizonte. SBMicro 2016. Belo Horizonte: Sociedade Brasileira de Microeletrônica, 2016. v. 1. p. 1-4.

2. Vinicius Vono Peruzzi ; Christian Renaux ; FLANDRE, Denis ; GIMENEZ, SALVADOR P. . Comparative Experimental Study Of The Improved Mosfets Matching By Using The Hexagonal Layout Style. In: 32nd Symposium on Microelectronics Technology and Devices (SBMicro 2017), 2017, Fortaleza, Ceará. Comparative Experimental Study Of The Improved Mosfets Matching By Using The Hexagonal Layout Style. Fortaleza, Ceará: SBMicro, 2017. v. 1. p. 18. 
3. PERUZZI, V. V. ; Christian Renaux ; FLANDRE, Denis ; GIMENEZ, S. P. . Using Statistical Student's t-Test to Qualify the Electrical Performance of the Diamond MOSFETs. In: SBMicro 2018, 2018, Bento Goncalves. SBMicro 2018, 2018. v. 1. p. 1-4.

4. Vinicius Vono Peruzzi; GIMENEZ, S. P. . Experimental Comparative Study Regarding the Mismatch Between the FISH nMOSFET and its Conventional Counterparts. In: Seminatec 2018, 2018, Sao Bernardo do Campo. Seminatec 2018, 2018. v. 1.p. 1-1.

5. PERUZZI, V. V. ; CRUZ, W. S. ; Gabriel Augusto da Silva ; Teixeira, R. C. ; Luis Eduardo Seixas ; GIMENEZ, S. P. . BOOSTING THE IONIZING RADIATION TOLERANCE IN THE MOSFETS MATCHING BY USING

DIAMOND LAYOUT STYLE. In: 34th SBMicro. Symposium on Microelectronics Technology and Devices, 2019, São Paulo. SBMicro. São Paulo: SBMicro, 2019. v. 1. p. 1-6. 